\title{
ipen
}

AUTARQUIA ASSOCIADA À UNIVERSIDADE DE SÃO PAULO

\section{AVALIAÇÃO DA VARIAÇÃO DA RADIOATIVIDADE NATURAL EM AREIAS DA PRAIA DE CAMBURI- VITÓRIA- ESPÍRITO SANTO COM FATORES CLIMATOLÓGICOS E GEOLÓGICOS DA REGIÃO.}

\author{
Lívia Fernandes Barros
}

Dissertação apresentada como parte dos requisitos para obtenção do Grau de Mestre em Ciências na Área de Tecnologia Nuclear - Aplicações

Orientadora:

Profa. Dra. Brigitte Roxana Soreanu Pecequilo 
INSTITUTO DE PESQUISAS ENERGÉTICAS E NUCLEARES

Autarquia associada à Universidade de São Paulo

\section{AVALIAÇÃO DA VARIAÇÃO DA RADIOATIVIDADE NATURAL EM AREIAS DA PRAIA DE CAMBURI- VITÓRIA- ESPÍRITO SANTO COM FATORES CLIMATOLÓGICOS E GEOLÓGICOS DA REGIÃO.}

Lívia Fernandes Barros

Dissertação apresentada como parte dos requisitos para obtenção do Grau de Mestre em Ciências na Área de Tecnologia Nuclear - Aplicações

Orientadora:

Profa. Dra. Brigitte Roxana Soreanu Pecequilo 
Dedico este trabalho aos meus pais. 


\section{Agradecimentos}

- Primeiramente a Deus, que me amparou nos momentos de aflição, deu forças para enfrentar as batalhas diárias, sustentou e guio-me a fim de concretizar este sonho. Fui imensamente abençoada!

- Ao Instituto de Pesquisas Energéticas e Nucleares pela oportunidade, especificamente ao Laboratório de Radiometria Ambiental, sob a gerência da Dra. Bárbara Paci Mazzili.

- À minha orientadora, Dra. Brigitte Roxana Soreanu Pecequilo pela oportunidade, apoio e pelos conhecimentos transferidos. Amadureci muito durante este trabalho. Agradeço imensamente pois seus ensinamentos possibilitaram-me um crescimento profissional e pessoal.

- À minha mãe, Elany Soraia Fernandes Barros e meu irmão Mateus Fernandes Barros pelo apoio e pela ajuda nas coletas mensais de areia. A meu padrasto Helvécio Quintão pelo incentivo. Agradeço por terem acreditado em mim e na minha capacidade, sempre.

- À Leonardo Fairich Santos pelo carinho, apoio único nos momentos em que mais precisei e pela disponibilidade incansável nas exaustantes e intermináveis coletas mensais de areia. Essencial para a realização deste trabalho. Eternamente grata.

- Ao meu pai, José Joaquim Pisa de Barros pelo apoio.

- Às minhas avós Jéssia Lima de Pisa Barros e Ezilda Alves Fernandes pelo apoio e consideração.

- Parafraseando Cícero: "Dos amores humanos, o menos egoísta, o mais puro e desinteressado é o amor da amizade”. Eternamente grata pela ajuda de todos vocês:

* À minha irmã de coração Emanuelle Zangerolame Santos, pelo apoio e amizade sincera, e por me lembrar de nunca deixar que os meus medos fossem maiores que os meus sonhos. Amiga, se cheguei até aqui foi pelo seu apoio.

* Aos amigos que conheci na disciplina da minha orientadora, Tatiane da Silva Nascimento, Yklys Santos Rodrigues e Paulo Oliveira, companheiros em todos os momentos. O apoio de vocês me fortaleceu a cada dia de batalha. Agradeço imensamente por todos os momentos que passamos juntos. 
* À amiga Glaura Caroena de Oliveira pela força, apoio e amizade sincera.

* Ao amigo Lucas Rodrigues dos Santos pelos conselhos.

- À Dra. Joselene de Oliveira. Agradeço imensamente sua atenção, seu carinho, apoio e oportunidade de ingressar no PAE. Obrigada pelas conversas, pelo incentivo, pela energia positiva, sempre, e por ser um exemplo de força e determinação a ser seguido.

- Ao Dr. Roberto Vicente, da Gerência de Rejeitos, pela oportunidade de ingressar no PAE.

- À todos do Laboratório de Radiometria Ambiental que me ajudaram. Dr. Ademar de Oliveira Ferreira, Dra. Sandra Regina Damatto, M.Sc. Marcelo Bessa, M.Sc. Flávia Valverde Lapa, Dr. Marcelo Francis Maduar, M.Sc. Reginaldo Ribeiro de Aquino, M.Sc. Marcos Medrado Alencar, Dra. Márcia Pires de Campos e muitos outros, meus agradecimentos.

- À toda minha família, amigos e conhecidos que de alguma forma contribuíram para a realização deste trabalho. Muito obrigada! 
"A vitória está reservada para aqueles que estão dispostos a pagar o preço." Sun Tzu

“ Há uma força motriz mais poderosa que o vapor, a eletricidade e a energia atômica: a vontade."

Albert Einstein

“Em todos os lugares e períodos ao longo de sua vida, aceite sinceramente o que o lugar e o momento podem lhe dar e encare as limitações como vantagens, não como problemas."

John Ruskin 


\section{AVALIAÇÃO DA VARIAÇÃO DA RADIOATIVIDADE NATURAL EM AREIAS DA PRAIA DE CAMBURI- VITÓRIA- ESPÍRITO SANTO COM FATORES CLIMATOLÓGICOS E GEOLÓGICOS DA REGIÃO.}

\section{Lívia Fernandes Barros}

\section{RESUMO}

A principal contribuição para a exposição externa aos seres humanos provem da radioatividade natural presente em solos, principalmente do ${ }^{40} \mathrm{~K}$ e das séries do ${ }^{238} \mathrm{U}$ e ${ }^{232} \mathrm{Th}$. No presente trabalho foram determinadas as concentrações de atividade de ${ }^{226} \mathrm{Ra}$ (série do ${ }^{238} \mathrm{U}$ ), ${ }^{232} \mathrm{Th}$ e ${ }^{40} \mathrm{~K}$ em amostras superficiais de areia coletadas mensalmente em 11 locais ao longo da Praia de Camburi durante o ano de 2011, selecionados para cobrir toda a extensão da praia. As amostras seladas foram medidas por espectrometria gama, após um tempo de espera de aproximadamente 30 dias, para que fosse atingido o equilíbrio radioativo nas séries do ${ }^{238} \mathrm{U}$ e ${ }^{232} \mathrm{Th}$. A concentração de atividade do ${ }^{226} \mathrm{Ra}$ foi determinada pela média ponderada das concentrações do ${ }^{214} \mathrm{~Pb}$ e do ${ }^{214} \mathrm{Bi}$, a concentração de atividade do ${ }^{232} \mathrm{Th}$ pela média ponderada das concentrações do ${ }^{212} \mathrm{~Pb}$, do ${ }^{212} \mathrm{Bi}$ e do ${ }^{228} \mathrm{Ac}$. A atividade do ${ }^{40} \mathrm{~K}$ foi determinada pela sua única transição gama de $1460,8 \mathrm{keV}$. Para todas as amostras, as concentrações foram corrigidas pelos fatores de autoatenuação gama. A partir destas concentrações foram avaliados os índices radiológicos, atividade equivalente em rádio $\left(R a_{e q}\right)$, índice de concentração de atividade $\left(I_{\gamma}\right)$, índice de risco à exposição gama externo $\left(H_{\text {ext }}\right)$, índice de risco à exposição gama interno $\left(H_{\text {int }}\right)$, taxa de dose gama absorvida no ar $(D)$ em nGy. $\mathrm{h}^{-1}$ e dose efetiva anual (E) em mSv.a ${ }^{-1}$. No local estudado foi realizada uma avaliação da correlação das concentrações de atividade de ${ }^{226} \mathrm{Ra},{ }^{232} \mathrm{Th}$ e ${ }^{40} \mathrm{~K}$ com os fatores geológicos, geográficos, climatológicos (precipitação pluviométrica e temperatura) e oceanográficos (variação da altura das marés). Devido à presença forte de monazita, a concentração de ${ }^{232} \mathrm{Th}$ é mais elevada do que a concentração de ${ }^{226} \mathrm{Ra}$ e ${ }^{40} \mathrm{~K}$. As concentrações de atividade encontradas variaram de 4 Bq. $\mathrm{kg}^{-1}$ a $1380 \mathrm{~Bq} \cdot \mathrm{kg}^{-1}$ para o ${ }^{226} \mathrm{Ra}$, de $9 \mathrm{~Bq} \cdot \mathrm{kg}^{-1}$ a $7453 \mathrm{~Bq} \cdot \mathrm{kg}^{-1}$ para o ${ }^{232} \mathrm{Th}$ e de $6 \mathrm{~Bq} \cdot \mathrm{kg}^{-1}$ a $504 \mathrm{~Bq} \cdot \mathrm{kg}^{-1}$ para o ${ }^{40} \mathrm{~K}$. A variação 
encontrada para o $R a_{e q}$ foi de 20 Bq. $\mathrm{kg}^{-1}$ a $12077 \mathrm{~Bq} \cdot \mathrm{kg}^{-1}$, para o $I_{\gamma}$ foi de 0,07 a 42,08, para o $H_{\text {ext }}$ foi de 0,05 a 32,61, para o $H_{\text {int }}$ foi de 0,06 a 36,34 e para a taxa de dose absorvida no ar foi de $9 \mathrm{nGy} \cdot \mathrm{h}^{-1}$ a $5160 \mathrm{nGy} \cdot \mathrm{h}^{-1}$. As baixas concentrações de atividade de ${ }^{226} \mathrm{Ra},{ }^{232} \mathrm{Th}$ e ${ }^{40} \mathrm{~K}$ em todos os pontos no mês de abril estão possivelmente relacionadas aos valores máximos da variação da altura das marés e da precipitação pluviométrica. A temperatura média de Vitória durante o ano de 2011 não interfere diretamente nas variações observadas nas concentrações de atividade de ${ }^{226} \mathrm{Ra},{ }^{232} \mathrm{Th}$ e ${ }^{40} \mathrm{~K}$ das areias. Foi realizada uma avaliação da dose efetiva anual para um indivíduo do público que frequenta a Praia de Camburi durante 8 horas diárias em 1 mês, em janeiro ou em julho, e todas as doses encontradas estão abaixo do limite de $1 \mathrm{mSv}^{-1}{ }^{-1}$, recomendado pela ICRP 60 para público em geral. 


\title{
ASSESSMENT OF THE VARIATION OF NATURAL RADIOACTIVITY IN SANDS OF CAMBURI BEACH-VITÓRIA-ESPÍRITO SANTO WITH
} CLIMATOLOGICAL AND GEOLOGICAL FACTORS OF THE REGION.

\section{Lívia Fernandes Barros}

\begin{abstract}
The main contribution to the external exposure to humans comes from gamma emitting radionuclides in soils, especially the ${ }^{40} \mathrm{~K}$ and ${ }^{238} \mathrm{U}$ and ${ }^{232} \mathrm{Th}$ series. In this work, the activity concentrations of ${ }^{226} \mathrm{Ra}\left({ }^{238} \mathrm{U}\right.$ serie $),{ }^{232} \mathrm{Th}$ and ${ }^{40} \mathrm{~K}$ in surface sand monthly collected at 11 sites along the Camburi beach during the year 2011, selected to cover the entire length of the beach, were determined. The samples were hermetically sealed and measured by high resolution gamma spectrometry, after a resting time of approximately 30 days, in order to attain the radioactive equilibrium in the ${ }^{238} \mathrm{U}$ and ${ }^{232} \mathrm{Th}$ series. The activity concentration of ${ }^{226} \mathrm{Ra}$ was determined by the weighted average concentrations of ${ }^{214} \mathrm{~Pb}$ and ${ }^{214} \mathrm{Bi}$, the activity concentration of ${ }^{232} \mathrm{Th}$ by the weighted average concentrations of ${ }^{212} \mathrm{~Pb},{ }^{212} \mathrm{Bi}$ and ${ }^{228} \mathrm{Ac}$. The activity of ${ }^{40} \mathrm{~K}$ was determined by its single transition of $1460,8 \mathrm{keV}$. For all samples the concentrations were corrected by self attenuation factors. From these concentrations, radiological indices like radium equivalent activity $\left(\mathrm{Ra}_{\mathrm{eq}}\right)$, activity concentration index $\left(I_{\gamma}\right)$, external exposure risk index $\left(H_{\text {ext }}\right)$, internal exposure risk index $\left(H_{\text {int }}\right)$, absorbed gamma dose rate in air $(D)$ in $\mathrm{nGy} \cdot \mathrm{h}^{-1}$ and annual effective dose $(E)$ in $\mathrm{mSv}^{-1} \mathrm{y}^{-1}$ were evaluated. In the studied area it was realized an assessment of the correlation of the activity concentrations of ${ }^{226} \mathrm{Ra}$, ${ }^{232} \mathrm{Th}$ and ${ }^{40} \mathrm{~K}$ with the geological, geographical, climatological (rainfall and temperature) and oceanographic (tidal height variation) factors. Due to the strong presence of monazite, the concentration of ${ }^{232} \mathrm{Th}$ is higher than the concentration of ${ }^{226} \mathrm{Ra}$ and ${ }^{40} \mathrm{~K}$. The activity concentrations found ranged from $4 \mathrm{~Bq} \cdot \mathrm{kg}^{-1}$ to $1380 \mathrm{~Bq} \cdot \mathrm{kg}^{-1}$ for ${ }^{226} \mathrm{Ra}$, from $9 \mathrm{~Bq} \cdot \mathrm{kg}^{-1}$ to $7453 \mathrm{~Bq} \cdot \mathrm{kg}^{-1}$ for ${ }^{232} \mathrm{Th}$ and $6 \mathrm{~Bq} \cdot \mathrm{kg}^{-1}$ to $504 \mathrm{~Bq} \cdot \mathrm{kg}^{-1}$ for ${ }^{40} \mathrm{~K}$. The variation of $R a_{e q}$ from $20 \mathrm{~Bq} \cdot \mathrm{kg}^{-1}$ to $12077 \mathrm{~Bq} \cdot \mathrm{kg}^{-1}$, of $I_{\gamma}$ from 0,07 to 42,08 , of $H_{e x t}$ from 0,05 to 32,61 , of $H_{\text {int }}$ from 0,06 to 36,34 and of absorbed gamma dose rate in air from $9 \mathrm{nGy} \cdot \mathrm{h}^{-1}$ to $5160 \mathrm{nGy} \cdot \mathrm{h}^{-1}$. The low activity concentrations of ${ }^{226} \mathrm{Ra},{ }^{232} \mathrm{Th}$ and ${ }^{40} \mathrm{~K}$
\end{abstract}


in all points in April, are possibly related to the maxima of the variation of the height of the tides and rainfall. The average temperature of Vitória during the year 2011 does not directly interfere in the observed variations in the activity concentrations of ${ }^{226} \mathrm{Ra},{ }^{232} \mathrm{Th}$ and ${ }^{40} \mathrm{~K}$ sands. The assessment of the annual effective dose to an individual from the public who attends the Camburi Beach throughout 8 hours per day in a month, in January or July, showed that all values are below the limit of $1 \mathrm{mSv} \cdot \mathrm{y}^{-1}$, recommended by the ICRP 60 for the general public. 


\section{SUMÁRIO}

Página

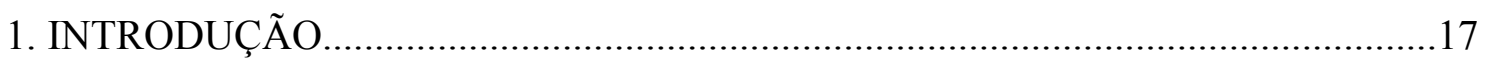

1.1 Radioatividade Natural e Séries Radioativas Naturais..........................................17

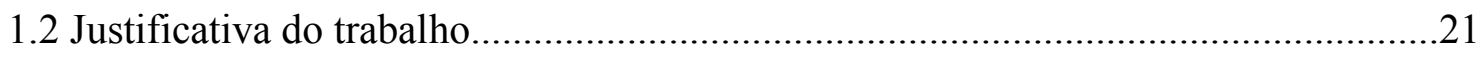

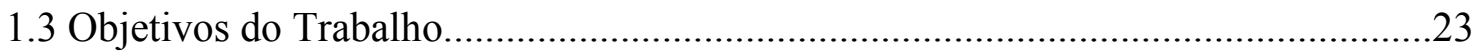

2. CARACTERÍSTICAS DA PRAIA DE CAMBURI................................................25

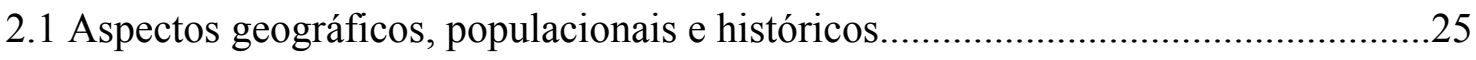

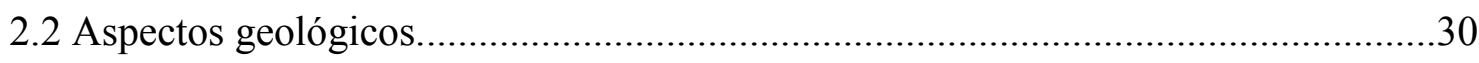

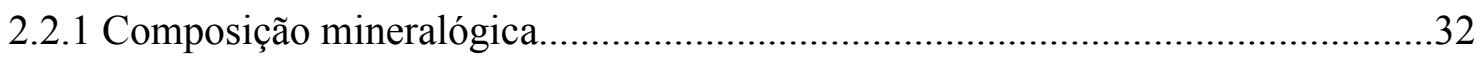

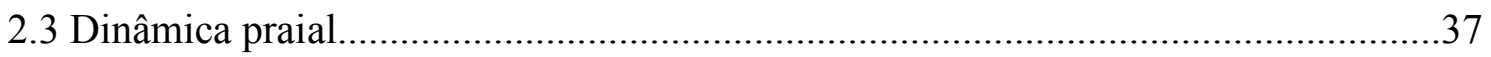

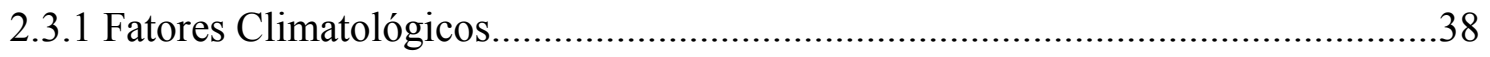

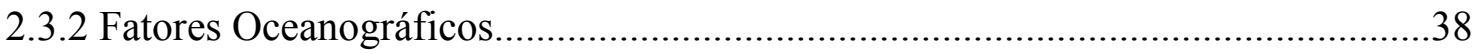

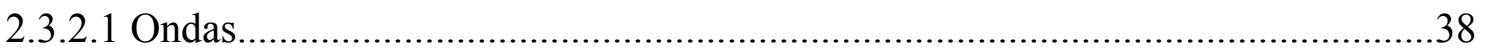

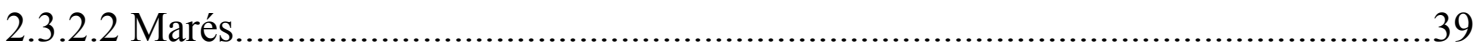

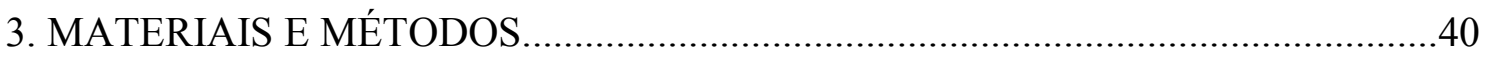

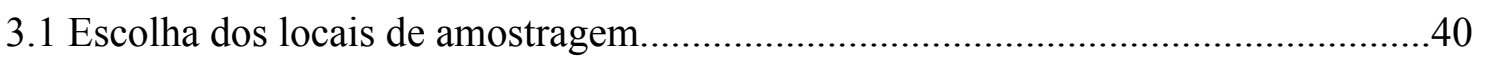

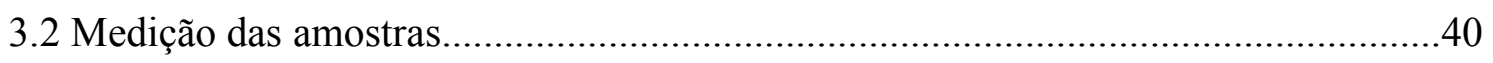

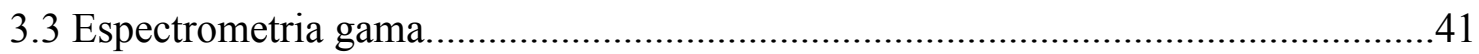

3.4 Cálculo da concentração de atividade de ${ }^{226} \mathrm{Ra},{ }^{232} \mathrm{Th}^{4}{ }^{40} \mathrm{~K}$....................................42

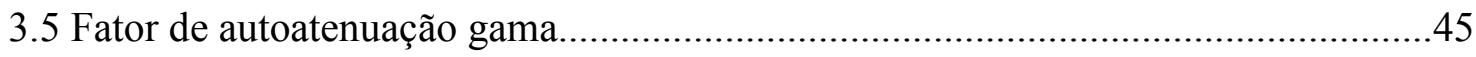

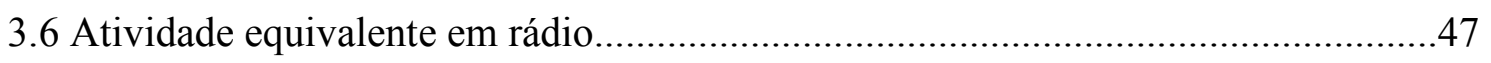

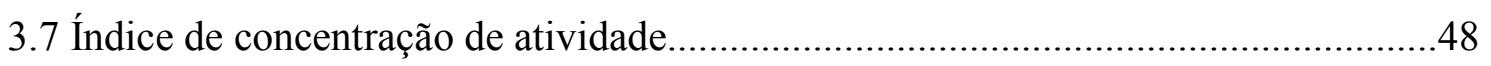

3.8 Índice de risco a exposição gama externo e interno...................................................48

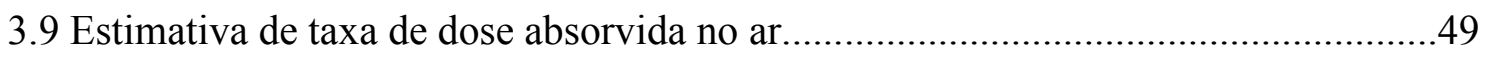

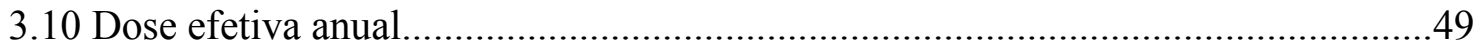

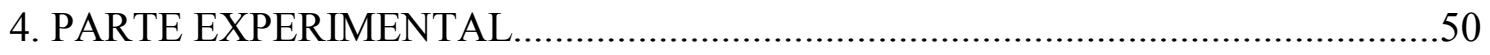

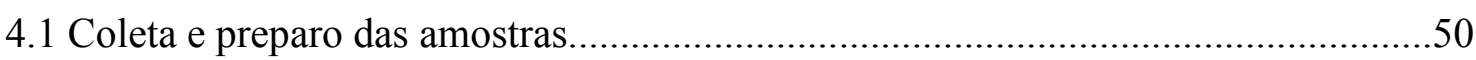

4.2 Detector Semicondutor de Germânio Hiperpuro e eletrônica associada....................53

4.2.1 Sistema de detecção da concentração de atividade de ${ }^{226} \mathrm{Ra},{ }^{232} \mathrm{Th}$ e ${ }^{40} \mathrm{~K} \ldots \ldots \ldots \ldots \ldots . . . .53$ 
4.2.2 Sistema de detecção utilizado na obtenção do fator de autoatenuação. 54

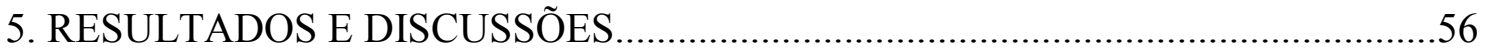

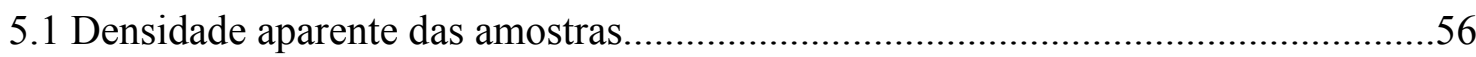

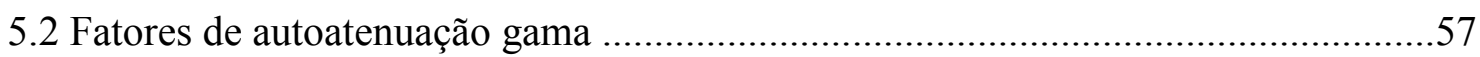

5.3 Concentração de atividade de ${ }^{226} \mathrm{Ra},{ }^{232} \mathrm{Th}$ e ${ }^{40} \mathrm{~K}$ no ano de 2011 ...........................61

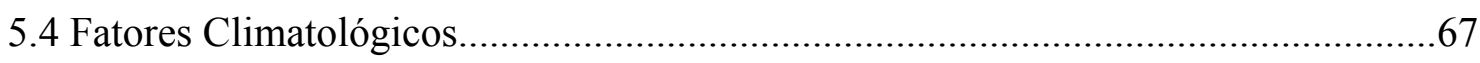

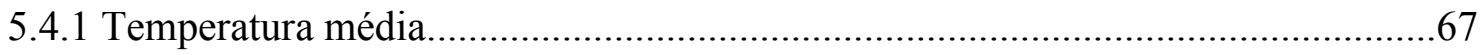

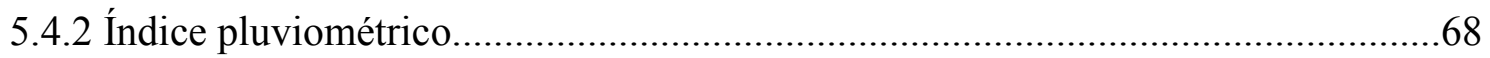

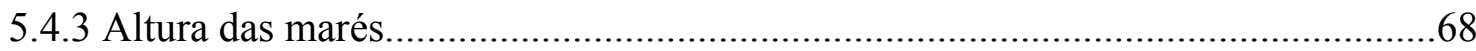

5.5 Relação das concentrações de atividade de ${ }^{226} \mathrm{Ra},{ }^{232} \mathrm{Th}$ e ${ }^{40} \mathrm{~K}$ com os fatores

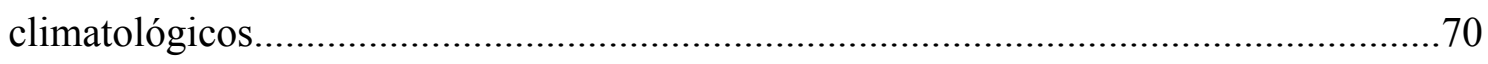

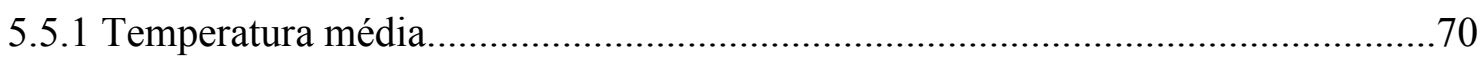

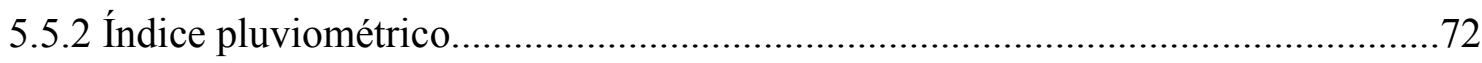

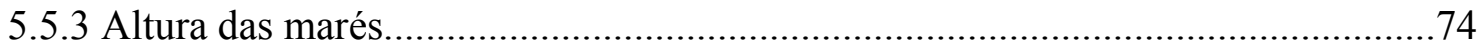

5.6 Concentrações de atividade de ${ }^{226} \mathrm{Ra},{ }^{232} \mathrm{Th}$ e ${ }^{40} \mathrm{~K}$ e fatores geológicos e

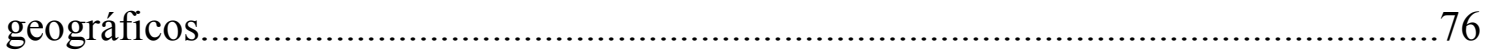

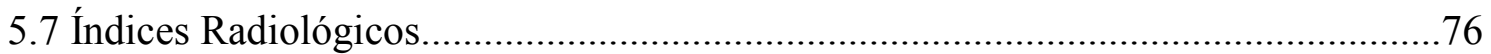

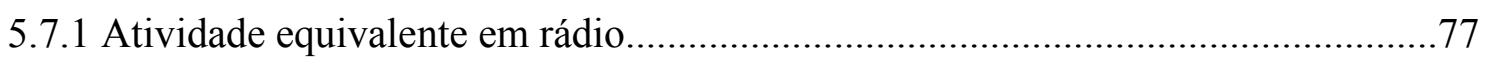

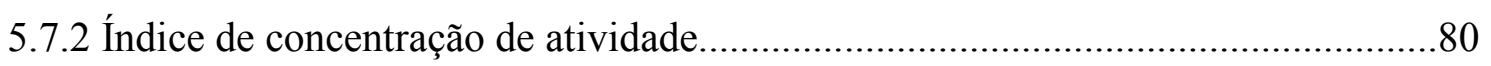

5.7.3 Índice de risco a exposição gama externo e interno..............................................81

5.7.4 Estimativa de taxa de dose absorvida no ar........................................................83

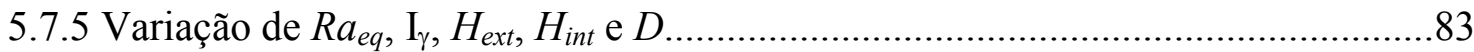

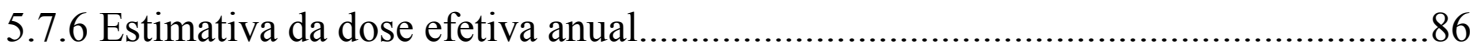

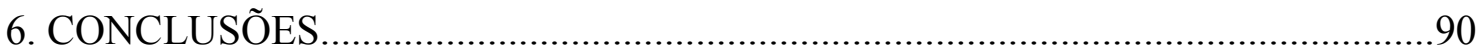

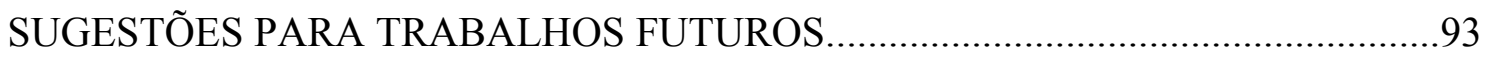

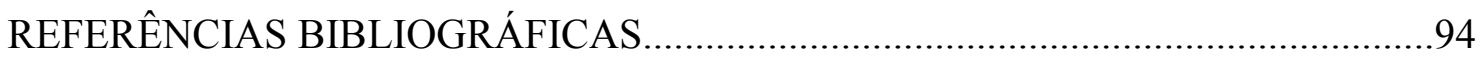

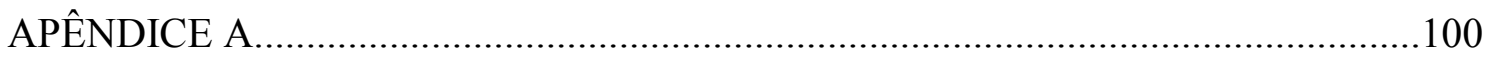

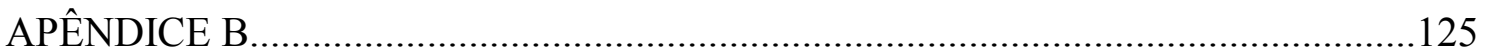


Figura 1 - Série radioativa do Urânio $\left({ }^{238} U\right)$ (Radiation Decay 4.0, 2005).................19

Figura 2 - Série Radioativa do Tório $\left({ }^{232} \mathrm{Th}\right.$ ) (Radiation Decay 4.0, 2005)

Figura 3 - Praia de Camburi, Vitória, Estado do Espírito Santo, Brasil. Fonte: Flávio Santos, 2004.

Figura 4 - (a) Mapa do Brasil com o Estado do Espírito Santo em vermelho. (b) Mapa do Estado do Espírito Santo com a cidade de Vitória em vermelho (ROTARY, 2012).

Figura 5 - Localização de Vitória na região metropolitana (região de número 1) do Estado do Espírito Santo, Brasil (ROTARY, 2012).

Figura 6 - Região da Praia de Camburi. Em destaque os Pontos de coleta (1-11), o Píer 1, Píer 2 e o Píer de Iemanjá, o Porto de Tubarão, a Baía de Vitória, o Porto de Vitória e a Ponta de Santa Luzia.....

Figura 7 - Região da Baía de Vitória, da Baía do Espírito Santo - onde localizamos a Praia de Camburi e a região de manguezal - após o Canal da Passagem (Rigo, 2004).

Figura 8 - Camburi em 1970 (CHS, 2012). 29

Figura 9 - Praia de Camburi, em primeiro plano o Pier de Iemanjá (Prefeitura de Vitória, 2012)......

Figura 10 - Mapa Geológico do Espírito Santo (IEMA, 2012).

Figura 11 - Minerais encontrados na areia. (a) Monazita (b) Ilmenita (c) Rutilo (d) Zircão (Mineralogia, 2013).......

Figura 12 - Localização geográfica dos pontos de coleta (1-11) na Praia de Camburi. 40

Figura 13 - Sistema de detecção e aquisição de dados por espectrometria gama de alta resolução. Modificado de (PO-LRA-0901, 2008). 41

Figura 14 - Areia da Praia de Camburi in situ, manchas escuras na região central da praia são visíveis devido a presença de ilmenita. Foto acervo pessoal, 2012 .51

Figura 15 - (a) Almofarizes utilizados para acondicionar a areia (b) Estufa utilizada para a secagem das areias. Foto acervo pessoal, 2012. .52 
Figura 16 - Frascos padrão de polietileno de alta densidade de $100 \mathrm{ml}$ com amostras, selados e envoltos em filme plástico transparente. Foto acervo pessoal, 2012 ...............52

Figura 17 - Detector HPGe utilizado para a medida das amostras. Foto acervo pessoal, 2012 .53

Figura 18 - (a) Posicionamento da amostra sobre o detector. (b) Amostra e detector dentro da blindagem. Foto acervo pessoal, 2012.

Figura 19 - Espectro obtido para a amostra coletada no Ponto 1 em dezembro de 2011. Foto acervo pessoal, 2012.

Figura 20 - Detector HPGe utilizado na obtenção dos fatores de autoatenuação. Foto acervo pessoal, 2012 . 55

Figura 21 - (a) Montagem experimental da amostra para obtenção dos fatores de autoatenuação dentro da blindagem. (b) Fontes pontuais padrão de ${ }^{152} \mathrm{Eu},{ }^{137} \mathrm{Cs},{ }^{133} \mathrm{Ba}$ e

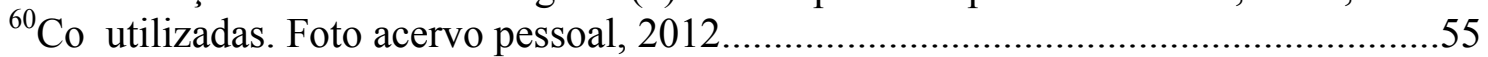

Figura 22 - Densidades aparentes das amostras de areia coletadas na Praia de Camburi por ponto de coleta a cada mês do ano de 2011 .... 57

Figura 23 - Curva de autoatenuação para a amostra coletada em março no ponto 11, de densidade aparente $1,81 \mathrm{~g} . \mathrm{cm}^{-3}$ .57

Figura 24 - Fator de autoatenuação por energia para as 132 amostras coletadas na Praia de Camburi no ano de 2011. .58

Figura 25 - Fator de autoatenuação em função da energia para as 9 amostras que possuem densidades de $1,62 \mathrm{~g} . \mathrm{cm}^{-3}$ coletadas na Praia de Camburi no ano de 2011 no respectivo mês e ponto de coleta .59

Figura 26 - Fator de autoatenuação em função da energia para as 10 amostras que possuem densidades de 1,67 g. $\mathrm{cm}^{-3}$ coletadas na Praia de Camburi no ano de 2011 no respectivo mês e ponto de coleta. .59

Figura 27 - Fator de autoatenuação em função da energia para as 13 amostras que possuem densidades de $1,68 \mathrm{~g} . \mathrm{cm}^{-3}$ coletadas na Praia de Camburi no ano de 2011 no respectivo mês e ponto de coleta.

Figura 28 - Concentração de atividade de ${ }^{226}$ Ra para as 132 amostras de areia coletadas na Praia de Camburi durante o ano de 2011.

Figura 29 - Concentração de atividade de ${ }^{232}$ Th para as 132 amostras de areia coletadas na Praia de Camburi durante o ano de 2011

Figura 30 - Concentração de atividade de ${ }^{40} \mathrm{~K}$ para as 132 amostras de areia coletadas na Praia de Camburi durante o ano de 2011. 
Figura 31 - Correlação entre as concentrações de atividade de ${ }^{226} \mathrm{Ra} \mathrm{e}^{232} \mathrm{Th}$ para as 132 amostras de areia coletadas na Praia de Camburi durante $o$ ano de 2011 . .63

Figura 32 - Temperatura média mensal $\left({ }^{\circ} \mathrm{C}\right)$ em Vitória durante o ano de 2011. (INCAPER, 2013).

Figura 33 - Variação da precipitação pluviométrica (mm) no ano de 2011 (INCAPER, 2013 .68

Figura 34 - Variação da altura das marés (m) dos Portos de Vitória e Tubarão no ano de 2011

Figura 35 - Variação da concentração de atividade de ${ }^{226} \mathrm{Ra}$ nos pontos de coleta e a variação da temperatura média mensal $\left({ }^{\circ} \mathrm{C}\right)$ em Vitória ao longo do ano de 2011. .70

Figura 36 - Variação da concentração de atividade de ${ }^{232} \mathrm{Th}$ nos pontos de coleta e a variação da temperatura média mensal $\left({ }^{\circ} \mathrm{C}\right)$ em Vitória ao longo do ano de 2011 .........71

Figura 37 - Variação da concentração de atividade de ${ }^{40} \mathrm{~K}$ nos pontos de coleta e a variação da temperatura média mensal $\left({ }^{\circ} \mathrm{C}\right)$ em Vitória ao longo do ano de 2011. .71

Figura 38 - Variação da concentração de atividade de ${ }^{226} \mathrm{Ra}$ nos pontos de coleta e a variação da índice de precipitação pluviométrica $(\mathrm{mm})$ em Vitória ao longo do ano de 2011. .72

Figura 39 - Variação da concentração de atividade de ${ }^{232}$ Th nos pontos de coleta e a variação da índice de precipitação pluviométrica $(\mathrm{mm})$ em Vitória ao longo do ano de 2011 ...... .73

Figura 40 - Variação da concentração de atividade de ${ }^{40} \mathrm{~K}$ nos pontos de coleta e a variação da índice de precipitação pluviométrica $(\mathrm{mm})$ em Vitória ao longo do ano de 2011 .73

Figura 41 - Variação da concentração de atividade de ${ }^{226} \mathrm{Ra}$ nos pontos de coleta e a variação das alturas das marés $(\mathrm{mm})$ do Porto de Tubarão e do Porto de Vitória ao longo do ano de 2011 .74

Figura 42 - Variação da concentração de atividade de ${ }^{232} \mathrm{Th}$ nos pontos de coleta e a variação das alturas das marés $(\mathrm{mm})$ do Porto de Tubarão e do Porto de Vitória ao longo do ano de 2011. .75

Figura 43 - Variação da concentração de atividade de ${ }^{40} \mathrm{~K}$ nos pontos de coleta e a variação das Alturas das marés $(\mathrm{mm})$ do Porto de Tubarão e do Porto de Vitória ao longo do ano de 2011 .75

Figura 44 - Atividade equivalente em rádio $\left(R a_{e q}\right)$ para as 132 amostras de areia coletadas na Praia de Camburi durante o ano de 2011.

Figura 45 - Atividade equivalente em rádio $\left(R a_{e q}\right)$ para as 132 amostras de areia coletadas na Praia de Camburi durante o ano de 2011, se utilizadas como contrapiso. Em azul o limite para $R a_{\text {eq }}$ de 370 Bq. $\mathrm{kg}^{-1}$. .78 
Figura 46 - Atividade equivalente em rádio $\left(R a_{e q}\right)$ para as 132 amostras de areia coletadas na Praia de Camburi durante o ano de 2011, se utilizadas como reboco/embosso interno, concreto de laje, calçada ou piso. Em azul o limite para $R a_{e q}$ de $370 \mathrm{~Bq} \cdot \mathrm{kg}^{-1}$..... 79

Figura 47 - Atividade equivalente em rádio $\left(R a_{e q}\right)$ para as 132 amostras de areia coletadas na Praia de Camburi durante o ano de 2011, se utilizadas como reboco/embosso externo. Em azul o limite para $R a_{e q}$ de $370 \mathrm{~Bq} \cdot \mathrm{kg}^{-1}$ .79

Figura 48 - Atividade equivalente em rádio $\left(R a_{e q}\right)$ para as 132 amostras de areia coletadas na Praia de Camburi durante o ano de 2011, se utilizadas como chapisco de parede. Em azul o limite para $R a_{e q}$ de $370 \mathrm{~Bq} \cdot \mathrm{kg}^{-1}$ .80

Figura 49 - Índice de concentração de atividade $\mathrm{I}_{\gamma}$ para as 132 amostras de areia coletadas na Praia de Camburi durante o ano de 2011. Em destaque em verde e azul respectivamente os limites $\mathrm{I} \leq 0,5$ e $\mathrm{I} \leq 1$

Figura 50 - Índice de risco a exposição gama externo $H_{\text {ext }}$ para as 132 amostras de areia coletadas na Praia de Camburi durante o ano de 2011. Em azul o limite $H_{\text {ext }}=1$. .82

Figura 51 - Índice de risco a exposição gama interno $H_{\text {int }}$ para as 132 amostras de areia coletadas na Praia de Camburi durante o ano de 2011. Em azul o limite $H_{\text {int }}=1$ 82

Figura 52 - Taxa de dose absorvida no ar $(D)$ para as 132 amostras de areia coletadas na Praia de Camburi durante o ano de 2011. .83

Figura 53 - Dose efetiva anual $(E)$ referente a 100\% de exposição (24 horas por dia) para as 132 amostras de areia coletadas na Praia de Camburi durante o ano de 2011. Em azul o limite de $1 \mathrm{mSv} \cdot \mathrm{a}^{-1}$ da ICRP 60 (ICRP, 1990) para público em geral. .86

Figura 54 - Dose efetiva anual (E) referente à 1 hora de exposição por dia para as 132 amostras de areia coletadas na Praia de Camburi durante o ano de 2011. Em azul o limite de $1 \mathrm{mSv} \cdot \mathrm{a}^{-1}$ da ICRP 60 (ICRP, 1990) para público em geral

Figura 55 - Dose efetiva anual (E) referente à 1 hora de exposição por dia em cada ponto de coleta (1-11) na Praia de Camburi durante o ano de 2011. .87

Figura 56 - Dose efetiva anual (E) referente à 8 horas de exposição por dia durante o mês de janeiro de 2011 em cada ponto de coleta (1-11) na Praia de Camburi. .88

Figura 57 - Dose efetiva anual (E) referente à 8 horas de exposição por dia durante o mês de julho de 2011 em cada ponto de coleta (1-11) na Praia de Camburi. .88 
Tabela 1 - Transições gama utilizadas para a determinação das concentrações de

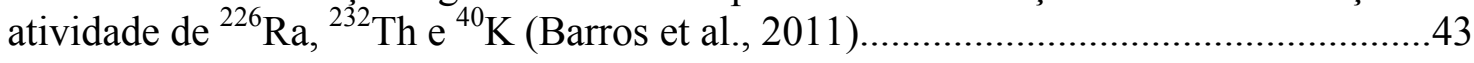

Tabela 2- Transições das energias dos raios gama selecionados para a determinação da

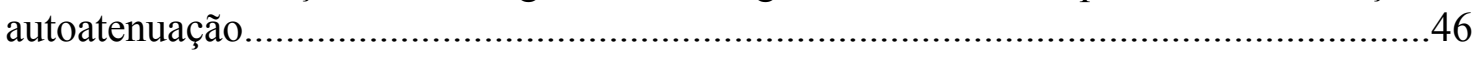

Tabela 3 - Coordenadas geográficas dos pontos de coleta da Praia de Camburi, 2011

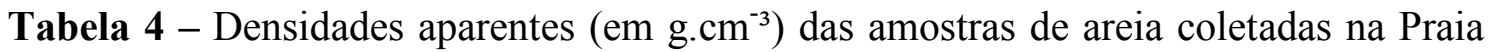
de Camburi no ano de 2011. A incerteza da densidade aparente é de 3\% .56

Tabela 5 - Faixas de concentrações de atividade de ${ }^{226} \mathrm{Ra},{ }^{232} \mathrm{Th}$ e ${ }^{40} \mathrm{~K}$ de amostras de areia da Praia de Camburi, Espírito Santo, Brasil. 65

Tabela 6 - Faixas de concentrações de atividade de ${ }^{226} \mathrm{Ra},{ }^{232} \mathrm{Th}$ e ${ }^{40} \mathrm{~K}$ de amostras de areia de praias do Brasil, Índia, Turquia, China e Egito

Tabela 7 - Fração de areia utilizada em cada tipo de material de construção (Aquino, 2010) .78

Tabela 8 - Faixas de variação dos índices radiológicos de amostras de areia da Praia de Camburi, Espírito Santo, Brasil. .84

Tabela 9 - Faixas de variação dos índices radiológicos de amostras de areia de praias do Brasil, Índia, Turquia, China e Egito. .85 


\section{INTRODUÇÃO}

\subsection{Radioatividade Natural e Séries Radioativas Naturais}

A exposição de seres humanos à radiação ionizante de fontes naturais é uma característica contínua e inevitável da vida sobre a Terra. Nosso planeta contém muitas espécies de radionuclídeos naturais, em praticamente tudo, organismos vivos, rochas, solos, água e atmosfera. A radioatividade natural é, reconhecidamente, a maior fonte de exposição a radiações ionizantes para a população mundial, cerca de $87 \%$ da dose de radiação recebida pela humanidade é devido a fontes naturais de radiação (UNSCEAR, 1993) e esta exposição excede a de todas as fontes artificiais combinadas, para a maioria dos indivíduos (UNSCEAR, 2008) .

As fontes de radioatividade natural classificam-se em dois tipos: as fontes externas que abrangem a radiação cosmogênica, produzida pela interação dos raios cósmicos de altas energias com o ar na atmosfera, principalmente por captura de nêutrons, e a radiação terrestre, decorrente dos radionuclídeos primordiais, que tiveram síntese nas estrelas e as fontes internas presentes no ar e nos alimentos que são inalados ou ingeridos. Estima-se que a dose anual média resultante de fontes naturais seja de $2,4 \mathrm{mSv}$ (UNSCEAR, 2000).

A radiação cósmica pode ser dividida em diferentes tipos de acordo com a sua origem de energia, tipo e densidade de fluxo das partículas. Além da blindagem fornecida pelo campo magnético da terra, a vida é protegida contra esta radiação por uma camada de ar de aproximadamente $1000 \mathrm{~g} / \mathrm{cm}^{2}$, que é comparável a $10 \mathrm{~m}$ de espessura da camada de água (UNSCEAR, 2008). Estes raios cósmicos interagem com os componentes dos núcleos da atmosfera para produzir uma cascata de produtos de reação provenientes de interações secundárias que contribuem para a exposição a raios cósmicos. As interações de raios cósmicos também produzem um número de núcleos de substâncias radioativas conhecidas como radionuclídeos cosmogênicos (UNSCEAR, 2008). 
Os radionuclídeos naturais de origem terrestre, também denominados radionuclídeos primordiais, estão presentes em vários graus em todos os meios ambientais, incluindo no corpo humano (UNSCEAR, 2008). Eles podem ocorrer de duas formas, isolados ou em séries radioativas; existem aproximadamente 12 radionuclídeos isolados, sendo o de maior importância o ${ }^{40} \mathrm{~K}$, pois, além de amplamente distribuído na crosta terrestre, é encontrado em todos os sistemas biológicos (seres vivos) (Kathren, 1998).

Apenas os radionuclídeos com meias-vidas comparáveis com a idade da terra e os seus produtos de decaimento existem em quantidade suficiente para contribuir significativamente para a exposição da população (UNSCEAR, 2008).

As séries radioativas naturais são chamadas série do urânio, série do actínio e série do tório (Kathren, 1998). A série do urânio corresponde ao decaimento do ${ }^{238} \mathrm{U}$, de meia vida de 4,51 bilhões de anos e abundância isotópica de 99,27\%, a série do actínio corresponde ao decaimento do ${ }^{235} \mathrm{U}$, de meia vida de 704 milhões de anos e abundância isotópica de $0,72 \%$ e a série do tório corresponde ao decaimento do ${ }^{232} \mathrm{Th}$, de meia vida de 14,1 bilhões de anos e abundância isotópica de 100\% (Kathren, 1998).

Em uma série radioativa o nuclídeo pai decai para o nuclídeo filho, que decai por sua vez, e assim por diante, até que se alcance um produto final estável (Evans, 1972). A série do ${ }^{238} \mathrm{U}$ termina no ${ }^{206} \mathrm{~Pb}$, de abundância isotópica de $26,26 \%$, a série do ${ }^{235} \mathrm{U}$ termina no ${ }^{207} \mathrm{~Pb}$, de abundância isotópica de $20,8 \%$ e a série do ${ }^{232} \mathrm{Th}$ termina no ${ }^{208} \mathrm{~Pb}$, de abundância isotópica de 51,55\%, todos isótopos estáveis (Kathren, 1998).

As séries radioativas do urânio $\left({ }^{238} \mathrm{U}\right)$ e do tório $\left({ }^{232} \mathrm{Th}\right)$ podem ser visualizadas nas FIG.1 e 2, respectivamente: 


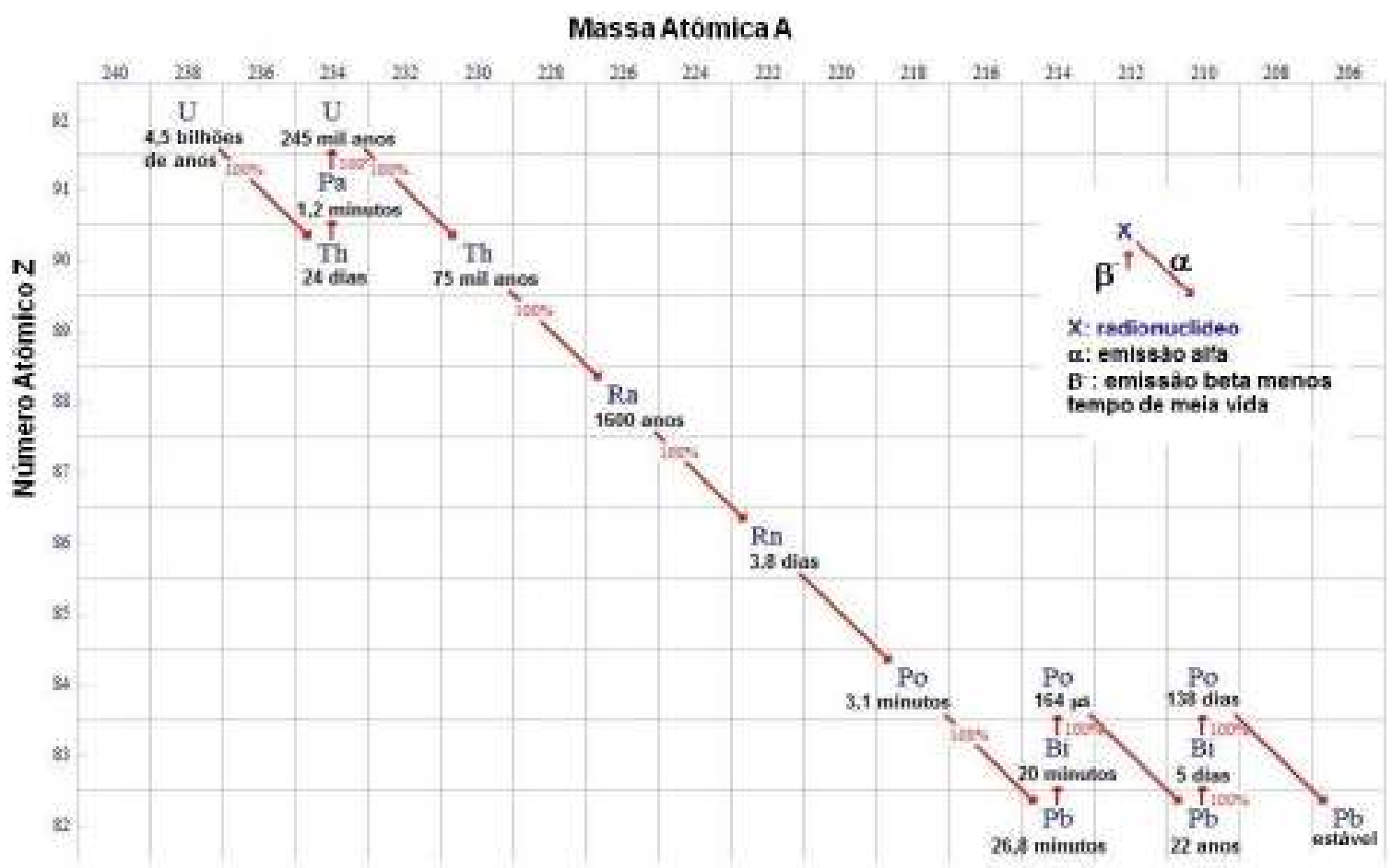

FIGURA 1 - Série radioativa do Urânio $\left({ }^{238} \mathrm{U}\right)$ (Radiation Decay 4.0, 2005).

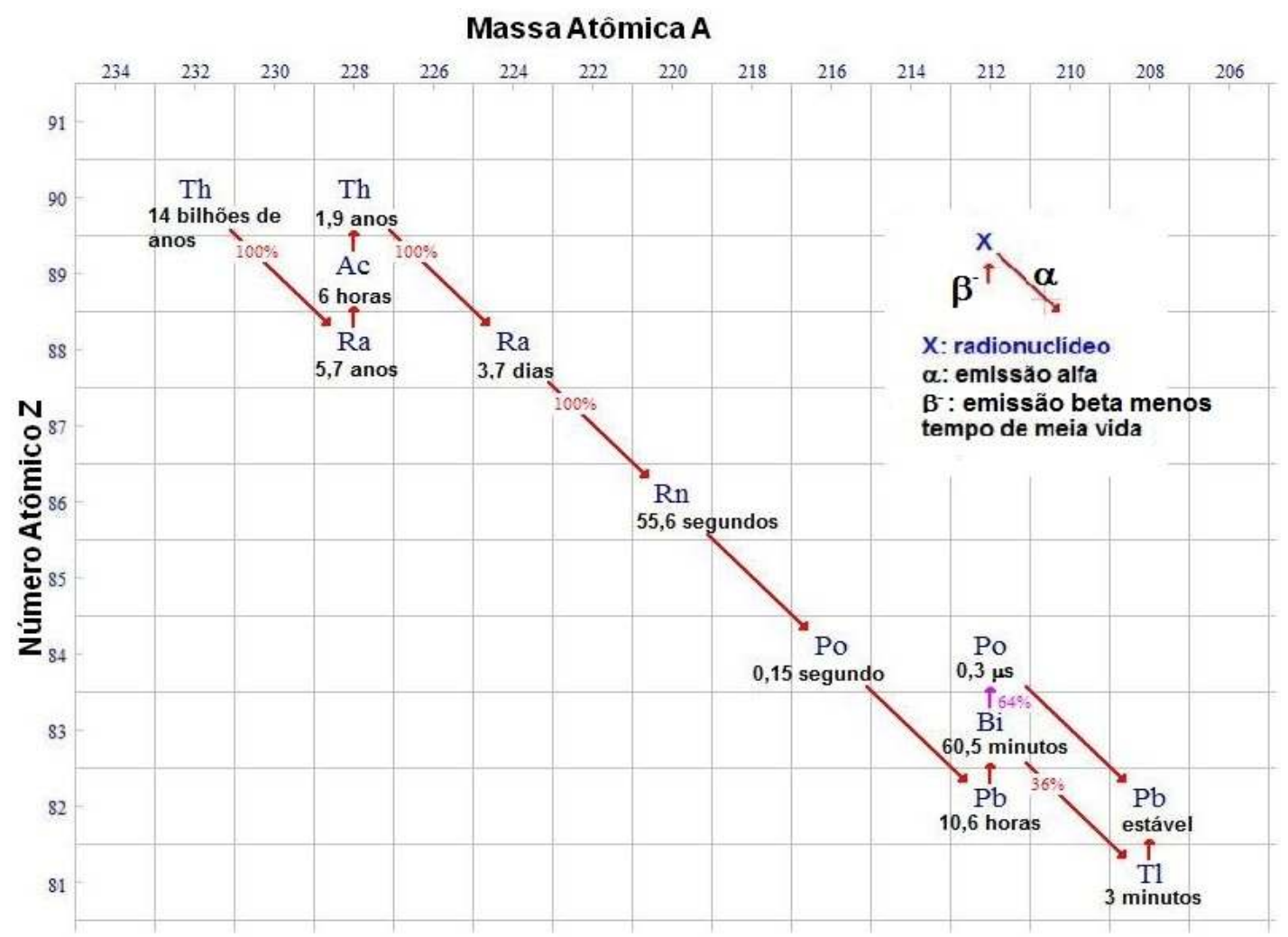

FIGURA 2 - Série Radioativa do Tório $\left({ }^{232} \mathrm{Th}\right)$ (Radiation Decay 4.0, 2005). 
$\mathrm{O}{ }^{40} \mathrm{~K}$, de meia vida de 1,28 bilhão de anos e abundância isotópica de $0,0118 \%$ é um radionuclídeo que ocorre isoladamente na natureza (Kathren, 1998). O ${ }^{40} \mathrm{~K}$ decai para o ${ }^{40} \mathrm{Ca}$ no estado fundamental com probabilidade de $89 \%$ por emissão $\beta^{-}$. Também decai para o estado fundamental do ${ }^{40} \mathrm{Ar}$ por captura eletrônica com probabilidade de $0,2 \%$, por emissão de pósitron com probabilidade de $0,001 \%$ e por captura eletrônica com probabilidade de $10,5 \%$ para o ${ }^{40} \mathrm{Ar}$ num estado excitado que emite um fóton de $1460 \mathrm{keV}$, utilizado para identificar e quantificar ${ }^{40} \mathrm{~K}$ por espectrometria gama (Kathren, 1998).

A principal contribuição para a exposição externa provem de radionuclídeos emissores gama presentes em solos, principalmente do ${ }^{40} \mathrm{~K}$ e das séries do ${ }^{238} \mathrm{U}$ e ${ }^{232} \mathrm{Th}$. Estes radionuclídeos, quando estão também presentes no corpo (ingeridos ou inalados), irradiam os vários órgãos com partículas alfa e beta, bem como com radiação gama (UNSCEAR, 2000).

Areias de praias localizadas em regiões que possuem níveis de exposição superiores aos considerados "de fundo normal" apresentam altas concentrações de atividade de ${ }^{226} \mathrm{Ra}$ (radionuclídeo da série do ${ }^{238} \mathrm{U}$ ), de ${ }^{232} \mathrm{Th}$ e de ${ }^{40} \mathrm{~K}$ em estudos anteriores devido a fontes naturais de radiação. É o caso de areias de praias do Egito (Uosif et al., 2008; Eissa et al., 2010), da China (Xinwei e Zhang, 2008), da Turquia (Cevik et al., 2009), da Índia (Kannan et al., 2002), de Bangladesh (Alam et al., 1998) e do Brasil (Veiga et al., 2006, Aquino, 2010), e também em outros países como Austrália, Áustria, França, Irã, África do Sul, Tailândia e Sri Lanka (Andrade, 2011).

No Brasil, os níveis de radioatividade de fundo elevados são devidos principalmente aos elementos associados em alguns minerais de terras raras, que ocorrem na monazita e em outros minerais pesados como a ilmenita, zirconita e o rutilo, encontrados em areia de praia (Andrade, 2011). O país está entre os que possuem os maiores e mais importantes depósitos de monazita no planeta Terra (Riedel e Eisenmenger, 1999).

Depósitos minerais de monazita, zircão, magnetita, ilmenita, rutilo e granada têm sido de interesse econômico nos últimos 50, 60 anos devido a sua ampla utilização para muitas finalidades. Areia de zircão é utilizada em indústrias de fundição e 
cerâmica. Por outro lado, a monazita é um dos mais importantes materiais geológicos ricos em tório (Alam et al., 1998).

O Estado do Espírito Santo, localizado na região sudeste do Brasil, é famoso por conter as areias monazíticas. A monazita pode conter até $10 \%$ de tório em seu peso e, quando misturada a ilmenita, possui um aspecto arenoso e de cor preta (Kathren, 1998).

Dentre as maiores anomalias na concentração de tório no solo no Brasil estão os depósitos de areia monazítica de Guarapari, no Estado do Espírito Santo (Eisenbud, 1987). A areia da Praia da Areia Preta em Guarapari foi objeto de estudo em 2003, quanto à variação sazonal dos seus altos níveis de radioatividade (Moura, 2003).

Aquino (2010) avaliou a concentração de atividade de ${ }^{226} \mathrm{Ra}$, de ${ }^{232} \mathrm{Th}$ e de ${ }^{40} \mathrm{~K}$ de 16 localizações ao longo da costa da região da Grande Vitória, no Estado do Espírito Santo, dentre elas as praias de Manguinhos, Jacaraípe, Praia do Canto, Praia de Camburi, Praia da Costa, Praia de Itapuã, Praia do Morro e a Praia da Areia Preta, constatando a radioatividade natural do local. Em seu trabalho, Aquino (2010) verificou que, além da Praia de Areia Preta, de Guarapari, a Praia de Camburi apresentava as maiores concentrações de atividade dentre as outras regiões estudadas.

\subsection{Justificativa do trabalho}

Dentre os lugares mais frequentados, as praias são visitadas por turistas e pela sociedade em geral durante todo o ano para a prática de atividades esportivas e de lazer, hábito que se intensifica no verão.

A Praia de Camburi (FIG. 3) localizada na cidade de Vitória, capital do Estado do Espírito Santo, Brasil, é bastante frequentada pela sociedade capixaba e por turistas. 


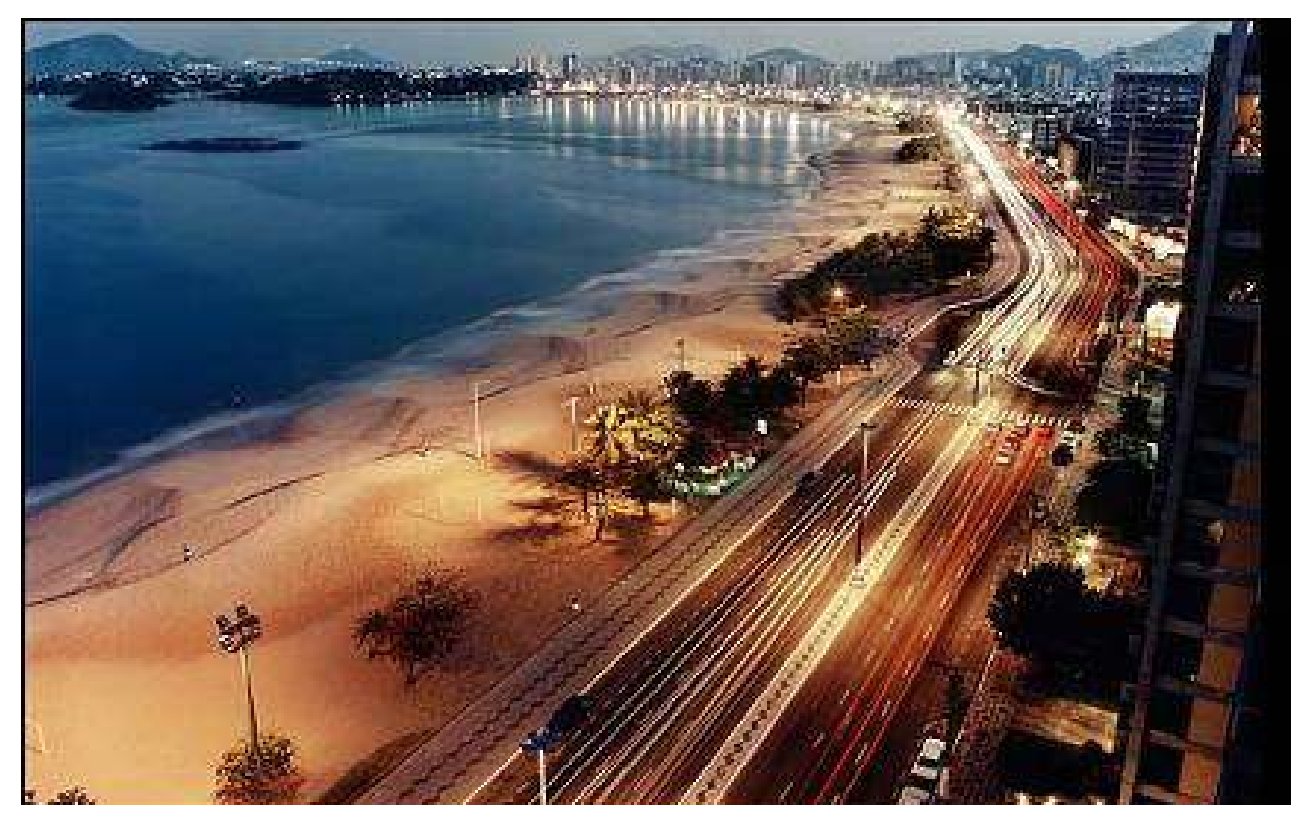

FIGURA 3 - Praia de Camburi, Vitória, Estado do Espírito Santo, Brasil. Fonte: Flávio Santos, 2004.

Na FIG. 3 é visível o padrão de manchas devido à concentração de ilmenita que se estende ao logo da praia. Rica em sílica $\left(\mathrm{SiO}_{2}\right)$, monazita $((\mathrm{Ce}$, $\left.\mathrm{La}, \mathrm{Nd}, \mathrm{Th}) \mathrm{PO}_{4}\right)$ e ilmenita $\left(\mathrm{FeTiO}_{3}\right)$, a Praia de Camburi contém altas concentrações de atividade de ${ }^{226} \mathrm{Ra}$, de ${ }^{232} \mathrm{Th}$ e de ${ }^{40} \mathrm{~K}$, verificadas por Aquino (2010). Em uma amostragem realizada no ano de 2008 em três diferentes locais de coleta ao longo da extensão da praia, Aquino (2010) verificou que as concentrações de atividade de ${ }^{226} \mathrm{Ra}$, de ${ }^{232} \mathrm{Th}$ e de ${ }^{40} \mathrm{~K}$ variavam.

O estudo da radioatividade natural das areias da Praia de Camburi, principalmente ao que se refere às concentrações de atividade de ${ }^{226} \mathrm{Ra},{ }^{232} \mathrm{Th}$ e ${ }^{40} \mathrm{~K}$ é de extrema relevância, tendo em vista que estes radionuclídeos têm participação fundamental na exposição externa da população devido sua emissão gama e possíveis implicações radiológicas (UNSCEAR, 2008).

Torna-se importante, portanto, fazer um estudo da radioatividade natural das areias da Praia de Camburi e avaliar o incremento da dose anual decorrente da permanência da população na praia e consequente exposição externa à radiação gama. 
Há apenas poucos estudos sobre a radioatividade natural das areias da Praia de Camburi, Vitória, Espírito Santo. Aquino (2010) utilizou um detector de germânio hiper puro medindo, em laboratório, areias coletadas em 3 pontos de amostragem (Camburi Norte, Central e Sul) e Sperandio (2011), um contador Geiger Müller medindo as areias no próprio local.

Na região central da Praia de Camburi, Aquino (2010) encontrou a maior concentração de atividade de ${ }^{226} \mathrm{Ra}$ e a segunda maior concentração de atividade de ${ }^{232} \mathrm{Th}$ dentre as 16 localizações por ele estudadas. Em sugestão para novos trabalhos, Aquino (2010) propôs que o estudo da radioatividade natural fosse estendido também a coletas realizadas ao longo das estações do ano.

Comparando-se os níveis de radioatividade das praias medidos na década de 60 com valores atuais, pode-se concluir que estes níveis vem aumentando, no entanto, efeitos de marés e correntes, tanto diários como sazonais, podem mascarar os resultados obtidos (Moura, 2003).

Os ventos, as ondas por eles geradas e as correntes marítimas que se desenvolvem quando ondas chegam à linha de costa, além das marés, atuam ininterruptamente sobre os materiais que se encontram na praia, erodindo, transportando e depositando sedimentos (Klein et al., 2005).

Por esta razão, fatores geológicos, geográficos, climatológicos (precipitação pluviométrica e temperatura) e oceonográficos (variação sazonal das marés) de Vitória serão investigados neste trabalho.

$\mathrm{O}$ índice de precipitação pluviométrica, a temperatura média $\left({ }^{\circ} \mathrm{C}\right)$ de Vitória e a variação das alturas do nível do mar de Vitória serão relacionados com as concentrações de atividade de ${ }^{40} \mathrm{~K},{ }^{226} \mathrm{Ra}$ e ${ }^{232} \mathrm{Th}$ obtidas para as amostras de areia analisadas.

\subsection{Objetivos do Trabalho}

Este estudo tem como principais objetivos: 
- Medir a concentração de atividade de ${ }^{226} \mathrm{Ra},{ }^{232} \mathrm{Th}$ e ${ }^{40} \mathrm{~K}$ ao longo da Praia de Camburi durante o ano de 2011, formando um banco de dados atualizado.

- Avaliar os índices radiológicos das amostras coletadas, como a atividade equivalente em rádio $R a_{e q}$, o índice de concentração de atividade $I_{\gamma}$, os índices de risco a exposição gama externo $\left(H_{\text {ext }}\right)$ e interno $\left(H_{\text {int }}\right)$, a taxa de dose gama absorvida no ar destes radionuclídeos (D) em nGy.h $\mathrm{h}^{-1}$ e a dose efetiva anual $(E)$ em $\mathrm{mSv} \cdot \mathrm{a}^{-1}$. Os resultados serão avaliados em relação aos limites de proteção radiológica recomendados para a população (Beretka e Mathew, 1985; EC, 1999; ICRP 60 , 1990).

- Investigar fatores geológicos, geográficos, climáticos, oceanográficos e históricos para tentar relacionar com as características radiológicas atuais da Praia de Camburi.

- Relacionar os valores de concentração de atividade encontrados com dados de comportamento sazonal, como os índices de precipitação pluviométrica, temperatura média $\left({ }^{\circ} \mathrm{C}\right)$ de Vitória e a variação das alturas do nível do mar, fornecido nas tábuas de marés do Banco Nacional de Dados Oceanográficos (BNDO, 2012). 


\section{CARACTERÍSTICAS DA PRAIA DE CAMBURI}

\subsection{Aspectos geográficos, populacionais e históricos.}

Vitória, capital do Estado do Espírito Santo, Brasil (FIG.4) está situada na região metropolitana, conforme a divisão regional do Estado (FIG.5).

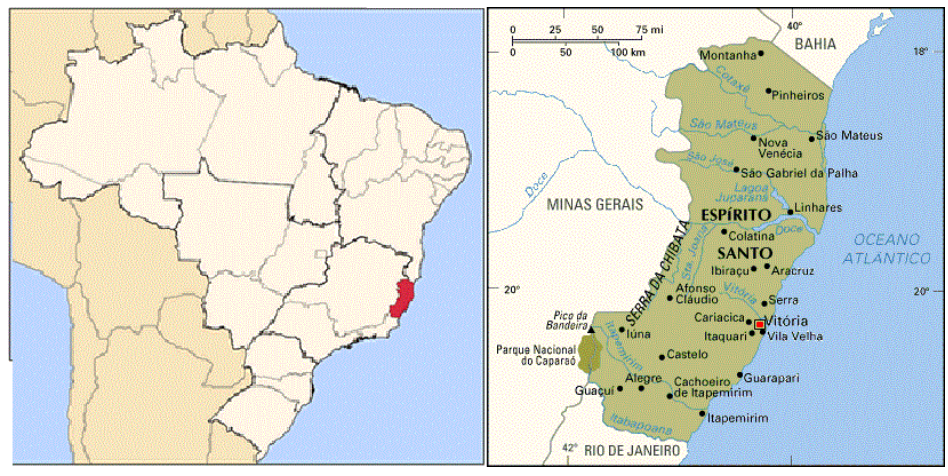

(a)

(b)

FIGURA 4 - (a) Mapa do Brasil com o Estado do Espírito Santo em vermelho. (b) Mapa do Estado do Espírito Santo com a cidade de Vitória em vermelho (ROTARY, 2012).

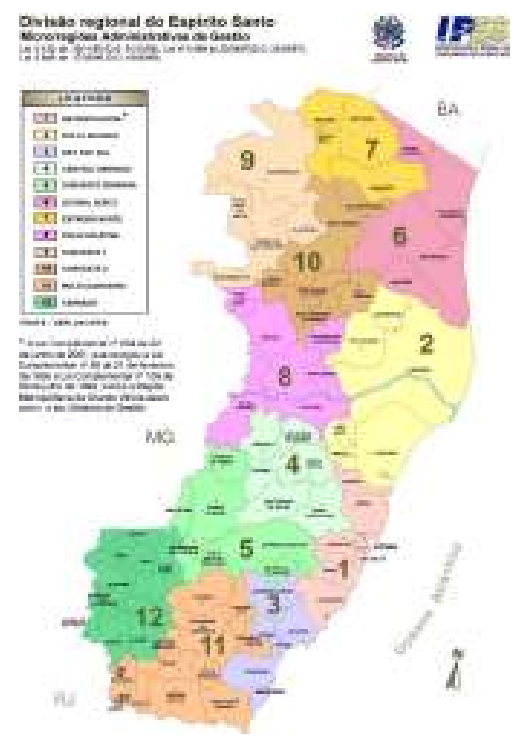

FIGURA 5 - Localização de Vitória na região metropolitana (região de número 1) do Estado do Espírito Santo, Brasil (ROTARY, 2012). 
Vitória é a terceira capital mais antiga do Brasil, construída logo depois de Recife (1548) e Salvador (1549) (Russo, 2012). Fundada em 1551, a capital do estado do Espírito Santo abriga um dos mais importantes portos do país, o Porto de Tubarão, por onde é escoada grande parte da carga de minérios exportada, oriunda dos estados de Minas Gerais e do Pará. Situada entre o mar e as montanhas, a cidade está dividida em duas zonas distintas: uma alta e outra baixa (Russo, 2012).

A Praia de Camburi está situada ao norte do município de Vitória. Exposta para sudeste, a praia de Camburi possui como limites ao sul os afloramentos do cristalino representados pela Ilha do Fato e Ponta Formosa (Morro do Colégio Sagrado Coração de Maria) de coordenada $20^{\circ} 15^{\prime}$ Sul (S) $40^{\circ} 15^{\prime}$ Oeste (O) e, ao norte por uma saliência dos Tabuleiros da Formação Barreiras e pelo Porto de Tubarão, de coordenada $20^{\circ} 17^{\prime}$ Sul(S) $40^{\circ} 17^{\prime}$ Oeste $(\mathrm{O})$ (Sperandio, 2011).

A Praia de Camburi é a maior praia da capital e é a única praia de Vitória localizada na parte continental da cidade, com $6 \mathrm{~km}$ de extensão. É bastante frequentada, tem a melhor estrutura hoteleira de Vitória e relevância no cenário turístico da capital, sobretudo é uma importante área de recreação e lazer para a sociedade capixaba. Vitória possui atualmente cerca de 327.801 habitantes e compõe uma área de $99 \mathrm{~km}^{2}$ com bioma de mata atlântica (IBGE, 2012).

Além da geologia e dos processos naturais de deposição dos minerais na praia, intervenções artificiais realizadas nas décadas de 1980, 1990 e 2000 intensificaram a presença destes minerais ao longo da praia, se apresentando como um padrão de manchas escuras.

Observamos na FIG.6 os pontos de coleta (1-11) na Praia de Camburi, o Píer 1, Píer 2 e o Píer de Iemanjá, o Porto de Tubarão, a entrada de mar ao lado do Ponto 1 de coleta, que corresponde ao Canal da Passagem e em seguida a Ponte da Passagem, logo abaixo a Baía de Vitória e a Ponta de Santa Luzia. 


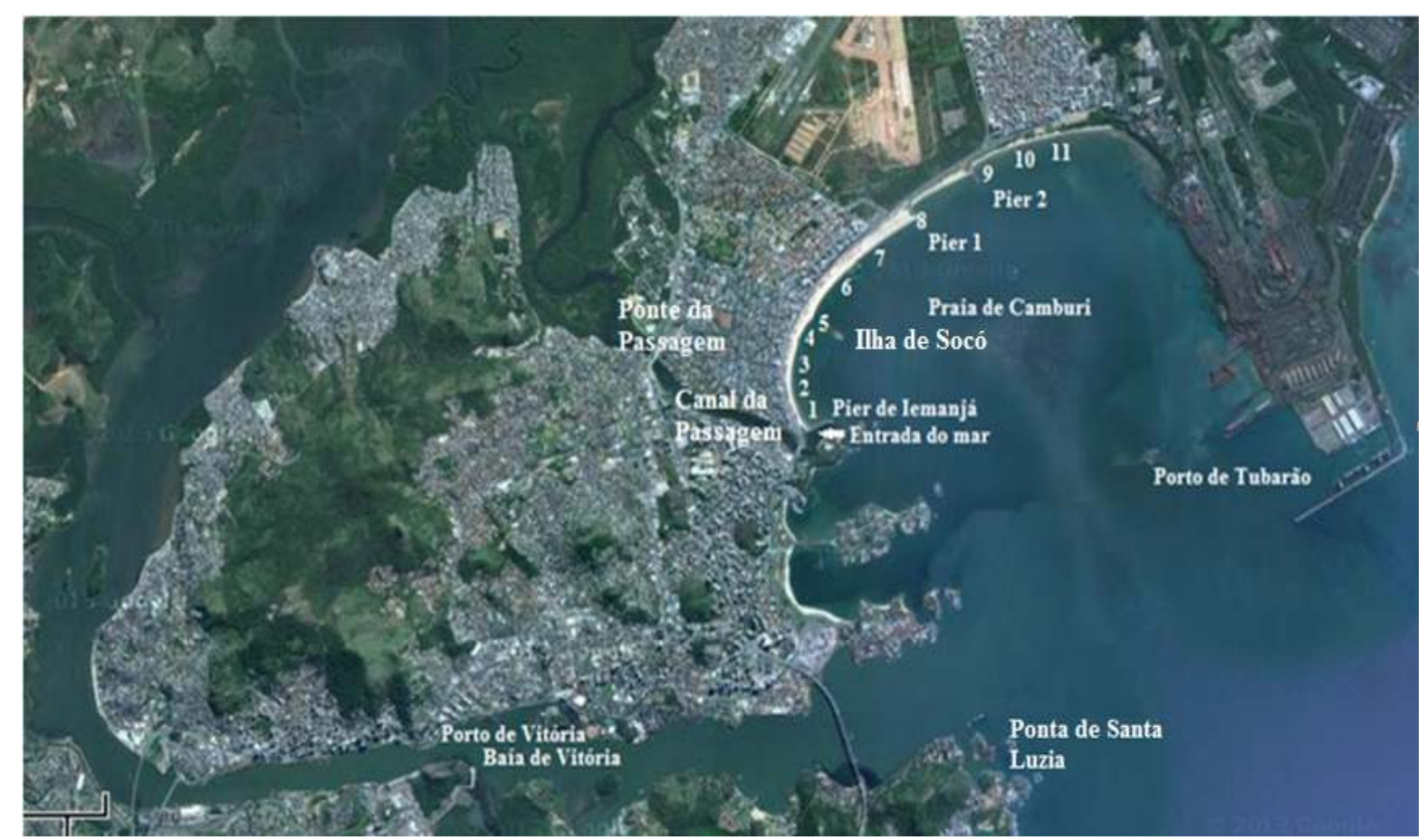

FIGURA 6 - Região da Praia de Camburi. Em destaque os Pontos de coleta (1-11), o Píer 1, Píer 2 e o Píer de Iemanjá, o Porto de Tubarão, a Baía de Vitória, o Porto de Vitória e a Ponta de Santa Luzia ${ }^{1}$.

A Ilha de Socó, que se localiza a 557 metros de distância da avenida que beira o mar, a Av. Dante Micheline, é visualizada na FIG.6 em frente ao Ponto 5 de coleta.

Segundo Rigo (2004), a Baía do Espírito Santo é limitada ao norte pela Ponta de Tubarão (onde se localiza o Porto de Tubarão) e ao sul pela Ponta de Santa Luzia (FIG.6) e a Baía de Vitória estende-se desde a desembocadura do Rio Santa Maria da Vitória até a Baía do Espírito Santo, contendo o Porto de Vitória e seu canal de acesso (FIG.7).

O Canal da Passagem liga a Baía do Espírito Santo, no início da Praia de Camburi, à porção norte da Baía de Vitória (FIG.7), recebendo a influência da maré em suas duas extremidades e drenando boa parte do manguezal existente (Rigo, 2004).

\footnotetext{
${ }^{1}$ Imagem modifcada do Google Maps. Disponível em: <https://maps.google.com.br/maps?hl=pt$\underline{\text { BR\&tab}=w l>}$. Acesso em: 12 abr. 2013.
} 
De acordo com Rigo (2004) a Baía de Vitória pode ser considerada parte do estuário do Rio Santa Maria da Vitória. A região de mangue contida logo após o Canal da Passagem é visualizada na FIG.7.

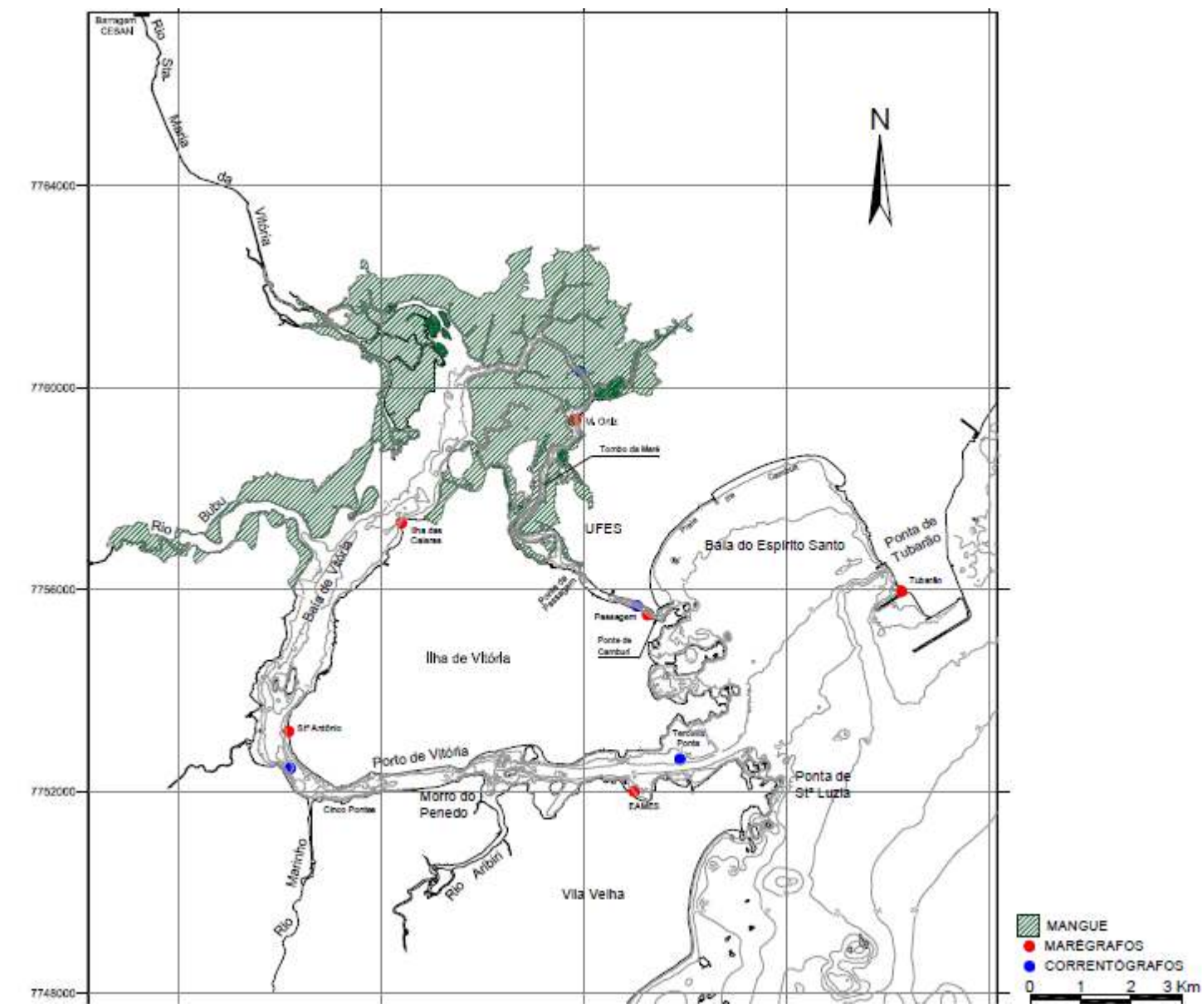

FIGURA 7 - Região da Baía de Vitória, da Baía do Espírito Santo - onde localizamos a

Praia de Camburi e a região de manguezal - após o Canal da Passagem (Rigo, 2004).

Desde a década de 1970, a Praia de Camburi passa por um grande processo de urbanização, determinado pelo desenvolvimento decorrente da instalação de indústrias, com a ocupação da área, que modificou severamente a paisagem costeira com substituição de uma grande área de espelho d'água por áreas aterradas. Observamos uma foto da praia em 1970 na FIG. 8. 


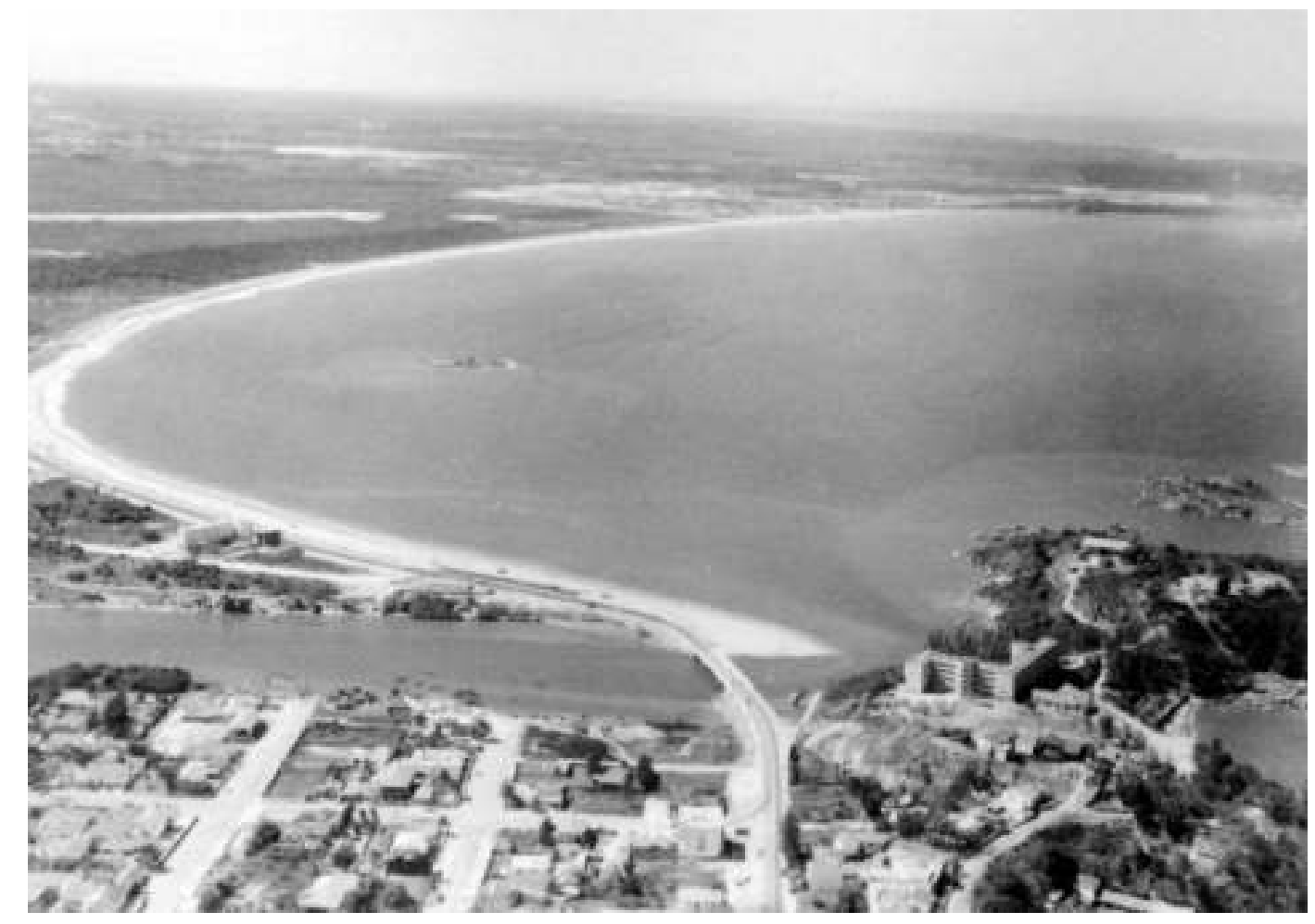

FIGURA 8 - Camburi em 1970 (CHS, 2012).

A erosão decorrente do processo de ocupação gerou diversas intervenções até os dias de hoje, como a construção de piers perpendiculares e engordamento artificial. O engordamento causou a maior reflexão da praia traduzida por perfis com alta declividade e areias médias (Sabaini, 2008).

Ocorreram já dois processos de engordamento artificial, o primeiro, em 1980, que não foi satisfatório e outro em 1999, onde se obteve bons resultados. Neste último, houve a retirada de 1 milhão de metros cúbicos de areias da zona submersa adjacente a praia, tornando-a mais refletiva e estável (Sperandio, 2011). Outras intervenções foram a construção do Píer 1 e Píer 2, do Píer de Iemanjá e a construção do Porto de Tubarão com constantes dragagens (escavações nos canais de acesso e áreas de atracação do porto para manutenção da profundidade) até os dias de hoje.

Atualmente a Praia de Camburi se encontra como na FIG.9, onde é visualizado o Pier de Iemanjá. 


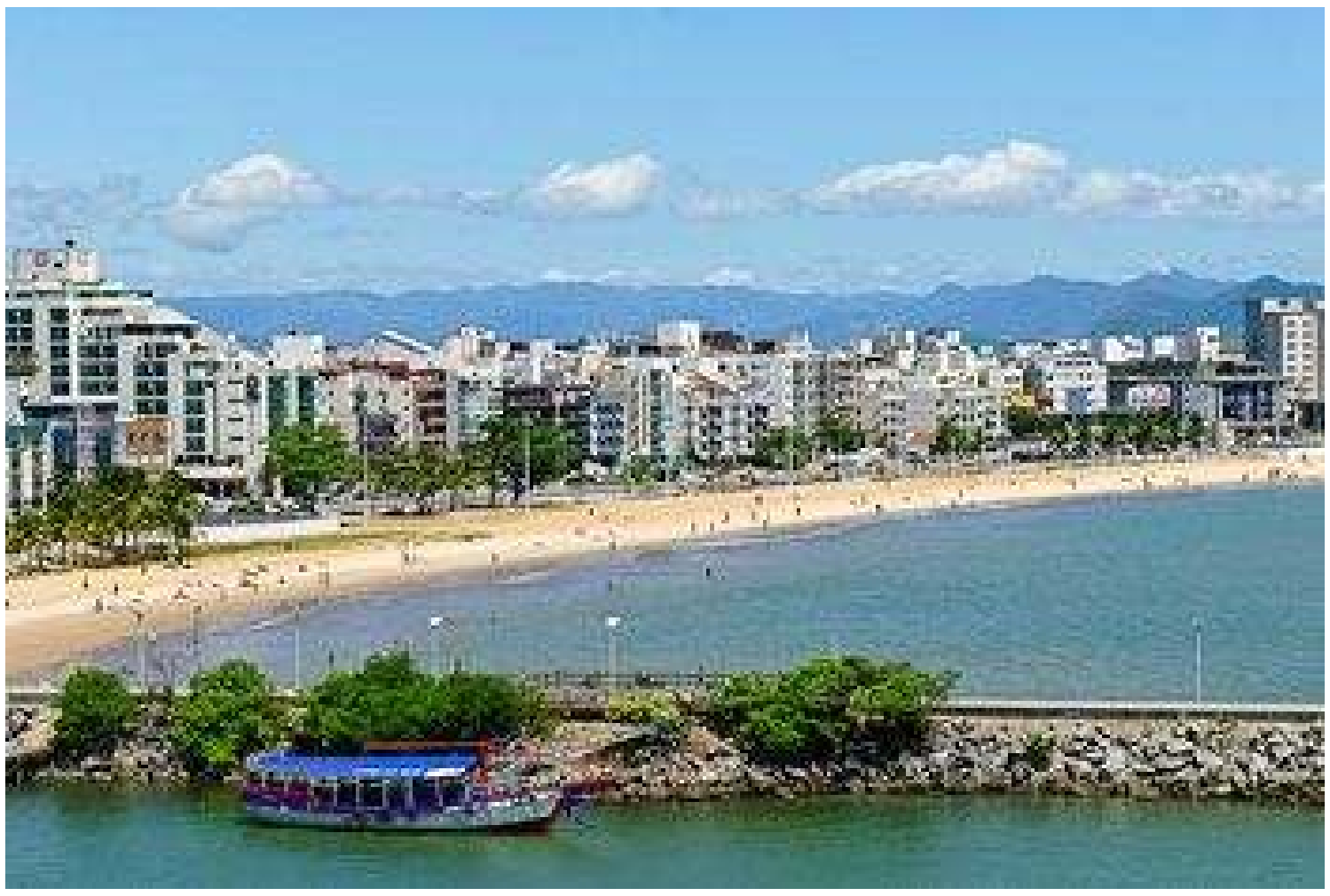

FIGURA 9 - Praia de Camburi, em primeiro plano o Pier de Iemanjá (Prefeitura de Vitória, 2012).

\subsection{Aspectos geológicos}

A geologia do Estado do Espírito Santo é composta por três grandes formações (IEMA, 2012):

- A Unidade do Pré-Cambriano: ou unidades primárias, com rochas muito antigas (mais de 500 milhões de anos), com algumas áreas de mais de 4 bilhões de anos, cobre a maior parte do Estado e é a borda do maciço brasileiro.

-A Unidade Terciária: Com rochas de idade entre 1 e 70 milhões de anos, cobre uma faixa relativamente estreita e ocorrem de norte a sul.

-Unidades Quaternárias: Existem em todo litoral e vão para o interior em direção ao Vale do Rio Doce, são mais recentes, com idade menor do que 1 milhão de anos (Lima, 2009).

Estas formações são visualizadas na FIG.10. 


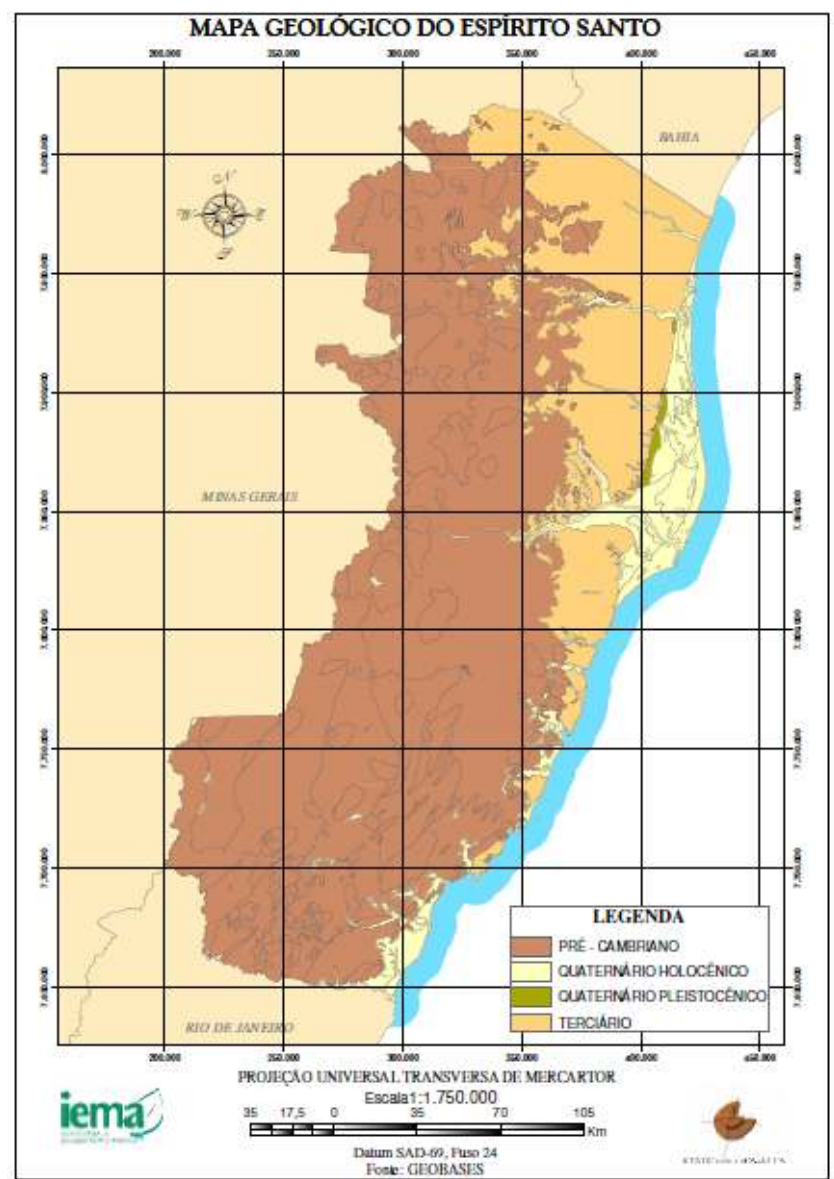

FIGURA 10 - Mapa Geológico do Espírito Santo (IEMA, 2012).

As regiões quaternárias são divididas em quaternário holocênico e quaternário pleistocênico. Na região de Vitória como mostrado na Fig.10 prevalecem as formações do quaternário hologênico e do terciário.

A radioatividade natural das rochas varia conforme sua natureza, em geral concentrações maiores são encontradas em rochas ígneas (magmáticas), mais do que em rochas sedimentares e metamórficas. Esta radioatividade é decorrente de três fontes: minerais acessórios razoavelmente radioativos; minerais essenciais pouco radioativos ou em material radioativo situado entre os grãos e em defeitos estruturais do cristal (Ferreira, 2013).

Minerais essenciais são aqueles que definem a natureza da rocha e minerais acessórios são aqueles que aparecem na rocha em quantidades pequenas e que não afetam sua classificação, podendo servir para definir uma variedade de rocha (CPRM, 2012). 
No Espírito Santo é notável a presença de rochas ígneas, principalmente as da família do granito, que se formaram pelo resfriamento e solidificação do magma (material em estado de fusão que existe abaixo da superfície terrestre) (Lima, 2009).

Rochas plutônicas ácidas (granitos, sienitos, aplitos, pegmatitos e gnaisses) e rochas vulcânicas ácidas (pórfiro, xisto e carbonatitos) apresentam maior conteúdo de urânio e tório (NRPA, 2000).

As areias de praia são rochas sedimentares. Rochas sedimentares são aquelas que se formam na superfície da crosta terrestre, sob temperaturas e pressões relativamente baixas, pela desagregação de rochas pré-existentes, seguida de transporte e deposição dos detritos, ou, menos comumente, por acumulação química (CPRM, 2012). É de suma importância o estudo da radioatividade natural das areias uma vez que a concentração de atividade varia conforme a composição mineralógica.

O Estado do Espírito Santo é um importante centro produtor de matérias primas de origem mineral, contendo grandes reservas de rochas ornamentais (granito e mármore), areia, brita, argila, calcário, dolomito, felspato, caulim, monazita, gemas (água marinha e turmalina), combustíveis minerais como petróleo e gás (Lima, 2009).

\subsubsection{Composição mineralógica}

Os principais minerais de alta densidade encontrados em areias de praia são ilmenita $\left(\mathrm{FeTiO}_{2}\right)$, rutilo $\left(\mathrm{TiO}_{2}\right)$, zircão $\left(\mathrm{ZrSiO}_{4}\right)$ e monazitas $(\mathrm{Ce}, \mathrm{La}, \mathrm{Nd}, \mathrm{Th}) \mathrm{PO}_{4}(\mathrm{Neves}$ et al., 2008; Machado et al., 2011). A geologia do Estado do Espírito Santo é rica nestes minerais, sobretudo a Praia de Camburi, em Vitória.

Um mineral contém elementos e compostos químicos inorgânicos, com composição química definida e estrutura cristalina característica (Neves et al., 2008).

Segundo Neves et al. (2008) estes minerais são formados naturalmente como resultado de vários tipos de processos geológicos e uma espécie mineralógica é definida por sua composição química e por suas propriedades cristalográficas.

Neves et al. (2008) afirmam que depósitos sedimentares incluem algumas das fontes minerais mais valiosas do planeta e que muitos depósitos, economicamente importantes, são formados pela segregação química e física decorrente de processos sedimentares. 
No caso, as areias de praia surgiram de processos sedimentares, de sedimentação física.

Conforme Neves et al. (2008), os principais depósitos formados pela concentração mecânica de minerais resistentes ao intemperismo físico e químico das rochas são os pláceres e neles são encontrados muitos depósitos ricos em minerais pesados, como os minerais de estanho, platina, nióbio, tântalo, zircônio e elementos de terras raras, além de ouro e diamantes.

Correntes fluviais favorecem a concentração de minerais uma vez que os de maior densidade são depositados antes dos mais leves e assim, se acumulam em leitos de rios ou em barras de canal, onde a corrente é forte o suficiente para transportar, em suspensão, os minerais mais leves, mas é relativamente fraca para movimentar os mais pesados. De maneira similar e por uma variação brusca de energia mecânica, as ondas dos oceanos depositam, preferencialmente minerais pesados sobre as praias (Neves et al., 2008).

Os principais minerais de alta densidade encontrados em areias de praia, com concentração de até 5\%, são ilmenita, rutilo, zircão, monazitas e granadas. No Brasil, ocorrem os depósitos ricos em almandina, rutilo e monazita em Guarapari, próximos a Vitória, Espírito Santo (Neves et al., 2008).

Tais minerais, como a monazita, ilmenita, rutilo, zircão (FIG. 11) são minerais ricos em elementos de terras raras (Andrade, 2011) e apresentam propriedades radioativas provenientes do ${ }^{40} \mathrm{~K}$ e dos elementos das séries radioativas do urânio e do tório (Alam et al., 1998).

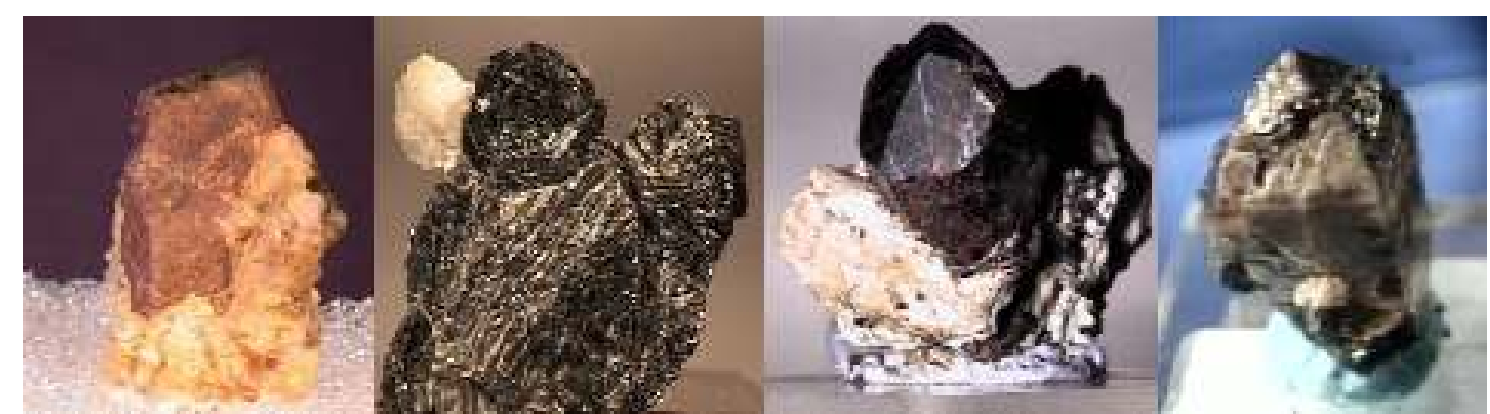

(a)

(b)

(c)

(d)

FIGURA 11 - Minerais encontrados na areia. (a) Monazita (b) Ilmenita (c) Rutilo (d) Zircão (Mineralogia, 2013). 
A monazita possui fórmula química (Ce, $\mathrm{La}, \mathrm{Nd}, \mathrm{Th}$ ) $\mathrm{PO}_{4}$ (fosfato de cério, lantânio, neodímio e tório) e composição de $16,9 \%$ de $\mathrm{La}_{2} \mathrm{O}_{3}, 34,1 \%$ de $\mathrm{Ce}_{2} \mathrm{O}_{3}, 5,5 \%$ de $\mathrm{ThO}_{2}, 29,5 \%$ de $\mathrm{P}_{2} \mathrm{O}_{5}, 14,0 \%$ de $\mathrm{Nd}_{2} \mathrm{O}_{3}$ ) (Machado et al., 2011). É um mineral altamente insolúvel e seus diferentes tipos podem ser descritos como argilas iônicas portadoras de terras raras (Andrade, 2011). Uma típica monazita brasileira contém aproximadamente $6 \%$ de óxido de tório e 0,3\% de óxido de urânio (Lauria e Rochedo, 2005).

A monazita está contida em granitos, gnáisses, aplitos e pegmatitos e em depósitos sedimentares (areias), possui cor que varia do vermelho ao amareloamarronzado, brilho lustroso a resinoso e densidade relativa entre 4,9 e 5,3 g.cm ${ }^{-3}$ (Machado et al., 2011). O nome monazita vem de uma palavra grega, monazein, que significa "estar só". É um nome apropriado, pois cristais típicos de monazita estão isolados em pegmatitos fosfatados, sendo basicamente cristais solitários em uma matriz cristalina diferente (Mineralogia, 2013). O Estado do Espírito Santo possui grande concentração de monazita nos pláceres praiais litorâneos de Aracruz, Serra, Vitória, Guarapari, Anchieta, Lagoa Juparanã e Iconha (Neves et al., 2008).

A ilmenita possui fórmula química $\mathrm{FeTiO}_{2}$ (óxido de ferro e titânio) e composição de $52,6 \%$ de $\mathrm{Ti}_{2} \mathrm{O}$ e $47,4 \%$ de $\mathrm{FeO}$. É um mineral de cor preta, marrom e às vezes, com matriz rosada ou violeta, com densidade relativa de 4,5 a $5 \mathrm{~g} / \mathrm{cm}^{3}$ e brilho submetálico a metálico. Pode apresentar magnetismo, densidade e brilho e ocorrência em rochas magmáticas e metamórficas (Machado et al., 2011). Frequentemente, ocorre como mineral acessório em rochas ígneas básicas, como gabros, noritos e em areias (aluviões costeiros e fluviais). É a principal fonte de titânio para a indústria. O nome ilmenita deriva do seu lugar de descoberta, no lago Ilmen nas montanhas Ilmen, Miask na porção sul dos Montes Urais da Rússia (Mineralogia, 2013). Guarapari e outras regiões litorâneas do Estado do Espírito Santo são ricas em ilmenita (Neves et al., 2008).

O grupo da sílica abrange minerais e mineralóides compostos basicamente por $\mathrm{SiO}_{2}$, que é um composto eletricamente neutro e não contém outras unidades estruturais a não ser o tetraedro. Existem pelo menos nove maneiras diferentes de arranjar os tetraedros de modo a compartilhar todos os oxigênios, gerando estrutura contínua e eletricamente neutra. Estes nove modos de arranjo geométrico correspondem aos nove polimorfos conhecidos de $\mathrm{SiO}_{2}$, dos quais alguns são conhecidos apenas como substâncias sintéticas, 
além de diversas variedades com estrutura cripto a microcristalina. Os minerais do grupo da sílica são a calcedônia, o opala, o quartzo e a tridimita (Machado et al., 2011).

O rutilo possui fórmula química $\mathrm{TiO}_{2}$ (óxido de titânio) e possui composição de $60 \%$ de $\mathrm{Ti}$ e $40 \%$ de $\mathrm{O}$, com densidade relativa de 4,1 a $4,2 \mathrm{~g} / \mathrm{cm}^{3}$, cores variadas (vermelho, marrom, azul, amarelo, violeta e preta) e brilho adamantino a metálico (Machado et al., 2011). É mineral comum em rochas ígneas e metamórficas em pláceres litorâneos e é uma importante fonte de titânio para a indústria sendo também aproveitado como gema para obtenção de pigmentos. Possui ocorrência significativa na Praia de Guarapari, Espírito Santo (Neves et al., 2008).

$\mathrm{O}$ zircão possui fórmula química $\mathrm{ZrSiO}_{4}$ (silicato de zircônio) e composição de $67,22 \%$ de $\mathrm{ZrO}_{2}$ e $32,78 \%$ de $\mathrm{SiO}_{2}$, estrutura cristalina piramidal tetragonal, com densidade relativa de 4,6 a 4,7 g. $\mathrm{cm}^{-3}$, de brilho resinoso a adamantino, sendo incolor, amarelopálido, amarelo-esverdeado, marrom-amarelado ou vermelho. É um mineral constituinte de rochas plutônicas, principalmente rochas ricas em sódio, em granitos, pegmatitos, nefelinasienitos, e em rochas sedimentares, como arenitos. O zircão é usado como gema, em produção de opacidantes cerâmicos, obtenção de óxido de zircônio para utilização em indústria química, entre outras (Machado et al., 2011).

O rutilo pode conter Al, Si, P, K, Ca, Sc, V, Cr, Mn, Fe, Rb, Sr, Y, Zr, Nb, Mo, $\mathrm{Sn}, \mathrm{Sb}, \mathrm{Cs}, \mathrm{Ba}, \mathrm{Hf}, \mathrm{Ta}, \mathrm{W}, \mathrm{Pb}, \mathrm{Th}, \mathrm{U}$ em quantidades detectáveis, sendo que os elementos $\mathrm{V}, \mathrm{Cr}, \mathrm{Fe}, \mathrm{Nb}$ e $\mathrm{Zr}$ estão presentes em concentrações apreciáveis, permitindo um contraste entre as variedades de vermelho e amarelo. O rutilo vermelho é relativamente enriquecido em V, Cr e Zr em comparação com rutilo amarelo, que em contrapartida, transporta maiores quantidades de Fe inter-relacionados e Nb (Philander e Rozendal, 2009).

Variações geológicas dos radionuclídeos do urânio, potássio e tório ocorrem da superfície até $30 \mathrm{~cm}$ de profundidade da Terra. Esta fina camada é sujeita aos efeitos de desgaste, o que leva à perda de $\mathrm{K}$, de $\mathrm{U}$ e $\mathrm{Th}$ em rochas que contém minerais silicatados, magmas e rochas ricas em elementos leves como o silício, oxigênio, alumínio, sódio e potássio. A extensão da perda depende de muitos fatores, mas é tipicamente 20 a 30 por cento para todos os três radioelementos (Dickson e Scott, 1997). 
Rochas intermediárias e básicas mostram pouca mudança nas concentrações de radioelementos durante o intemperismo (conjunto de fenômenos físicos e químicos que levam à degradação e enfraquecimento das rochas), mas a pedogênese (processo no qual determinado solo é formado) pode resultar em solos com 2 a 3 vezes o conteúdo de urânio e tório da rocha-mãe. No entanto, ampla gama de composições de radioelementos ocorrem para um dado tipo de rocha e seus produtos intemperizados. Processos de mineralização também podem afetar a quantidade de radioelementos. Solos transportados podem disfarçar ou alterar as assinaturas das rochas muitas vezes de formas inesperadas (Dickson e Scott, 1997).

Sobretudo, a concentração de atividade de ${ }^{40} \mathrm{~K},{ }^{226} \mathrm{Ra}$ (fillho do ${ }^{238} \mathrm{U}$ ) e ${ }^{232} \mathrm{Th}$ em areias de praia varia devido à composição mineralógica das rochas pré-existentes, aos processos de intemperismo a elas relacionados, à profundidade ao qual esta se encontra da superfície, processos de mineralização e à dinâmica com que as porções de areia se deslocam constantemente devido a fatores climáticos.

O urânio pode estar presente em rochas e minerais como óxidos e silicatos, tais como a monazita e o zircão, em quantidades traço de outros minerais formadores de rocha, ou ao longo dos limites de grão, possivelmente como óxidos de urânio ou silicatos. Somente o zircão e monazita são estáveis durante o intemperismo e podem acumular depósitos de minerais pesados na areia. O urânio liberado pela quebra de minerais durante o intemperismo pode ser retido em óxidos de ferro, em minerais de argila ou precipitado sob condições redutoras, formando depósitos de urânio, em circunstâncias favoráveis (Dickson e Scott, 1997).

O tório pode estar presente na monazita e no zircão com quantidades maiores que 1000 ppm. O tório liberado pela decomposição de minerais durante o intemperismo pode ser retido em óxidos e hidróxidos de Fe e Ti e em argilas. Tal como acontece com o urânio, o tório também pode ser transportado, interagindo quimicamente e sendo retido em argilas e óxidos de ferro (Dickson e Scott, 1997). A concentração de potássio pode ser relativamente alta em minerais silicatados, como granitos e areia de praia (Dickson e Scott, 1997). 


\subsection{Dinâmica praial}

A linha da costa muda constantemente em várias escalas temporais (diárias, sazonais, decadais, seculares e milenares), sendo uma das feições mais dinâmicas do planeta. Fatores de origem natural, intrinsecamente relacionados à dinâmica costeira e intervenções humanas nesta área, como obras de engenharia e dragagens afetam a posição da linha da costa, que pode avançar mar adentro, recuar em direção ao continente (processo de erosão) ou permanecer em equilíbrio (Dominguez, 2005).

Os principais casos de erosão são resultados de dispersão e transporte de sedimentos na zona costeira e de intervenções humanas pela construção de obras de engenharia (Dominguez, 2005), como ocorrido na Praia de Camburi desde a década de 1970, por um grande processo de obras de ocupação, conforme item 2.1. A estabilização da linha da costa, realizada pela construção de Píers e pelo engordamento artificial ocorreu segundo o item 2.1 .

A dinâmica no transporte de porções de areia depende da densidade, do diâmetro e da forma de seus grãos, formando-se padrões observados de separação mineral (Komar, 2007). A monazita, ilmenita, rutilo e zircão, contidos na areia de praia possuem densidade, diâmetro, forma e estrutura cristalina diferentes, possuindo dinâmicas de transporte diferentes. Desta forma, uma porção de areia analisada está sujeita a ter diferentes concentrações de monazita, ilmenita, rutilo e zircão e consequentemente diferentes concentrações de atividade de ${ }^{226} \mathrm{Ra},{ }^{232} \mathrm{Th}$ e de ${ }^{40} \mathrm{~K}$.

A dinâmica no transporte de areia envolve os ventos, as ondas, as correntes litorâneas e as marés, que atuam ininterruptamente sobre os materiais que se encontram na praia, erodindo, transportando e depositando sedimentos (Klein et al., 2005).

Dentre os fatores de origem natural que afetam a posição da linha da costa e que participam na dinâmica de transporte de porções de areia estão os fatores climatológicos e oceanográficos. 


\subsubsection{Fatores Climatológicos}

O clima no mundo é profundamente afetado pelas correntes marítimas, uma vez que os oceanos e a atmosfera vivem um processo de interatividade permanente. A precipitação pluviométrica está diretamente relacionada à circulação atmosférica geral de 0 a 12 quilômetros de altitude (Vieira et al., 2005). Como fatores climatológicos podemos citar a precipitação pluviométrica e a temperatura.

O Brasil, por ser um país de grande extensão territorial, apresenta diferentes regimes de precipitação e temperatura. A Região Sudeste possui estação seca bem definida no inverno e estação chuvosa de verão com chuvas convectivas (Quadro et al., 2013).

\subsubsection{Fatores Oceanográficos}

\subsubsection{Ondas}

Segundo Klein et al. (2005), a quebra de uma onda na praia é um processo altamente complexo e de difícil estudo, devido à distorção de sua forma em relação à forma senoidal idealizada. Quando a onda rebenta, a energia recebida do vento é transferida para a praia, sendo dissipada. Porém, existem vários tipos de arrebentação de ondas que dependem da natureza do fundo e das características das ondas (Klein et al., 2005).

Parte da energia das ondas é transferida aos grãos de areia e os coloca em movimento e essa interação continuamente forma e reforma as praias e o transporte de sedimentos ao longo da costa (Sabaini, 2008). Em cada movimento da onda o grão é carregado a uma pequena distância, as ondas chegam em uma série contínua e como resultado os sedimentos podem ser movidos de poucos metros a $1 \mathrm{~km}$ por dia (Sabaini, 2008). 


\subsubsection{Marés}

A ação da força gravitacional da Lua na Terra gera no planeta o fenômeno das marés. Variações do nível do mar são observadas em algumas horas pelo efeito das marés e, durante anos, essas variações podem alterar a configuração de uma praia (Cavalcante, 2005).

Segundo o Banco Nacional de Dados Oceanográficos (BNDO, 2011) há duas marés altas e duas marés baixas diariamente. O horário da maré alta e da maré baixa oscila de acordo com a fase da lua (minguante, crescente, cheia ou nova). 


\section{MATERIAIS E MÉTODOS}

\subsection{Escolha dos locais de amostragem}

Amostras de areia superficial, com aproximadamente $2 \mathrm{~cm}$ de profundidade, foram coletadas em 11 pontos da Praia de Camburi, de forma a cobrir a extensão de $6 \mathrm{~km}$ da praia (FIG. 12). A profundidade foi escolhida devido ao fato de uma pessoa, ao sentar sobre a areia, afundar aproximadamente $2 \mathrm{~cm}$. A distância entre os pontos de coleta é, em média, de $0,5 \mathrm{~km}$.

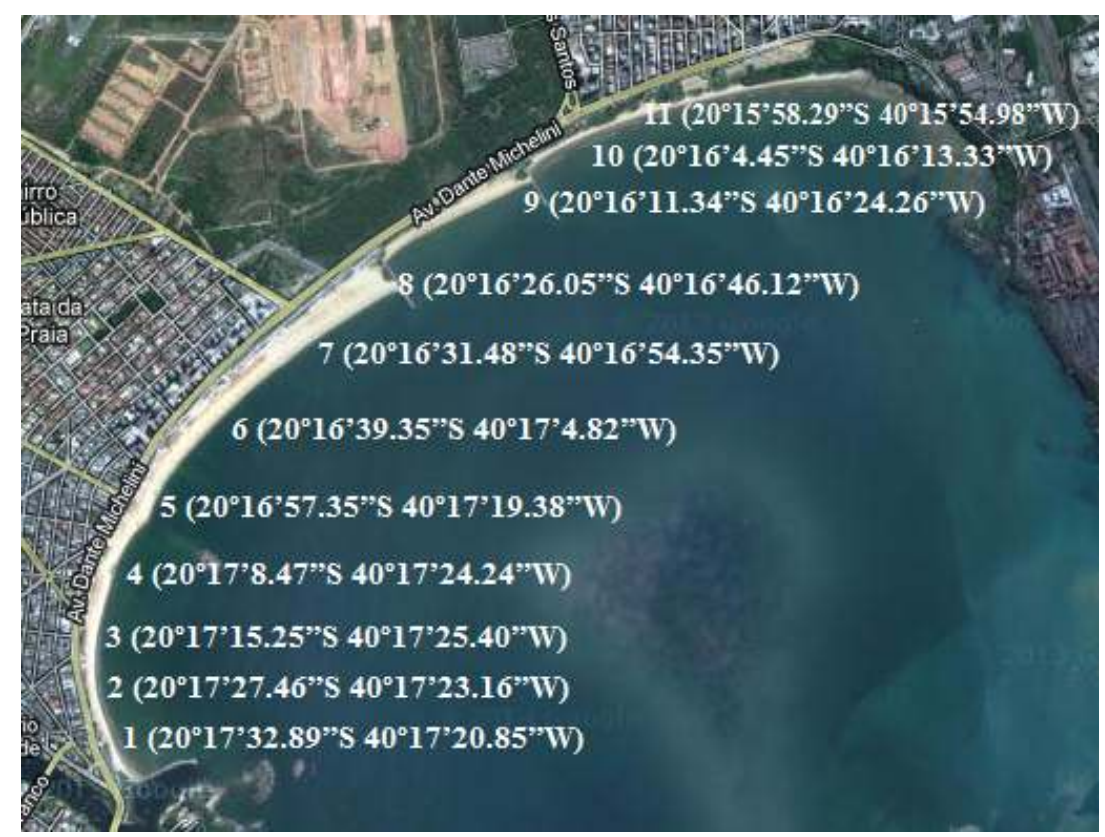

FIGURA 12 - Localização geográfica dos pontos de coleta (1-11) na Praia de Camburi.

\subsection{Medição das amostras}

A medição das amostras foi realizada por espectrometria gama de alta resolução. A calibração em eficiência foi obtida com uma solução padrão aquosa radioativa multielemental e a radiação de fundo, com uma amostra de água ultrapura. Todas as medições foram realizadas na mesma geometria. 


\subsection{Espectrometria gama}

A espectrometria gama é a principal técnica utilizada em laboratórios que realizam medidas de radioatividade por ser um método não destrutivo e por analisar simultaneamente em uma mesma amostra vários radionuclídeos sem a necessidade de separação radioquímica.

Muitos elementos que ocorrem naturalmente têm isótopos radioativos, entretanto, somente o potássio e os isótopos radioativos da série de decaimento do urânio e do tório produzem raios gama de energia e intensidade suficiente para serem medidos por espectrometria gama. Isto é porque são relativamente abundantes no ambiente natural (IAEA- TECDOC-1363, 2003).

Um espectrômetro gama típico é constituído de um detector para a detecção da radiação gama, acoplado a um sistema eletrônico formado por: fonte de alta tensão, préamplificador, amplificador linear, analisador multicanal com conversor analógico (ADC) e sistema para registro de saída dos dados (PO-LRA-0901, 2008). O sistema de detecção e aquisição de dados é visualizado na FIG. 13.

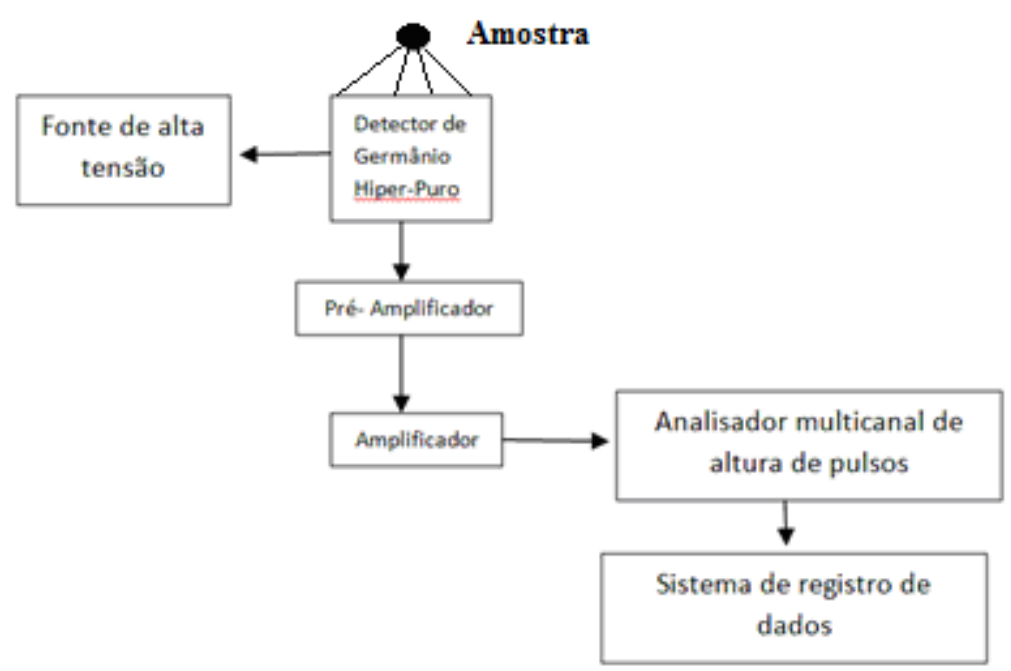

FIGURA 13 - Sistema de detecção e aquisição de dados por espectrometria gama de alta resolução. Modificado de (PO-LRA-0901, 2008).

O detector semicondutor de germânio hiperpuro (HPGe) é colocado numa blindagem de chumbo para que a radiação de fundo do ambiente não interfira na medida. 
Ao atingir o volume sensível do detector, os fótons gama geram pulsos elétricos, que são amplificados, analisados e registrados por dispositivos eletrônicos associados. A altura do pulso é dependente da energia do fóton gama incidente e, desta forma, é gerado um espectro de altura de pulsos.

Neste espectro, um pico de absorção total é formado pela acumulação dos pulsos gerados por fótons gama que perdem toda a sua energia para o meio detector.

Uma vez que a localização deste pico é característica da energia gama incidente, este espectro é chamado espectro gama, e permite identificar o respectivo radionuclídeo emissor gama. A área sob o pico de absorção total é proporcional à atividade do respectivo radionuclídeo na amostra, desde que corrigida pela eficiência absoluta do sistema de contagem (Knoll, 1999).

\subsection{Cálculo da concentração de atividade de ${ }^{226} \mathrm{Ra},{ }^{232} \mathrm{Th}$ e ${ }^{40} \mathrm{~K}$}

As amostras de areia foram armazenadas por aproximadamente quatro semanas antes da medição, isto para garantir o equilíbrio radioativo (Evans, 1972), conforme item 4.1. Mantido o equilíbrio radioativo, a concentração de atividade do ${ }^{226} \mathrm{Ra}$ foi determinada pela média ponderada das concentrações de seus filhos, ${ }^{214} \mathrm{~Pb}$ e ${ }^{214} \mathrm{Bi}$, e a concentração de atividade do ${ }^{232} \mathrm{Th}$ pela média ponderada das concentrações de seus filhos, ${ }^{228} \mathrm{Ac},{ }^{212} \mathrm{~Pb}$ e ${ }^{212} \mathrm{Bi}$.

A atividade $A_{i}$ para uma i-ésima transição gama é obtida pela equação (1) (Knoll, 1999), abaixo:

$$
A_{i}\left(E_{\gamma i}\right)=\frac{C}{\varepsilon_{\gamma i} \cdot \mathrm{I}_{j i} \cdot t_{u} \cdot m} \times f\left(E_{\gamma}\right)
$$

Onde:

$$
\begin{aligned}
& A_{i}\left(E_{\gamma i}\right)=\text { concentração de atividade }\left(\mathrm{Bq} \cdot \mathrm{kg}^{-1}\right) \\
& C=\text { área líquida do pico de absorção total }
\end{aligned}
$$


$\varepsilon_{\gamma i}=$ eficiência de detecção para a i-ésima transição gama

$\mathrm{I}_{\gamma i}=$ probabilidade de emissão da i-ésima transição gama

$t_{u}=$ intervalo de tempo útil da medida

$m=$ massa da amostra $(\mathrm{kg})$

$f\left(E_{\gamma i}\right)=$ fator de autoatenuação para a i-ésima transição gama.

As concentrações de atividade do ${ }^{214} \mathrm{~Pb},{ }^{228} \mathrm{Ac}$ e do ${ }^{212} \mathrm{~Pb}$ foram determinadas pela média ponderada das concentrações de atividade de suas respectivas transições gama (TAB.1), conforme a equação (2). Os desvios associados a estas concentrações de atividade foram calculados conforme a equação (3) (PO-0901, 2008).

TABELA 1: Transições gama utilizadas para a determinação das concentrações de atividade de ${ }^{226} \mathrm{Ra},{ }^{232} \mathrm{Th}$ e ${ }^{40} \mathrm{~K}$.

\begin{tabular}{|c|c|c|}
\hline Radionuclídeos & Isótopos & Transições (keV) \\
\hline & & (INTERWINNER6.0, 2004) \\
\hline \multirow[t]{3}{*}{${ }^{226} \mathrm{Ra}$} & ${ }^{214} \mathrm{~Pb}$ & 295,21 \\
\hline & & 351,92 \\
\hline & ${ }^{214} \mathrm{Bi}$ & 609,32 \\
\hline \multirow[t]{5}{*}{${ }^{232} \mathrm{Th}$} & ${ }^{228} \mathrm{Ac}$ & 911,07 \\
\hline & & 968,90 \\
\hline & ${ }^{212} \mathrm{~Pb}$ & 238,63 \\
\hline & & 300,09 \\
\hline & ${ }^{212} \mathrm{Bi}$ & 727,33 \\
\hline${ }^{40} \mathrm{~K}$ & & 1460,83 \\
\hline
\end{tabular}




$$
\begin{aligned}
\bar{A}^{214} \mathrm{~Pb}^{228} A c^{212} \mathrm{~Pb} & =\frac{\left(\frac{A_{1}}{\sigma_{1}^{2}}+\frac{A_{2}}{\sigma_{2}^{2}}\right)}{\left(\frac{1}{\sigma_{1}^{2}}+\frac{1}{\sigma_{2}^{2}}\right)} \\
\sigma_{\left.\bar{A}^{214} \mathrm{~Pb}\right|^{228} A c^{212} \mathrm{~Pb}} & =\sqrt{\frac{1}{\left(\frac{1}{\sigma_{1}^{2}}+\frac{1}{\sigma_{2}^{2}}\right)}}
\end{aligned}
$$

Onde $A_{1}$ e $A_{2}$ são as atividades para cada transição gama do radionuclídeo e seus respectivos desvios $\sigma_{1}$ e $\sigma_{2}$.

A concentração de atividade do ${ }^{226} \mathrm{Ra}$ foi determinada pela média ponderada das concentrações do ${ }^{214} \mathrm{~Pb}$ e do ${ }^{214} \mathrm{Bi}$ e a concentração de atividade do ${ }^{232} \mathrm{Th}$ pela média ponderada das concentrações do ${ }^{212} \mathrm{~Pb}$, do ${ }^{212} \mathrm{Bi}$ e do ${ }^{228} \mathrm{Ac}$, utilizando-se as transições gama da TAB. 1 e conforme a equação (4).

Os desvios associados a estas concentrações de atividade são calculados conforme a equação (5).

$$
\begin{array}{r}
\bar{A}=\frac{\left(\frac{A_{1}}{\sigma_{1}^{2}}+\frac{A_{2}}{\sigma_{2}^{2}}+\frac{A_{3}}{\sigma_{3}^{2}}+\ldots+\frac{A_{n}}{\sigma_{n}^{2}}\right)}{\left(\frac{1}{\sigma_{1}^{2}}+\frac{1}{\sigma_{2}^{2}}+\frac{1}{\sigma_{3}^{2}}+\ldots+\frac{1}{\sigma_{n}^{2}}\right)} \\
\sigma_{\bar{A}}=\sqrt{\frac{1}{\left(\frac{1}{\sigma_{1}^{2}}+\frac{1}{\sigma_{2}^{2}}+\frac{1}{\sigma_{3}^{2}}+\ldots .+\frac{1}{\sigma_{n}^{2}}\right)}}
\end{array}
$$

Onde $A_{1}, A_{2}, \ldots, A_{n}$ são as atividades calculadas para cada radionuclídeo da subsérie (para $\mathrm{n}$ radionuclídeos) e seus respectivos desvios $\sigma_{1}, \sigma_{2}, \ldots, \sigma_{n}$.

A atividade do ${ }^{40} \mathrm{~K}$ foi determinada pela sua única transição gama de 1460,8 keV conforme a equação (1). 


\subsection{Fator de autoatenuação gama}

Quando a radiação eletromagnética atravessa a matéria sofre atenuação. A equação (6) nos fornece como a intensidade do feixe de fótons transmitidos através de um material pode ser avaliada (Evans, 1972).

$$
I=I_{0} e^{-\mu x}
$$

onde $I$ é a intensidade do feixe de fótons transmitidos em uma energia específica, $I_{0}$ é a intensidade do feixe de fótons não atenuados na energia específica, $\mu$ é o coeficiente de atenuação linear total da amostra e $x$ é a distância percorrida pelo fóton sem sofrer interação por efeito fotoelétrico, efeito Compton e por produção de pares.

Ao ser emitida pelos radionuclídeos da amostra, a radiação gama sofre atenuação pelo material da própria amostra e a esse processo denomina-se autoatenuação. O estudo da autoatenuação é fundamental em análises por espectrometria gama que contenham grande variedade de amostras, de densidades e conteúdos mineralógicos diferentes. A densidade da amostra utilizada na obtenção da curva de eficiência deve ser a mais próxima possível a das amostras analisadas.

Como todas as amostras de areia analisadas apresentam densidades na faixa de 1,26 g.cm $\mathrm{cm}^{-3}$ a 2,35 g.cm ${ }^{-3}$ e a curva de eficiência foi obtida com uma solução padrão aquosa radioativa multielemental de composição diferente à das amostras, os fatores de autoatenuação são necessários.

Estes fatores foram obtidos experimentalmente pelo método de Cutshall et al. (1983), medindo-se num detector HPGe a transmissão para fontes radioativas pontuais, tanto para as amostras de areia como para uma amostra de água ultrapura. Neste trabalho foram utilizadas 4 fontes radioativas pontuais, de ${ }^{152} \mathrm{Eu},{ }^{137} \mathrm{Cs},{ }^{133} \mathrm{Ba} \mathrm{e}{ }^{60} \mathrm{Co}$, com transições gama numa faixa de $80 \mathrm{keV}$ a $1408 \mathrm{keV}$ (TAB.2). Esta faixa foi selecionada por conter as energias das transições gama dos radionuclídeos de interesse, exceto a energia de $1460,83 \mathrm{keV}$ do ${ }^{40} \mathrm{~K}$ (TAB.1); contudo, como este valor é próximo da energia de 1408,03 $\mathrm{keV}$ do ${ }^{152} \mathrm{Eu}$ (TAB.2), podemos considerar o fator de atenuação dado pela curva ajustada.

Para cada amostra foram ajustadas curvas do fator de autoatenuação em função da energia (keV), obtidas a partir dos fatores de autoatenuação encontrados para as 
energias da TAB.2. As equações das curvas ajustadas foram utilizadas na determinação dos fatores de autoatenuação correspondentes às energias das transições gama dos radionuclídeos presentes na TAB.1, cujas concentrações de atividade precisam ser determinadas (Barros e Pecequilo, 2013b).

Tanto as amostras de areia como a amostra de água ultrapura foram medidas na mesma geometria com as fontes pontuais em um detector 20\% HPGe ORTEC EG\&G com um sistema ACE-2K, durante um tempo de 2000 segundos cada.

TABELA 2 - Transições das energias dos raios gama selecionados para a determinação da autoatenuação.

\begin{tabular}{|c|c|c|}
\hline $\begin{array}{c}\text { IAEA Fontes gama padrão } \\
\text { (IAEA, 1982) }\end{array}$ & $\begin{array}{c}\text { Energia }(\mathrm{keV}) \\
\text { (INTERWINNER6.0, 2004) }\end{array}$ & $\begin{array}{c}\text { Intensidade (\%) } \\
\text { (INTERWINNER6.0, 2004) }\end{array}$ \\
\hline \multirow[t]{9}{*}{${ }^{152} \mathrm{Eu}$} & 121,78 & 28,4 \\
\hline & 244,69 & 7,54 \\
\hline & 344,28 & 26,52 \\
\hline & 778,90 & 12,94 \\
\hline & 867,39 & 4,21 \\
\hline & 964,05 & 14,6 \\
\hline & 1085,84 & 10,0 \\
\hline & 1112,08 & 13,56 \\
\hline & 1408,03 & 20,8 \\
\hline \multirow[t]{2}{*}{${ }^{60} \mathrm{Co}$} & 1173,24 & 99,89 \\
\hline & 1332,50 & 99,98 \\
\hline${ }^{137} \mathrm{Cs}$ & 661,66 & 85,20 \\
\hline \multirow[t]{5}{*}{${ }^{133} \mathrm{Ba}$} & 80,99 & 34,10 \\
\hline & 276,39 & 7,17 \\
\hline & 302,84 & 18,32 \\
\hline & 356,01 & 62,00 \\
\hline & 383,85 & 8,93 \\
\hline
\end{tabular}

O fator de autoatenuação foi calculado conforme a equação (7) (Cutshall et al.,1983). 


$$
f_{i}=\frac{\ln \left(\frac{A_{i}}{P_{i}}\right)}{\left(\frac{A_{i}}{P_{i}}-1\right)}
$$

Onde:

$f_{i}=$ fator de autoatenuação

$A_{i}=$ intensidade do feixe transmitido através da amostra de areia

$P_{i}=$ intensidade do feixe transmitido através da amostra de água ultrapura

Duas considerações são importantes para que o método de Cutshall et al.(1983) seja aplicado corretamente, a primeira é de que a fonte, a amostra e o detector estejam centrados coaxialmente, e a segunda é que os fótons vindos da amostra incidam perpendicularmente (ou ao menos aproximadamente) no detector (Ferreira, 2013). Para tal foi utilizado um suporte de lucite e um colimador de chumbo desenvolvido no Laboratório de Radiometria Ambiental (Venturini e Nisti, 1997). Dentro da blindagem foram estabelecidos pontos de referência para que no momento das medições o supote de lucite fosse encaixado no detector sempre na mesma posição.

\subsection{Atividade equivalente em rádio}

A distribuição de ${ }^{226} \mathrm{Ra},{ }^{232} \mathrm{Th}$ e ${ }^{40} \mathrm{~K}$ não é uniforme em amostras ambientais. Cada amostra contém diferentes concentrações de atividade destes radionuclídeos dependendo da sua composição mineralógica.

Considerando que as atividades de $370 \mathrm{~Bq} \cdot \mathrm{kg}^{-1}$ de ${ }^{226} \mathrm{Ra}, 259 \mathrm{~Bq} \cdot \mathrm{kg}^{-1} \mathrm{de}{ }^{232} \mathrm{Th}$ e 4810 Bq. $\mathrm{kg}^{-1}$ de ${ }^{40} \mathrm{~K}$ em materiais de construção ocasionem a mesma dose de $1,5 \mathrm{mSv} \cdot \mathrm{a}^{-1}$, foi introduzido o índice radiológico "atividade equivalente em rádio" $\left(R a_{e q}\right)$ (Beretka e Mathew, 1985), que permite avaliar o nível atual de atividade do ${ }^{226} \mathrm{Ra},{ }^{232} \mathrm{Th}$ e

${ }^{40} \mathrm{~K}$ e os danos de radiação associados com estes radionuclídeos, a partir da equação (8). O $R a_{e q}$ é um índice útil para avaliar as normas de segurança de proteção radiológica para indivíduos do público em suas residências. 


$$
R a_{e q}=A_{R a}+1,43 A_{T h}+0,077 A_{K}
$$

Onde $R a_{e q}, A_{R a}, A_{T h}$ e $A_{K}$ são, respectivamente, a atividade equivalente em rádio em Bq.kg-1 e as concentrações de atividade do ${ }^{226} \mathrm{Ra},{ }^{232} \mathrm{Th}$ e ${ }^{40} \mathrm{~K}$ em Bq.kg ${ }^{-1}$ (Beretka e Mathew, 1985, Barros e Pecequilo, 2013c;).

\section{7 Índice de concentração de atividade}

De acordo com princípios da proteção radiológica a respeito da radioatividade natural de materiais de construção citados pela Comissão Européia (EC, 1999), os limites de dose em materiais de construção são definidos a partir do índice de concentração de atividade $I_{\gamma}$, que é relacionado com a dose anual devida à radiação gama externa e pode ser calculado a partir da equação (9).

$$
I_{\gamma}=\frac{A_{R a}}{300}+\frac{A_{T h}}{200}+\frac{A_{K}}{3000}
$$

Onde $I_{\gamma}, A_{R a}, A_{T h}$ e $A_{K}$ são, respectivamente, o índice de concentração de atividade e as concentrações de atividade do ${ }^{226} \mathrm{Ra},{ }^{232} \mathrm{Th}^{40}{ }^{40}$ em Bq.kg-1 .

\section{8 Índice de risco a exposição gama externo e interno}

Podemos definir o índice de risco a exposição gama externo $\left(H_{\text {ext }}\right)$ e interno $\left(H_{\text {int }}\right)$ respectivamente a partir das equações (10) e (11) (Beretka e Mathew, 1985). O índice de risco a exposição gama externo $H_{\text {ext }}$ considera a exposição à radiação gama. $\mathrm{O}$ índice de risco a exposição gama interno $H_{\text {int }}$ considera o risco de inalação por acúmulo de radônio e seus produtos de decaimento de meia vida curta.

$$
\begin{aligned}
& H_{\text {ext }}=\frac{A_{R a}}{370}+\frac{A_{T h}}{259}+\frac{A_{K}}{4810} \leq 1, \\
& H_{\text {int }}=\frac{A_{R a}}{185}+\frac{A_{T h}}{259}+\frac{A_{K}}{4810} \leq 1
\end{aligned}
$$


Onde $A_{R a}, A_{T h}$ e $A_{K}$ são as concentrações de atividade respectivamente do ${ }^{226} \mathrm{Ra}$, ${ }^{232} \mathrm{Th} \mathrm{e}^{40} \mathrm{~K}$, em Bq.kg- ${ }^{-1}$.

Os valores do índice de risco a exposição gama externo $\left(H_{\text {ext }}\right)$ e interno $\left(H_{\text {int }}\right)$ devem ser menores do que 1 , a fim de manter o risco radiológico abaixo dos limites de segurança recomendado (OECD, 1979). Este critério considera o risco devido a exposição à radiação gama e corresponde à recomendação da Organização para Cooperação e Desenvolvimento Econômico (OECD, 1979) para uma utilização segura em materiais de construção de que o valor de $R a_{e q}$ não exceda o limite de $370 \mathrm{~Bq} \cdot \mathrm{kg}^{-1}$.

\subsection{Estimativa de taxa de dose absorvida no ar}

A taxa de dose absorvida gama $\left(n G y \cdot \mathrm{h}^{-1}\right)$ no ar em 1 metro acima da superfície do solo numa distribuição uniforme dos radionuclídeos ${ }^{226} \mathrm{Ra},{ }^{232} \mathrm{Th}$ e ${ }^{40} \mathrm{~K}$ é computada com base nas diretrizes fornecidas pela UNSCEAR (2000) pela equação (12).

$$
D=0.462 A_{R a}+0.604 A_{T h}+0.0417 A_{K}
$$

Onde $D, A_{R a}, A_{T h}$ e $A_{K}$ são, respectivamente, a taxa de dose absorvida gama em $\mathrm{nGy} \cdot \mathrm{h}^{-1} \mathrm{e}$ as concentrações de atividade do ${ }^{226} \mathrm{Ra},{ }^{232} \mathrm{Th} \mathrm{e}^{40} \mathrm{~K}$ em Bq. $\mathrm{kg}^{-1}$.

\subsection{Dose efetiva anual}

A dose efetiva anual em mSv.a ${ }^{-1}$ é descrita pela equação (13) (Aquino, 2010; Sowmya et al., 2010):

$$
E=\text { D.t. } 0,7 \cdot 10^{-6}
$$

Onde $E$ é a dose efetiva anual em $\mathrm{mSv} \cdot \mathrm{a}^{-1}, D$ é a taxa de dose absorvida gama $\left(\mathrm{nGy}^{-1} \mathrm{~h}^{-1}\right), t$ é o tempo em horas de exposição por ano (24 horas X 365 Dias X fração de tempo do dia de exposição à radiação), 0,7 é o fator de conversão de unidade em Sv.Gy ${ }^{-1}$.

O termo $10^{-6}$ na eq.(13) aparece pois $D$ está em nGy.h ${ }^{-1}\left(10^{-9}\right.$ Gy.h $\left.h^{-1}\right)$ e a dose efetiva anual está em $\mathrm{mSv} \cdot \mathrm{a}^{-1}\left(10^{-3} \mathrm{~Sv} \cdot \mathrm{a}^{-1}\right)$. 


\section{PARTE EXPERIMENTAL}

\subsection{Coleta e preparo das amostras}

Aproximadamente $1 \mathrm{~kg}$ de areia foi coletado em cada ponto da Praia de Camburi conforme coordenadas geográficas da TAB. 3, de janeiro de 2011 a dezembro de 2011, todo dia 15 do mês, totalizando 132 amostras distintas. No laboratório foram retirados manualmente das amostras de areia conchas e resíduos como pedaços de madeira, plástico e restos de cigarro.

TABELA 3. Coordenadas geográficas dos pontos de coleta da Praia de Camburi, 2011.

\begin{tabular}{|c|c|}
\hline Pontos de coleta & Latitude e longitude \\
\hline 1 & $20^{\circ} 17^{\prime} 32.89^{\prime \prime} \mathrm{S} 40^{\circ} 17^{\prime} 20.85^{\prime \prime} \mathrm{W}$ \\
\hline 2 & $20^{\circ} 17^{\prime} 27.46^{\prime \prime} \mathrm{S} 40^{\circ} 17^{\prime} 23.16^{\prime \prime} \mathrm{W}$ \\
\hline 3 & $20^{\circ} 17^{\prime} 15.25^{\prime \prime} \mathrm{S} 40^{\circ} 17^{\prime} 25.40^{\prime \prime} \mathrm{W}$ \\
\hline 4 & $20^{\circ} 17^{\prime} 8.47^{\prime \prime S} 40^{\circ} 17^{\prime} 24.24^{\prime \prime} \mathrm{W}$ \\
\hline 5 & $20^{\circ} 16^{\prime} 57.35^{\prime \prime S} 40^{\circ} 17^{\prime} 19.38^{\prime \prime} \mathrm{W}$ \\
\hline 6 & $20^{\circ} 16^{\prime} 39.35^{\prime \prime S} 40^{\circ} 17^{\prime} 4.82^{\prime \prime} \mathrm{W}$ \\
\hline 7 & $20^{\circ} 16^{\prime} 31.48^{\prime \prime} \mathrm{S} 40^{\circ} 16^{\prime} 54.35^{\prime \prime} \mathrm{W}$ \\
\hline 8 & $20^{\circ} 16^{\prime} 26.05^{\prime \prime} \mathrm{S} 40^{\circ} 16^{\prime} 46.12^{\prime \prime} \mathrm{W}$ \\
\hline 9 & $20^{\circ} 16^{\prime} 11.34^{\prime \prime} \mathrm{S} 40^{\circ} 16^{\prime} 24.26^{\prime \prime} \mathrm{W}$ \\
\hline 10 & $20^{\circ} 16^{\prime} 4.45^{\prime \prime} \mathrm{S} 40^{\circ} 16^{\prime} 13.33^{\prime \prime} \mathrm{W}$ \\
\hline 11 & $20^{\circ} 15^{\prime} 58.29^{\prime \prime} \mathrm{S} 40^{\circ} 15^{\prime} 54.98^{\prime \prime} \mathrm{W}$ \\
\hline
\end{tabular}


Na FIG.14 visualizamos a Praia de Camburi in situ (Barros e Pecequilo, 2013a).
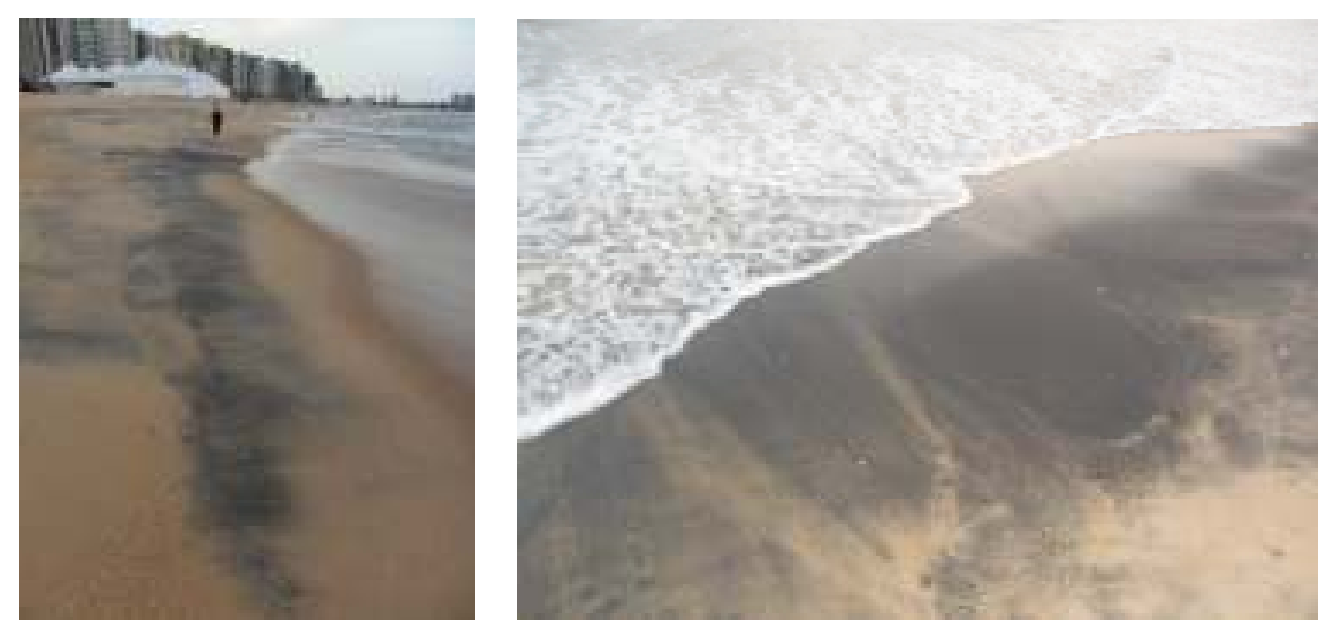

FIGURA 14 - Areia da Praia de Camburi in situ, manchas escuras na região central da praia são visíveis devido a presença de ilmenita. Foto acervo pessoal, 2012.

As amostras colocadas em almofarizes (FIG.15a) foram secas em estufa (FIG. $15 \mathrm{~b}$ ) por 24 horas a $80^{\circ} \mathrm{C}$ e acondicionadas em frascos padrão de polietileno de alta densidade (PEAD) de $100 \mathrm{ml}$ com batoque e tampa. Por ter uma alta densidade, o polietileno dos frascos retém os gases ${ }^{222} \mathrm{Rn}$ e ${ }^{220} \mathrm{Rn}$ e garante o equilíbrio radioativo das séries do ${ }^{238} \mathrm{U}$ e ${ }^{232} \mathrm{Th}$. A estanqueidade do frasco foi experimentalmente comprovada por pesquisadores do Laboratório de Radiometria Ambiental por meio de programas de intercomparação e testes de proficiência (LRA, 2013).

A medição da massa das amostras foi realizada em uma balança semi-analítica modelo GEHAKA BK3000. Os frascos PEAD contendo as amostras foram hermeticamente selados com fita isolante e armazenados por aproximadamente quatro semanas, para garantir o equilíbrio radioativo (Evans, 1972) entre o ${ }^{226} \mathrm{Ra}$ e o ${ }^{222} \mathrm{Rn}$.

Este procedimento é necessário tendo em vista que as concentrações de atividade do ${ }^{226} \mathrm{Ra}$ foram determinadas pela média ponderada do ${ }^{214} \mathrm{~Pb}$ e ${ }^{214} \mathrm{Bi}$, filhos do ${ }^{222} \mathrm{Rn}$. Antes do procedimento de contagem, as amostras foram envoltas em filme plástico transparente (FIG.16), para evitar a contaminação do detector. 


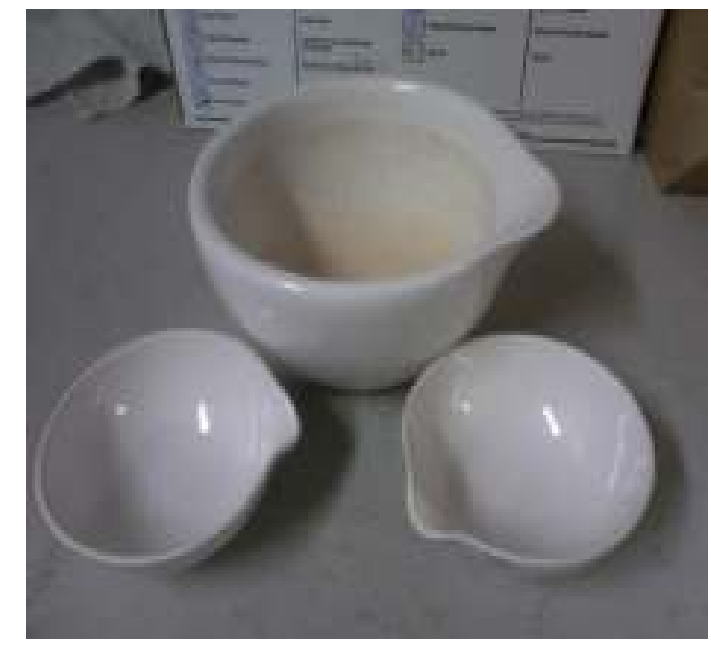

(a)

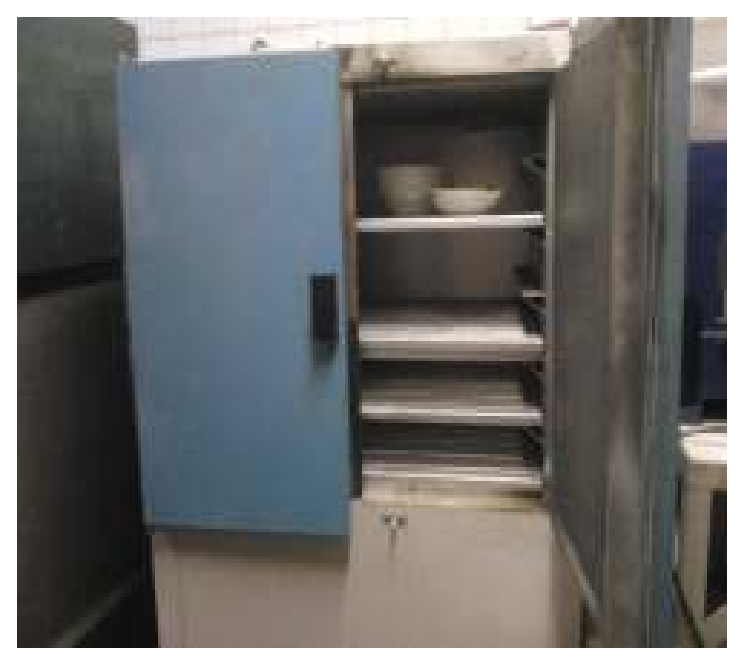

(b)

FIGURA 15 - (a) Almofarizes utilizados para acondicionar a areia (b) Estufa utilizada para a secagem das areias. Foto acervo pessoal, 2012.

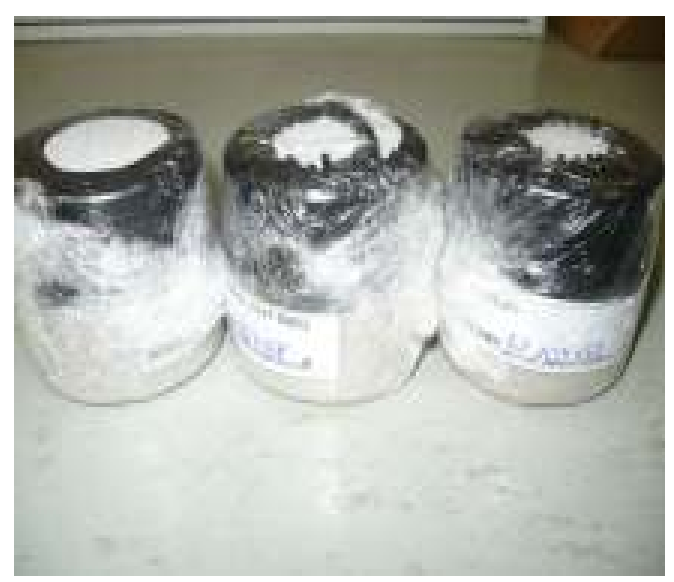

FIGURA 16 - Frascos padrão de polietileno de alta densidade de $100 \mathrm{ml}$ com amostras, selados e envoltos em filme plástico transparente. Foto acervo pessoal, 2012.

A metodologia de medida por espectrometria gama do Laboratório de Radiometria Ambiental é periodicamente verificada com sucesso, em programas de intercomparação e testes de proficiência (LRA, 2013) . 


\subsection{Detector Semicondutor de Germânio Hiperpuro e eletrônica associada}

\subsubsection{Sistema de detecção da concentração de atividade de ${ }^{226} \mathrm{Ra},{ }^{232} \mathrm{Th}$ e ${ }^{40} \mathrm{~K}$}

Para a medição de concentração de atividade foram utilizados dois detectores HPGe ORTEC EG\&G 15\% com blindagem de chumbo e eletrônica associada convencional. A aquisição dos dados foi realizada com um analisador multicanal SpectrumMaster 4k 919 ORTEC EG\&G. Na FIG. 17 pode ser visualizado um dos detectores e a eletrônica associada. A resolução efetiva do ${ }^{60} \mathrm{Co}$ na energia de $1332 \mathrm{keV}$ é $2,8 \mathrm{keV}$. O tempo de contagem para cada amostra foi de $150000 \mathrm{~s}$. A geometria utilizada pode ser visualizada na FIG.18.
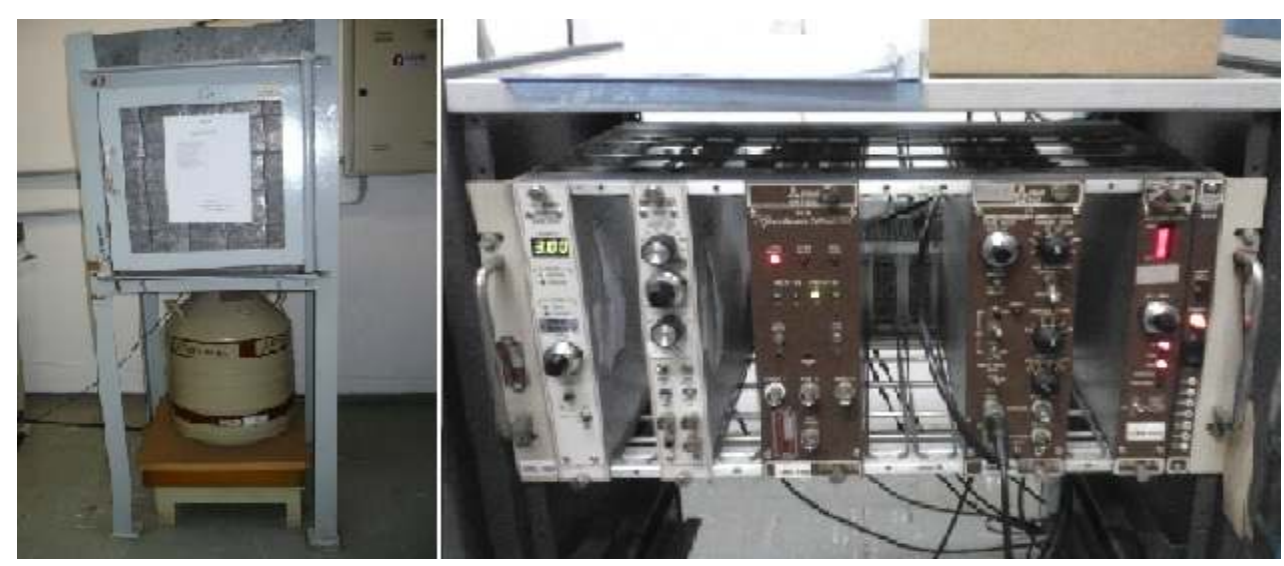

FIGURA 17 - Detector HPGe utilizado para a medida das amostras. Foto acervo pessoal, 2012.

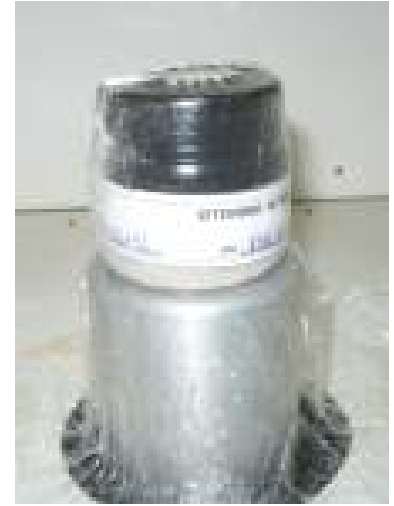

(a)

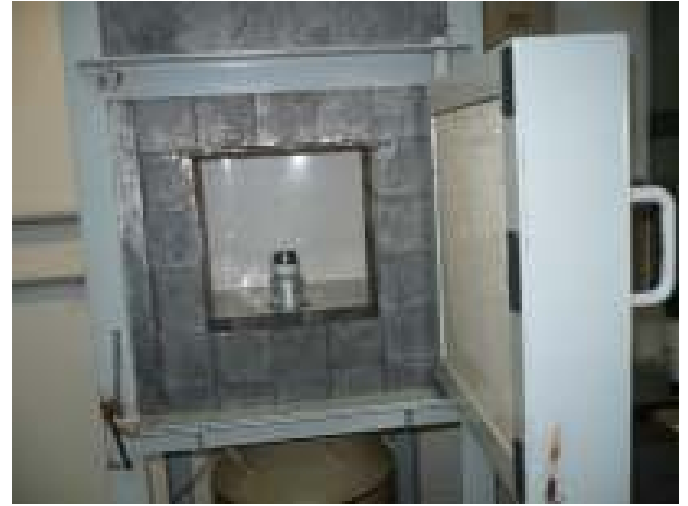

(b)

FIGURA 18 - (a) Posicionamento da amostra sobre o detector. (b) Amostra e detector dentro da blindagem. Foto acervo pessoal, 2012. 
Os espectros foram analisados com o software InterWinner 6.0 (INTERWINNER6.0, 2004). Um espectro típico obtido para a amostra coletada no Ponto 1 em dezembro de 2011 pode ser visualizado na FIG. 19.

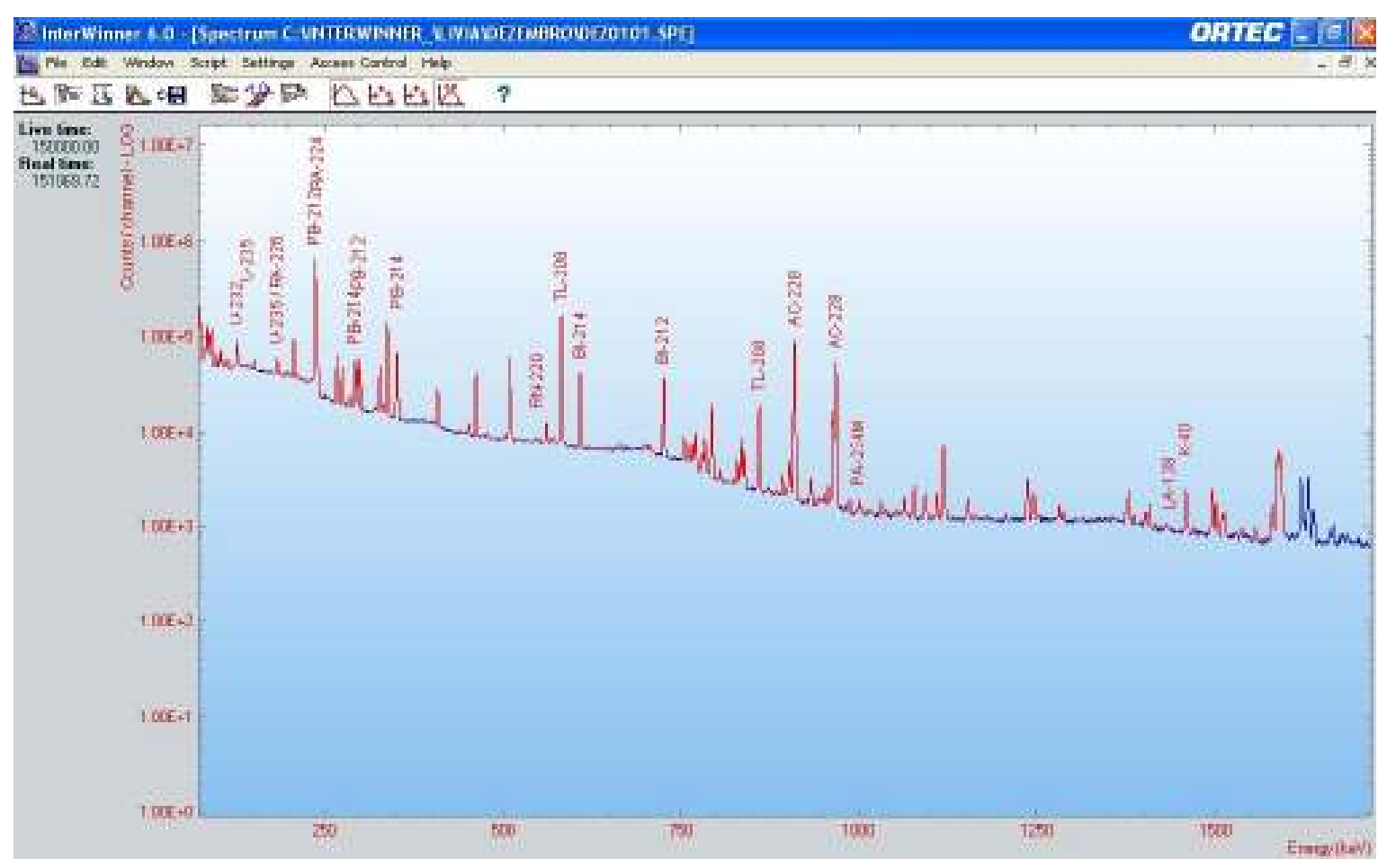

FIGURA 19 - Espectro obtido para a amostra coletada no Ponto 1 em dezembro de 2011. Foto acervo pessoal, 2012.

\subsubsection{Sistema de deteç̧ão utilizado na obtenção do fator de autoatenuação}

Os fatores de autoatenuação foram determinados num detector HPGe ORTEC EG\&G 20\%, com eletrônica convencional e analisador multicanal ACE-2K (FIG. 20), com tempo de contagem de 2000 segundos. A amostra coletada no Ponto 5 em junho de 2011, de densidade $2,35 \mathrm{~g} / \mathrm{cm}^{3}$ foi contada em 4000 segundos para obter uma estatística de contagem melhor. As densidades aparentes foram calculadas conforme o item 5.1.

A geometria e as fontes utilizadas podem ser visualizadas na Fig. 21. Na montagem experimental foi utilizado um suporte de lucite e um colimador, para o posicionamento correto das fontes pontuais utilizadas (FIG. 21). 


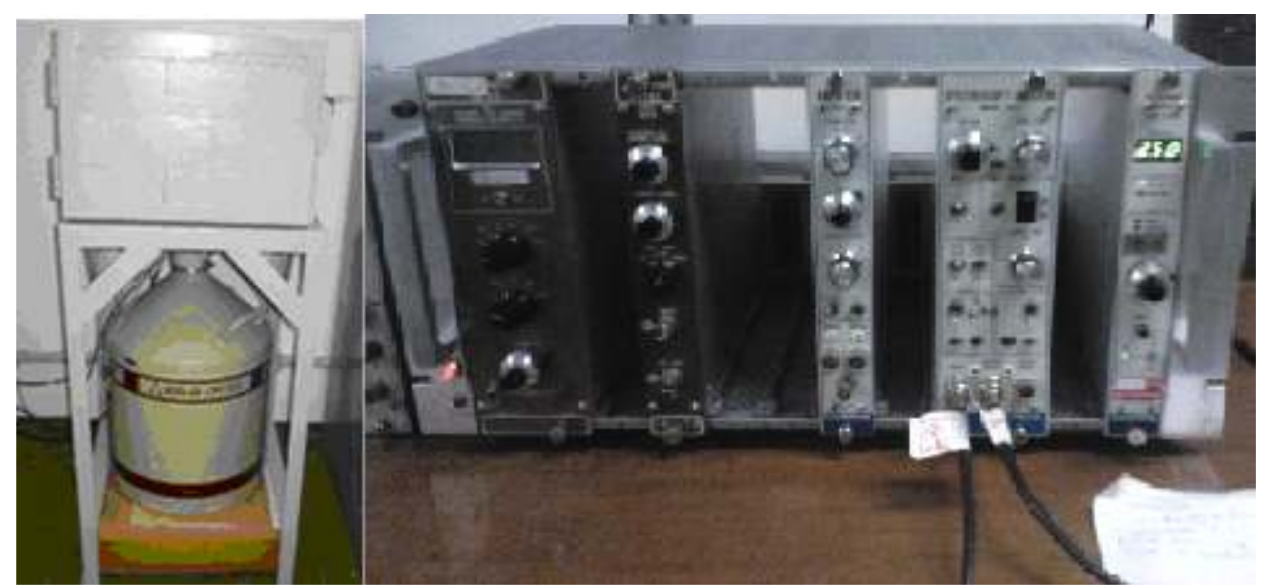

FIGURA 20 - Detector HPGe utilizado na obtenção dos fatores de autoatenuação.

Foto acervo pessoal, 2012.

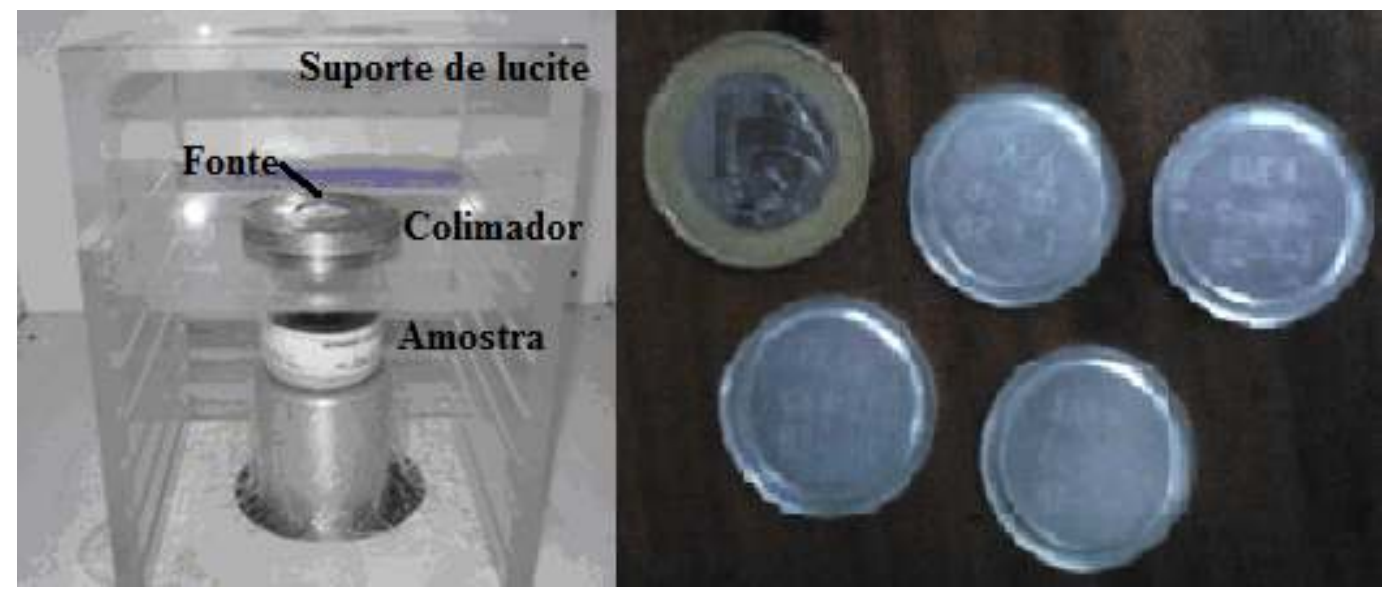

(a)

(b)

FIGURA 21 - (a) Montagem experimental da amostra para obtenção dos fatores de autoatenuação dentro da blindagem. (b) Fontes pontuais padrão de ${ }^{152} \mathrm{Eu},{ }^{137} \mathrm{Cs},{ }^{133} \mathrm{Ba} \mathrm{e}$ ${ }^{60}$ Co utilizadas. Foto acervo pessoal, 2012.

Os espectros foram analisados com o software InterWinner 6.0

(INTERWINNER6.0, 2004). 


\section{RESULTADOS E DISCUSSÕES}

\subsection{Densidade aparente das amostras}

A densidade aparente $(\rho)$ em g. $\mathrm{cm}^{-3}$ foi calculada pelo método clássico:

$$
\rho=\frac{m}{V}
$$

Onde $m$ é a massa da amostra em gramas (g), medida conforme item 4.1 e $V$ é o volume de $100 \mathrm{ml}\left(100 \mathrm{~cm}^{3}\right)$ do frasco de polietileno. As massas e respectivas densidades aparentes das amostras variaram por ponto coletado ao longo do ano de 2011. Na TAB. 4 e na FIG. 22, temos as densidades encontradas por mês de 2011 e por ponto de coleta.

TABELA 4 - Densidades aparentes $\left(\mathrm{em} \mathrm{g} \mathrm{cm}^{-3}\right)$ das amostras de areia coletadas na Praia de Camburi no ano de 2011. A incerteza da densidade aparente é de 3\% .

\begin{tabular}{|c|c|c|c|c|c|c|c|c|c|c|c|}
\hline \multirow[t]{2}{*}{ Mês } & \multicolumn{11}{|c|}{ Densidade $\left(\mathrm{g} / \mathrm{cm}^{3}\right)$} \\
\hline & Ponto1 & Ponto2 & Ponto3 & Ponto4 & Ponto5 & Ponto6 & Ponto7 & Ponto8 & Ponto9 & Ponto10 & Ponto11 \\
\hline janeiro & 1,36 & 1,76 & 1,59 & 1,74 & 1,79 & 1,68 & 1,72 & 1,70 & 1,74 & 1,63 & 1,76 \\
\hline fevereiro & 1,53 & 1,64 & 1,71 & 1,74 & 1,75 & 1,69 & 1,62 & 1,83 & 1,48 & 1,67 & 1,68 \\
\hline março & 1,62 & 1,64 & 1,68 & 1,68 & 1,82 & 1,73 & 1,70 & 1,62 & 1,68 & 1,67 & 1,81 \\
\hline abril & 1,79 & 1,65 & 1,58 & 1,66 & 1,73 & 1,77 & 1,77 & 1,69 & 1,72 & 1,68 & 1,69 \\
\hline maio & 1,68 & 1,65 & 1,65 & 1,67 & 1,84 & 1,77 & 1,76 & 1,75 & 1,67 & 1,68 & 1,66 \\
\hline junho & 1,27 & 1,86 & 1,75 & 1,70 & 2,35 & 1,78 & 1,77 & 1,75 & 1,71 & 1,69 & 1,69 \\
\hline julho & 1,26 & 1,78 & 1,70 & 1,70 & 1,89 & 1,69 & 1,76 & 1,70 & 1,66 & 1,76 & 1,68 \\
\hline agosto & 1,57 & 1,84 & 1,67 & 1,65 & 1,63 & 1,64 & 1,64 & 1,62 & 1,67 & 1,62 & 1,62 \\
\hline setembro & 1,56 & 1,88 & 1,63 & 1,64 & 1,67 & 1,68 & 1,71 & 1,76 & 1,58 & 1,68 & 1,65 \\
\hline outubro & 1,66 & 1,61 & 1,62 & 1,59 & 1,81 & 1,68 & 1,57 & 1,67 & 1,61 & 1,63 & 1,64 \\
\hline novembro & 1,54 & 1,56 & 1,59 & 1,65 & 1,61 & 1,75 & 1,71 & 1,60 & 1,62 & 1,62 & 1,71 \\
\hline dezembro & 1,96 & 1,63 & 1,59 & 1,61 & 1,70 & 1,68 & 1,69 & 1,67 & 1,61 & 1,66 & 1,67 \\
\hline
\end{tabular}




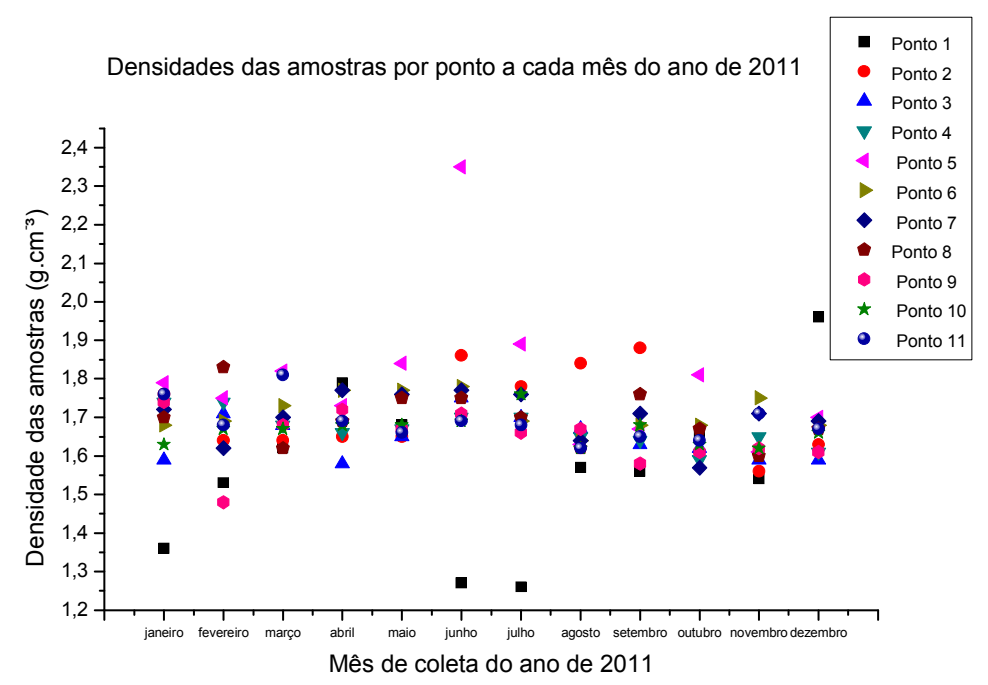

FIGURA 22 - Densidades aparentes das amostras de areia coletadas na Praia de Camburi por ponto de coleta a cada mês do ano de 2011 .

\subsection{Fatores de autoatenuação gama}

As curvas dos fatores de autoatenuação em função das energias das transições gama das fontes pontuais (TAB.2) foram ajustadas por uma função exponencial pelo software Origin7.5 (ORIGINLAB7.5, 2011). Na FIG. 23 pode se visualizar uma curva típica de autoatenuação. Todas as curvas apresentaram o mesmo comportamento. Para cada amostra foi ajustada uma curva.

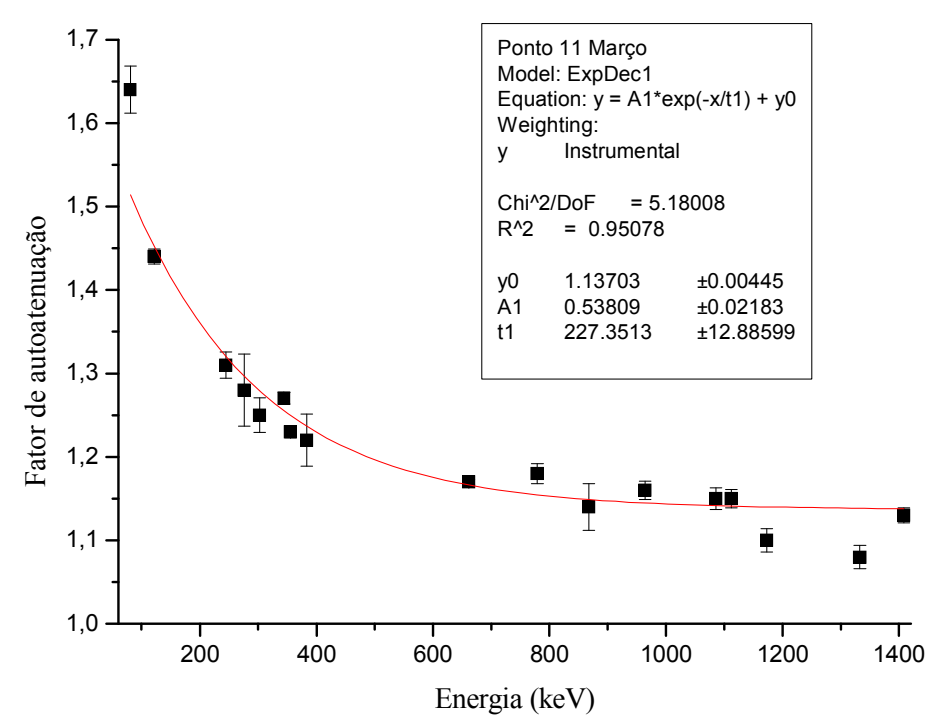

FIGURA 23 - Curva de autoatenuação para a amostra coletada em março no ponto 11, de densidade aparente $1,81 \mathrm{~g} . \mathrm{cm}^{-3}$. 
Os fatores de autoatenuação correspondentes às energias da TAB. 2 para as 132 amostras analisadas se encontram no APÊNDICE A.

Na FIG.24 temos os fatores de autoatenuação encontrados com as energias da TAB.2 para as 132 amostras, ordenadas pelo mês e ponto de coleta.

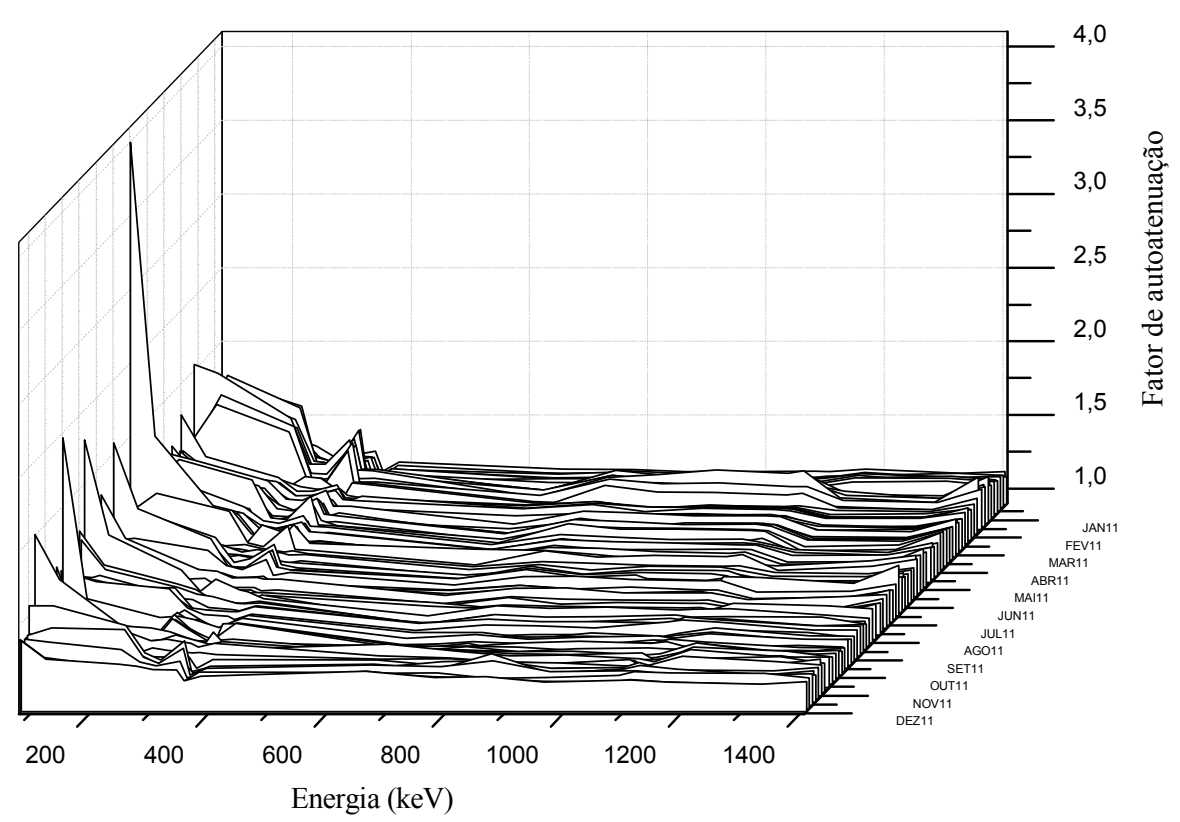

FIGURA 24 - Fator de autoatenuação por energia para as 132 amostras coletadas na Praia de Camburi no ano de 2011.

Analisando as 132 amostras diferentes, encontramos várias amostras com a mesma densidade, inclusive em pontos e meses de coleta diferentes. Três densidades entre as presentes na TAB. 4 aparecem em maior quantidade, nove amostras com densidade de $1,62 \mathrm{~g} . \mathrm{cm}^{-3}$, dez amostras com densidade de $1,67 \mathrm{~g} . \mathrm{cm}^{-3}$ e 13 amostras com densidade de $1,68 \mathrm{~g} . \mathrm{cm}^{-3}$. Com o interesse de analisar como o fator de autoatenuação varia com a energia para uma determinada densidade única foram construídos os gráficos das FIG. 25, 26 e 27.

Na FIG. 25 é mostrado o fator de autoatenuação em função da energia (keV) para as 9 amostras que possuem densidades de 1,62 g. $\mathrm{cm}^{-3}$ coletadas na Praia de Camburi no ano de 2011. 


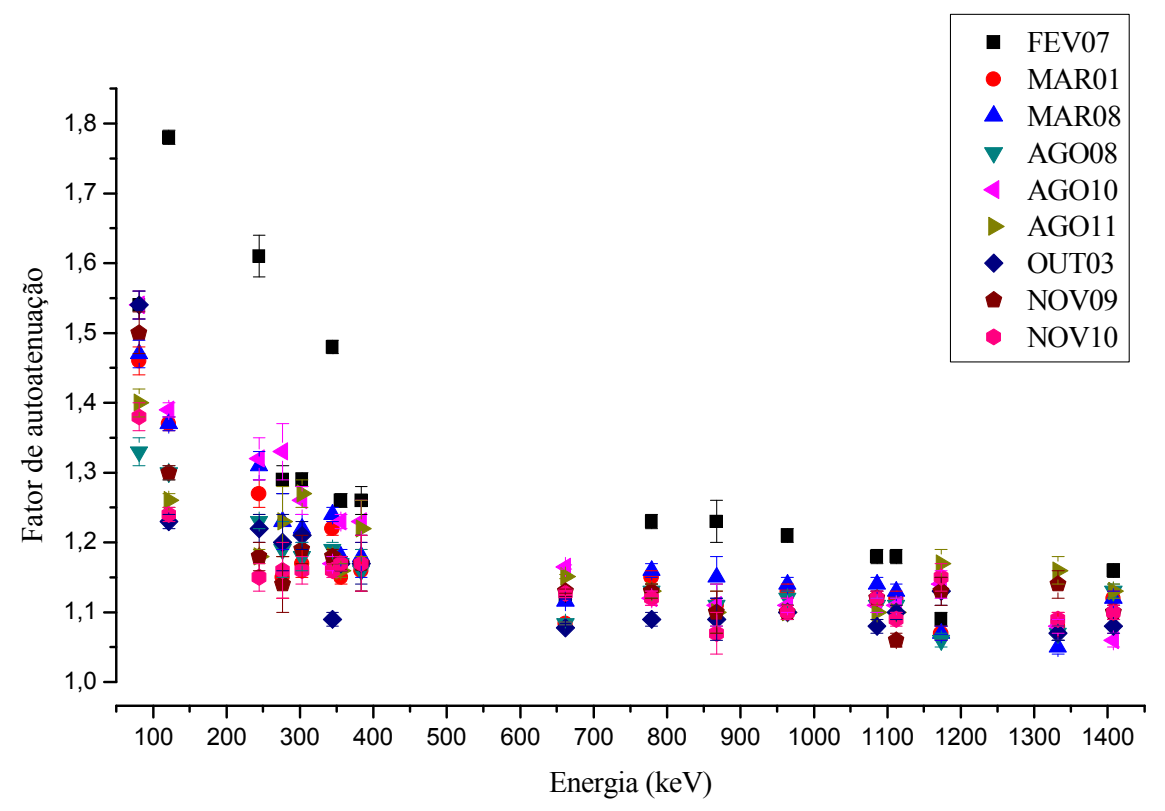

FIGURA 25 - Fator de autoatenuação em função da energia para as 9 amostras que possuem densidades de 1,62 g.cm $\mathrm{cm}^{-3}$ coletadas na Praia de Camburi no ano de 2011 no respectivo mês e ponto de coleta.

Na FIG. 26 temos o fator de autoatenuação em função da energia $(\mathrm{keV})$ para as 10 amostras que possuem densidades de $1,67 \mathrm{~g} . \mathrm{cm}^{-3}$ coletadas na Praia de Camburi no ano de 2011.

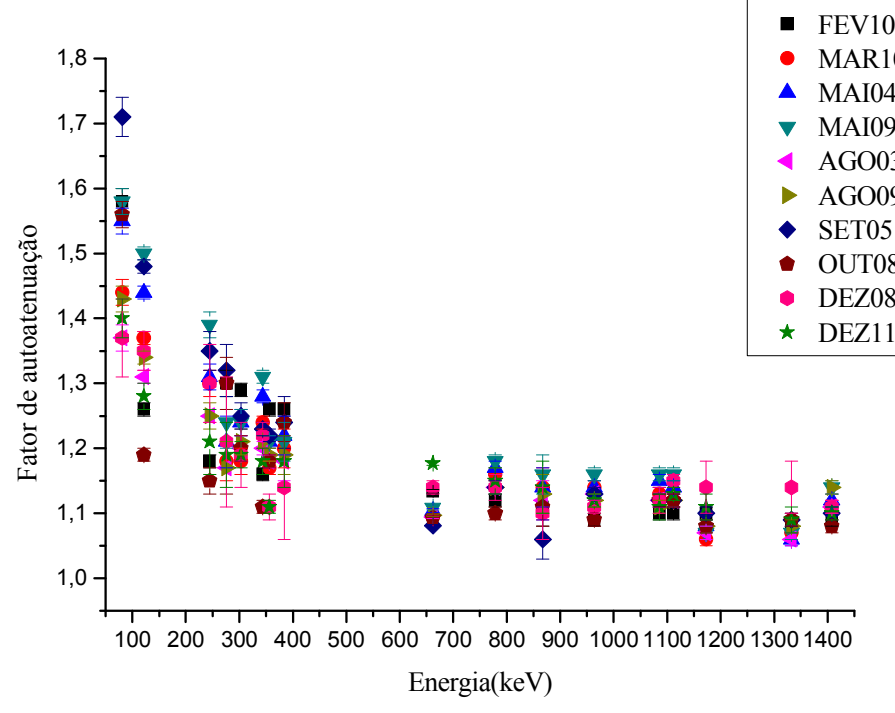

FIGURA 26 - Fator de autoatenuação em função da energia para as 10 amostras que possuem densidades de 1,67 g. $\mathrm{cm}^{-3}$ coletadas na Praia de Camburi no ano de 2011 no respectivo mês e ponto de coleta. 
Na FIG. 27 temos os pontos do fator de autoatenuação em função da energia (keV) para as 13 amostras que possuem densidades de $1,68 \mathrm{~g} . \mathrm{cm}^{-3}$ coletadas na Praia de Camburi no ano de 2011.

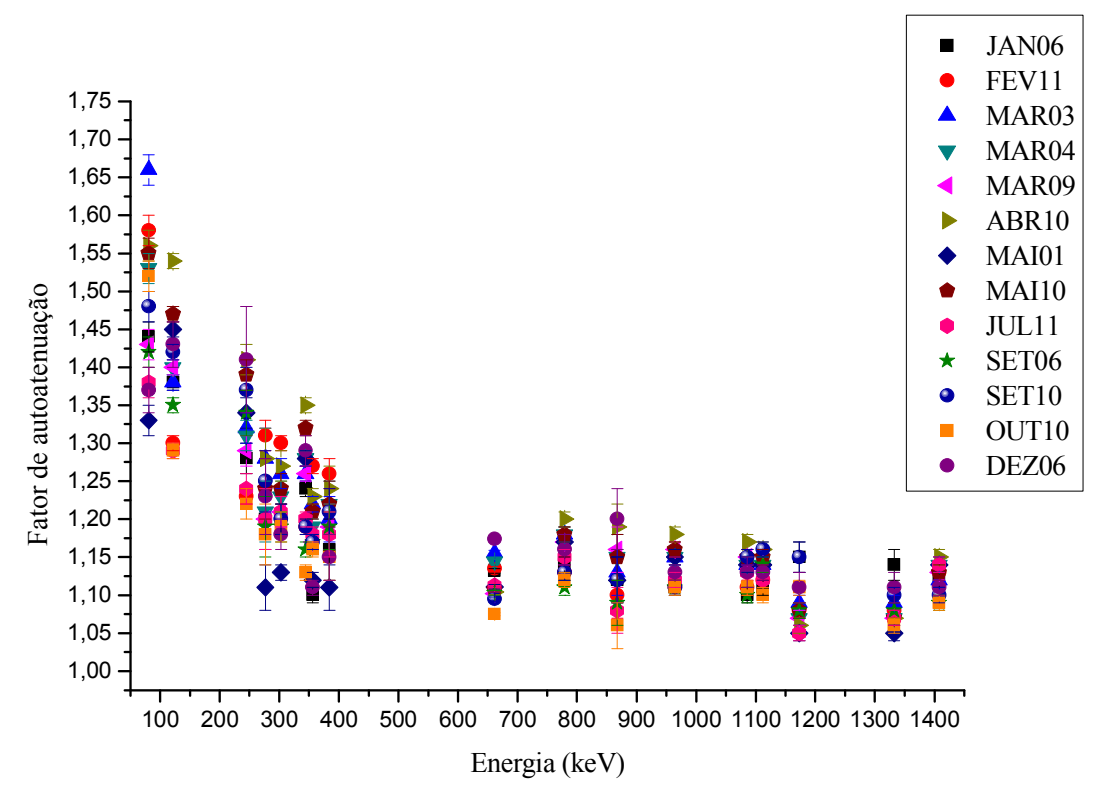

FIGURA 27 - Fator de autoatenuação em função da energia para as 13 amostras que possuem densidades de 1,68 g.cm ${ }^{-3}$ coletadas na Praia de Camburi no ano de 2011 no respectivo mês e ponto de coleta.

Nas FIG. 25, 26 e 27 visualizamos que o fator de autoatenuação para cada energia (TAB.2) variou. Apesar das amostras apresentarem uma mesma densidade aparente, elas foram coletadas em pontos de coleta e meses diferentes, provavelmente com composição mineralógica e química diferente. O mesmo comportamento é observado considerando-se as amostras em faixas de densidades aparentes próximas.

O processo de atenuação da radiação gama com a matéria depende da energia dos fótons e do número atômico do meio (Evans, 1972). Como a areia é uma mistura de vários elementos, a atenuação depende do número atômico médio ponderado pela concentração do elemento na areia. (Ferreira, 2013)

Desta forma, se a composição mineralógica e química das amostras com mesma densidade for diferente, o número atômico médio ponderado pela concentração do elemento na areia é diferente, logo o processo de autoatenuação será diferente nestas 
amostras, o que é confirmado por diferentes fatores de autoatenuação encontrados numa mesma energia (FIG. 25, 26 e 27).

Por esta razão, curvas como a da FIG. 23 foram ajustadas para cada uma das amostras e não por densidade aparente encontrada.

\subsection{Concentração de atividade de ${ }^{226} \mathrm{Ra},{ }^{232} \mathrm{Th}$ e ${ }^{40} \mathrm{~K}$ no ano de 2011}

Os valores de concentração de atividade de ${ }^{226} \mathrm{Ra},{ }^{232} \mathrm{Th}$ e ${ }^{40} \mathrm{~K}$ encontrados para cada amostra estão no APÊNDICE B. As concentrações de atividade foram calculadas pela equação 4 e seus respectivos desvios pela equação 5 , do item 3.4 .

As concentrações de atividade de ${ }^{226} \mathrm{Ra}$ e ${ }^{232} \mathrm{Th}$ das amostras de areia da Praia de Camburi por mês e por ponto de coleta são mostradas nas FIG.28 e 29, respectivamente. A FIG. 30 mostra a concentração de atividade de ${ }^{40} \mathrm{~K}$ das amostras de areia da Praia de Camburi por mês e por ponto de coleta. A correlação linear entre as concentrações de atividade de ${ }^{226} \mathrm{Ra} \mathrm{e}{ }^{232} \mathrm{Th}$ pode ser visualizada na FIG. 31.

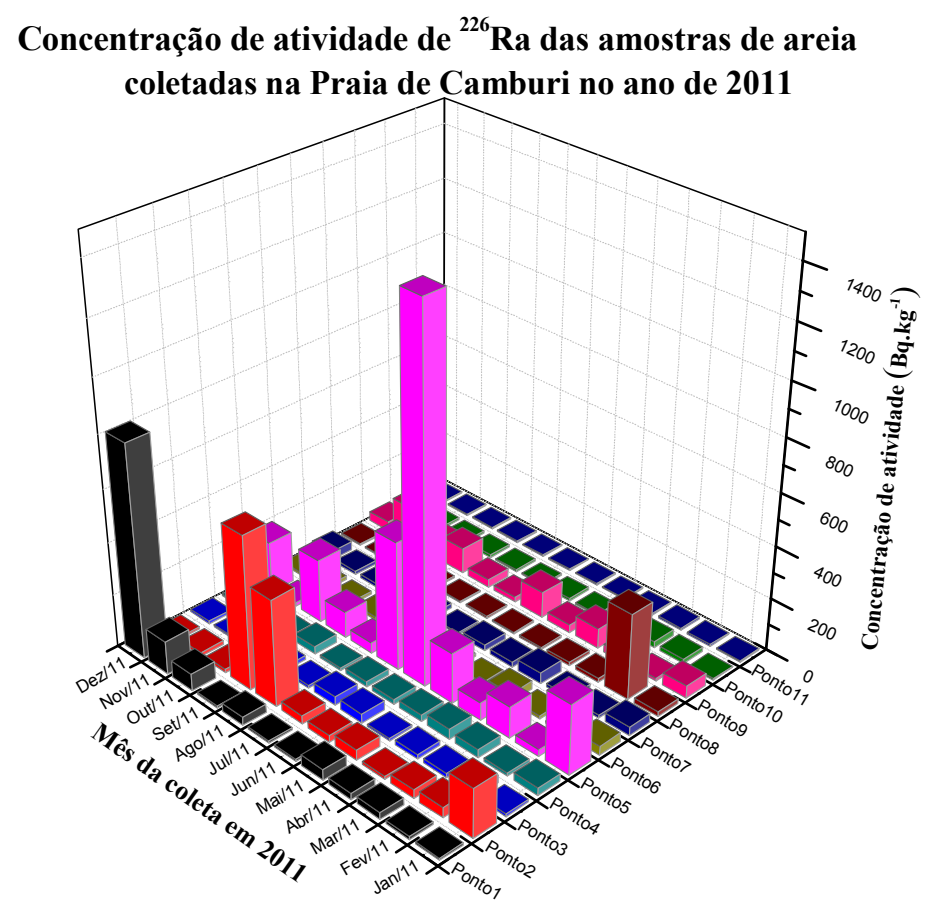

FIGURA 28 - Concentração de atividade de ${ }^{226}$ Ra para as 132 amostras de areia coletadas na Praia de Camburi durante o ano de 2011. 


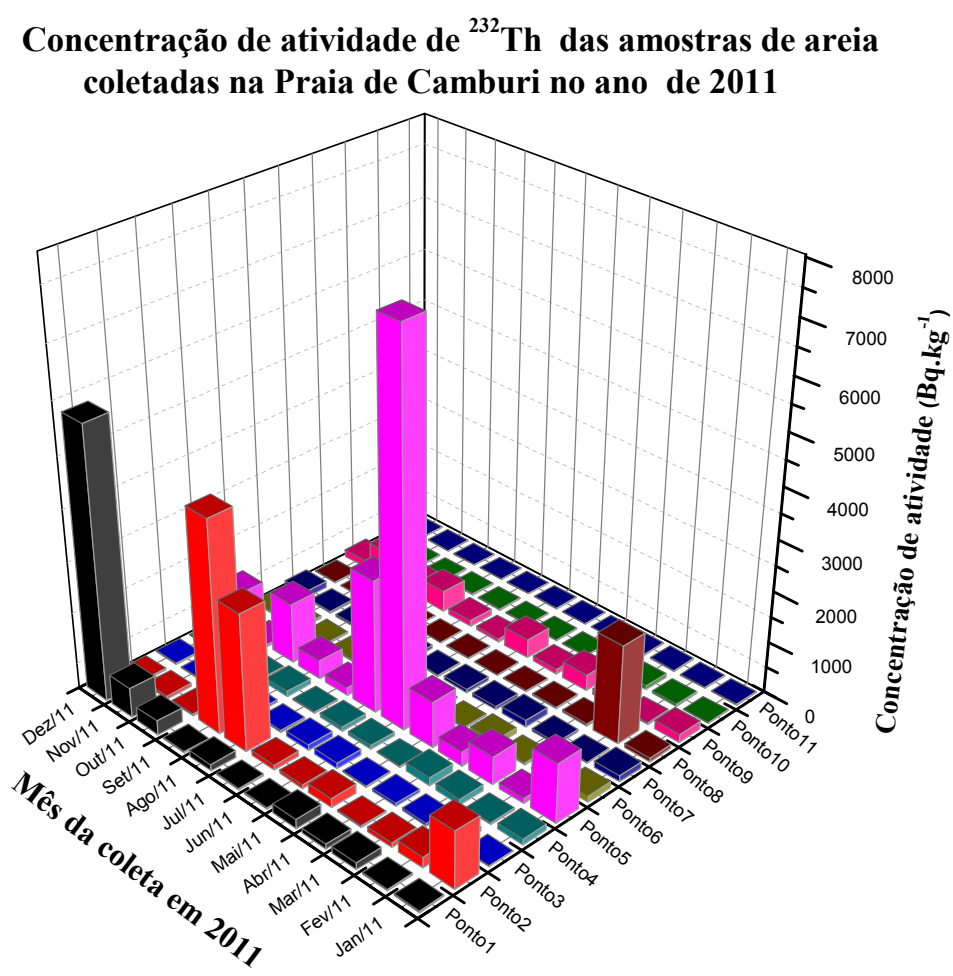

FIGURA 29 - Concentração de atividade de ${ }^{232}$ Th para as 132 amostras de areia coletadas na Praia de Camburi durante o ano de 2011.

\section{Concentração de atividade de ${ }^{40} \mathrm{~K}$ das amostras de areia}

coletadas na Praia de Camburi no ano de 2011

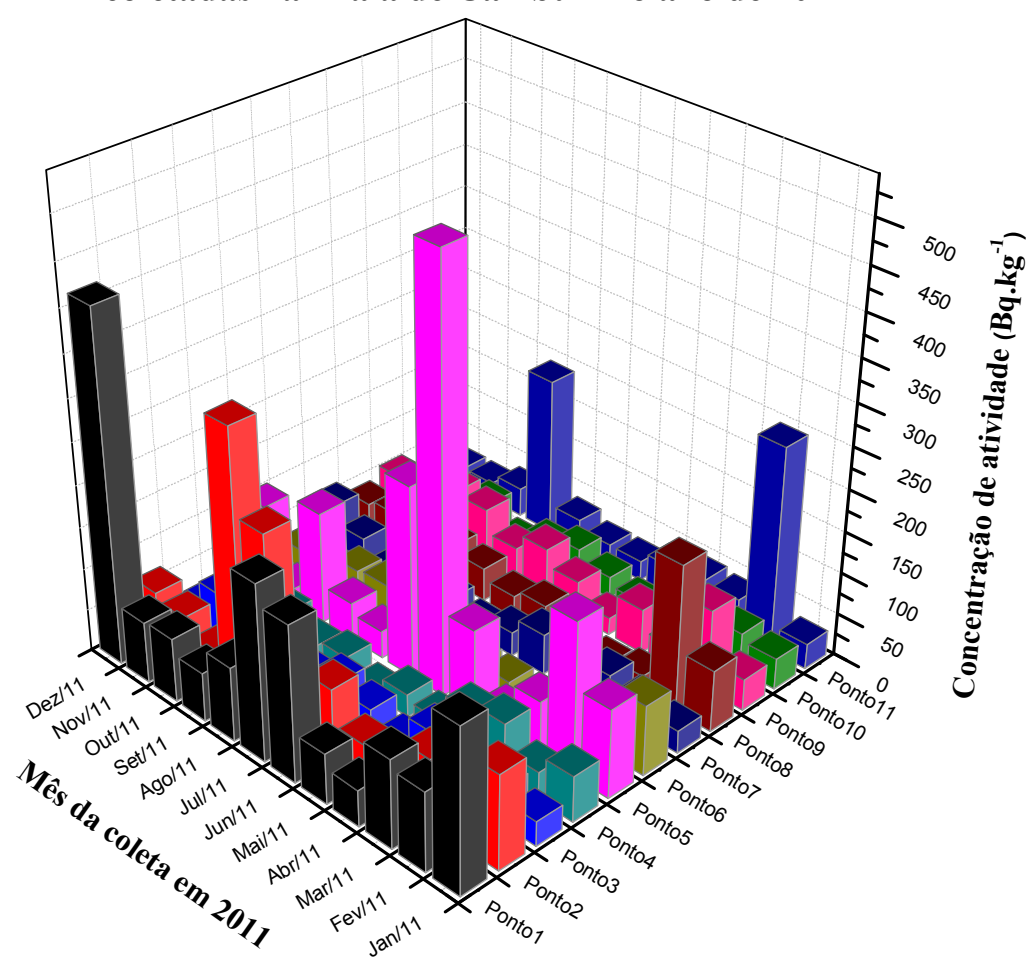

FIGURA 30 - Concentração de atividade de ${ }^{40} \mathrm{~K}$ para as 132 amostras de areia coletadas na Praia de Camburi durante o ano de 2011. 


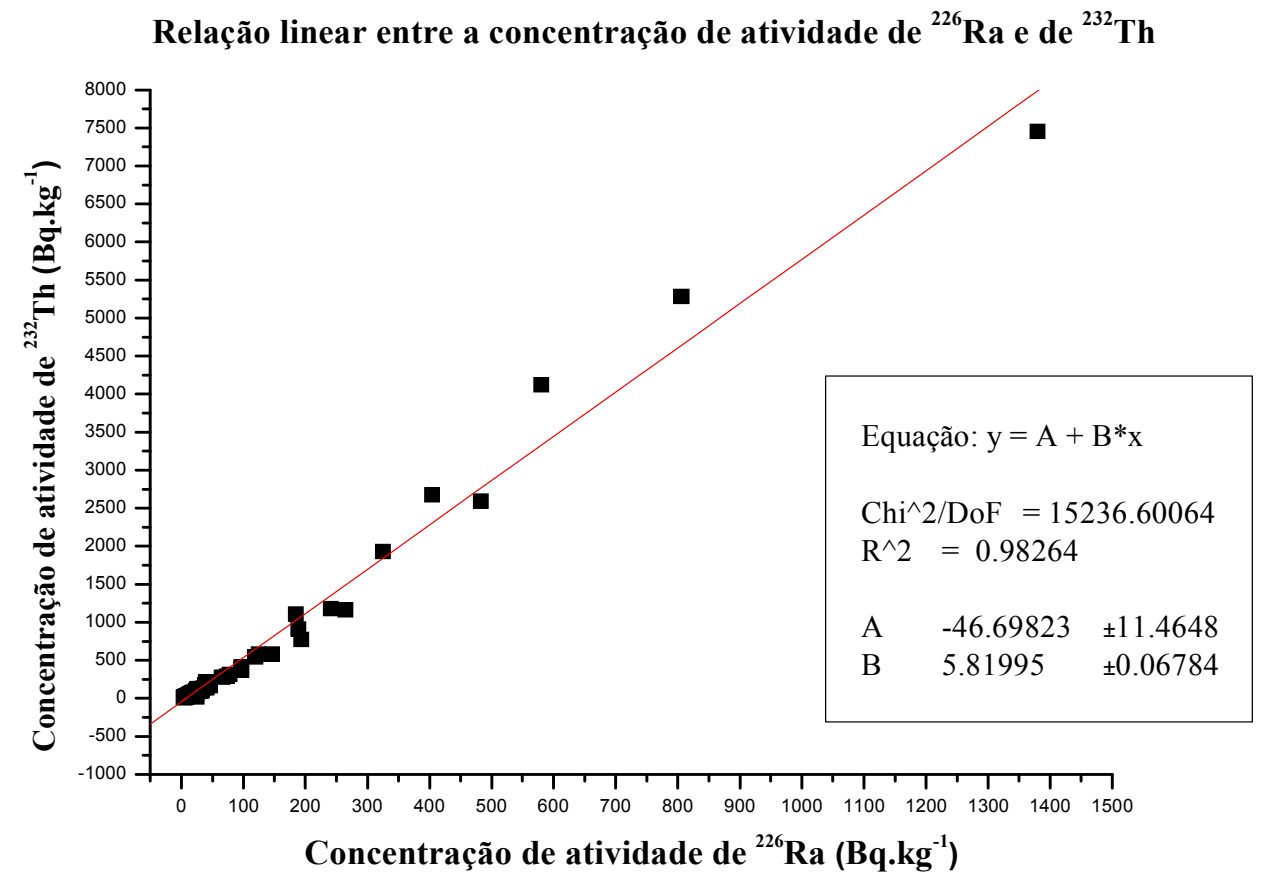

FIGURA 31 - Correlação entre as concentrações de atividade de ${ }^{226} \mathrm{Ra}$ e ${ }^{232} \mathrm{Th}$ para as 132 amostras de areia coletadas na Praia de Camburi durante o ano de 2011.

A maior concentração de atividade de ${ }^{226} \mathrm{Ra}$ e ${ }^{232} \mathrm{Th}$ se desloca do Ponto $8 \mathrm{em}$ fevereiro, ao Ponto 5 em junho, ao Ponto 2 em setembro, ao Ponto 1 em dezembro, sugerindo uma circulação anual.

Foi observado que o Ponto 5 apresentou os maiores valores de concentração de atividade de ${ }^{226} \mathrm{Ra}(1380 \pm 62) \mathrm{Bq} \cdot \mathrm{kg}^{-1},{ }^{232} \mathrm{Th}(7453 \pm 274) \mathrm{Bq} \cdot \mathrm{kg}^{-1}$ e ${ }^{40} \mathrm{~K}(504 \pm 41)$ Bq. $\mathrm{kg}^{-1}$ no mês de junho, seguido do Ponto $1 \mathrm{em}$ dezembro, com concentração de atividade de ${ }^{226} \mathrm{Ra}(806 \pm 39) \mathrm{Bq} \cdot \mathrm{kg}^{-1},{ }^{232} \mathrm{Th}(5283 \pm 206) \mathrm{Bq} \cdot \mathrm{kg}^{-1}$ e ${ }^{40} \mathrm{~K}(415 \pm 36) \mathrm{Bq} \cdot \mathrm{kg}^{-1}$ e pelo Ponto 2 em setembro, com concentração de atividade de ${ }^{226} \mathrm{Ra}(580 \pm 26) \mathrm{Bq} \cdot \mathrm{kg}^{-1},{ }^{232} \mathrm{Th}$ $(4122 \pm 150) \mathrm{Bq} \cdot \mathrm{kg}^{-1}$ e ${ }^{40} \mathrm{~K}(320 \pm 26) \mathrm{Bq} \cdot \mathrm{kg}^{-1}$. Maiores valores de concentração de atividade de ${ }^{226} \mathrm{Ra}$ podem estar relacionados com uma maior concentração de ilmenita, enquanto maiores valores de concentração de atividade de ${ }^{232} \mathrm{Th}$, uma maior concentração de monazita (Aquino, 2010).

Os pontos de coleta 1, 2, 5 e 8 apresentaram pontos de máximo de concentração de atividade de ${ }^{226} \mathrm{Ra},{ }^{232} \mathrm{Th}$ e ${ }^{40} \mathrm{~K}$ e o Ponto 11 apresentou picos de concentração de atividade de ${ }^{40} \mathrm{~K}$. Os pontos de coleta 3, 4, 10 e 11 apresentaram os menores valores de 
concentração de atividade de ${ }^{226} \mathrm{Ra}$ e ${ }^{232} \mathrm{Th}$ ao longo do ano de 2011 , já o ponto 4 apresentou os menores valores de ${ }^{40} \mathrm{~K}$.

A boa correlação encontrada entre as concentrações de atividade de ${ }^{226} \mathrm{Ra}$ e ${ }^{232} \mathrm{Th}$ para as 132 amostras coletadas durante o ano de 2011 (FIG. 31) pode estar relacionada ao fato de a proporção de ${ }^{226} \mathrm{Ra}$ e ${ }^{232} \mathrm{Th}$ variar muito pouco entre os vários grãos de areia existentes nas amostras, supondo que ambos $\left({ }^{226} \mathrm{Ra} \mathrm{e}^{232} \mathrm{Th}\right)$ estejam ligados de alguma forma em uma rede cristalina num único grão. $\mathrm{O}{ }^{226} \mathrm{Ra}$ é decorrente da série radioativa do ${ }^{238} \mathrm{U}$ não tendo, portanto, relação direta com o ${ }^{232} \mathrm{Th}$, que é da série radioativa do ${ }^{232}$ Th.

A TAB. 5 apresenta as faixas de concentrações de atividade de ${ }^{226} \mathrm{Ra},{ }^{232} \mathrm{Th}$ e ${ }^{40} \mathrm{~K}$ de amostras de areia da Praia de Camburi, no Estado do Espírito Santo, Brasil. As faixas de concentração de atividade obtidas neste trabalho são referentes às variações ocorridas de janeiro de 2011 a dezembro de 2011. Camburi Norte, Camburi Central e Camburi Sul são pontos de coleta de Aquino (2010). Camburi Norte é um ponto de coleta próximo aos Pontos 10 e 11 deste trabalho. Camburi Central é um ponto de coleta próximo ao Ponto 5 deste trabalho. Camburi Sul é um ponto de coleta próximo aos Pontos 1 e 2 deste trabalho. A TAB. 6 apresenta faixas de concentrações de atividade de ${ }^{226} \mathrm{Ra},{ }^{232} \mathrm{Th}$ e ${ }^{40} \mathrm{~K}$ de amostras de areia de praias do Brasil, Índia, Turquia, China e Egito. 
TABELA 5 - Faixas de concentrações de atividade de ${ }^{226} \mathrm{Ra},{ }^{232} \mathrm{Th}$ e ${ }^{40} \mathrm{~K}$ de amostras de areia da Praia de Camburi, Espírito Santo, Brasil.

\begin{tabular}{|c|c|c|c|c|c|c|c|c|c|c|c|c|c|c|}
\hline \multirow[b]{2}{*}{$\begin{array}{c}\text { Concentração } \\
\text { de atividade } \\
\left(\mathrm{Bq} \cdot \mathrm{kg}^{-1}\right)\end{array}$} & \multicolumn{14}{|c|}{ 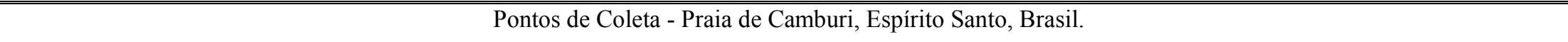 } \\
\hline & 1 & 2 & 3 & 4 & 5 & 6 & 7 & 8 & 9 & 10 & 11 & $\begin{array}{c}\text { Camburi } \\
\text { Norte }\end{array}$ & $\begin{array}{c}\text { Camburi } \\
\text { Central }\end{array}$ & $\begin{array}{c}\text { Camburi } \\
\text { Sul }\end{array}$ \\
\hline${ }^{226} \mathrm{Ra}$ & $7-806$ & $8-580$ & $8-33$ & $6-39$ & $13-1380$ & $6-33$ & $7-41$ & $5-325$ & $11-146$ & $5-22$ & $4-8$ & 6 & 755 & 258 \\
\hline${ }^{232} \mathrm{Th}$ & $22-5283$ & $28-4122$ & $15-106$ & $13-161$ & $38-7453$ & $16-126$ & $22-136$ & $9-1929$ & $37-580$ & $13-71$ & $10-21$ & 16 & 4155 & 1441 \\
\hline${ }^{40} \mathrm{~K}$ & $43-415$ & $31-320$ & $7-58$ & $7-65$ & $20-504$ & $6-83$ & $15-48$ & $11-175$ & $20-97$ & $8-45$ & $22-245$ & 29 & 377 & 140 \\
\hline Referência & $\begin{array}{c}\text { Este } \\
\text { trabalho }\end{array}$ & $\begin{array}{c}\text { Este } \\
\text { trabalho }\end{array}$ & $\begin{array}{c}\text { Este } \\
\text { trabalho }\end{array}$ & $\begin{array}{c}\text { Este } \\
\text { trabalho }\end{array}$ & $\begin{array}{c}\text { Este } \\
\text { trabalho }\end{array}$ & $\begin{array}{c}\text { Este } \\
\text { trabalho }\end{array}$ & $\begin{array}{l}\text { Este } \\
\text { trabalho }\end{array}$ & $\begin{array}{c}\text { Este } \\
\text { trabalho }\end{array}$ & $\begin{array}{c}\text { Este } \\
\text { trabalho }\end{array}$ & $\begin{array}{c}\text { Este } \\
\text { trabalho }\end{array}$ & $\begin{array}{c}\text { Este } \\
\text { trabalho }\end{array}$ & $\begin{array}{c}\text { Aquino, } \\
2010\end{array}$ & $\begin{array}{c}\text { Aquino, } \\
2010\end{array}$ & $\begin{array}{c}\text { Aquino, } \\
2010\end{array}$ \\
\hline
\end{tabular}


TABELA 6 - Faixas de concentrações de atividade de ${ }^{226} \mathrm{Ra},{ }^{232} \mathrm{Th}$ e ${ }^{40} \mathrm{~K}$ de amostras de areia de praias do Brasil, Índia, Turquia,

China e Egito.

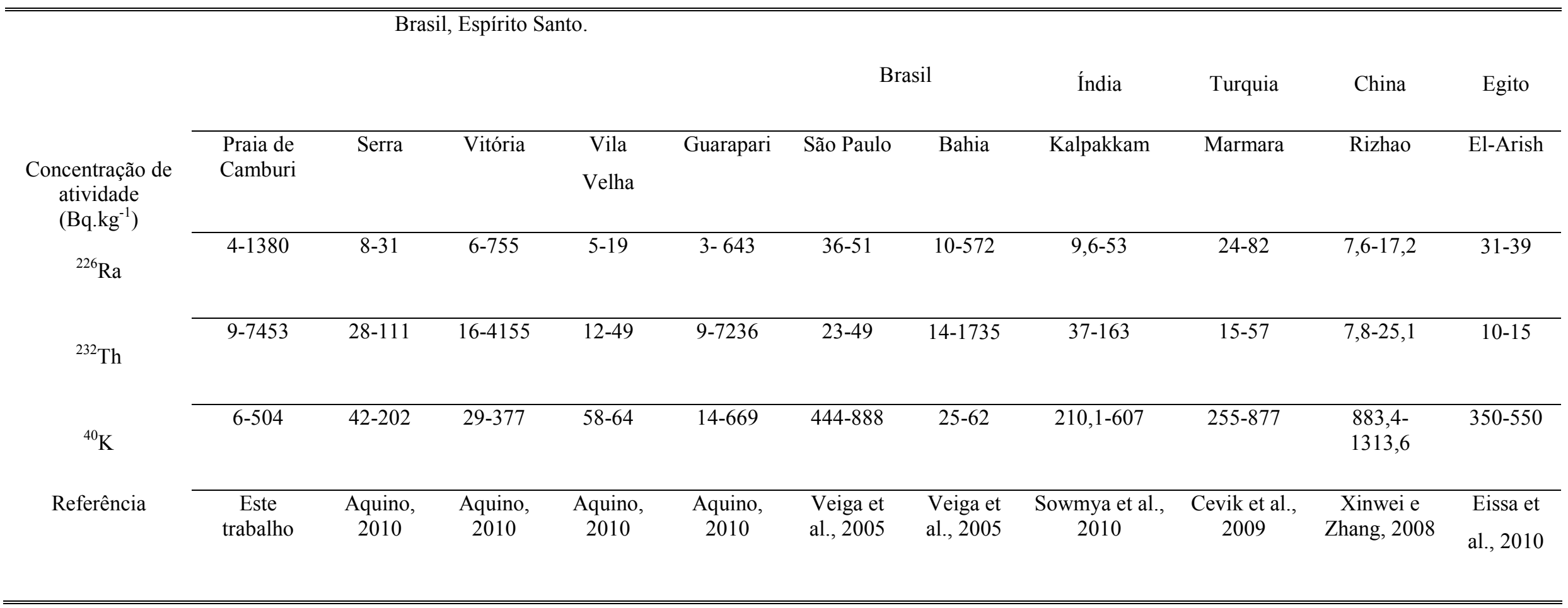


Os resultados deste trabalho estão dentro do intervalo de valores encontrados na literatura para areias semelhantes, provenientes de regiões com nível elevado de radiação natural.

Comparando os valores do atual trabalho com as de outras referências (TAB.6) observamos que os maiores valores encontrados para a concentração de atividade de ${ }^{226} \mathrm{Ra}$ $\mathrm{e}^{232}$ Th são obtidos neste trabalho no ponto 5 da Praia de Camburi (em junho), maiores até do que os valores obtidos para a Praia da Areia Preta (Aquino, 2010).

Notamos que os valores em Camburi Norte, Camburi Central e Camburi Sul (Aquino, 2010) estão nas faixas de concentração encontradas neste trabalho.

\subsection{Fatores Climatológicos}

\subsubsection{Temperatura média}

A variação da temperatura média $\left({ }^{\circ} \mathrm{C}\right)$ ao longo do ano de 2011 é encontrada na FIG.32. Os dados foram extraídos a partir de gráficos do Instituto Capixaba de Pesquisa, Assistência e Extensão Rural (INCAPER, 2013).

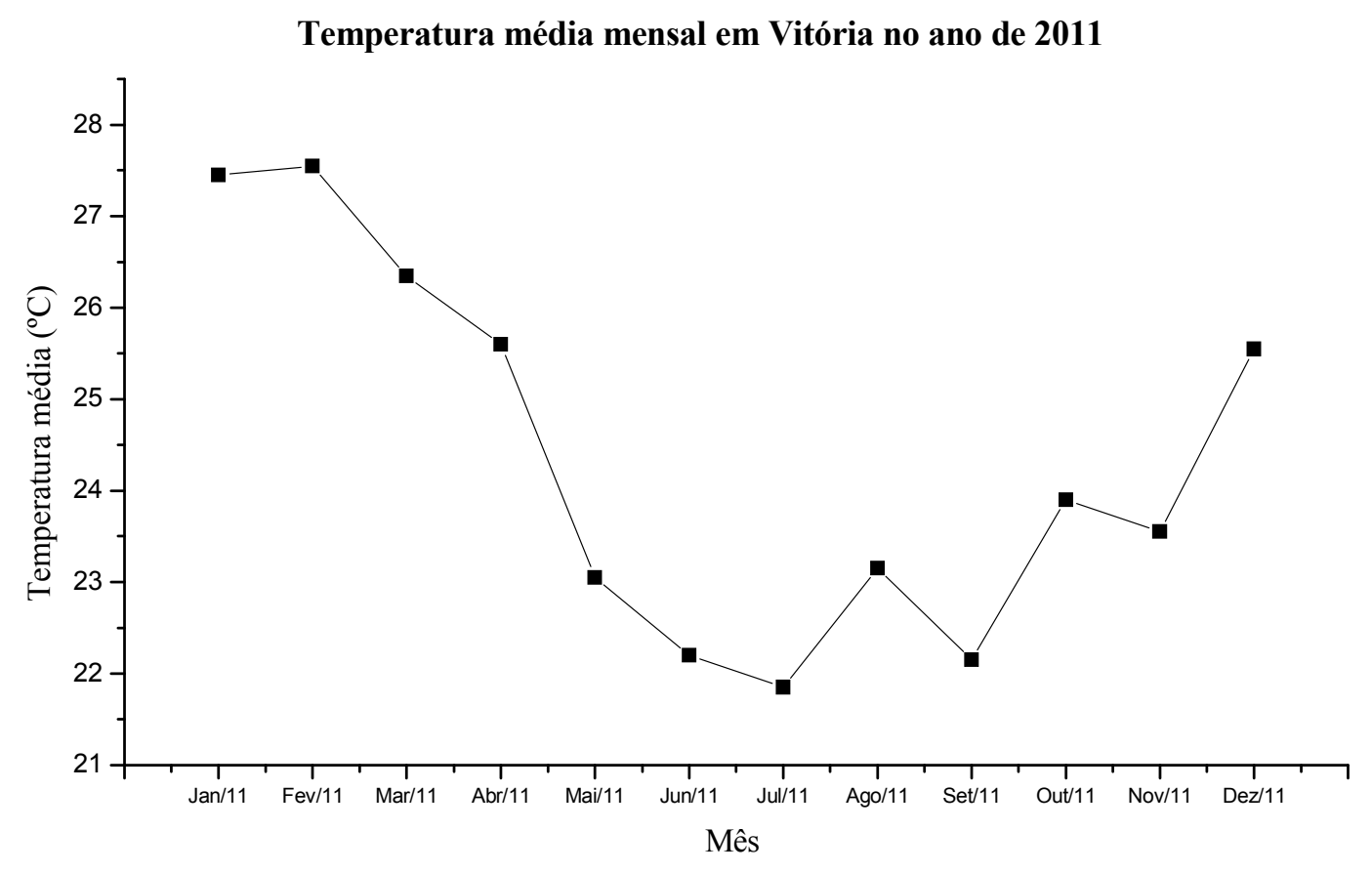

FIGURA 32 - Temperatura média mensal $\left({ }^{\circ} \mathrm{C}\right)$ em Vitória durante o ano de 2011.

(INCAPER, 2013) 


\subsection{2 Índice pluviométrico}

A variação dos índices de precipitação pluviométrica no ano de 2011 é mostrada na FIG. 33. Pode-se observar um ponto de máximo localizado em abril de 2011. Os dados foram extraídos a partir de gráficos do Instituto Capixaba de Pesquisa, Assistência e Extensão Rural (INCAPER, 2013).

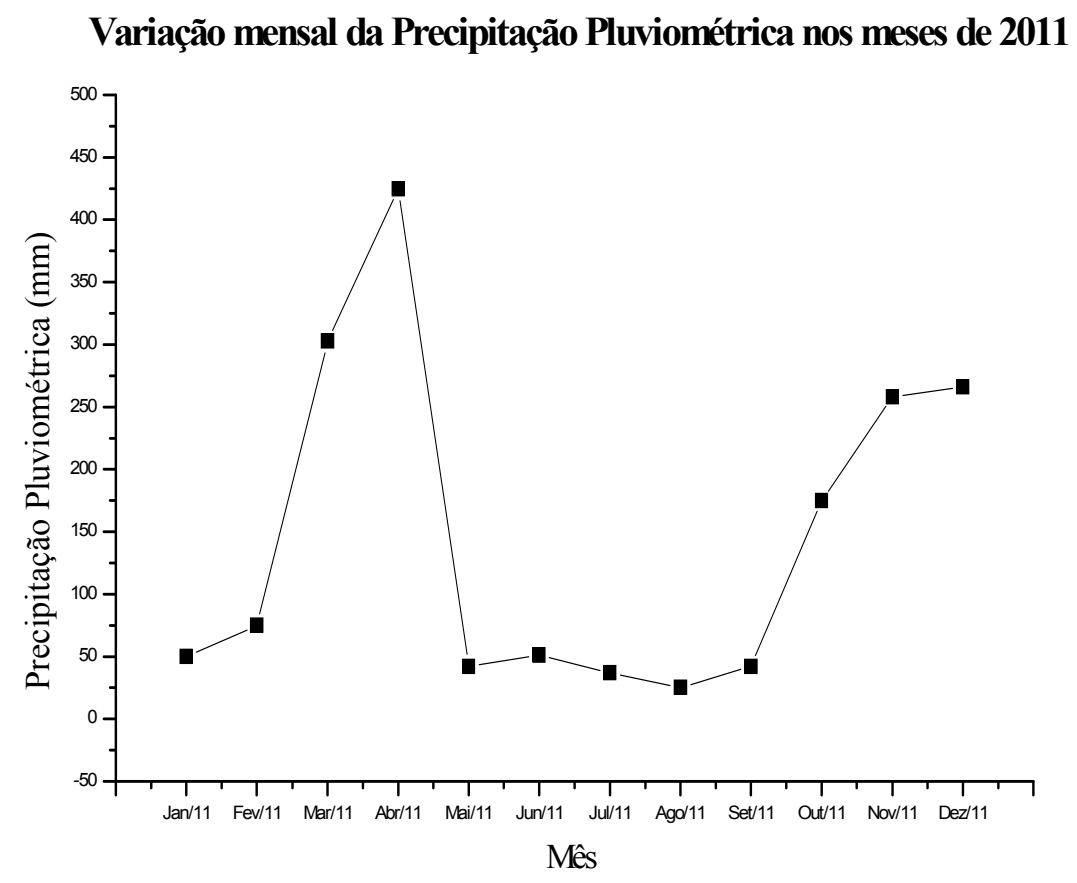

FIGURA 33 - Variação da precipitação pluviométrica (mm) no ano de 2011.

(INCAPER, 2013)

\subsubsection{Altura das marés}

A variação da altura das marés dos Portos de Vitória e Tubarão é mostrada na FIG.34.

Os valores das alturas das marés utilizados para a construção da FIG. 34 foram obtidos a partir do Banco Nacional de Dados Oceanográficos (BNDO,2012).

O intervalo de dias escolhidos para a análise da variação da altura das marés referente à coleta do dia 15 de janeiro de 2011 foi de 1 de janeiro de 2011 a 15 de janeiro de 2011; referente à coleta do dia 15 de fevereiro foi de 16 de janeiro de 2011 a 15 de fevereiro de 2011; referente à coleta do dia 15 de março foi de 16 de fevereiro de 2011 a 
15 de março de 2011, e assim sucessivamente até a referente coleta do dia 15 de dezembro onde a análise da variação das marés ocorreu do dia 16 de novembro a 15 de dezembro.

A variação das marés foi obtida a partir da maior elevação no nível das marés nos intervalos analisados subtraída da menor elevação no nível das marés nos intervalos analisados.

Pode-se observar pontos de máximo na variação das marés, um ocorrido em abril para ambos os portos, um em setembro para o Porto de Vitória e outro em outubro para o Porto de Tubarão e dois pontos de mínimo, ocorridos em janeiro e junho, para ambos os portos.

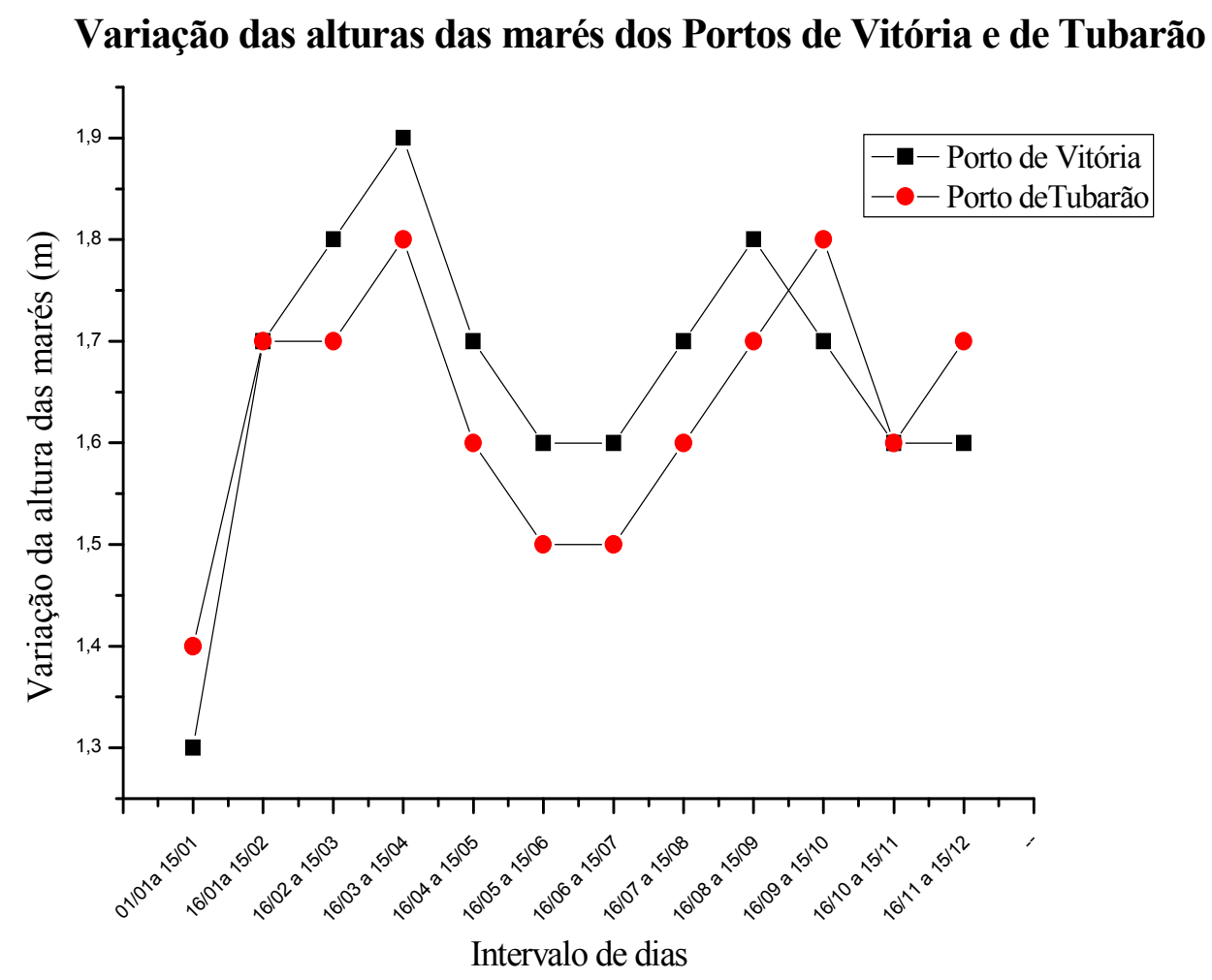

FIGURA 34 - Variação da altura das marés (m) dos Portos de Vitória e Tubarão no ano de 2011.

A partir dos dados obtidos pelo Banco Nacional de Dados Oceanográficos (BNDO,2012) observamos que no período de 16 de março a 15 de abril de 2011 obteve-se a altura máxima das marés, de 1,7 metros no Porto de Tubarão e de 1,8 metros no Porto de Vitória. 
5.5 Relação das concentrações de atividade de ${ }^{226} \mathrm{Ra},{ }^{232} \mathrm{Th}$ e ${ }^{40} \mathrm{~K}$ com os fatores climatológicos

\subsubsection{Temperatura média}

As FIG. 35, 36 e 37 apresentam respectivamente gráficos da variação da concentração de atividade de ${ }^{226} \mathrm{Ra},{ }^{232} \mathrm{Th}$ e ${ }^{40} \mathrm{~K}$ nas areias coletadas na Praia de Camburi e a variação da temperatura média mensal $\left({ }^{\circ} \mathrm{C}\right)$ em Vitória ao longo do ano de 2011 . Os dados da temperatura média mensal foram extraídos a partir de gráficos do Instituto Capixaba de Pesquisa, Assistência e Extensão Rural (INCAPER, 2013).

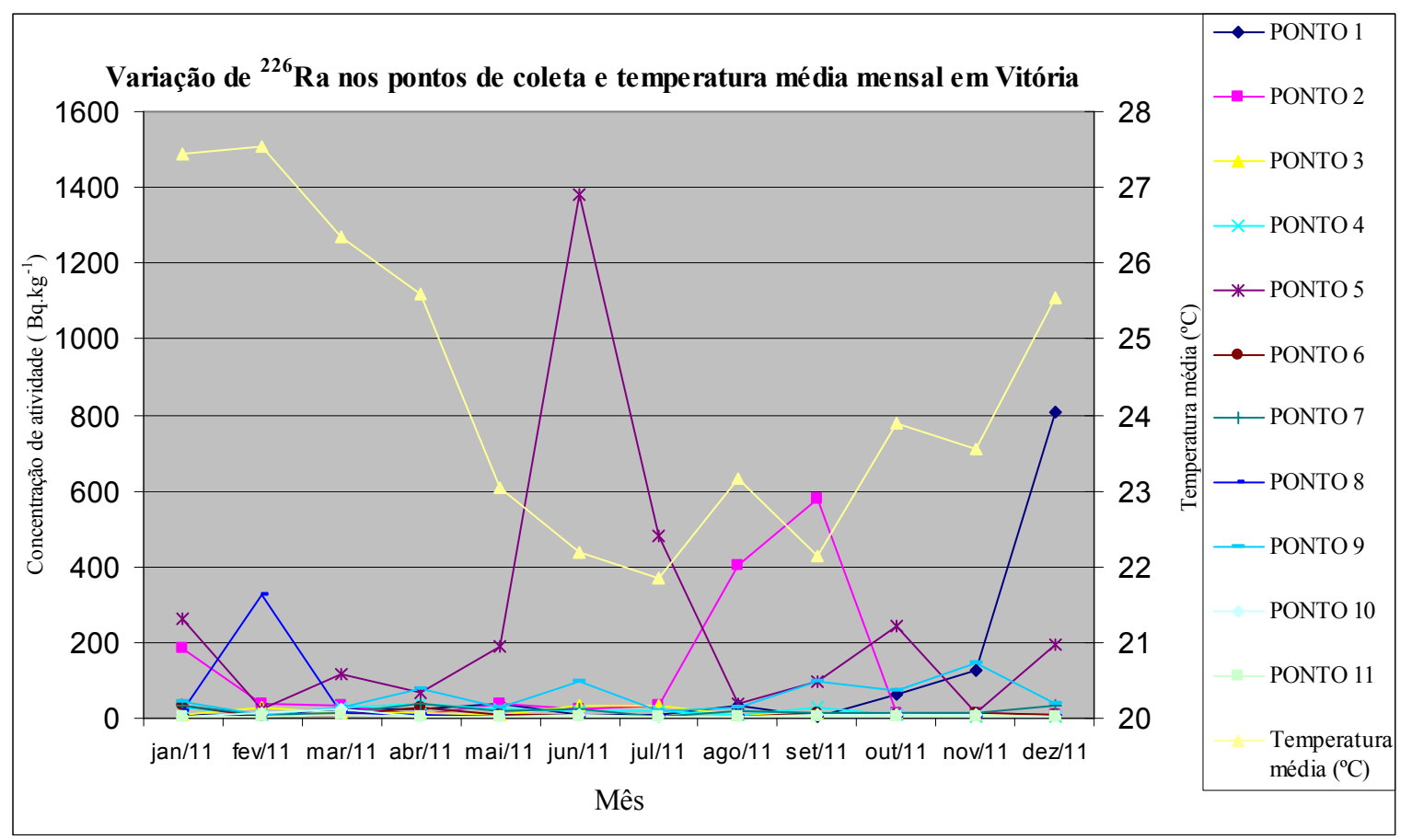

FIGURA 35 - Variação da concentração de atividade de ${ }^{226}$ Ra nos pontos de coleta e a variação da temperatura média mensal $\left({ }^{\circ} \mathrm{C}\right)$ em Vitória ao longo do ano de 2011. 


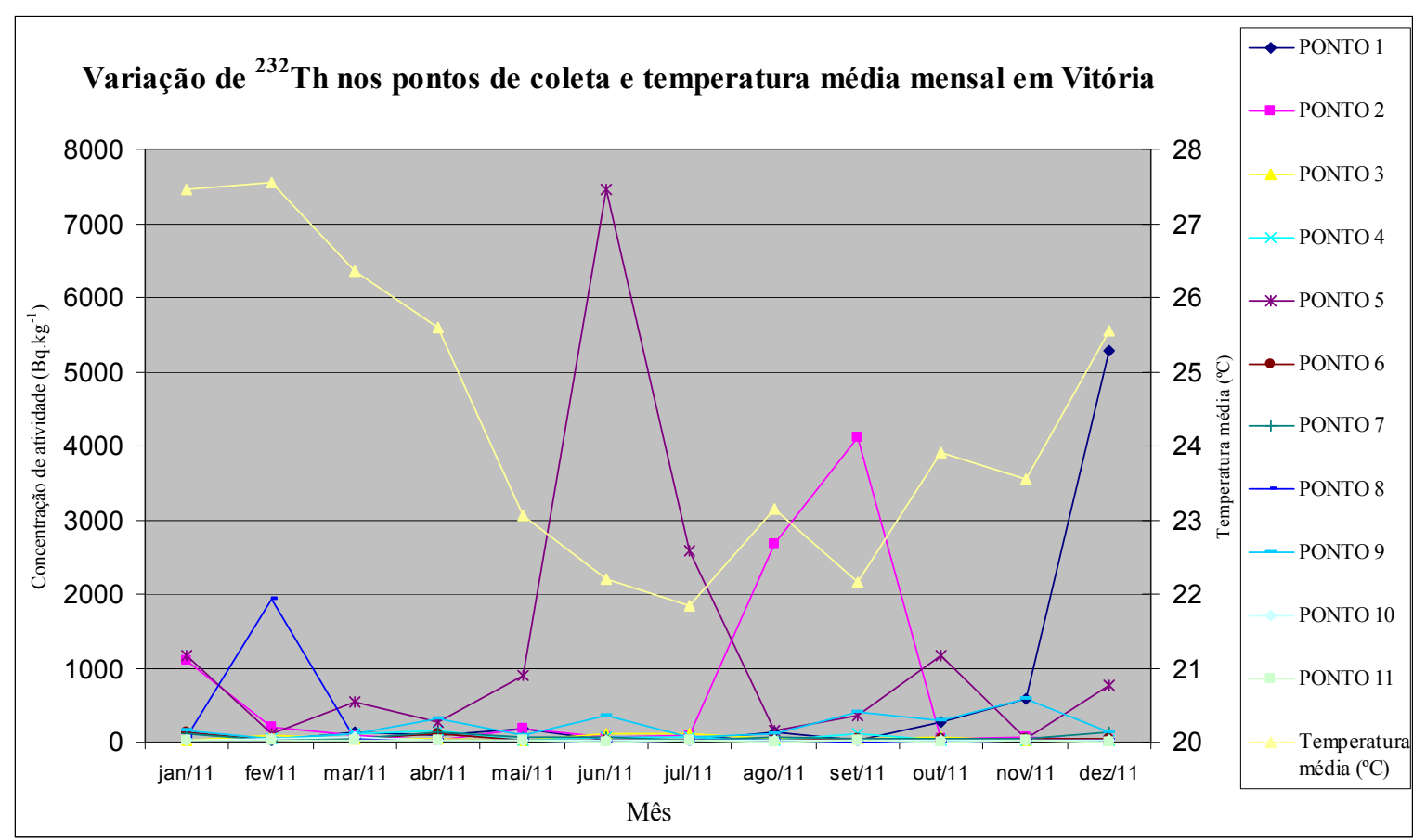

FIGURA 36 - Variação da concentração de atividade de ${ }^{232} \mathrm{Th}$ nos pontos de coleta e a variação da temperatura média mensal $\left({ }^{\circ} \mathrm{C}\right)$ em Vitória ao longo do ano de 2011.

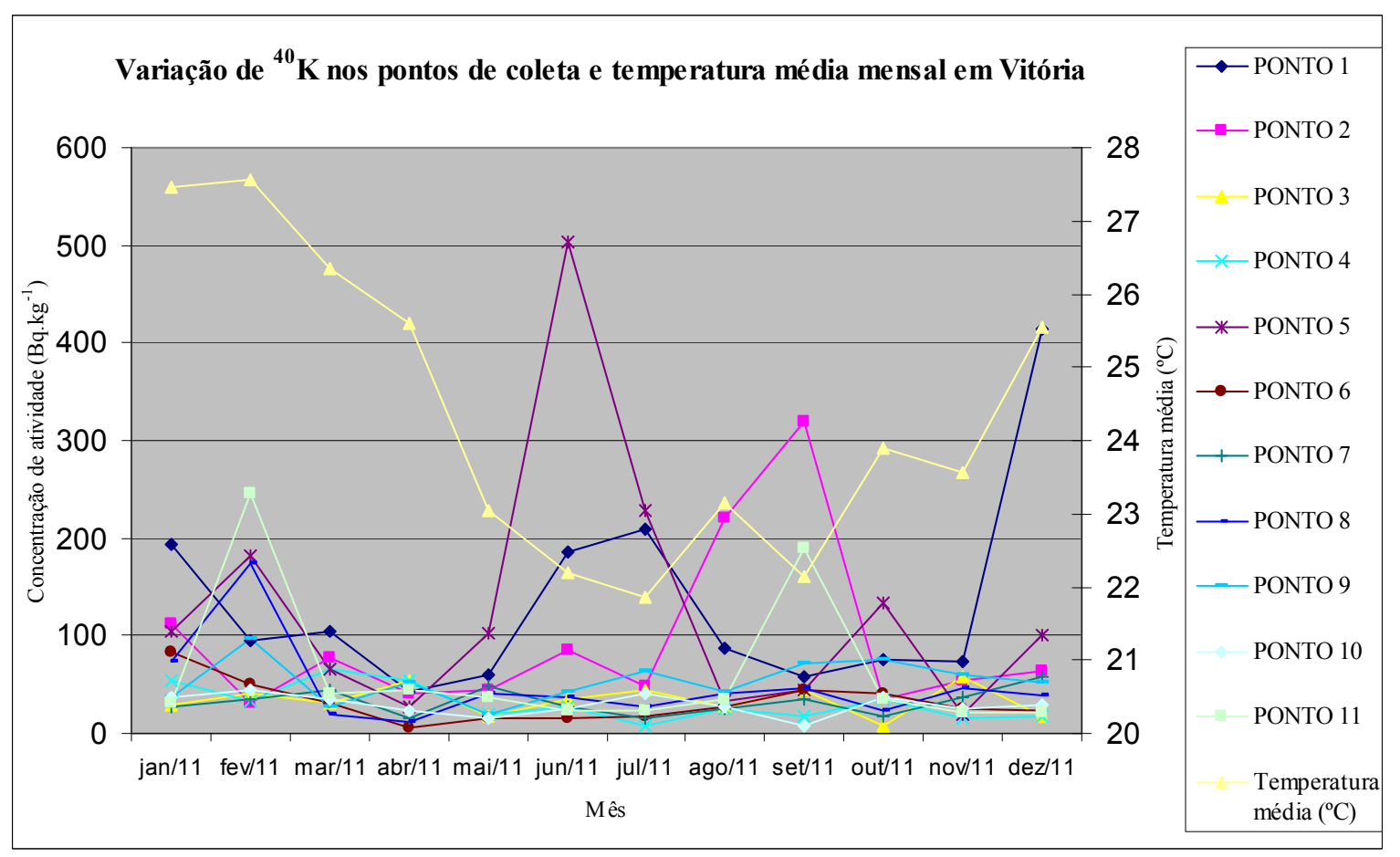

FIGURA 37 - Variação da concentração de atividade de ${ }^{40} \mathrm{~K}$ nos pontos de coleta e a variação da temperatura média mensal $\left({ }^{\circ} \mathrm{C}\right)$ em Vitória ao longo do ano de 2011. 
A temperatura média mensal em Vitória no ano de 2011 tem pontos de máximo localizados em fevereiro, agosto e outubro e pontos de mínimo localizados em julho e setembro.

Não foi possível estabelecer uma relação direta entre os valores de temperatura média mensal em Vitória no ano de 2011 e as variações observadas nas concentrações de atividade de ${ }^{226} \mathrm{Ra}^{232} \mathrm{Th}$ e ${ }^{40} \mathrm{~K}$ das amostras de areia da Praia de Camburi.

\subsection{2 Índice pluviométrico}

As FIG. 38, 39 e 40 apresentam gráficos da variação da concentração de atividade de ${ }^{226} \mathrm{Ra},{ }^{232} \mathrm{Th}$ e ${ }^{40} \mathrm{~K}$ das amostras de areia coletadas na Praia de Camburi e a variação do índice de precipitação pluviométrica $(\mathrm{mm})$ em Vitória ao longo do ano de 2011. Os dados do índice de precipitação pluviométrica foram extraídos a partir de gráfícos do Instituto Capixaba de Pesquisa, Assistência e Extensão Rural (INCAPER, 2013).

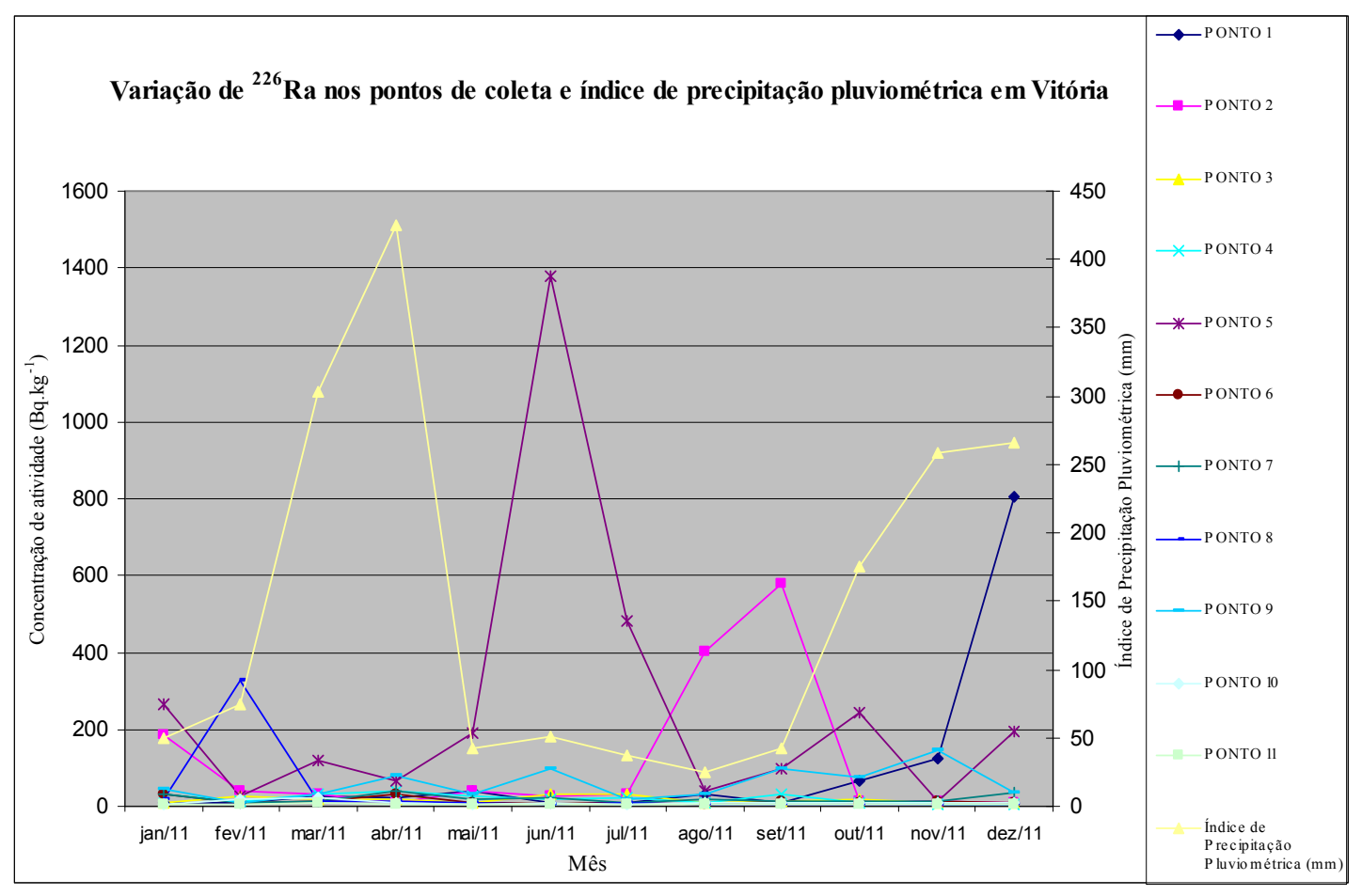

FIGURA 38 - Variação da concentração de atividade de ${ }^{226}$ Ra nos pontos de coleta e a variação da índice de precipitação pluviométrica $(\mathrm{mm})$ em Vitória ao longo do ano de 2011. 


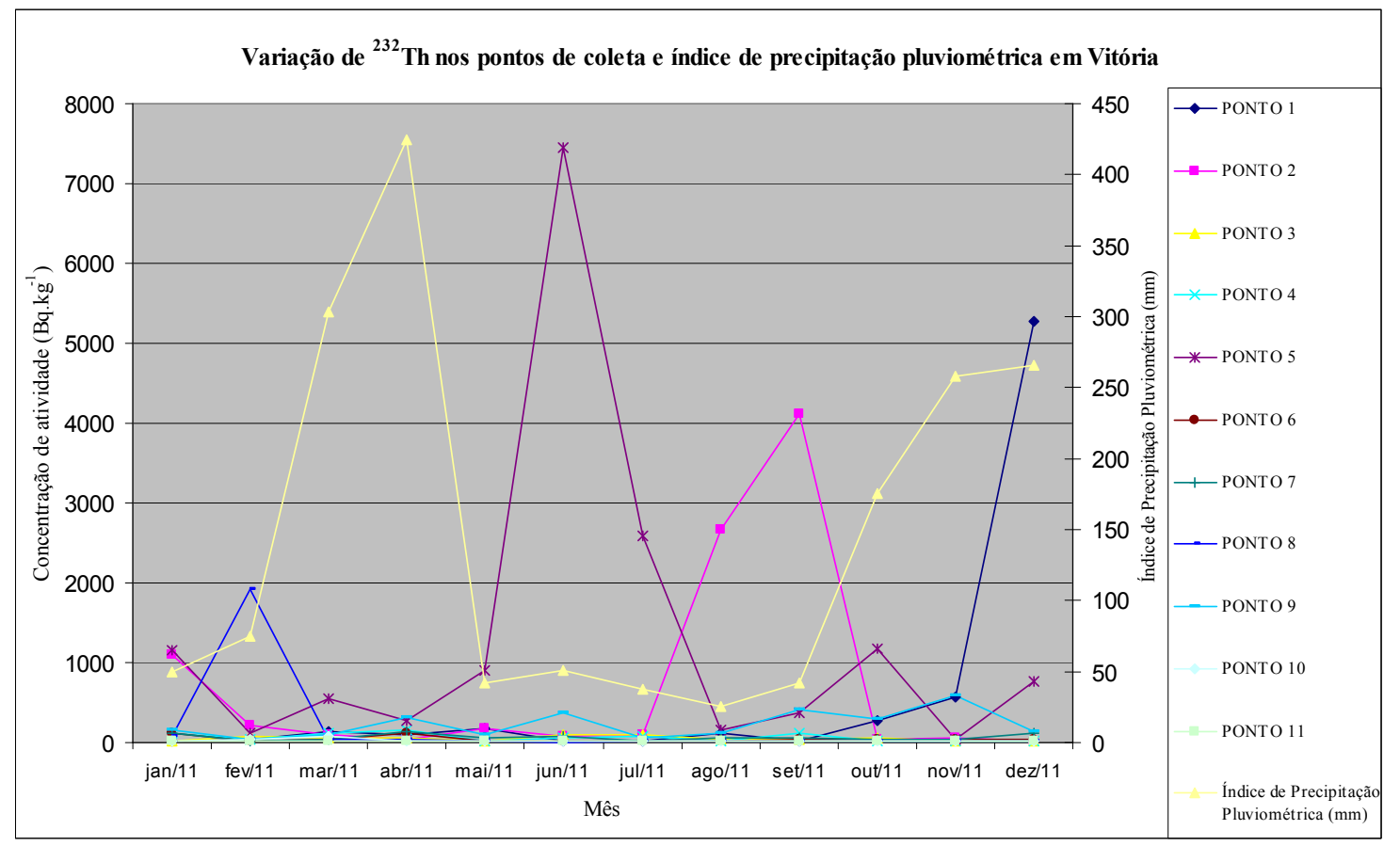

FIGURA 39 - Variação da concentração de atividade de ${ }^{232}$ Th nos pontos de coleta e a variação da índice de precipitação pluviométrica $(\mathrm{mm})$ em Vitória ao longo do ano de 2011.

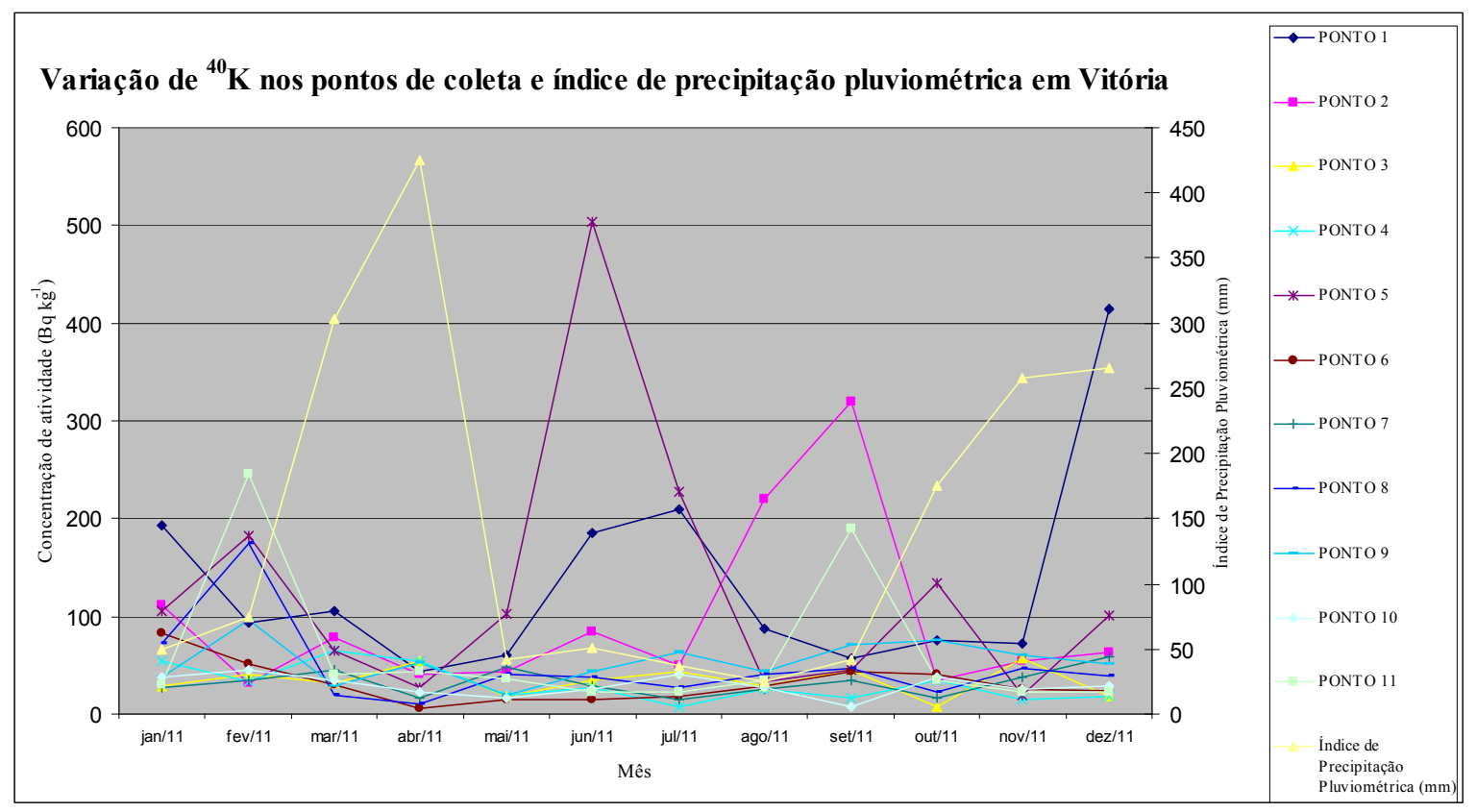

FIGURA 40 - Variação da concentração de atividade de ${ }^{40} \mathrm{~K}$ nos pontos de coleta e a variação da índice de precipitação pluviométrica $(\mathrm{mm})$ em Vitória ao longo do ano de 2011. 
O índice de precipitação pluviométrica tem um valor de máximo ocorrido durante o mês de abril e outro em dezembro.

As baixas concentrações de atividade de ${ }^{226} \mathrm{Ra},{ }^{232} \mathrm{Th}$ e ${ }^{40} \mathrm{~K}$ em abril e dezembro poderiam estar relacionadas aos valores máximos do índice de precipitação pluviométrica, com exceção do ponto 1 em dezembro. Muita chuva (alto nível de precipitação pluviométrica) pode favorecer a dispersão dos minerais que contém ${ }^{226} \mathrm{Ra},{ }^{232} \mathrm{Th}$ e ${ }^{40} \mathrm{~K}$ na areia.

\subsubsection{Altura das marés}

As FIG. 41, 42 e 43 apresentam gráficos da variação da concentração de atividade de ${ }^{226} \mathrm{Ra},{ }^{232} \mathrm{Th}$ e ${ }^{40} \mathrm{~K}$ nos pontos de coleta e a variação das alturas das marés (mm) do Porto de Tubarão e do Porto de Vitória ao longo do ano de 2011. Os valores das alturas das marés utilizados nas FIG. 37, 38 e 39 foram obtidos a partir do Banco Nacional de Dados Oceanográficos (BNDO,2012).

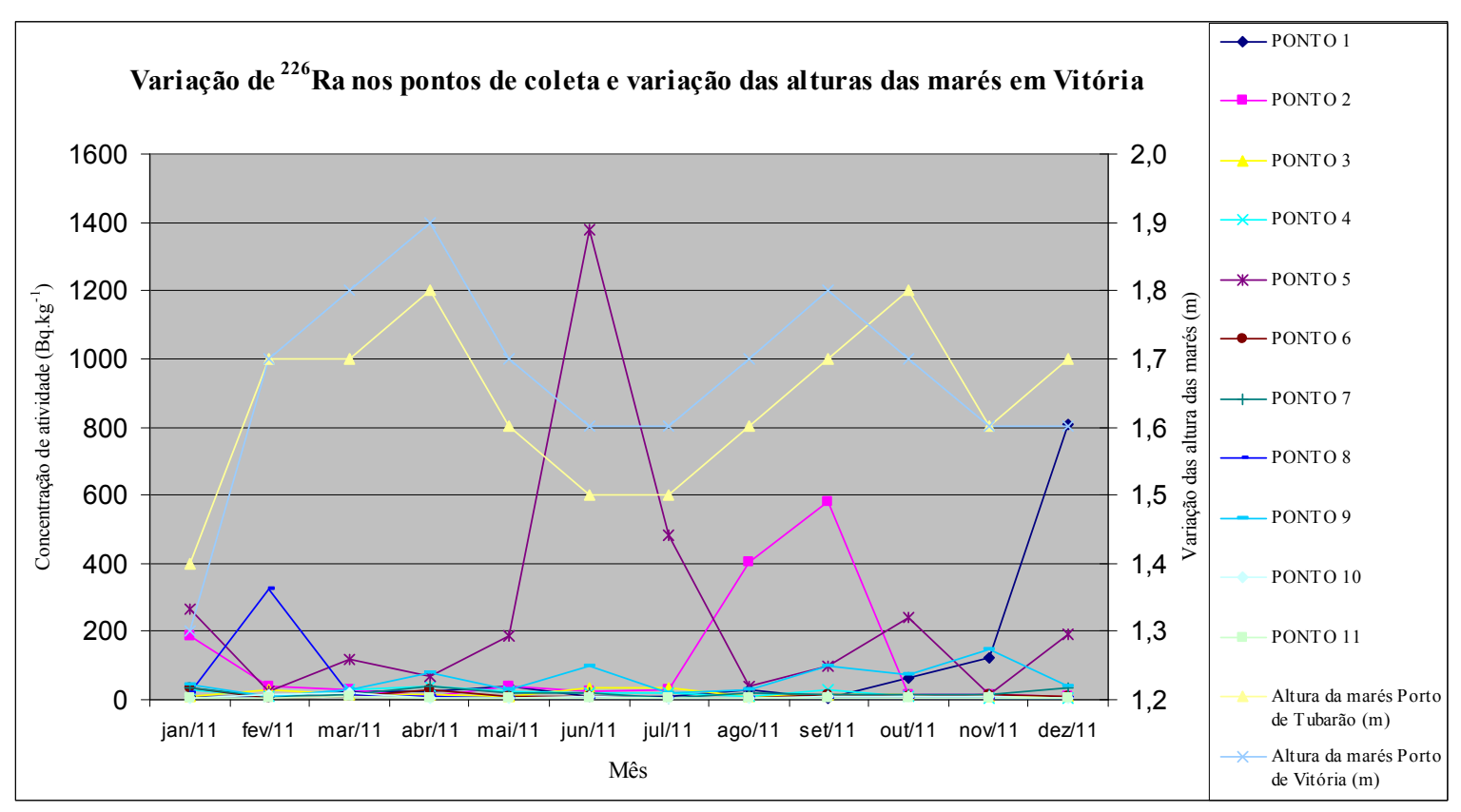

FIGURA 41 - Variação da concentração de atividade de ${ }^{226}$ Ra nos pontos de coleta e a variação das alturas das marés $(\mathrm{mm})$ do Porto de Tubarão e do Porto de Vitória ao longo do ano de 2011. 


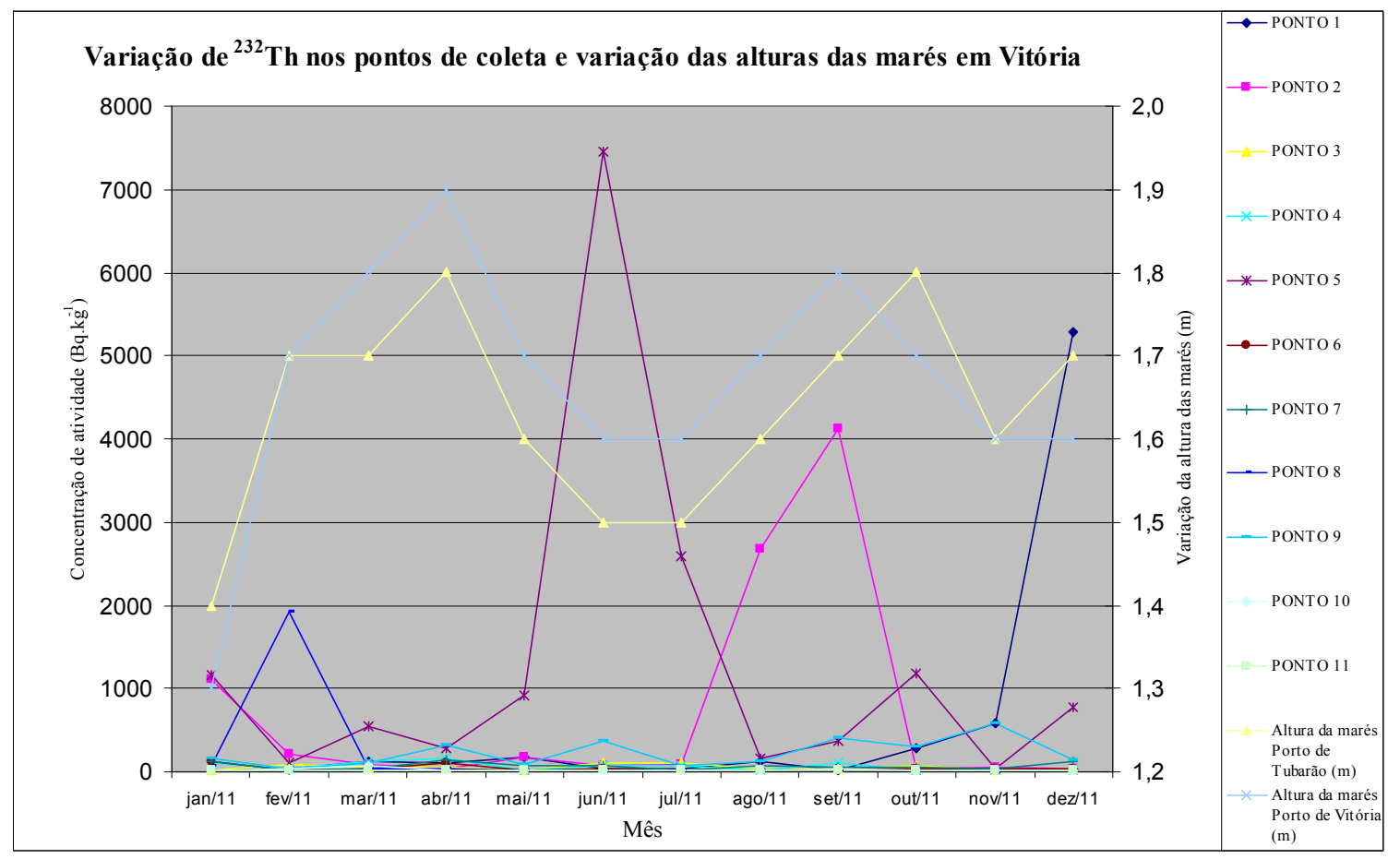

FIGURA 42 - Variação da concentração de atividade de ${ }^{232}$ Th nos pontos de coleta e a variação das alturas das marés $(\mathrm{mm})$ do Porto de Tubarão e do Porto de Vitória ao longo do ano de 2011.

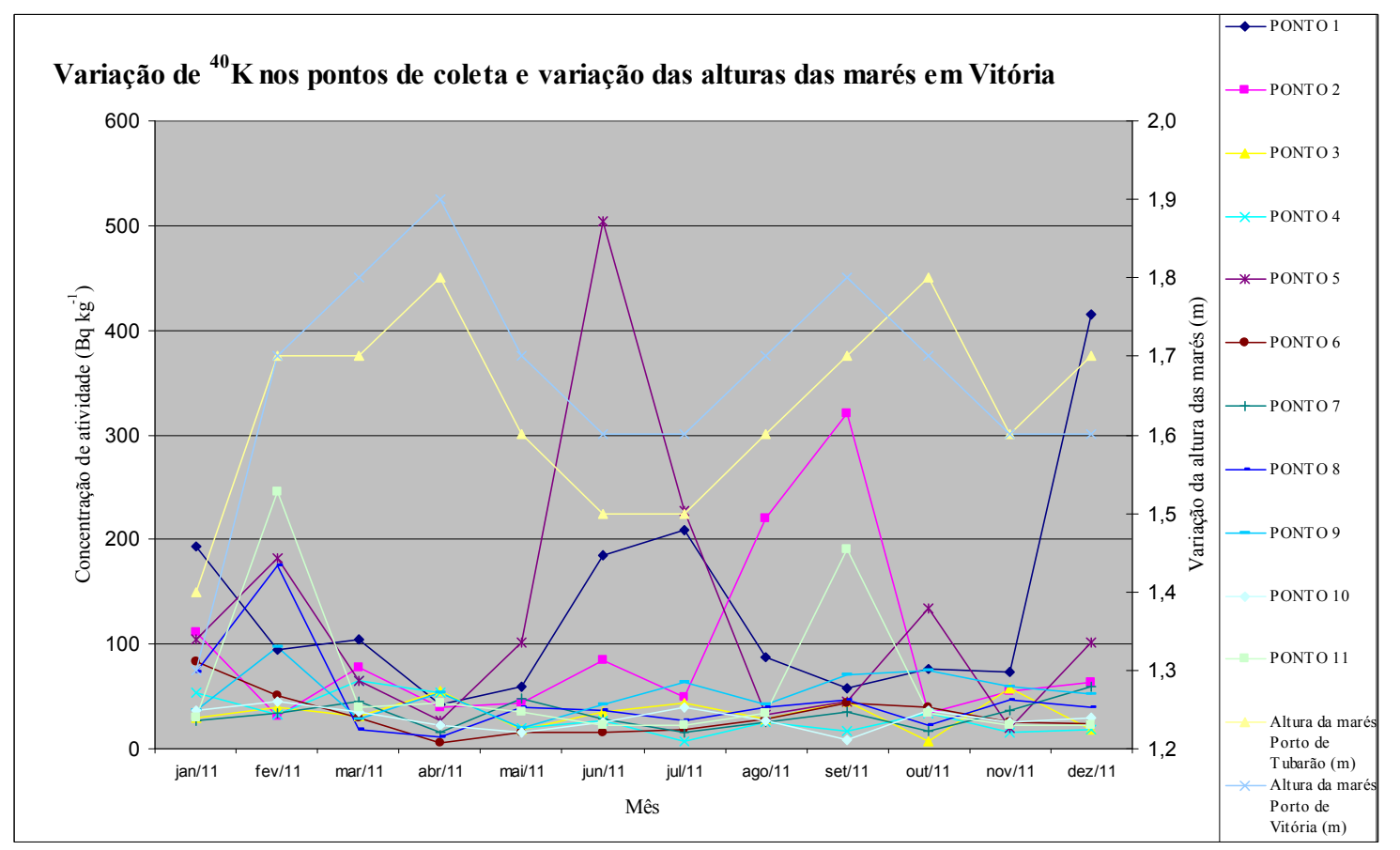

FIGURA 43 - Variação da concentração de atividade de ${ }^{40} \mathrm{~K}$ nos pontos de coleta e a variação das alturas das marés $(\mathrm{mm})$ do Porto de Tubarão e do Porto de Vitória ao longo do ano de 2011. 
A variação da altura das marés tem um valor de máximo ocorrido durante o mês de abril em ambos os portos, um em setembro para o Porto de Vitória e um em outubro para o Porto de Tubarão. O Porto de Tubarão está mais próximo da Praia de Camburi (logo após o Ponto 11 de coleta, ao norte da Praia de Camburi) do que o Porto de Vitória.

As baixas concentrações de atividade de ${ }^{226} \mathrm{Ra}^{232} \mathrm{Th}$ e ${ }^{40} \mathrm{~K}$ em todos os pontos de coleta em abril e em outubro pode estar relacionada com a alta variação da altura das marés encontradas nesses meses no Porto de Tubarão. A alta variação da altura das marés pode favorecer a dispersão dos minerais que contém ${ }^{226} \mathrm{Ra},{ }^{232} \mathrm{Th}$ e ${ }^{40} \mathrm{~K}$ na areia.

\subsection{Concentrações de atividade de ${ }^{226} \mathrm{Ra},{ }^{232} \mathrm{Th}$ e ${ }^{40} \mathrm{~K}$ e fatores geológicos e geográficos}

Devido à presença forte de monazita, a concentração de ${ }^{232}$ Th é mais elevada do que a concentração de ${ }^{226} \mathrm{Ra} \mathrm{e}{ }^{40} \mathrm{~K}$ em todas as amostras analisadas.

A posição geográfica do Ponto 5, com a ilha de Socó localizada logo a sua frente (FIG. 6), pode ter influenciado nas altas concentrações de atividade de ${ }^{226} \mathrm{Ra},{ }^{232} \mathrm{Th}$ e ${ }^{40} \mathrm{~K}$ encontrados neste ponto ao longo de todo o ano, especialmente em junho, como mostram as FIG. 28, 29 e 30.

A ilha de Socó em frente ao Ponto 5 é como uma "barreira protetora", pois é um obstáculo que impede que as ondas cheguem com maior energia ao Ponto 5, já que, antes disto, são desviadas pelo contorno da ilha. Uma vez que as ondas não chegam com tanta energia cinética ao Ponto 5, um acúmulo de minerais pesados pode ocorrer neste ponto, pois a dispersão deles na areia é dificultada. Desta forma, as altas concentrações de atividade de ${ }^{226} \mathrm{Ra},{ }^{232} \mathrm{Th}$ e ${ }^{40} \mathrm{~K}$ encontrados neste ponto são justificáveis. Eventualmente, também há a possibilidade de que com alguma dragagem realizada na região, areia retirada do fundo do mar tenha sido depositada no Ponto 5.

\section{7 Índices Radiológicos}

Para organizarmos as amostras, relacionamos um número contínuo de identificação (ID), conforme a ordem da coleta. Assim, em janeiro temos amostras 
de 1 a 11, em fevereiro, de 12 a 22, e assim sucessivamente, até dezembro, com amostras de 122 a 132.

\subsubsection{Atividade equivalente em rádio}

A atividade equivalente em rádio $\left(R a_{e q}\right)$ calculada pela equação (8), item 3.6, é mostrada na FIG. 44. Para uma utilização segura em materiais de construção utilizados em residências, recomenda-se que o valor de $R a_{e q}$ não exceda o limite de 370 Bq. $\mathrm{kg}^{-1}$ (Beretka e Mathew, 1985), destacado em azul (FIG. 44).

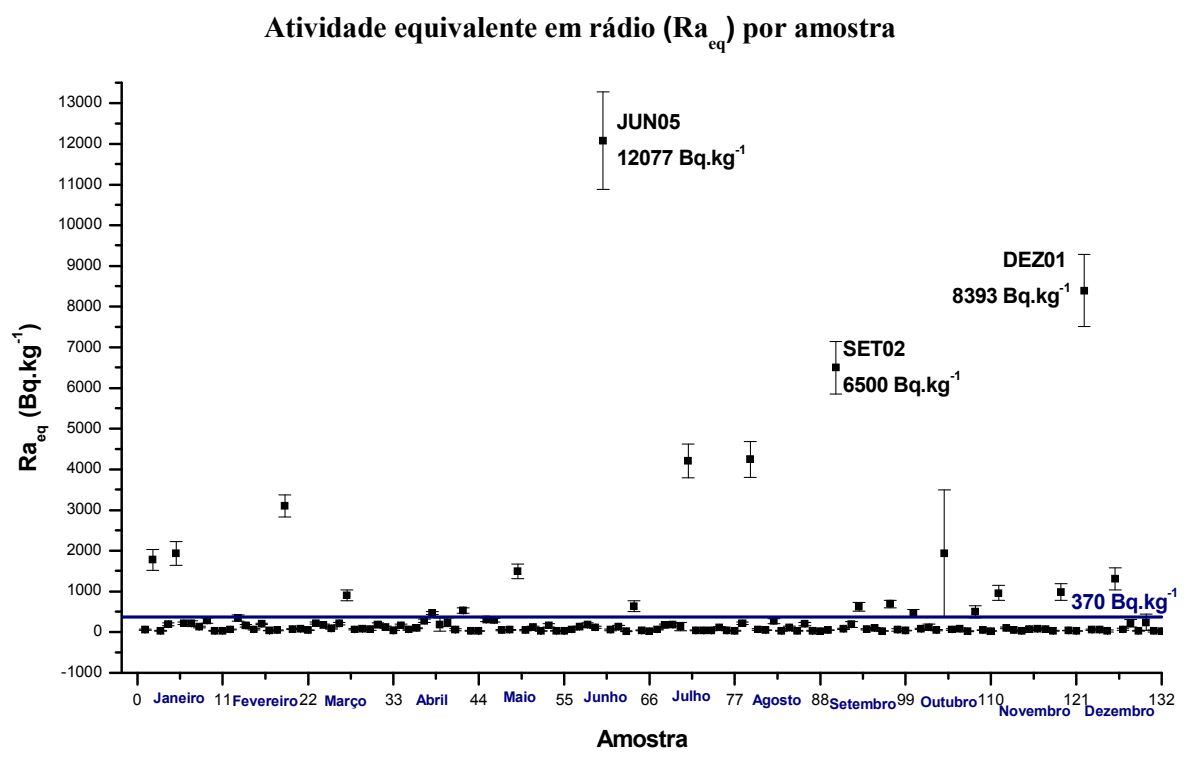

FIGURA 44 - Atividade equivalente em rádio $\left(R a_{e q}\right)$ para as 132 amostras de areia coletadas na Praia de Camburi durante o ano de 2011.

Deve-se destacar que as areias da Praia de Camburi não podem ser utilizadas como areia de material de construção. Entretanto uma avaliação da atividade equivalente em rádio $\left(R a_{e q}\right)$ é de grande importância no âmbito de monitoração ambiental. Se fosse utilizada como material de costrução, a areia seria misturada a outros componentes. Os valores encontrados de $R a_{e q}$ mostrados na FIG. 44 não consideraram a porcentagem de areia utilizada em cada tipo de material de construção. 
Uma vez que a areia é utilizada em proporções variadas em diferentes materiais de construção (contrapiso, reboco, chapisco de parede, etc), foi feito um comparativo para a contribuição do rádio equivalente no tipo de material de construção, mostrado nas FIG. 45, 46, 47, e 48, utilizando as proporções da TAB. 7:

TABELA 7 - Fração de areia utilizada em cada tipo de material de construção (Aquino, 2010).

\begin{tabular}{|cc|}
\hline Aplicações de areia & Fração de areia \\
\hline Contrapiso & $80 \%$ \\
Reboco/Embosso interno & $50 \%$ \\
Reboco/Embosso externo & $40 \%$ \\
Chapisco de parede & $75 \%$ \\
Concreto de laje & $50 \%$ \\
Calçada & $50 \%$ \\
Piso & $50 \%$ \\
Assentamento de tijolos & $83 \%$ \\
Toda construção & $59 \%$ \\
\hline
\end{tabular}

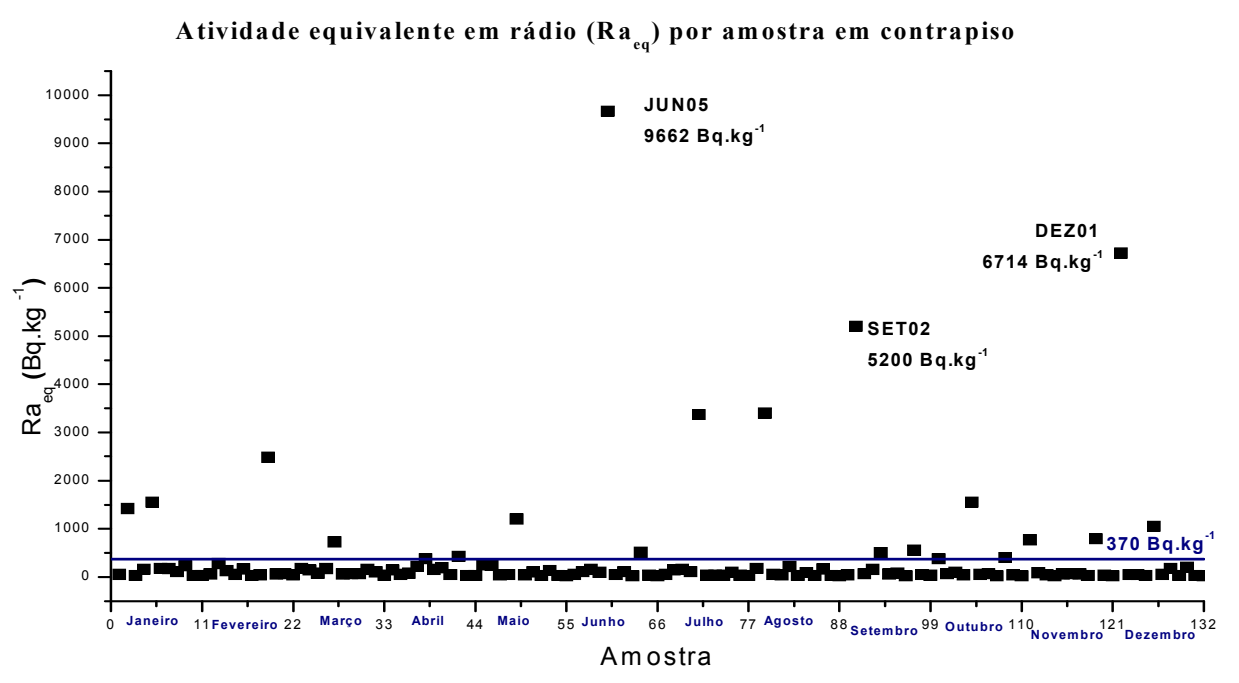

FIGURA 45 - Atividade equivalente em rádio $\left(R a_{e q}\right)$ para as 132 amostras de areia coletadas na Praia de Camburi durante o ano de 2011, se utilizadas como contrapiso. Em azul o limite para $R a_{e q}$ de $370 \mathrm{~Bq} \cdot \mathrm{kg}^{-1}$. 


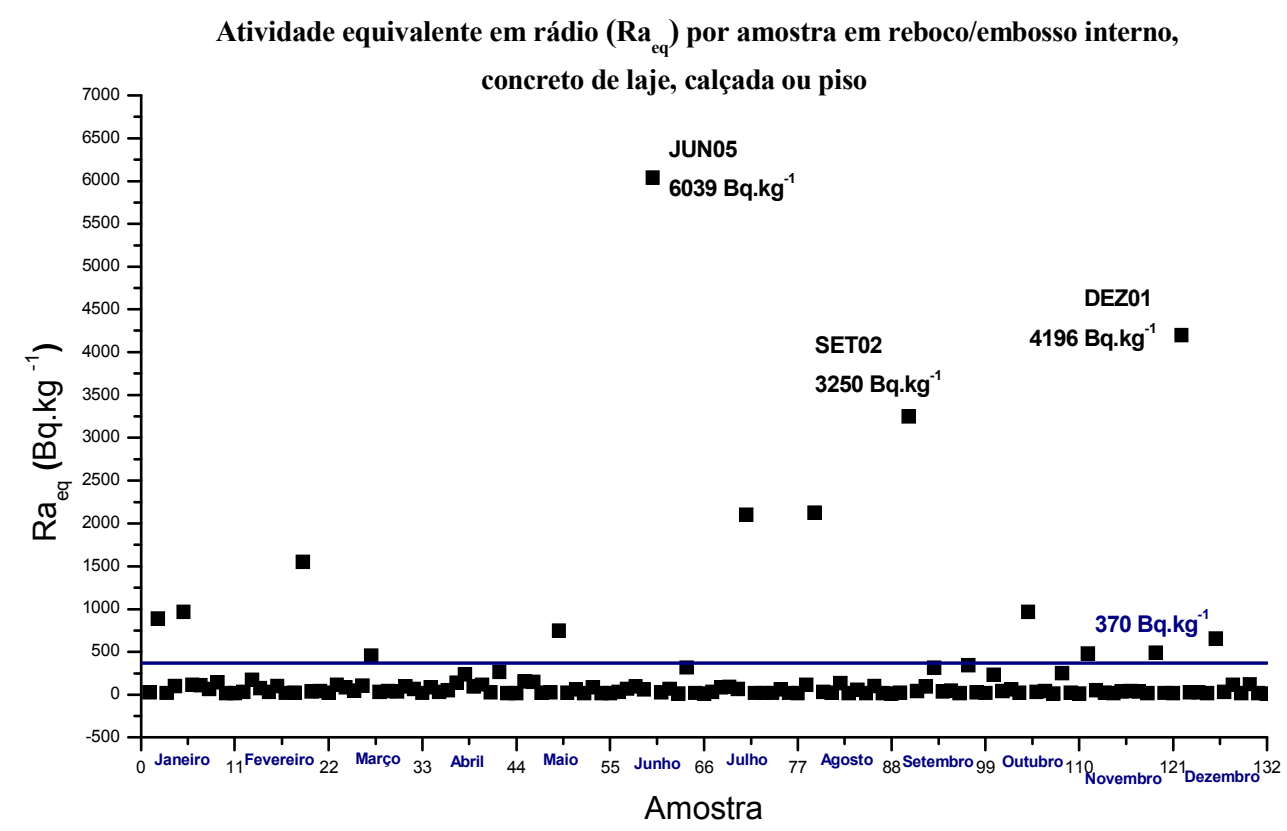

FIGURA 46 - Atividade equivalente em rádio $\left(R a_{e q}\right)$ para as 132 amostras de areia coletadas na Praia de Camburi durante o ano de 2011, se utilizadas como reboco/embosso interno, concreto de laje, calçada ou piso . Em azul o limite para $R a_{e q}$ de $370 \mathrm{~Bq} \cdot \mathrm{kg}^{-1}$.

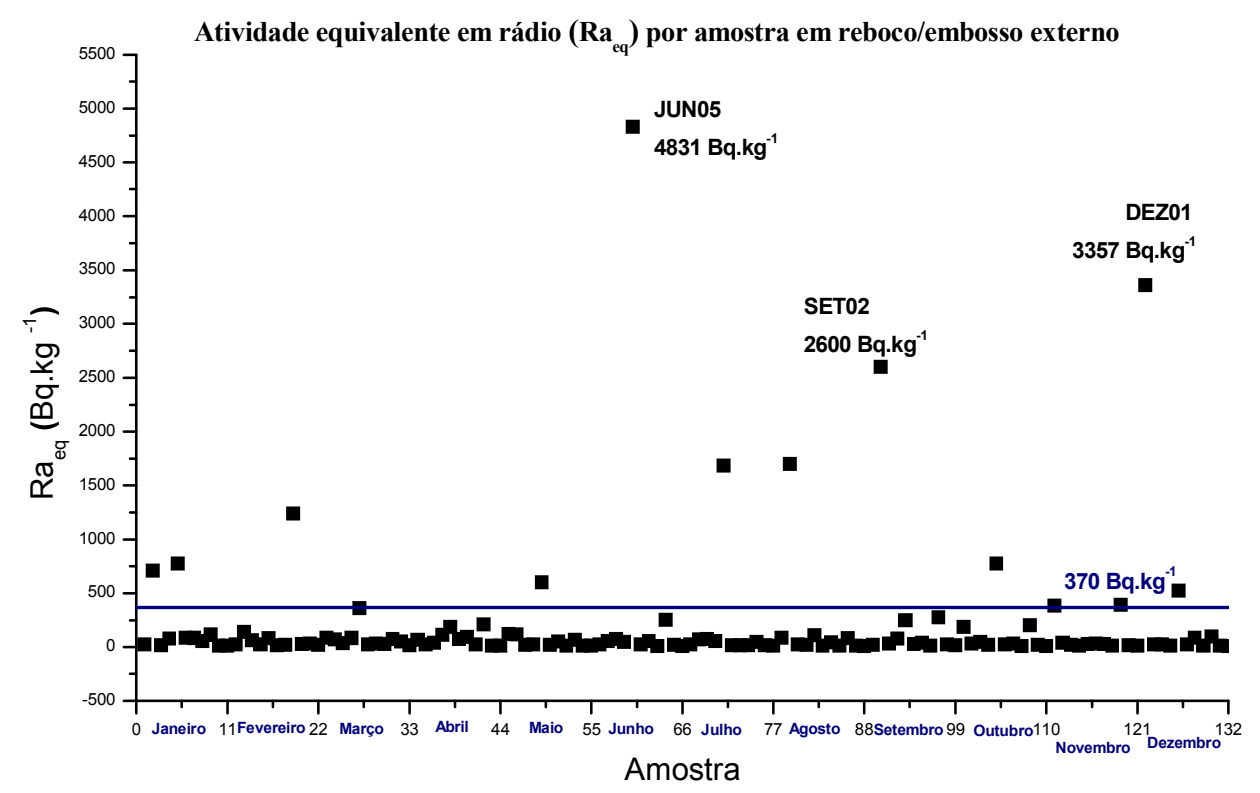

FIGURA 47 - Atividade equivalente em rádio $\left(R a_{e q}\right)$ para as 132 amostras de areia coletadas na Praia de Camburi durante o ano de 2011, se utilizadas como reboco/embosso externo. Em azul o limite para $R a_{e q}$ de 370 Bq. $\mathrm{kg}^{-1}$. 


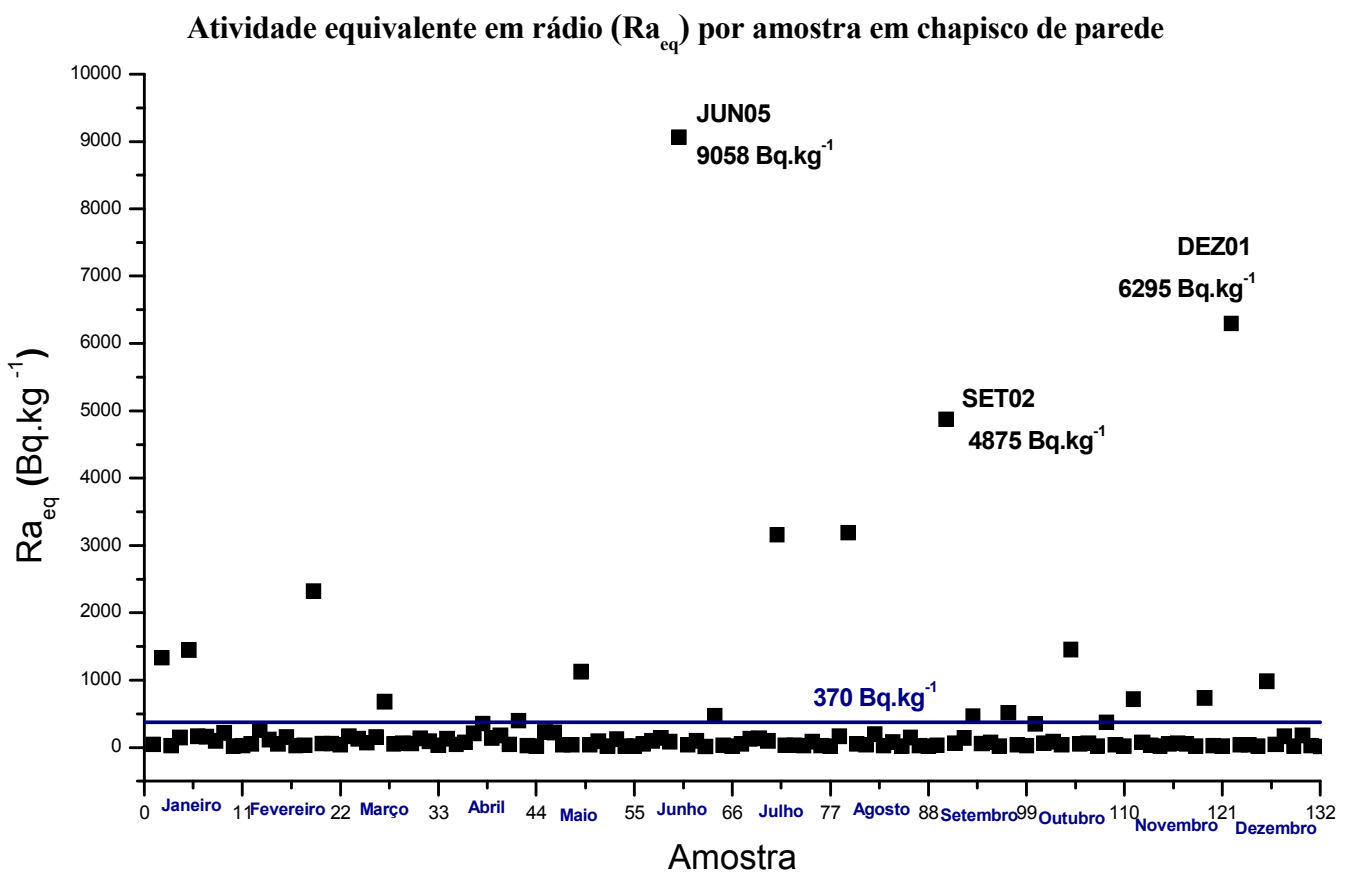

FIGURA 48 - Atividade equivalente em rádio $\left(R a_{e q}\right)$ para as 132 amostras de areia coletadas na Praia de Camburi durante o ano de 2011, se utilizadas como chapisco de parede. Em azul o limite para $R a_{e q}$ de $370 \mathrm{~Bq} \cdot \mathrm{kg}^{-1}$.

\subsection{2 Índice de concentração de atividade}

O índice de concentração de atividade $\left(I_{\gamma}\right)$ calculado pela equação (9), item 3.7, pode ser visualizado na FIG. 49. Segundo a Comissão Européia (EC, 1999), para materiais vendidos a granel, como o concreto, o limite primário de dose é de $\mathrm{I}_{\gamma} \leq 1$, que corresponde a $1 \mathrm{mSv} \cdot \mathrm{a}^{-1}$ e para restrição de dose temos $\mathrm{I}_{\gamma} \leq 0,5$; que corresponde a $0,3 \mathrm{mSv} \cdot \mathrm{a}^{-1}$. 


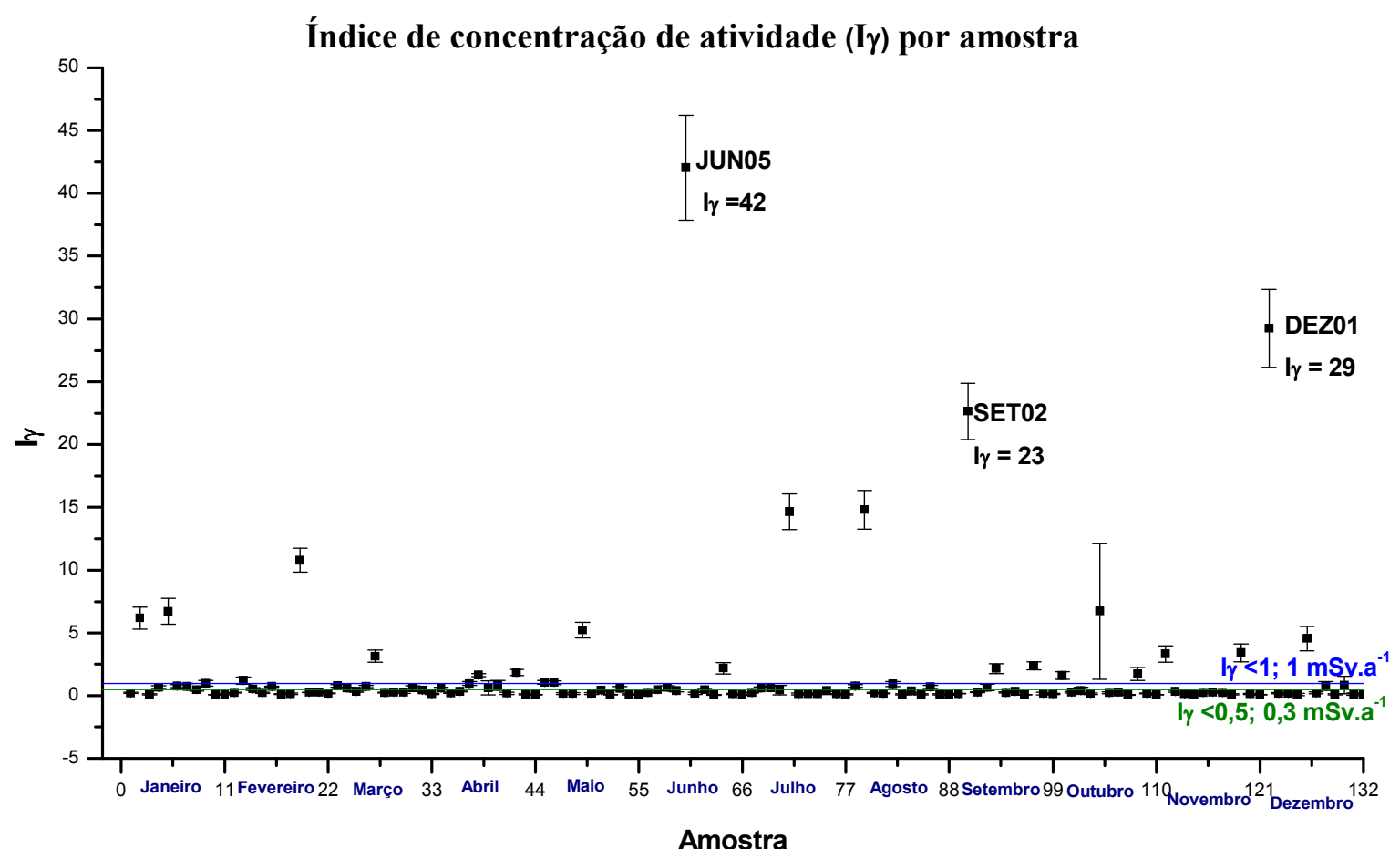

FIGURA 49 - Índice de concentração de atividade $\mathrm{I}_{\gamma}$ para as 132 amostras de areia coletadas na Praia de Camburi durante o ano de 2011. Em destaque em verde e azul respectivamente os limites $\mathrm{I} \leq 0,5$ e $\mathrm{I} \leq 1$.

\subsection{3 Índice de risco a exposição gama externo e interno}

Os índices de risco à exposição gama externo $\left(H_{\text {ext }}\right)$ e interno $\left(H_{\text {int }}\right)$ calculados pelas equações (10) e (11), respectivamente, no item 3.8 são mostrados nas FIG. 50 e 51. Em destaque, em azul, os limites $H_{\text {ext }}=1$ e $H_{\text {int }}=1$ correspondem à recomendação da Organização para Cooperação e Desenvolvimento Econômico (OECD, 1979) para uma utilização segura em materiais de construção, de que o valor de $R a_{e q}$ não exceda o limite de 370 Bq. $\mathrm{kg}^{-1}$ (item 3.8). 


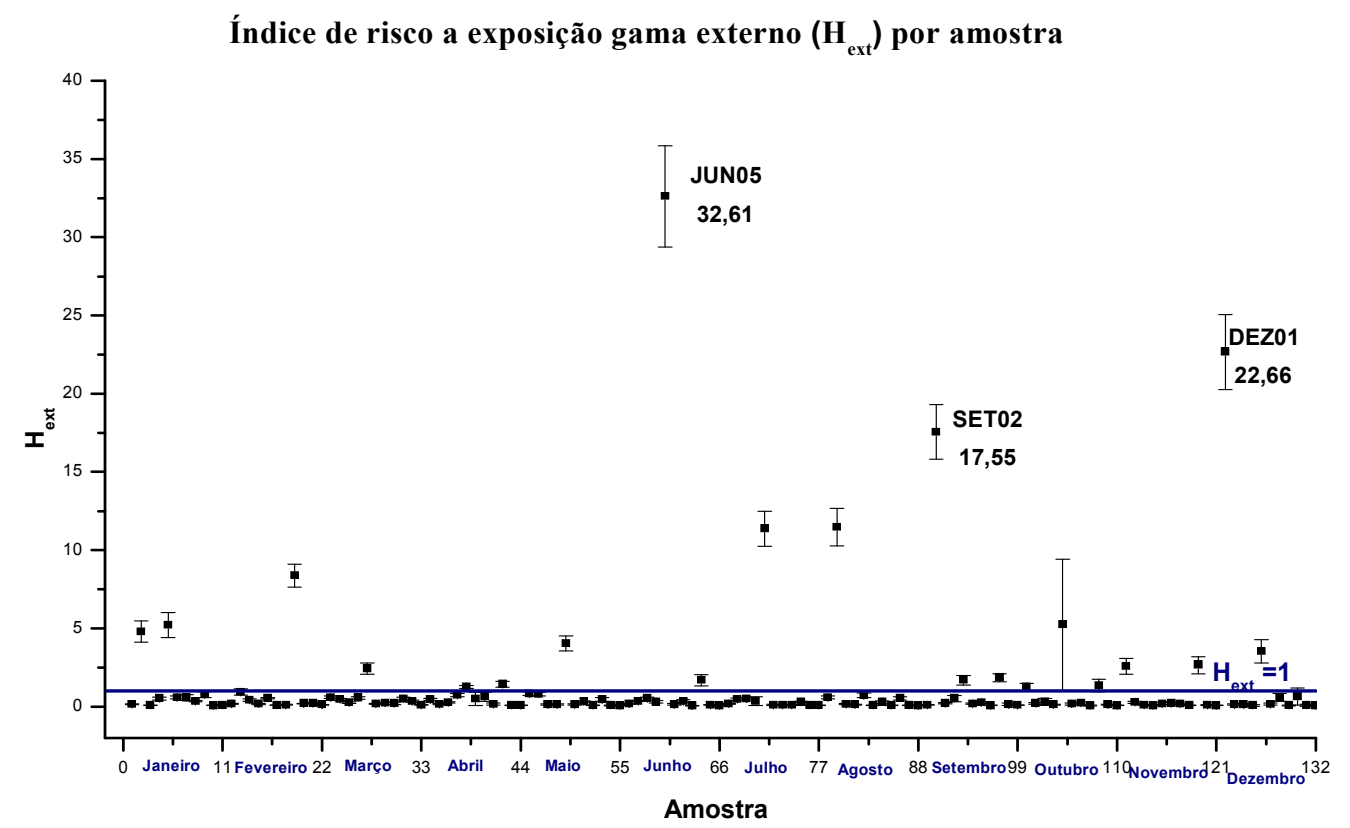

FIGURA 50 - Índice de risco a exposição gama externo $H_{\text {ext }}$ para as 132 amostras de areia coletadas na Praia de Camburi durante o ano de 2011. Em azul o limite $H_{\text {ext }}=1$.

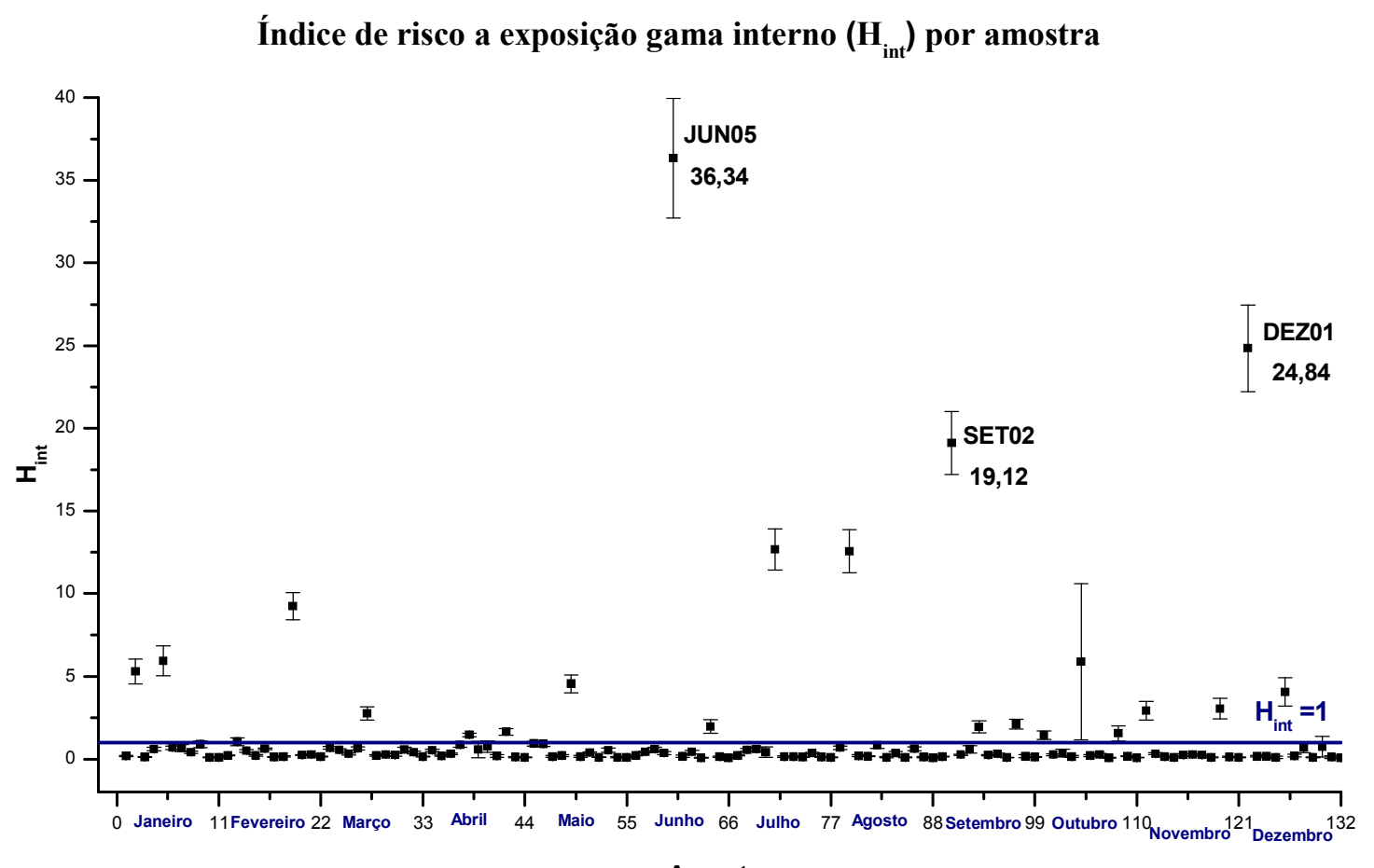

FIGURA 51 - Índice de risco a exposição gama interno $H_{\text {int }}$ para as 132 amostras de areia coletadas na Praia de Camburi durante o ano de 2011. Em azul o limite $H_{\text {int }}=1$. 


\subsubsection{Estimativa de taxa de dose absorvida no ar}

A Taxa de dose absorvida no ar $(D)$ a 1 metro do solo, em nGy.h ${ }^{-1}$, calculada pela equação (12),item 3.9, pode ser visualizada na FIG. 52.

Taxa de dose absorvida no ar (D) das amostras de areia nos Pontos de coleta (1-11) de janeiro a dezembro do ano de 2011

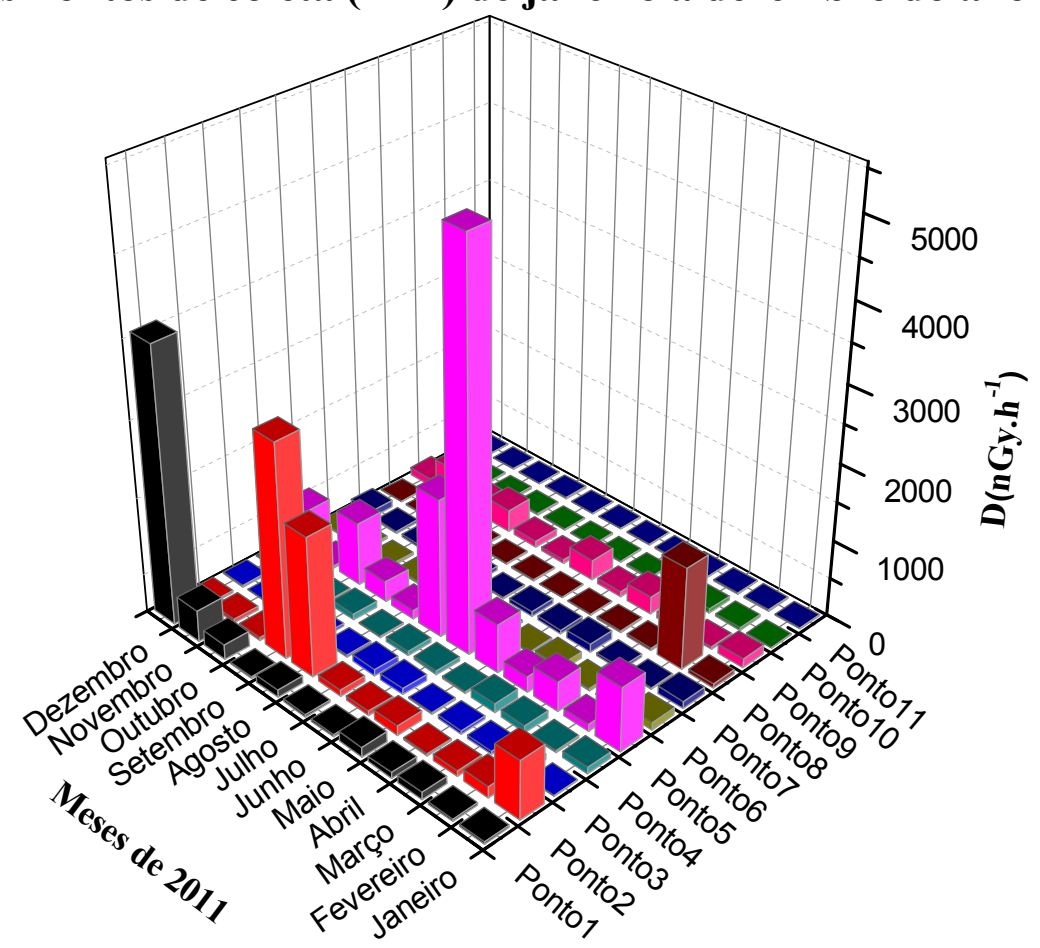

FIGURA 52 - Taxa de dose absorvida no ar $(D)$ para as 132 amostras de areia coletadas na Praia de Camburi durante o ano de 2011.

\subsubsection{Variação de $R a_{e q}, I_{\gamma}, H_{e x t}, H_{i n t}$ e $D$}

A TAB. 8 apresenta as faixas de variação dos índices radiológicos de amostras de areia da Praia de Camburi. As faixas dos índices radiológicos obtidos neste trabalho são referentes às variações ocorridas de janeiro de 2011 a dezembro de 2011.

A TAB. 9 apresenta as faixas de variação dos índices radiológicos de amostras de areia de praias do Brasil, Índia, Turquia, China e Egito. 
TABELA 8 - Faixas de variação dos índices radiológicos de amostras de areia da Praia de Camburi, Espírito Santo, Brasil.

\begin{tabular}{|c|c|c|c|c|c|c|c|c|c|c|c|c|c|c|}
\hline \multirow[b]{2}{*}{$\begin{array}{l}\text { Índices } \\
\text { radiológicos }\end{array}$} & \multicolumn{14}{|c|}{ Pontos de Coleta - Praia de Camburi, Espírito Santo, Brasil. } \\
\hline & 1 & 2 & 3 & 4 & 5 & 6 & 7 & 8 & 9 & 10 & 11 & $\begin{array}{l}\text { Camburi } \\
\text { Norte }\end{array}$ & $\begin{array}{c}\text { Camburi } \\
\text { Central }\end{array}$ & $\begin{array}{c}\text { Camburi } \\
\text { Sul }\end{array}$ \\
\hline $\begin{array}{c}R a_{e q} \\
\left(\mathrm{~Bq} \mathrm{~kg}^{-1}\right)\end{array}$ & $43-8393$ & $53-6500$ & $33-187$ & $26-274$ & $\begin{array}{c}70- \\
12077\end{array}$ & $31-219$ & $40-237$ & $20-3097$ & $72-980$ & $27-126$ & $20-46$ & 30 & 6294 & 2180 \\
\hline$I_{\gamma}$ & $\begin{array}{l}0,15- \\
29,24\end{array}$ & $\begin{array}{l}0,19- \\
22,65\end{array}$ & $\begin{array}{l}0,12- \\
0,65\end{array}$ & $\begin{array}{l}0,09- \\
0,96\end{array}$ & $\begin{array}{l}0,24- \\
42,03\end{array}$ & $\begin{array}{l}0,11- \\
0,77\end{array}$ & $\begin{array}{c}0,14- \\
0,82\end{array}$ & $\begin{array}{l}0,07- \\
10,79\end{array}$ & $\begin{array}{l}0,25- \\
3,41\end{array}$ & $\begin{array}{l}0,09- \\
0,44\end{array}$ & $\begin{array}{l}0,09- \\
0,44\end{array}$ & - & - & - \\
\hline$H_{e x t}$ & $\begin{array}{l}0,12- \\
22,66\end{array}$ & $\begin{array}{l}0,14- \\
17,55\end{array}$ & $0,09-0,5$ & $\begin{array}{l}0,07- \\
0,74\end{array}$ & $\begin{array}{l}0,19- \\
32,61\end{array}$ & $\begin{array}{l}0,08- \\
0,59\end{array}$ & $\begin{array}{l}0,11- \\
0,64\end{array}$ & $\begin{array}{l}0,06- \\
8,36\end{array}$ & $\begin{array}{l}0,22- \\
3,04\end{array}$ & $\begin{array}{l}0,07- \\
0,34\end{array}$ & $\begin{array}{l}0,05- \\
0,12\end{array}$ & 0,09 & 18,2 & 6,3 \\
\hline$H_{\text {int }}$ & $\begin{array}{l}0,14- \\
24,84\end{array}$ & $\begin{array}{l}0,16- \\
19,12\end{array}$ & $\begin{array}{l}0,11- \\
0,59\end{array}$ & $\begin{array}{c}0,09- \\
0,85\end{array}$ & $\begin{array}{l}0,22- \\
36,34\end{array}$ & $0,1-0,68$ & $\begin{array}{c}0,13- \\
0,75\end{array}$ & $\begin{array}{l}0,07- \\
9,24\end{array}$ & $\begin{array}{l}0,22- \\
3,04\end{array}$ & $0,09-0,4$ & $\begin{array}{c}0,06- \\
0,14\end{array}$ & 0,10 & 20 & 7 \\
\hline $\begin{array}{c}D \\
\left(\mathrm{nGy} \mathrm{h}^{-1}\right)\end{array}$ & $19-3581$ & $23-2771$ & $15-81$ & $11-118$ & $30-5160$ & $14-95$ & $18-102$ & $9-1323$ & $32-420$ & $12-54$ & $9-22$ & 14 & 2874 & 995 \\
\hline Referência & $\begin{array}{c}\text { Este } \\
\text { trabalho }\end{array}$ & $\begin{array}{c}\text { Este } \\
\text { trabalho }\end{array}$ & $\begin{array}{c}\text { Este } \\
\text { trabalho }\end{array}$ & $\begin{array}{c}\text { Este } \\
\text { trabalho }\end{array}$ & $\begin{array}{c}\text { Este } \\
\text { trabalho }\end{array}$ & $\begin{array}{c}\text { Este } \\
\text { trabalho }\end{array}$ & $\begin{array}{c}\text { Este } \\
\text { trabalho }\end{array}$ & $\begin{array}{c}\text { Este } \\
\text { trabalho }\end{array}$ & $\begin{array}{c}\text { Este } \\
\text { trabalho }\end{array}$ & $\begin{array}{c}\text { Este } \\
\text { trabalho }\end{array}$ & $\begin{array}{c}\text { Este } \\
\text { trabalho }\end{array}$ & $\begin{array}{l}\text { Aquino, } \\
2010\end{array}$ & $\begin{array}{l}\text { Aquino, } \\
2010\end{array}$ & $\begin{array}{l}\text { Aquino, } \\
2010\end{array}$ \\
\hline
\end{tabular}


TABELA 9 - Faixas de variação dos índices radiológicos de amostras de areia de praias do Brasil, Índia, Turquia, China e Egito.

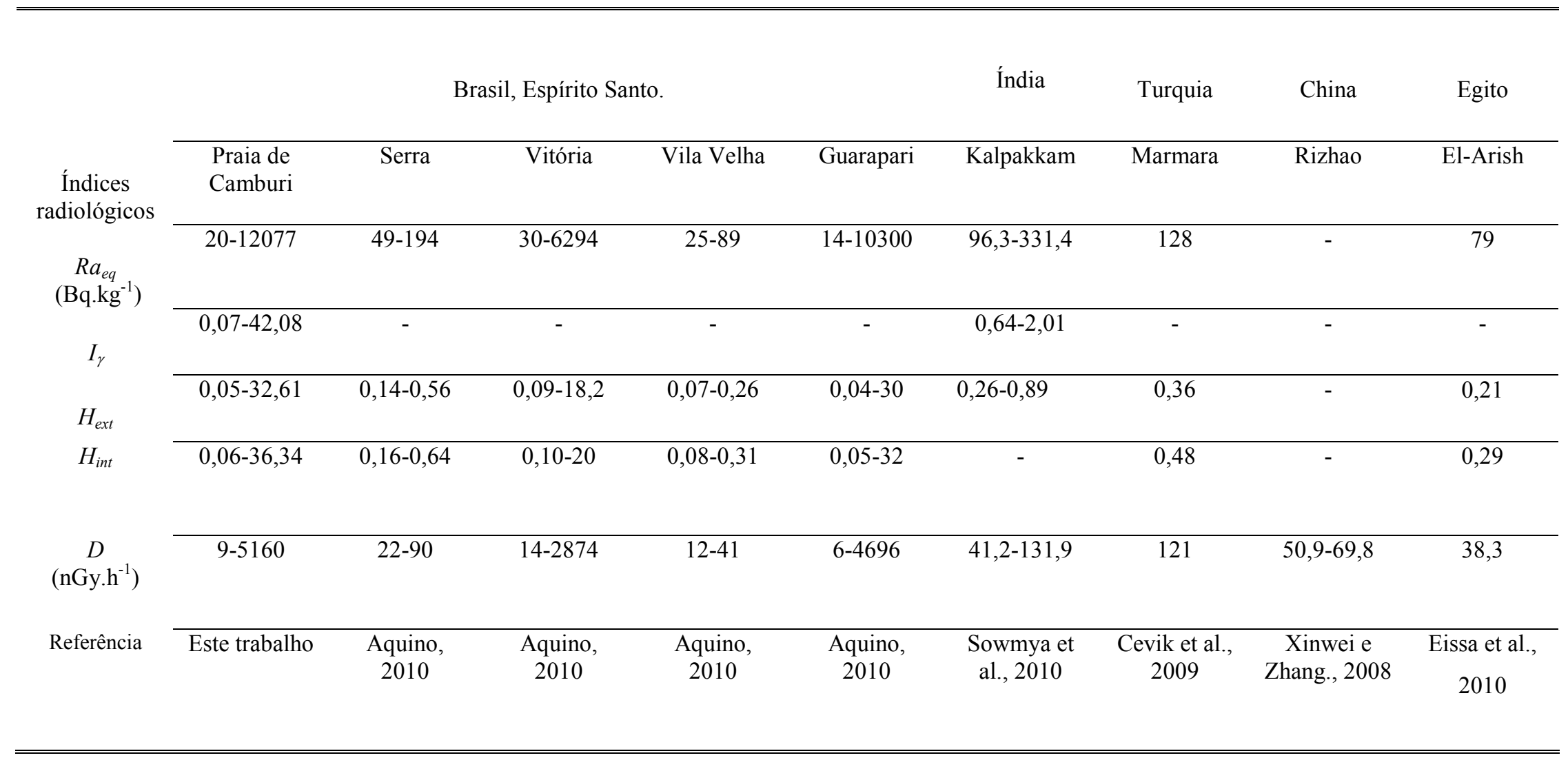




\subsubsection{Estimativa de dose efetiva anual}

A Dose efetiva anual $(E)$ referente a 100\% de exposição (24 horas por dia) nos pontos da praia onde foram coletadas as amostras em dias específicos, 15 de janeiro, 15 de fevereiro e assim sucessivamente, durante todo o ano, foi calculada pela equação 13, item 3.10 e pode ser visualizada na FIG.53. O valor recomendado pela ICRP 60 (ICRP, 1990) é de $1 \mathrm{mSv} \cdot \mathrm{a}^{-1}$ para público em geral.

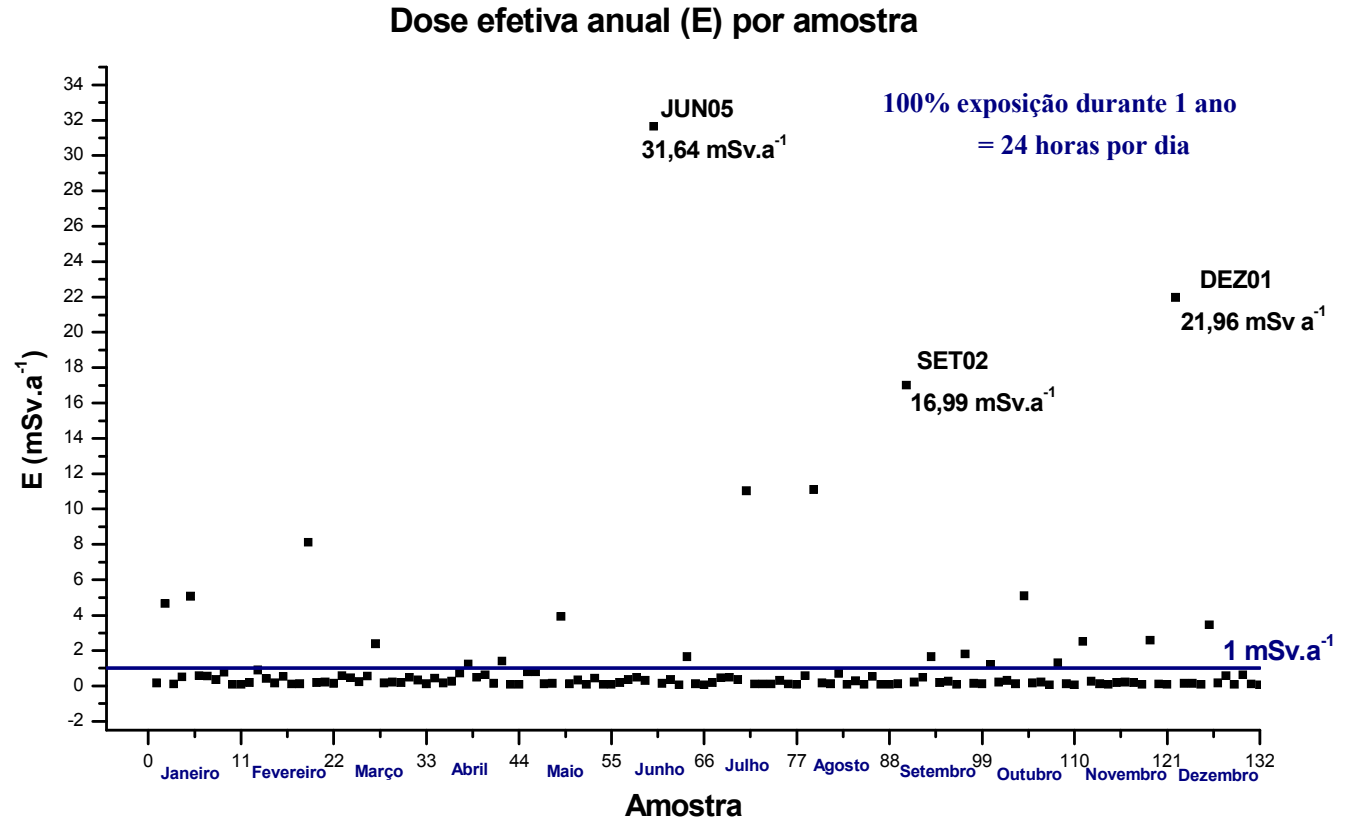

FIGURA 53 - Dose efetiva anual $(E)$ referente a $100 \%$ de exposição (24 horas por dia) para as 132 amostras de areia coletadas na Praia de Camburi durante o ano de 2011. Em azul o limite de $1 \mathrm{mSv} \cdot \mathrm{a}^{-1}$ da ICRP 60 (ICRP, 1990) para público em geral.

O valor da dose efetiva anual excedeu o valor de 1 mSv. $\mathrm{a}^{-1}$ em algumas amostras, entretanto, as doses efetivas anuais estabelecidas na FIG. 53 são para um indivíduo que ficou 24 horas por dia, durante 1 ano, em contato com alguma amostra de areia coletada. Esta condição de 100\% de exposição (24 horas por dia) a uma amostra de areia coletada na Praia de Camburi é a condição possível mais extrema, um acontecimento improvável. A Dose efetiva anual (E) referente à exposição de 1 hora por dia pode ser visualizada pela FIG. 54. 


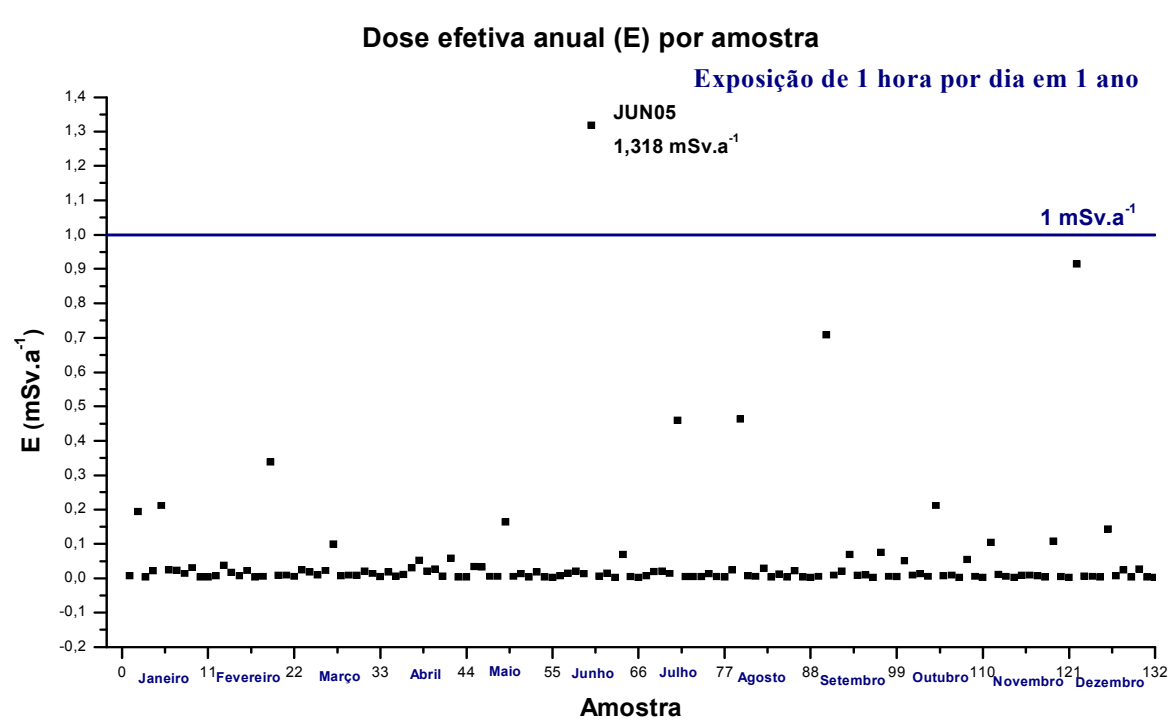

FIGURA 54 - Dose efetiva anual (E) referente a 1 hora de exposição por dia para as 132 amostras de areia coletadas na Praia de Camburi durante o ano de 2011. Em azul o limite de $1 \mathrm{mSv} . \mathrm{a}^{-1}$ da ICRP 60 (ICRP, 1990) para público em geral.

Considerando uma exposição de 1 hora por dia de cada amostra em um ano, somente a amostra referente ao Ponto 5 em junho excedeu $1 \mathrm{mSv} \cdot \mathrm{a}^{-1}$.

Uma avaliação da dose efetiva anual para um morador de Camburi que frequenta a praia durante todo o ano e que vá a um único ponto da praia todo dia com um tempo de exposição de 1 hora por dia, imaginando-se que ele fique descansando, sentado na areia, é mostrada na FIG. 55.

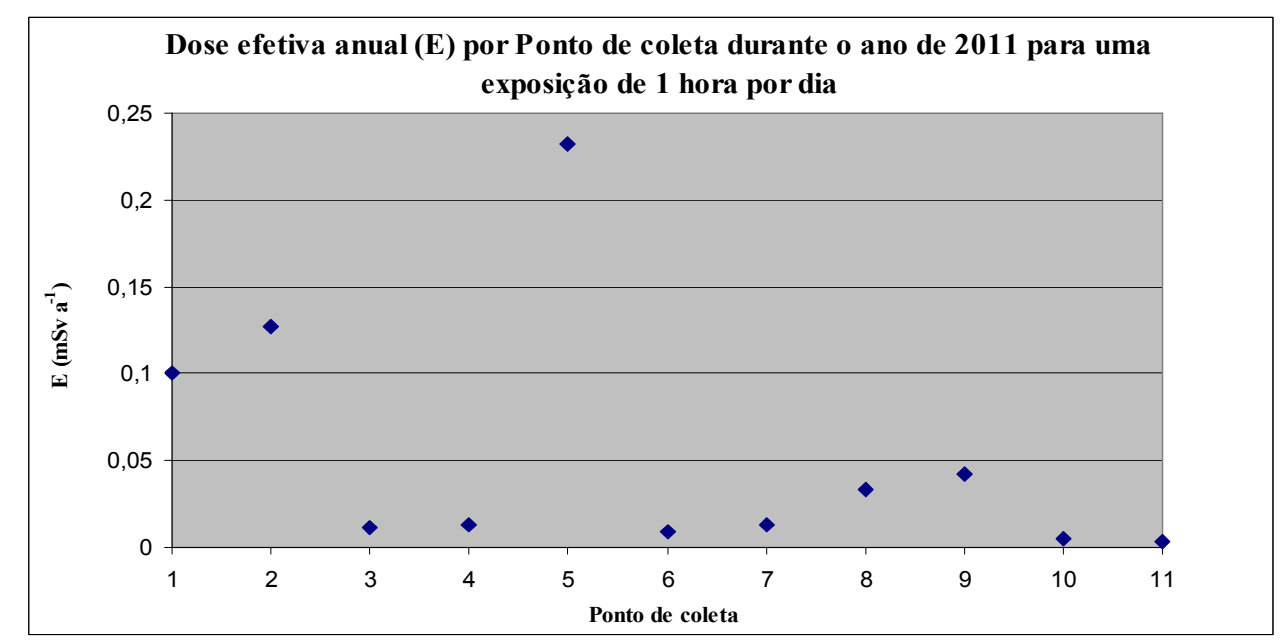

FIGURA 55 - Dose efetiva anual (E) referente a 1 hora de exposição por dia em cada ponto de coleta (1-11) na Praia de Camburi durante o ano de 2011. 
O valor da dose efetiva anual variou de $0,003 \mathrm{mSv} \cdot \mathrm{a}^{-1}$ referente ao Ponto 11 até $0,232 \mathrm{mSv} \cdot \mathrm{a}^{-1}$ referente ao Ponto 5. Portanto, os valores encontrados não excederam o limite de $1 \mathrm{mSv}^{-1}$.

Uma avaliação da dose efetiva anual também foi feita para um turista que frequenta a praia nas férias de janeiro (FIG.56) e o outro turista que frequenta a praia nas férias de julho (FIG.57), ambos com tempo de exposição de 1 mês durante 8 horas diárias.

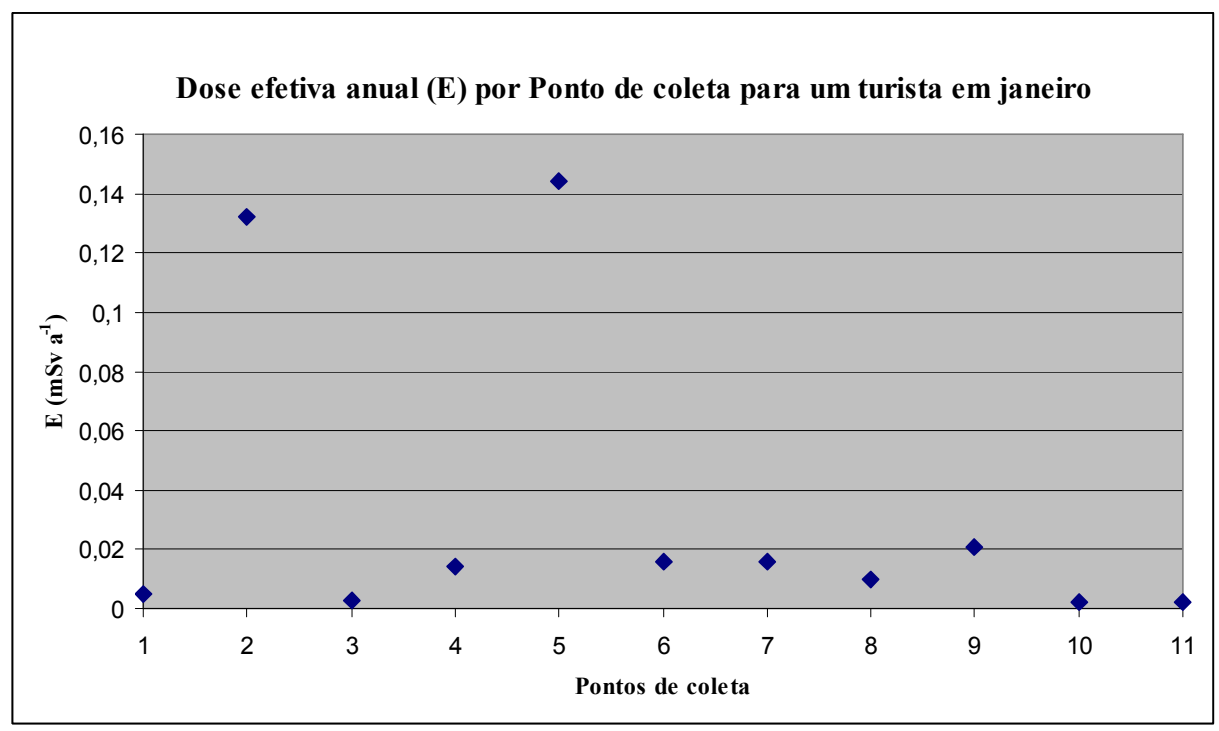

FIGURA 56 - Dose efetiva anual (E) referente a 8 horas de exposição por dia durante o mês de janeiro de 2011 em cada ponto de coleta (1-11) na Praia de Camburi.

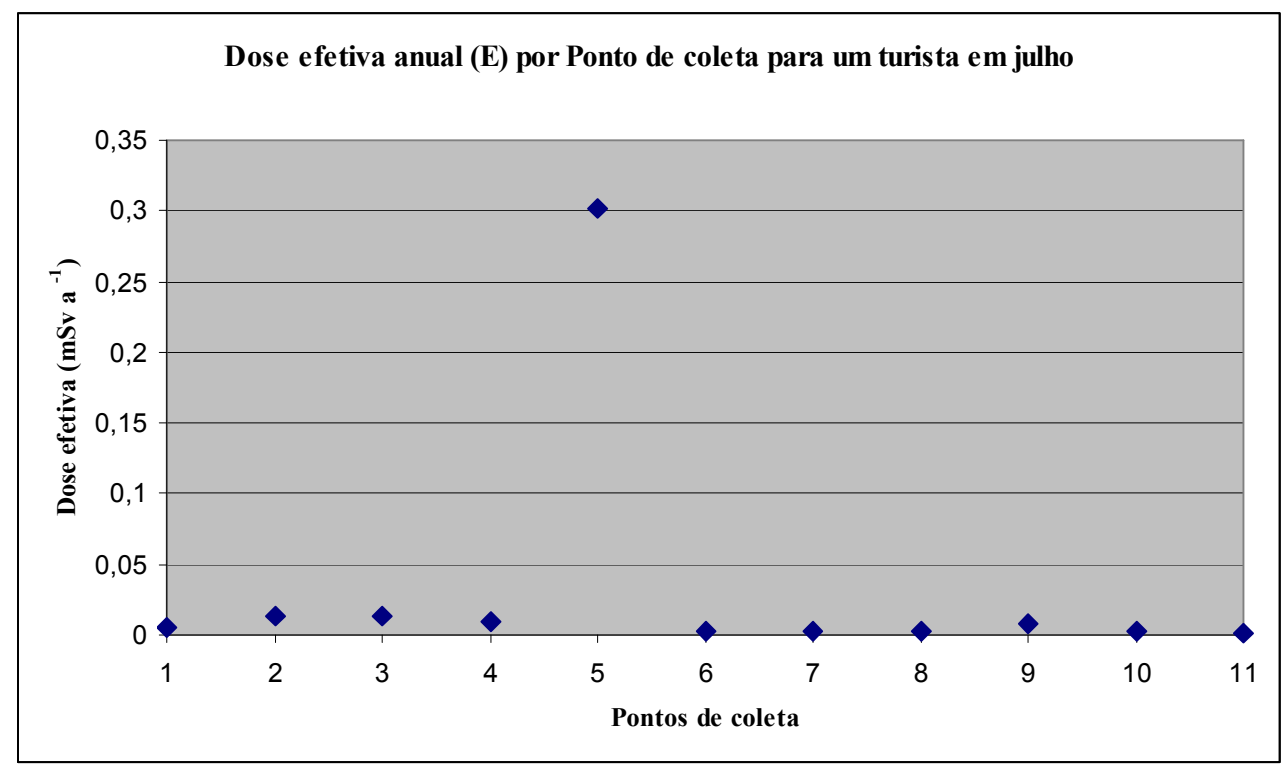

FIGURA 57 - Dose efetiva anual (E) referente a 8 horas de exposição por dia durante o mês de julho de 2011 em cada ponto de coleta (1-11) na Praia de Camburi. 
A Dose efetiva anual (E) referente a 8 horas de exposição por dia durante o mês de janeiro de 2011 variou de $0,002 \mathrm{mSv}^{-\mathrm{a}^{-1}}$ referente aos Pontos 10 e 11 até 0,144 $\mathrm{mSv} \cdot \mathrm{a}^{-1}$ referente ao Ponto 5.

A Dose efetiva anual (E) referente à 8 horas de exposição por dia durante o mês de julho de 2011 variou de $0,002 \mathrm{mSv} \cdot \mathrm{a}^{-1}$ referente ao Ponto 11 até $0,302 \mathrm{mSv} \cdot \mathrm{a}^{-1}$ referente ao Ponto 5.

Portanto, os valores encontrados para janeiro e julho não excederam o limite de $1 \mathrm{mSv} \cdot \mathrm{a}^{-1}$ para os turistas nas condições supostas de exposição. 


\section{CONCLUSÕES}

A análise das 132 amostras de areia da Praia de Camburi coletadas durante o ano de 2011 resultou num banco de dados de concentrações de atividade de ${ }^{226} \mathrm{Ra},{ }^{232} \mathrm{Th}$ e ${ }^{40} \mathrm{~K}$, presente no APÊNDICE B. As concentrações de atividade determinadas estão na mesma faixa da variação encontrada para amostras de areia de regiões com radioatividade natural elevada.

Em relação aos pontos de coleta observa-se que o Ponto 5 em junho é o que obteve maiores valores de concentração de atividade de ${ }^{226} \mathrm{Ra},{ }^{232} \mathrm{Th}$ e ${ }^{40} \mathrm{~K}$ e dos índices $R a_{e q}, I_{\gamma}, H_{\text {ext }}, H_{\text {int }}, D$ e $E$, seguido do Ponto 1 em dezembro e do Ponto 2 em setembro.

$\mathrm{O}$ fato da amostra coletada em abril possuir baixas concentrações de atividade de ${ }^{226} \mathrm{Ra},{ }^{232} \mathrm{Th}$ e ${ }^{40} \mathrm{~K}$ em todos os pontos pode estar relacionado com o fato de que, no intervalo anterior ao da coleta, do dia 16 de março de 2011 a 15 de abril de 2011, ocorreu a máxima variação da altura das marés para os Portos de Vitória e de Tubarão (FIG. 34, item 5.4.3) somado ao fato de que o índice de precipitação pluviométrica foi, em abril, o maior do ano (FIG. 33, item 5.4.2).

Uma alta variação da altura das marés juntamente com um índice de precipitação pluviométrica elevado pode alterar a dinâmica no transporte de porções de areia nos pontos de coleta, diminuindo a concentração dos minerais pesados (ilmenita, monazita, rutilo e zircão) que contém ${ }^{226} \mathrm{Ra},{ }^{232} \mathrm{Th}$ e ${ }^{40} \mathrm{~K}$ em sua composição.

As baixas concentrações de atividade de ${ }^{226} \mathrm{Ra},{ }^{232} \mathrm{Th}$ e ${ }^{40} \mathrm{~K}$ em todos os pontos em outubro podem estar relacionadas com a alta variação da altura das marés encontradas neste período. Como já dito, uma alta variação da altura das marés pode alterar a dinâmica no transporte de porções de areia nos pontos de coleta, diminuindo a concentração de ${ }^{226} \mathrm{Ra},{ }^{232} \mathrm{Th}$ e ${ }^{40} \mathrm{~K}$ das areias.

Nos outros meses não há uma relação direta entre a variação da altura das marés e a precipitação pluviométrica com as concentrações de atividade de ${ }^{226} \mathrm{Ra},{ }^{232} \mathrm{Th}$ e ${ }^{40} \mathrm{~K}$. 
A posição geográfica do Ponto 5, com a ilha de Socó localizada logo a sua frente, pode ter influenciado nas altas concentrações de atividade de ${ }^{226} \mathrm{Ra},{ }^{232} \mathrm{Th}$ e ${ }^{40} \mathrm{~K}$ encontrados neste ponto ao longo de todo o ano. Isto porque a ilha é um obstáculo que impede que as ondas cheguem com maior energia ao Ponto 5, que pode ter favorecido um acúmulo de minerais pesados. Eventualmente, também há a possibilidade de que com alguma dragagem realizada na região, areia retirada do fundo do mar tenha sido depositada no Ponto 5.

A temperatura média de Vitória durante o ano de 2011 não interfere diretamente nas variações observadas nas concentrações de atividade de ${ }^{226} \mathrm{Ra},{ }^{232} \mathrm{Th}$ e ${ }^{40} \mathrm{~K}$ das areias.

Os valores dos índices radiológicos apresentaram pontos de máximo nos Pontos 1,2 e 8 . Nenhum mês em especial se destaca por conter índices radiológicos elevados em todos os pontos, entretanto o mês de abril se destaca por ter baixos índices radiológicos durante todo o ano de 2011.

A grande maioria das amostras analisadas apresenta o valor de $R a_{e q}$ inferior a $370 \mathrm{~Bq} \cdot \mathrm{kg}^{-1}$, considerando-se a utilização da areia como material de construção de duas formas distintas, uma em sua totalidade, com $100 \%$ do material de construção sendo areia e outra, com a areia utilizada em porcentagens fracionadas nos materiais de construção. A grande maioria das amostras analisadas apresentam o valor de $I_{\gamma}$ inferior aos critérios de dose para materiais de construção vendidos a granel, apresentam valores de $H_{\text {ext }}$ e $H_{\text {int }}$ inferiores a 1 e o valor de $E$ inferior a $1 \mathrm{mSv} \cdot \mathrm{a}^{-1}$.

Considerando uma exposição de 1 hora por dia à cada amostra, somente a amostra referente ao Ponto 5 em junho excedeu $1 \mathrm{mSv} \cdot \mathrm{a}^{-1}$.

Este estudo analisou a radioatividade natural das areias da Praia de Camburi, em 11 locais de coleta, por meio de medições de concentração de atividade de ${ }^{226} \mathrm{Ra},{ }^{232} \mathrm{Th}$ $\mathrm{e}^{40} \mathrm{~K}$. Devido à presença forte de monazita, a concentração de ${ }^{232} \mathrm{Th}$ é mais elevada do que a concentração de ${ }^{226} \mathrm{Ra}$ e ${ }^{40} \mathrm{~K}$. Logo, a concentração de atividade de ${ }^{232}$ Th contribuiu mais no valor da dose efetiva anual. 
A dose efetiva anual encontrada para um morador da Praia de Camburi que frequenta a praia durante todo o ano e que vá a um único ponto da praia todo dia com um tempo de exposição de 1 hora por dia está abaixo do limite de $1 \mathrm{mSv} \cdot \mathrm{a}^{-1}$ para indivíduos do público (ICRP, 1990).

Para um turista que frequenta a praia nas férias, em janeiro ou em julho, com tempo de exposição de 1 mês, durante 8 horas diárias, doses efetivas anuais apresentaram valores abaixo do limite de $1 \mathrm{mSv} \cdot \mathrm{a}^{-1}$ para indivíduos do público (ICRP, 1990).

Portanto, conclui-se que as areias estudadas não apresentam riscos radiológicos à população, considerando os tempos de exposição avaliados neste trabalho.

Deve-se atentar ao fato de que a praia é modificada constantemente com dragagens, portanto a validade do estudo é limitada. 


\section{SUGESTÕES PARA TRABALHOS FUTUROS}

- Avaliar a concentração de atividade de ${ }^{226} \mathrm{Ra},{ }^{232} \mathrm{Th}$ e ${ }^{40} \mathrm{~K}$ em amostras de areia em suspensão contida na água do mar da Praia de Camburi e em amostras colhidas em solo marinho.

- Avaliar a concentração de atividade de ${ }^{226} \mathrm{Ra},{ }^{232} \mathrm{Th}$ e ${ }^{40} \mathrm{~K}$ em amostras de areia da Praia de Camburi, não somente areias superficiais mas amostras obtidas com perfilagem em diferentes profundidades.

- Avaliar a concentração de atividade de ${ }^{226} \mathrm{Ra},{ }^{232} \mathrm{Th}$ e ${ }^{40} \mathrm{~K}$ e os índices radiológicos associados em outras praias do Espírito Santo, com vários pontos de coleta e amostragens sazonais. Alguns trabalhos a esse respeito já estão sendo realizados por outros pesquisadores do Laboratório de Radiometria Ambiental do IPEN. 


\section{REFERÊNCIAS BIBLIOGRÁFICAS}

ALAM, M.N.; CHOWDHURY, M.I.; KAMAL, M.; GHOSE, S.; ISLAM, M.N.; MUSTAFA M.N.; MIAH M.M.H.; ANSARY M.M. The ${ }^{226} \mathrm{Ra},{ }^{232} \mathrm{Th}$ and ${ }^{40} \mathrm{~K}$ activities in beach sandminerals and beach soils of Cox's Bazar, Bangladesh, Journal of Environmental Radioactivity, v.46, 243-250, 1998.

ANDRADE, R.H.P., DNPM. Departamento Nacional de Produção Mineral. Sumário Mineral 2010. Terras Raras. Mato Grosso do Sul, 2010. Disponível em: <

https://sistemas.dnpm.gov.br/publicacao/mostra_imagem.asp?IDBancoArquivoArquivo=5 492>. Acesso em: 01 nov. 2011.

ANJOS, R.M., VEIGA, R., SOARES, T., SANTOS, A.M.A., AGUIAR, J.G., FRASCA, M.H.B.O., BRAGE, J.A.P., UZEDA, D., MANGIA, L., FACURE, A., MOSQUERA, B., CARVALHO, C., GOMES, P.R.S., Natural radionuclide distribution in Brazilian commercial granites, Radiation Measurements, v. 39, p.245 - 253, 2005.

AQUINO, R. R. Avaliação da radioatividade natural em areias das Praias da Grande Vitória, Espírito Santo. 2010. Dissertação (Mestrado) - Instituto de Pesquisas Energéticas e Nucleares, São Paulo.

BARROS, L.F., PECEQUILO, B.R.S. e AQUINO, R.R. Gamma radiation measurements in select sand samples from Camburi Beach - Vitória, Espírito Santo, Brasil: Preliminary results. In: 2011 INTERNATIONAL NUCLEAR ATLANTIC CONFERENCE - INAC 2011, Belo Horizonte, Anais...INAC.

BARROS, L.F e PECEQUILO, B.R.S. Evaluation of Ra, Th, K and Radium Equivalent Activity in sand samples from Camburi Beach, Vitória, Espírito Santo, Brazil. In: IX Latin American IRPA Regional Congress on Radiation Protection and Safety - IRPA 2013, Rio de Janeiro, Anais... IRPA, 2013a.

BARROS, L.F e PECEQUILO, B.R.S. Self-Attenuation factors in gamma-ray spectrometry of select sand samples from Camburi Beach- Vitória, Espírito Santo, Brazil, Radiation Physics and Chemistry. v. 45, p. 339-341, 2013 b.

BARROS, L.F e PECEQUILO, B.R.S. Radiation Hazards Evaluation for selected sand samples from Camburi beach, Vitória, Espírito Santo, Brazil. In: 2013 INTERNATIONAL NUCLEAR ATLANTIC CONFERENCE - INAC 2013, Recife, Anais...INAC, 2013c.

BERETKA, J.; MATHEW, P. J. Natural Radioactivity of Australian Building Materials, Industrial Wastes and By-products. Health Physics. v. 48(1), p.87-95, 1985.

BNDO, Banco Nacional de Dados Oceanográficos. Disponível em: < http://www.mar.mil.br/dhn/chm/tabuas/index.htm>. Acesso em: 12 ago. 2012.

CANBAZ, B.; CAM,N.F.; YAPRAK, G; CANDAN,O. Natural Radioactivity $\left({ }^{226} \mathrm{Ra},{ }^{232} \mathrm{Th}\right.$ and ${ }^{40} \mathrm{~K}$ ) and assessment of radiological hazards in the Kestanbol granitoid, Turkey,

Radiation Protection Dosimetry, v.141, p. 192-198, 2010. 
CAVALCANTE, M.F. Nìvel do mar. Geografia : ensino fundamental e ensino médio : O mar no espaço geográfico brasileiro. Ministério da Educação, Secretaria de Educação Básica. Brasília, 2005. 304 p. (Coleção explorando o ensino, v. 8). Disponível em: $<$ http://portal.mec.gov.br/seb/arquivos/pdf/EnsMed/expensgeo 7e8.pdf $>$. Acesso em: 22 jul. 2013.

CEVIK, U., DAMLA, N., KOBYA, A.I., CELIK, N., CELIK, A., VAN, A.A., Assessment of natural radioactivity of sand used in Turkey, Journal of Radiological Protection, v. 29, p.61-74, 2009.

CHS Engenharia. Seção Fotos antigas de Vitória. Disponível em:

$<$ http://www.chsengenharia.com.br/pg/1245/curiosidades-fotos-antigas-de-vitoria/3/>. Acesso em: 21 nov. 2012.

CPRM. Companhia de Pesquisa de Recursos Minerais. Serviço Geológico do Brasil. Disponível em: < http://www.cprm.gov.br/ >. Acesso em: 16 jun. 2012.

CUTSHALL, N. H., LARSEN, I. L. e OLSEN, C.R. Direct analysis of ${ }^{210} \mathrm{~Pb}$ in sediment samples: self-absorption corrections, Nuclear Instruments and Methods in Physics Research, v. 206, p.309-312, 1983.

DICKSON, B.L e SCOTT, K. M. Interpretation of aerial gamma-ray surveys-adding the geochemical factors. AGSO Journal of Australian Geology e Geophysics, v. 17(2), p.187-200, 1997.

DOMINGUEZ, J.M.L. Erosão costeira. Geografia : ensino fundamental e ensino médio : O mar no espaço geográfico brasileiro. Ministério da Educação, Secretaria de Educação Básica. Brasília, 2005. 304 p. (Coleção explorando o ensino , v. 8). Disponível em: $<$ http://portal.mec.gov.br/seb/arquivos/pdf/EnsMed/expensgeo_7e8.pdf $>$. Acesso em: 22 jul. 2013.

EC Radiological protection principles concerning the natural radioactivity of building materials, radiation protection report RP-112. Technical report, European Comission. Radiation Protection Unit, Luxembourg, (1999).

EISENBUD, M. Environmental Radioactivity. $2^{\text {nd }}$ ed. Academic Press, Orlando, 1987.

EISSA, H.S.; MEDHAT, M.E.; SAID, S.A.; ELMAGHRABY, E.K. Radiation dose estimation of sand samples collect from different Egyptian beaches, Radiation Protection Dosimetry, v.147, p. 533-540, 2010.

EVANS, R.D. The Atomic Nucleus. McGraw Hill, New York, 1972.

FERREIRA, A. O. Avaliação da radioatividade natural em algumas rochas graníticas do estado do Paraná e sua utilização na construção civil. 2013. Tese (Doutorado) Instituto de Pesquisas Energéticas e Nucleares, São Paulo.

IAEA Set of 8 calibrated gamma-emitting sources (ems). Viena, jan de 1982, (1982). 
IAEA-TECDOC-1363 Guidelines for radioelement mapping using gamma ray spectrometry data. Technical report, International Atomic Energy Agency (IAEA). 2003.

IBGE. Instituto Brasileiro de Geografia e Estatística. Disponível em:

$<$ http://www.ibge.gov.br/cidadesat/topwindow.htm?1>. Acesso em: 05 jun. 2012.

ICRP 60. International Commission on Radiological Protection, Recommendation of the ICRP, publication 60, Ed. Pergamon Press, Oxford, 1990.

IEMA. Instituto Estadual de Meio Ambiente e Recursos Hídricos. Portal do Governo do Estado do Espírito Santo. Mapa geológico do Espírito Santo. Disponível em:

$<$ http://www.meioambiente.es.gov.br/download/mapa_es_mapa_geologico.pdf $>$. Acesso em: 16 jun. 2012

INCAPER. Instituto Capixaba de Pesquisa, Assistência e Extensão Rural 2013. Disponível $\mathrm{em}:<$ http://hidrometeorologia.incaper.es.gov.br/?pagina=vitoria_sh $>$. Acesso em: 13 jan. 2013 .

INTERWINNER6.0. Mca emulation, data acquisition and analysis software for gamma ray and alpha spectroscopy.ORTEC, Oak Ridge, TN, USA, 2004.

KANNAN, V., RAJAN, M.P., IYENGAR, M.A.R, RAMESH, R. Distribution of natural and anthropogenic radionuclides in soil and beach sand samples of Kalpakkam (India) using hyper pure germanium (HPGe) gamma ray spectrometry, Applied Radiation and Isotopes, p. 109-119, 2002.

KATHREN, R. L., NORM Sources and Their Origins. Applied Radiation and Isotopes, v. 49, p. $149-168,1998$.

KLEIN, A.H.F.; TRUCCOLO, E.; DIEHL, F.L.; VINTÉM, G. Praias arenosas. Morfologia Praial. Geografia : ensino fundamental e ensino médio : O mar no espaço geográfico brasileiro. Ministério da Educação, Secretaria de Educação Básica. Brasília, 2005. 304 p. (Coleção explorando o ensino , v. 8). Disponível em:

$<$ http://portal.mec.gov.br/seb/arquivos/pdf/EnsMed/expensgeo 7e8.pdf $>$. Acesso em: 22 jul. 2013.

KNOLL, G. F. Radiation Detection and Measurement. Third Printing, New York, United States, 1999.

KOMAR, P. D. The Entrainment, Transport and Sorting of Heavy Minerals by Waves and Currents. Em: MANGE, M.A.; WRIGHT, D. T. (Ed.). Heavy Minerals in Use.

Developments in Sedimentology, 2007. v. 58. p. 3-48. Disponível em: $<$ http://ac.elscdn.com/S0070457107580015/1-s2.0-S0070457107580015-main.pdf? tid=54fc943e-0f4c$11 \mathrm{e} 3-9 \mathrm{dc} 0-00000 \mathrm{aab0f} 27 \& \mathrm{acdnat}=1377630806$ cb1f0e37d90912d2207583bf916ffcca $>$ Acesso em: 27 ago. 2013.

LAURIA, D. C.; ROCHEDO, E. R. R. The legacy of monazite processing in Brazil. Radiation Protection and Dosimetry, vol. 114, n.4, p. 546 -550, 2005. 
LIMA, J.A.T.L. Geologia e Recursos Naturais do Espírito Santo. Geologia do Espírito Santo. Vitória, Espírito Santo. 2009.

LRA Laboratório de Radiometria Ambiental. Indicadores de Qualidade - LRA, 2013.

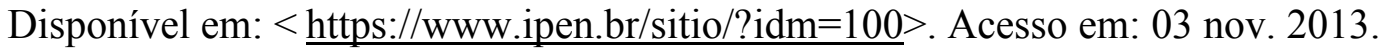

MACHADO, F. B., MOREIRA, C. A., ZANARDO, A., ANDRE, A.C., GODOY, A. M., FERREIRA, J. A., GALEMBECK, T., NARDY, A. J. R., ARTUR, A.C., OLIVEIRA, M.

A. F. de Enciclopédia Multimídia de Minerais. [on-line]. ISBN: 85-89082-11-3. Disponível em: < http://www.rc.unesp.br/museudpm/>. Acesso em: 18 jan. 2013.

MEDHAT, M.E. Assessment of radiation hazards due to natural radioactivity in some building materials used in Egyptian dwellings. Radiation Protection Dosimetry, vol.133, p. $177-185,2009$.

MINERALOGIA. A ciência dos materiais: banco de dados. Disponível em: < http://www.geologiadobrasil.com.br/mineralogia.html>. Acesso em: 08 jan. 2013

MOURA, J.C. Estudo da Variação Sazonal dos Níveis de Radiação Gama da Praia da Areia Preta, Guaraparí, Espírito Santo, Brasil: Radiometria e Análise de Risco. 2003. Dissertação (Mestrado) - Universidade Federal do Espírito Santo, Espírito Santo.

NEVES, P. C. P.; SCHENATO, F., BACCHI, F. A. Introdução à Mineralogia Prática. $2^{\circ}$ ed. Editora ULBRA. Canoas, 2008.

NRPA (Nordic Radiation Protection Authorities). Naturally Occurring in the Nordic Countries- Recommendations. The Radiation Protection Authorities in Denmark, Finland, Iceland, Norway and Sweden. 2000.

ORIGINLAB7.5 Data Analysis and Graphing Software, version 7.5. Copyright 2011 OriginLab Corporation, 2011.

PHILANDER, C.; ROZENDAL, A. Mineral intricacies of Namakwa mineral resource. The $7^{\text {th }}$ International Heavy Minerals Conference 'What next', The Southern African Institute of Mining and Metallurgy, 2009.

PO-LRA-0901. Espectrometria Gama. Procedimento Operacional. Sistema da Qualidade LRA, IPEN, São Paulo, 2008.

PREFEITURA DE VITÓRIA. Vitória, 2012. Apresenta imagem da Praia de Camburi. Disponível em: $<$ http://www.vitoria.es.gov.br/turismo.php?pagina=praiadecamburi $>$. Acesso em: 09 jun. 2012.

QUADRO, M. F. L.; MACHADO, L. H. R.; CALBETE, S.; BATISTA, N.N.M.; OLIVEIRA, G. S. Climatologia de precipitação e temperatura. Centro de Previsão de Tempo e Estudos Climáticos - CPTEC/INPE. Disponível em: $<$ http://climanalise.cptec.inpe.br/ rclimanl/boletim/cliesp10a/chuesp.html $>$. Acesso em: 27 ago. 2013.

RADIATION DECAY 4.0. Nuclear calculator software. Griffith University, 2005. Acesso em: 10 mai. 2012. 
RIEDEL, W.; EISENMENGER, A Problems in monitoring for thorium intakes by workers. KERNTECHNIK, v. 64, n. 1-2, p. 72-85, 1999.

RIGO, D. Análise do escoamento em regiões estuarinas com manguesais- Medições e Modelagem na Baia de Vitória, ES. 2004. Tese (Doutorado) - Universidade Federal do Rio de Janeiro, Rio de Janeiro.

ROTARY International. Distrito 4410 (Espírito Santo, Brasil). Mapa do Espírito Santo. Disponível em: < http://www.rotary4410.org.br/yep/espiritosanto.html >. Acesso em: 16 jun. 2012.

RUSSO, M. Revista Turismo., Vitória, abr. 2011. Seção Dicas de Viagem. Disponível em: $<$ http://www.brazilnet.com.br/contexts/brasilrevistas.html>. Acesso em: 05 jun. 2012.

SABAINI, R. S. Determinação da taxa de transporte de sedimentos na zona de espraiamento de um trecho da praia de Camburi. 2008. Dissertação (Mestrado) Universidade Federal do Espírito Santo, Espírito Santo.

SANTOS, F. Foto da Praia de Camburi. Disponível em:

$<$ http://www.skyscrapercity.com/showthread.php?t=305911>. Acesso em: 03 abr. 2012.

SPERANDIO, E.F. Radioatividade Natural e Composição das Areias da Praia de

Camburi (Vitória- ES, Brasil). 2011. Dissertação (Mestrado) - Universidade Federal do Espírito Santo, Espírito Santo.

SOWMYA M. ; SENTHILKUMAR B.; SESHAN B. R. R.; HARIHARAN G.; PURVAJA R. ; RAMKUMAR S. e RAMESH R. Some natural radioactivity and associated dose rates in soil samples from Kalpakkam, South India. Radiation Protection Dosimetry, v.141, p. 239-247, 2010.

UNSCEAR, Sources and effects of ionizing radiation. United Scientific Committee on the Effects of Atomic Radiation, New York, 1993.

UNSCEAR, Sources and effects of ionizing radiation. United Scientific Committee on the Effects of Atomic Radiation, New York, 2000.

UNSCEAR, Sources and effects of ionizing radiation. United Scientific Committee on the Effects of Atomic Radiation, New York, 2008. annex B

UOSIF, M. A.M.; EL-TAHER, A.; ABBADY, A.G.E. Radiological significance of beach sand used for climatotherapy from Safaga,Egypt. Radiation Protection Dosimetry, v.131, p. 331-339, 2008.

VEIGA, R., SANCHES, N., ANJOS, R.M., MACARIO, K., BASTOS, J., IGUATEMY, M., AGUIAR, J.G., SANTOS, A.M.A., MOSQUERA, B., CARVALHO, C., FILHO, M.B., UMISEDO, N.K., Measurement of natural radioactivity in Brazilian beach sands. Radiation Measurements, v.41, p.189-196, 2006.

VENTURINI, L.; NISTI, M.,B. Correção de auto-absorção na espectrometria gama de amostras ambientais. In: XI ENFIR/IV ENAN. Joint Nuclear Conference, Poços De Caldas, Minas Gerais, 1997. 
VIEIRA, A. C. M.; MATSCHINSKE, E. G.; ALVES, D. S. C. El niño la niña. Geografia : ensino fundamental e ensino médio : O mar no espaço geográfico brasileiro. Ministério da Educação, Secretaria de Educação Básica. Brasília, 2005. 304 p. (Coleção explorando o ensino , v. 8). Disponível em:

$<$ http://portal.mec.gov.br/seb/arquivos/pdf/EnsMed/expensgeo_7e8.pdf $>$. Acesso em: 22 jul. 2013.

XINWEI, L. e ZHANG, X., Measurement of natural radioactivity in beach sands from Rizhao bathing beach, China, Radiation Protection Dosimetry, v. 130, p. 385-388, 2008. 
APÊNDICE A - Fatores de autoatenuação por densidade das amostras de areia (mês e ponto de coleta) da Praia de Camburi analisadas durante 0 ano de 2011 nas energias de transição gama das fontes pontuais utilizadas (INTERWINNER6.0, 2004).

Fatores de autoatenuação para as amostras de densidade $1,26 \mathrm{~g} \cdot \mathrm{cm}^{-3}$

\begin{tabular}{|c|c|c|c|c|c|c|c|c|c|c|c|c|c|c|c|c|c|}
\hline & \multicolumn{17}{|c|}{ Energia $(\mathrm{keV})$} \\
\hline & ${ }^{133} \mathrm{Ba}$ & ${ }^{152} \mathrm{Eu}$ & ${ }^{152} \mathrm{Eu}$ & ${ }^{133} \mathrm{Ba}$ & ${ }^{133} \mathrm{Ba}$ & ${ }^{152} \mathrm{Eu}$ & ${ }^{133} \mathrm{Ba}$ & ${ }^{133} \mathrm{Ba}$ & ${ }^{37} \mathrm{Cs}$ & ${ }^{152} \mathrm{Eu}$ & ${ }^{152} \mathrm{Eu}$ & ${ }^{152} \mathrm{Eu}$ & ${ }^{152} \mathrm{Eu}$ & ${ }^{152} \mathrm{Eu}$ & ${ }^{60} \mathrm{Co}$ & ${ }^{60} \mathrm{Co}$ & ${ }^{152} \mathrm{Eu}$ \\
\hline & 80,99 & 121,78 & 244,69 & 276,39 & 302,85 & 344,28 & 356,01 & 383,85 & 661,66 & 778,9 & 867,39 & 964,05 & 1085,84 & 1112,08 & 1173,24 & 1332,5 & 1408,02 \\
\hline Amostra & \multicolumn{17}{|c|}{ Fator de autoatenuação } \\
\hline JUL01 & $1,29 \pm 0,02$ & $1,32 \pm 0,01$ & $1,23 \pm 0,01$ & $1,12 \pm 0,03$ & $1,12 \pm 0,01$ & $1,19 \pm 0,01$ & $1,10 \pm 0,01$ & $1,10 \pm 0,01$ & $1,030 \pm 0,002$ & $1,12 \pm 0,01$ & $1,11 \pm 0,03$ & $1,09 \pm 0,01$ & $1,09 \pm 0,01$ & $1,09 \pm 0,01$ & $1,02 \pm 0,01$ & $1,02 \pm 0,01$ & $1,12 \pm 0,01$ \\
\hline
\end{tabular}

Fatores de autoatenuação para as amostras de densidade $1,27 \mathrm{~g} . \mathrm{cm}^{-3}$

\begin{tabular}{|c|c|c|c|c|c|c|c|c|c|c|c|c|c|c|c|c|c|}
\hline & \multicolumn{17}{|c|}{ Energia (keV) } \\
\hline & ${ }^{133} \mathrm{Ba}$ & ${ }^{152} \mathrm{Eu}$ & ${ }^{152} \mathrm{Eu}$ & ${ }^{133} \mathrm{Ba}$ & ${ }^{133} \mathrm{Ba}$ & ${ }^{152} \mathrm{Eu}$ & ${ }^{133} \mathrm{Ba}$ & ${ }^{133} \mathrm{Ba}$ & ${ }^{37} \mathrm{Cs}$ & ${ }^{152} \mathrm{Eu}$ & ${ }^{152} \mathrm{Eu}$ & ${ }^{152} \mathrm{Eu}$ & ${ }^{152} \mathrm{Eu}$ & ${ }^{152} \mathrm{Eu}$ & ${ }^{60} \mathrm{Co}$ & ${ }^{60} \mathrm{Co}$ & ${ }^{152} \mathrm{Eu}$ \\
\hline & 80,99 & 121,78 & 244,69 & 276,39 & 302,85 & 344,28 & 356,01 & 383,85 & 661,66 & 778,9 & 867,39 & 964,05 & 1085,84 & 1112,08 & 1173,24 & 1332,5 & 1408,02 \\
\hline Amostra & \multicolumn{17}{|c|}{ Fator de autoatenuação } \\
\hline JUN01 & $1,48 \pm 0,02$ & $1,38 \pm 0,01$ & $1,30 \pm 0,02$ & $1,15 \pm 0,03$ & $1,14 \pm 0,02$ & $1,24 \pm 0,01$ & $1,13 \pm 0,01$ & $1,16 \pm 0,03$ & $1,047 \pm 0,002$ & $1,12 \pm 0,01$ & $1,11 \pm 0,03$ & $1,11 \pm 0,01$ & $1,10 \pm 0,01$ & $1,11 \pm 0,01$ & $1,03 \pm 0,01$ & $1,04 \pm 0,01$ & $1,09 \pm 0,01$ \\
\hline
\end{tabular}


Fatores de autoatenuação para as amostras de densidade $1,36 \mathrm{~g} \cdot \mathrm{cm}^{-3}$

\begin{tabular}{|c|c|c|c|c|c|c|c|c|c|c|c|c|c|c|c|c|c|}
\hline & \multicolumn{17}{|c|}{ Energia (keV) } \\
\hline & ${ }^{133} \mathrm{Ba}$ & ${ }^{152} \mathrm{Eu}$ & ${ }^{152} \mathrm{Eu}$ & ${ }^{133} \mathrm{Ba}$ & ${ }^{133} \mathrm{Ba}$ & ${ }^{152} \mathrm{Eu}$ & ${ }^{133} \mathrm{Ba}$ & ${ }^{133} \mathrm{Ba}$ & ${ }^{37} \mathrm{Cs}$ & ${ }^{152} \mathrm{Eu}$ & ${ }^{152} \mathrm{Eu}$ & ${ }^{152} \mathrm{Eu}$ & ${ }^{152} \mathrm{Eu}$ & ${ }^{152} \mathrm{Eu}$ & ${ }^{60} \mathrm{Co}$ & ${ }^{60} \mathrm{Co}$ & ${ }^{152} \mathrm{Eu}$ \\
\hline & 80,99 & 121,78 & 244,69 & 276,39 & 302,85 & 344,28 & 356,01 & 383,85 & 661,66 & 778,9 & 867,39 & 964,05 & 1085,84 & 1112,08 & 1173,24 & 1332,5 & 1408,02 \\
\hline Amostra & \multicolumn{17}{|c|}{ Fator de autoatenuação } \\
\hline JAN01 & $1,35 \pm 0,02$ & $1,27 \pm 0,01$ & $1,19 \pm 0,02$ & $1,07 \pm 0,04$ & $1,14 \pm 0,02$ & $1,16 \pm 0,01$ & $1,04 \pm 0,01$ & $1,12 \pm 0,03$ & $1,082 \pm 0,002$ & $1,08 \pm 0,01$ & $1,08 \pm 0,03$ & $1,07 \pm 0,01$ & $1,06 \pm 0,01$ & $1,07 \pm 0,01$ & $1,07 \pm 0,01$ & $1,07 \pm 0,01$ & $1,09 \pm 0,01$ \\
\hline \multicolumn{18}{|c|}{ Fatores de autoatenuação para as amostras de densidade $1,48 \mathrm{~g} \cdot \mathrm{cm}^{-3}$} \\
\hline & \multicolumn{17}{|c|}{ Energia (keV) } \\
\hline & ${ }^{133} \mathrm{Ba}$ & ${ }^{152} \mathrm{Eu}$ & ${ }^{152} \mathrm{Eu}$ & ${ }^{133} \mathrm{Ba}$ & ${ }^{133} \mathrm{Ba}$ & ${ }^{152} \mathrm{Eu}$ & ${ }^{133} \mathrm{Ba}$ & ${ }^{133} \mathrm{Ba}$ & ${ }^{37} \mathrm{Cs}$ & ${ }^{152} \mathrm{Eu}$ & ${ }^{152} \mathrm{Eu}$ & ${ }^{152} \mathrm{Eu}$ & ${ }^{152} \mathrm{Eu}$ & ${ }^{152} \mathrm{Eu}$ & ${ }^{60} \mathrm{Co}$ & ${ }^{60} \mathrm{Co}$ & ${ }^{152} \mathrm{Eu}$ \\
\hline & 80,99 & 121,78 & 244,69 & 276,39 & 302,85 & 344,28 & 356,01 & 383,85 & 661,66 & 778,9 & 867,39 & 964,05 & 1085,84 & 1112,08 & 1173,24 & 1332,5 & 1408,02 \\
\hline Amostra & \multicolumn{17}{|c|}{ Fator de autoatenuação } \\
\hline FEV09 & $1,54 \pm 0,02$ & $1,78 \pm 0,01$ & $1,59 \pm 0,03$ & $1,26 \pm 0,02$ & $1,23 \pm 0,01$ & $1,47 \pm 0,01$ & $1,21 \pm 0,01$ & $1,21 \pm 0,01$ & $1,073 \pm 0,002$ & $1,23 \pm 0,01$ & $1,18 \pm 0,03$ & $1,18 \pm 0,01$ & $1,17 \pm 0,01$ & $1,18 \pm 0,01$ & $1,08 \pm 0,01$ & $1,07 \pm 0,01$ & $1,15 \pm 0,01$ \\
\hline
\end{tabular}


Fatores de autoatenuação para as amostras de densidade $1,59 \mathrm{~g} . \mathrm{cm}^{-3}$

\begin{tabular}{|c|c|c|c|c|c|c|c|c|c|c|c|c|c|c|c|c|c|}
\hline & \multicolumn{17}{|c|}{ Energia $(\mathrm{keV})$} \\
\hline & ${ }^{133} \mathrm{Ba}$ & ${ }^{152} \mathrm{Eu}$ & ${ }^{152} \mathrm{Eu}$ & ${ }^{133} \mathrm{Ba}$ & ${ }^{133} \mathrm{Ba}$ & ${ }^{152} \mathrm{Eu}$ & ${ }^{133} \mathrm{Ba}$ & ${ }^{133} \mathrm{Ba}$ & ${ }^{37} \mathrm{Cs}$ & ${ }^{152} \mathrm{Eu}$ & ${ }^{152} \mathrm{Eu}$ & ${ }^{152} \mathrm{Eu}$ & ${ }^{152} \mathrm{Eu}$ & ${ }^{152} \mathrm{Eu}$ & ${ }^{60} \mathrm{Co}$ & ${ }^{60} \mathrm{Co}$ & ${ }^{152} \mathrm{Eu}$ \\
\hline & 80,99 & 121,78 & 244,69 & 276,39 & 302,85 & 344,28 & 356,01 & 383,85 & 661,66 & 778,9 & 867,39 & 964,05 & 1085,84 & 1112,08 & 1173,24 & 1332,5 & 1408,02 \\
\hline Amostra & \multicolumn{17}{|c|}{ Fator de autoatenuação } \\
\hline JAN03 & $1,36 \pm 0,02$ & $1,36 \pm 0,01$ & $1,25 \pm 0,02$ & $1,20 \pm 0,05$ & $1,19 \pm 0,02$ & $1,24 \pm 0,01$ & $1,1 \pm 0,01$ & $1,18 \pm 0,04$ & $1,127 \pm 0,003$ & $1,14 \pm 0,01$ & $1,12 \pm 0,03$ & $1,12 \pm 0,01$ & $1,10 \pm 0,01$ & $1,10 \pm 0,01$ & $1,14 \pm 0,02$ & $1,10 \pm 0,01$ & $1,12 \pm 0,01$ \\
\hline NOV03 & $1,36 \pm 0,02$ & $1,22 \pm 0,01$ & $1,16 \pm 0,02$ & $1,09 \pm 0,04$ & $1,16 \pm 0,02$ & $1,15 \pm 0,01$ & $1,16 \pm 0,01$ & $1,15 \pm 0,03$ & $1,123 \pm 0,003$ & $1,13 \pm 0,02$ & $1,11 \pm 0,03$ & $1,10 \pm 0,01$ & $1,10 \pm 0,01$ & $1,08 \pm 0,01$ & $1,16 \pm 0,02$ & $1,08 \pm 0,01$ & $1,08 \pm 0,01$ \\
\hline DEZ03 & $1,32 \pm 0,02$ & $1,25 \pm 0,01$ & $1,17 \pm 0,02$ & $1,2 \pm 0,05$ & $1,17 \pm 0,02$ & $1,16 \pm 0,01$ & $1,10 \pm 0,01$ & $1,14 \pm 0,04$ & $1,155 \pm 0,003$ & $1,11 \pm 0,01$ & $1,07 \pm 0,03$ & $1,10 \pm 0,01$ & $1,10 \pm 0,01$ & $1,06 \pm 0,01$ & $1,09 \pm 0,02$ & $1,08 \pm 0,02$ & $1,11 \pm 0,01$ \\
\hline
\end{tabular}

Fatores de autoatenuação para as amostras de densidade $1,60 \mathrm{~g} . \mathrm{cm}^{-3}$

\begin{tabular}{|c|c|c|c|c|c|c|c|c|c|c|c|c|c|c|c|c|c|}
\hline & \multicolumn{17}{|c|}{ "Energia (keV) } \\
\hline & ${ }^{133} \mathrm{Ba}$ & ${ }^{152} \mathrm{Eu}$ & ${ }^{152} \mathrm{Eu}$ & ${ }^{133} \mathrm{Ba}$ & ${ }^{133} \mathrm{Ba}$ & ${ }^{152} \mathrm{Eu}$ & ${ }^{133} \mathrm{Ba}$ & ${ }^{133} \mathrm{Ba}$ & ${ }^{37} \mathrm{Cs}$ & ${ }^{152} \mathrm{Eu}$ & ${ }^{152} \mathrm{Eu}$ & ${ }^{152} \mathrm{Eu}$ & ${ }^{152} \mathrm{Eu}$ & ${ }^{152} \mathrm{Eu}$ & ${ }^{60} \mathrm{Co}$ & ${ }^{60} \mathrm{Co}$ & ${ }^{152} \mathrm{Eu}$ \\
\hline & 80,99 & 121,78 & 244,69 & 276,39 & 302,85 & 344,28 & 356,01 & 383,85 & 661,66 & 778,9 & 867,39 & 964,05 & 1085,84 & 1112,08 & 1173,24 & 1332,5 & 1408,02 \\
\hline Amostra & \multicolumn{17}{|c|}{ Fator de autoatenuação } \\
\hline NOV08 & $1,35 \pm 0,02$ & $1,26 \pm 0,01$ & $1,18 \pm 0,02$ & $1,11 \pm 0,04$ & $1,16 \pm 0,02$ & $1,18 \pm 0,01$ & $1,17 \pm 0,01$ & $1,15 \pm 0,03$ & $1,126 \pm 0,003$ & $1,12 \pm 0,01$ & $1,12 \pm 0,03$ & $1,10 \pm 0,01$ & $1,10 \pm 0,01$ & $1,10 \pm 0,01$ & $1,14 \pm 0,02$ & $1,14 \pm 0,02$ & $1,09 \pm 0,01$ \\
\hline
\end{tabular}


Fatores de autoatenuação para as amostras de densidade $1,61 \mathrm{~g} . \mathrm{cm}^{-3}$

\begin{tabular}{|c|c|c|c|c|c|c|c|c|c|c|c|c|c|c|c|c|c|}
\hline & \multicolumn{17}{|c|}{ Energia (keV) } \\
\hline & ${ }^{133} \mathrm{Ba}$ & ${ }^{152} \mathrm{Eu}$ & ${ }^{152} \mathrm{Eu}$ & ${ }^{133} \mathrm{Ba}$ & ${ }^{133} \mathrm{Ba}$ & ${ }^{152} \mathrm{Eu}$ & ${ }^{133} \mathrm{Ba}$ & ${ }^{133} \mathrm{Ba}$ & ${ }^{37} \mathrm{Cs}$ & ${ }^{152} \mathrm{Eu}$ & ${ }^{152} \mathrm{Eu}$ & ${ }^{152} \mathrm{Eu}$ & ${ }^{152} \mathrm{Eu}$ & ${ }^{152} \mathrm{Eu}$ & ${ }^{60} \mathrm{Co}$ & ${ }^{60} \mathrm{Co}$ & ${ }^{152} \mathrm{Eu}$ \\
\hline & 80,99 & 121,78 & 244,69 & 276,39 & 302,85 & 344,28 & 356,01 & 383,85 & 661,66 & 778,9 & 867,39 & 964,05 & 1085,84 & 1112,08 & 1173,24 & 1332,5 & 1408,02 \\
\hline Amostra & \multicolumn{17}{|c|}{ Fator de autoatenuação } \\
\hline OUT02 & $1,44 \pm 0,02$ & $1,23 \pm 0,01$ & $1,18 \pm 0,02$ & $1,22 \pm 0,04$ & $1,18 \pm 0,02$ & $1,1 \pm 0,01$ & $1,16 \pm 0,01$ & $1,19 \pm 0,03$ & $1,092 \pm 0,002$ & $1,09 \pm 0,01$ & $1,10 \pm 0,03$ & $1,10 \pm 0,01$ & $1,08 \pm 0,01$ & $1,09 \pm 0,01$ & $1,13 \pm 0,02$ & $1,11 \pm 0,02$ & $1,08 \pm 0,01$ \\
\hline OUT09 & $1,63 \pm 0,03$ & $1,19 \pm 0,01$ & $1,13 \pm 0,02$ & $1,28 \pm 0,04$ & $1,21 \pm 0,02$ & $1,11 \pm 0,01$ & $1,17 \pm 0,01$ & $1,25 \pm 0,03$ & $1,081 \pm 0,002$ & $1,10 \pm 0,01$ & $1,12 \pm 0,03$ & $1,13 \pm 0,01$ & $1,11 \pm 0,01$ & $1,12 \pm 0,01$ & $1,06 \pm 0,01$ & $1,07 \pm 0,01$ & $1,06 \pm 0,01$ \\
\hline NOV05 & $1,39 \pm 0,02$ & $1,24 \pm 0,01$ & $1,16 \pm 0,02$ & $1,08 \pm 0,04$ & $1,18 \pm 0,02$ & $1,15 \pm 0,01$ & $1,16 \pm 0,01$ & $1,13 \pm 0,03$ & $1,125 \pm 0,003$ & $1,12 \pm 0,01$ & $1,11 \pm 0,03$ & $1,10 \pm 0,01$ & $1,09 \pm 0,01$ & $1,09 \pm 0,01$ & $1,15 \pm 0,02$ & $1,08 \pm 0,01$ & $1,10 \pm 0,01$ \\
\hline DEZ04 & $1,36 \pm 0,02$ & $1,25 \pm 0,02$ & $1,19 \pm 0,05$ & $1,17 \pm 0,04$ & $1,15 \pm 0,02$ & $1,15 \pm 0,02$ & $1,09 \pm 0,01$ & $1,14 \pm 0,04$ & $1,157 \pm 0,003$ & $1,12 \pm 0,02$ & $1,10 \pm 0,04$ & $1,09 \pm 0,01$ & $1,12 \pm 0,02$ & $1,15 \pm 0,01$ & $1,12 \pm 0,02$ & $1,08 \pm 0,02$ & $1,09 \pm 0,01$ \\
\hline DEZ09 & $1,33 \pm 0,02$ & $1,26 \pm 0,02$ & $1,18 \pm 0,05$ & $1,19 \pm 0,04$ & $1,17 \pm 0,02$ & $1,18 \pm 0,02$ & $1,08 \pm 0,01$ & $1,07 \pm 0,03$ & $1,162 \pm 0,003$ & $1,12 \pm 0,02$ & $1,10 \pm 0,04$ & $1,10 \pm 0,01$ & $1,11 \pm 0,02$ & $1,11 \pm 0,01$ & $1,08 \pm 0,02$ & $1,08 \pm 0,02$ & $1,10 \pm 0,01$ \\
\hline
\end{tabular}


Fatores de autoatenuação para as amostras de densidade $1,62 \mathrm{~g} . \mathrm{cm}^{-3}$

\begin{tabular}{|c|c|c|c|c|c|c|c|c|c|c|c|c|c|c|c|c|c|}
\hline & \multicolumn{17}{|c|}{ Energia $(\mathrm{keV})$} \\
\hline & ${ }^{133} \mathrm{Ba}$ & ${ }^{152} \mathrm{Eu}$ & ${ }^{152} \mathrm{Eu}$ & ${ }^{133} \mathrm{Ba}$ & ${ }^{133} \mathrm{Ba}$ & ${ }^{152} \mathrm{Eu}$ & ${ }^{133} \mathrm{Ba}$ & ${ }^{133} \mathrm{Ba}$ & ${ }^{37} \mathrm{Cs}$ & ${ }^{152} \mathrm{Eu}$ & ${ }^{152} \mathrm{Eu}$ & ${ }^{152} \mathrm{Eu}$ & ${ }^{152} \mathrm{Eu}$ & ${ }^{152} \mathrm{Eu}$ & ${ }^{60} \mathrm{Co}$ & ${ }^{60} \mathrm{Co}$ & ${ }^{152} \mathrm{Eu}$ \\
\hline & 80,99 & 121,78 & 244,69 & 276,39 & 302,85 & 344,28 & 356,01 & 383,85 & 661,66 & 778,9 & 867,39 & 964,05 & 1085,84 & 1112,08 & 1173,24 & 1332,5 & 1408,02 \\
\hline Amostra & \multicolumn{17}{|c|}{ Fator de autoatenuação } \\
\hline FEV07 & $1,54 \pm 0,02$ & $1,78 \pm 0,01$ & $1,61 \pm 0,03$ & $1,29 \pm 0,02$ & $1,29 \pm 0,01$ & $1,48 \pm 0,01$ & $1,26 \pm 0,01$ & $1,26 \pm 0,02$ & $1,121 \pm 0,002$ & $1,23 \pm 0,01$ & $1,23 \pm 0,03$ & $1,21 \pm 0,01$ & $1,18 \pm 0,01$ & $1,18 \pm 0,01$ & $1,09 \pm 0,01$ & $1,08 \pm 0,01$ & $1,16 \pm 0,01$ \\
\hline MAR01 & $1,46 \pm 0,02$ & $1,37 \pm 0,01$ & $1,27 \pm 0,02$ & $1,15 \pm 0,03$ & $1,17 \pm 0,02$ & $1,22 \pm 0,01$ & $1,15 \pm 0,01$ & $1,16 \pm 0,03$ & $1,084 \pm 0,002$ & $1,15 \pm 0,01$ & $1,11 \pm 0,03$ & $1,13 \pm 0,01$ & $1,12 \pm 0,01$ & $1,12 \pm 0,01$ & $1,07 \pm 0,01$ & $1,08 \pm 0,02$ & $1,12 \pm 0,01$ \\
\hline MAR08 & $1,47 \pm 0,02$ & $1,37 \pm 0,01$ & $1,31 \pm 0,02$ & $1,23 \pm 0,04$ & $1,22 \pm 0,02$ & $1,24 \pm 0,01$ & $1,18 \pm 0,01$ & $1,18 \pm 0,03$ & $1,116 \pm 0,003$ & $1,16 \pm 0,01$ & $1,15 \pm 0,03$ & $1,14 \pm 0,01$ & $1,14 \pm 0,01$ & $1,13 \pm 0,01$ & $1,07 \pm 0,01$ & $1,05 \pm 0,01$ & $1,12 \pm 0,01$ \\
\hline AGO08 & $1,33 \pm 0,02$ & $1,30 \pm 0,01$ & $1,23 \pm 0,01$ & $1,19 \pm 0,04$ & $1,18 \pm 0,02$ & $1,19 \pm 0,01$ & $1,17 \pm 0,01$ & $1,16 \pm 0,03$ & $1,084 \pm 0,002$ & $1,13 \pm 0,01$ & $1,11 \pm 0,03$ & $1,12 \pm 0,01$ & $1,11 \pm 0,01$ & $1,11 \pm 0,01$ & $1,06 \pm 0,01$ & $1,07 \pm 0,01$ & $1,13 \pm 0,01$ \\
\hline AGO10 & $1,54 \pm 0,02$ & $1,39 \pm 0,01$ & $1,32 \pm 0,03$ & $1,33 \pm 0,04$ & $1,26 \pm 0,02$ & $1,17 \pm 0,01$ & $1,23 \pm 0,01$ & $1,23 \pm 0,03$ & $1,165 \pm 0,003$ & $1,12 \pm 0,01$ & $1,11 \pm 0,03$ & $1,11 \pm 0,01$ & $1,11 \pm 0,01$ & $1,11 \pm 0,01$ & $1,14 \pm 0,02$ & $1,08 \pm 0,01$ & $1,06 \pm 0,01$ \\
\hline AGO11 & $1,40 \pm 0,02$ & $1,26 \pm 0,01$ & $1,18 \pm 0,01$ & $1,23 \pm 0,05$ & $1,27 \pm 0,02$ & $1,18 \pm 0,01$ & $1,16 \pm 0,01$ & $1,22 \pm 0,04$ & $1,151 \pm 0,003$ & $1,13 \pm 0,01$ & $1,10 \pm 0,03$ & $1,10 \pm 0,01$ & $1,10 \pm 0,01$ & $1,10 \pm 0,01$ & $1,17 \pm 0,02$ & $1,16 \pm 0,02$ & $1,13 \pm 0,01$ \\
\hline OUT03 & $1,54 \pm 0,02$ & $1,23 \pm 0,01$ & $1,22 \pm 0,02$ & $1,20 \pm 0,04$ & $1,21 \pm 0,02$ & $1,09 \pm 0,01$ & $1,17 \pm 0,01$ & $1,17 \pm 0,03$ & $1,078 \pm 0,002$ & $1,09 \pm 0,01$ & $1,09 \pm 0,03$ & $1,10 \pm 0,01$ & $1,08 \pm 0,01$ & $1,10 \pm 0,01$ & $1,13 \pm 0,02$ & $1,07 \pm 0,01$ & $1,08 \pm 0,01$ \\
\hline NOV09 & $1,50 \pm 0,03$ & $1,30 \pm 0,01$ & $1,18 \pm 0,02$ & $1,14 \pm 0,04$ & $1,19 \pm 0,02$ & $1,18 \pm 0,01$ & $1,17 \pm 0,01$ & $1,17 \pm 0,04$ & $1,13 \pm 0,003$ & $1,13 \pm 0,01$ & $1,10 \pm 0,03$ & $1,10 \pm 0,01$ & $1,12 \pm 0,01$ & $1,06 \pm 0,01$ & $1,13 \pm 0,02$ & $1,14 \pm 0,02$ & $1,10 \pm 0,01$ \\
\hline NOV10 & $1,38 \pm 0,02$ & $1,24 \pm 0,01$ & $1,15 \pm 0,02$ & $1,16 \pm 0,04$ & $1,16 \pm 0,02$ & $1,16 \pm 0,01$ & $1,17 \pm 0,01$ & $1,17 \pm 0,04$ & $1,127 \pm 0,003$ & $1,12 \pm 0,01$ & $1,07 \pm 0,03$ & $1,10 \pm 0,01$ & $1,12 \pm 0,01$ & $1,09 \pm 0,01$ & $1,15 \pm 0,02$ & $1,09 \pm 0,01$ & $1,10 \pm 0,01$ \\
\hline
\end{tabular}


Fatores de autoatenuação para as amostras de densidade 1,63 g.cm ${ }^{-3}$

\begin{tabular}{|c|c|c|c|c|c|c|c|c|c|c|c|c|c|c|c|c|c|}
\hline & \multicolumn{17}{|c|}{ Energia (keV) } \\
\hline & ${ }^{133} \mathrm{Ba}$ & ${ }^{152} \mathrm{Eu}$ & ${ }^{152} \mathrm{Eu}$ & ${ }^{133} \mathrm{Ba}$ & ${ }^{133} \mathrm{Ba}$ & ${ }^{152} \mathrm{Eu}$ & ${ }^{133} \mathrm{Ba}$ & ${ }^{133} \mathrm{Ba}$ & ${ }^{37} \mathrm{Cs}$ & ${ }^{152} \mathrm{Eu}$ & ${ }^{152} \mathrm{Eu}$ & ${ }^{152} \mathrm{Eu}$ & ${ }^{152} \mathrm{Eu}$ & ${ }^{152} \mathrm{Eu}$ & ${ }^{60} \mathrm{Co}$ & ${ }^{60} \mathrm{Co}$ & ${ }^{152} \mathrm{Eu}$ \\
\hline & 80,99 & 121,78 & 244,69 & 276,39 & 302,85 & 344,28 & 356,01 & 383,85 & 661,66 & 778,9 & 867,39 & 964,05 & 1085,84 & 1112,08 & 1173,24 & 1332,5 & 1408,02 \\
\hline Amostra & \multicolumn{17}{|c|}{ Fator de autoatenuação } \\
\hline JAN10 & $1,38 \pm 0,02$ & $1,35 \pm 0,01$ & $1,25 \pm 0,02$ & $1,28 \pm 0,05$ & $1,19 \pm 0,02$ & $1,19 \pm 0,01$ & $1,09 \pm 0,01$ & $1,19 \pm 0,02$ & $1,126 \pm 0,003$ & $1,13 \pm 0,01$ & $1,1 \pm 0,03$ & $1,12 \pm 0,01$ & $1,11 \pm 0,01$ & $1,11 \pm 0,01$ & $1,14 \pm 0,02$ & $1,10 \pm 0,01$ & $1,12 \pm 0,01$ \\
\hline AGO05 & $1,36 \pm 0,02$ & $1,31 \pm 0,01$ & $1,24 \pm 0,02$ & $1,18 \pm 0,03$ & $1,20 \pm 0,02$ & $1,20 \pm 0,01$ & $1,18 \pm 0,01$ & $1,18 \pm 0,03$ & $1,085 \pm 0,002$ & $1,14 \pm 0,01$ & $1,12 \pm 0,03$ & $1,12 \pm 0,01$ & $1,11 \pm 0,01$ & $1,11 \pm 0,01$ & $1,07 \pm 0,01$ & $1,06 \pm 0,01$ & $1,11 \pm 0,01$ \\
\hline SET03 & $1,64 \pm 0,03$ & $1,44 \pm 0,01$ & $1,35 \pm 0,03$ & $1,24 \pm 0,04$ & $1,24 \pm 0,02$ & $1,21 \pm 0,01$ & $1,21 \pm 0,01$ & $1,26 \pm 0,04$ & $1,072 \pm 0,002$ & $1,13 \pm 0,02$ & $1,14 \pm 0,03$ & $1,12 \pm 0,01$ & $1,13 \pm 0,01$ & $1,16 \pm 0,01$ & $1,08 \pm 0,01$ & $1,08 \pm 0,01$ & $1,10 \pm 0,01$ \\
\hline OUT10 & $1,52 \pm 0,02$ & $1,29 \pm 0,01$ & $1,22 \pm 0,02$ & $1,18 \pm 0,04$ & $1,19 \pm 0,02$ & $1,13 \pm 0,01$ & $1,16 \pm 0,01$ & $1,15 \pm 0,03$ & $1,075 \pm 0,002$ & $1,12 \pm 0,01$ & $1,06 \pm 0,03$ & $1,11 \pm 0,01$ & $1,11 \pm 0,01$ & $1,10 \pm 0,01$ & $1,11 \pm 0,01$ & $1,06 \pm 0,01$ & $1,09 \pm 0,01$ \\
\hline DEZ02 & $1,35 \pm 0,02$ & $1,28 \pm 0,01$ & $1,22 \pm 0,02$ & $1,19 \pm 0,04$ & $1,19 \pm 0,02$ & $1,18 \pm 0,01$ & $1,11 \pm 0,01$ & $1,17 \pm 0,04$ & $1,165 \pm 0,003$ & $1,12 \pm 0,01$ & $1,08 \pm 0,03$ & $1,11 \pm 0,01$ & $1,11 \pm 0,01$ & $1,11 \pm 0,01$ & $1,10 \pm 0,02$ & $1,09 \pm 0,02$ & $1,11 \pm 0,01$ \\
\hline
\end{tabular}


Fatores de autoatenuação para as amostras de densidade $1,64 \mathrm{~g} . \mathrm{cm}^{-3}$

\begin{tabular}{|c|c|c|c|c|c|c|c|c|c|c|c|c|c|c|c|c|c|}
\hline & \multicolumn{17}{|c|}{ Energia $(\mathrm{keV})$} \\
\hline & ${ }^{133} \mathrm{Ba}$ & ${ }^{152} \mathrm{Eu}$ & ${ }^{152} \mathrm{Eu}$ & ${ }^{133} \mathrm{Ba}$ & ${ }^{133} \mathrm{Ba}$ & ${ }^{152} \mathrm{Eu}$ & ${ }^{133} \mathrm{Ba}$ & ${ }^{133} \mathrm{Ba}$ & ${ }^{37} \mathrm{Cs}$ & ${ }^{152} \mathrm{Eu}$ & ${ }^{152} \mathrm{Eu}$ & ${ }^{152} \mathrm{Eu}$ & ${ }^{152} \mathrm{Eu}$ & ${ }^{152} \mathrm{Eu}$ & ${ }^{60} \mathrm{Co}$ & ${ }^{60} \mathrm{Co}$ & ${ }^{152} \mathrm{Eu}$ \\
\hline & 80,99 & 121,78 & 244,69 & 276,39 & 302,85 & 344,28 & 356,01 & 383,85 & 661,66 & 778,9 & 867,39 & 964,05 & 1085,84 & 1112,08 & 1173,24 & 1332,5 & 1408,02 \\
\hline Amostra & \multicolumn{17}{|c|}{ Fator de autoatenuação } \\
\hline FEV02 & $1,45 \pm 0,02$ & $1,90 \pm 0,02$ & $1,68 \pm 0,03$ & $1,28 \pm 0,02$ & $1,28 \pm 0,01$ & $1,53 \pm 0,01$ & $1,25 \pm 0,01$ & $1,24 \pm 0,01$ & $1,123 \pm 0,002$ & $1,26 \pm 0,01$ & $1,22 \pm 0,03$ & $1,21 \pm 0,01$ & $1,20 \pm 0,01$ & $1,21 \pm 0,01$ & $1,09 \pm 0,01$ & $1,09 \pm 0,01$ & $1,22 \pm 0,01$ \\
\hline MAR02 & $1,41 \pm 0,02$ & $1,36 \pm 0,01$ & $1,28 \pm 0,01$ & $1,16 \pm 0,03$ & $1,15 \pm 0,02$ & $1,22 \pm 0,01$ & $1,16 \pm 0,01$ & $1,16 \pm 0,03$ & $1,090 \pm 0,002$ & $1,16 \pm 0,01$ & $1,13 \pm 0,03$ & $1,13 \pm 0,01$ & $1,13 \pm 0,01$ & $1,12 \pm 0,01$ & $1,06 \pm 0,01$ & $1,06 \pm 0,01$ & $1,11 \pm 0,01$ \\
\hline AGO06 & $1,34 \pm 0,02$ & $1,32 \pm 0,01$ & $1,25 \pm 0,01$ & $1,20 \pm 0,04$ & $1,21 \pm 0,02$ & $1,21 \pm 0,01$ & $1,18 \pm 0,01$ & $1,18 \pm 0,03$ & $1,094 \pm 0,002$ & $1,15 \pm 0,01$ & $1,11 \pm 0,03$ & $1,12 \pm 0,01$ & $1,12 \pm 0,01$ & $1,12 \pm 0,01$ & $1,08 \pm 0,01$ & $1,07 \pm 0,01$ & $1,12 \pm 0,01$ \\
\hline AGO07 & $1,34 \pm 0,02$ & $1,30 \pm 0,01$ & $1,25 \pm 0,01$ & $1,21 \pm 0,04$ & $1,20 \pm 0,02$ & $1,20 \pm 0,01$ & $1,17 \pm 0,01$ & $1,17 \pm 0,03$ & $1,085 \pm 0,002$ & $1,13 \pm 0,01$ & $1,12 \pm 0,03$ & $1,12 \pm 0,01$ & $1,11 \pm 0,01$ & $1,11 \pm 0,01$ & $1,07 \pm 0,01$ & $1,06 \pm 0,01$ & $1,10 \pm 0,01$ \\
\hline SET04 & $1,64 \pm 0,03$ & $1,44 \pm 0,01$ & $1,32 \pm 0,03$ & $1,27 \pm 0,04$ & $1,26 \pm 0,02$ & $1,21 \pm 0,01$ & $1,21 \pm 0,01$ & $1,22 \pm 0,03$ & $1,077 \pm 0,002$ & $1,13 \pm 0,01$ & $1,12 \pm 0,03$ & $1,12 \pm 0,01$ & $1,13 \pm 0,01$ & $1,12 \pm 0,01$ & $1,12 \pm 0,02$ & $1,12 \pm 0,02$ & $1,07 \pm 0,01$ \\
\hline OUT11 & $1,49 \pm 0,02$ & $1,28 \pm 0,01$ & $1,24 \pm 0,02$ & $1,22 \pm 0,04$ & $1,18 \pm 0,02$ & $1,12 \pm 0,01$ & $1,16 \pm 0,01$ & $1,16 \pm 0,03$ & $1,076 \pm 0,002$ & $1,11 \pm 0,01$ & $1,08 \pm 0,03$ & $1,10 \pm 0,01$ & $1,11 \pm 0,01$ & $1,10 \pm 0,01$ & $1,09 \pm 0,01$ & $1,08 \pm 0,01$ & $1,09 \pm 0,01$ \\
\hline
\end{tabular}


Fatores de autoatenuação para as amostras de densidade 1,65 g.cm ${ }^{-3}$

\begin{tabular}{|c|c|c|c|c|c|c|c|c|c|c|c|c|c|c|c|c|c|}
\hline & \multicolumn{17}{|c|}{ Energia (keV) } \\
\hline & ${ }^{133} \mathrm{Ba}$ & ${ }^{152} \mathrm{Eu}$ & ${ }^{152} \mathrm{Eu}$ & ${ }^{133} \mathrm{Ba}$ & ${ }^{133} \mathrm{Ba}$ & ${ }^{152} \mathrm{Eu}$ & ${ }^{133} \mathrm{Ba}$ & ${ }^{133} \mathrm{Ba}$ & ${ }^{37} \mathrm{Cs}$ & ${ }^{152} \mathrm{Eu}$ & ${ }^{152} \mathrm{Eu}$ & ${ }^{152} \mathrm{Eu}$ & ${ }^{152} \mathrm{Eu}$ & ${ }^{152} \mathrm{Eu}$ & ${ }^{60} \mathrm{Co}$ & ${ }^{60} \mathrm{Co}$ & ${ }^{152} \mathrm{Eu}$ \\
\hline & 80,99 & 121,78 & 244,69 & 276,39 & 302,85 & 344,28 & 356,01 & 383,85 & 661,66 & 778,9 & 867,39 & 964,05 & 1085,84 & 1112,08 & 1173,24 & 1332,5 & 1408,02 \\
\hline Amostra & \multicolumn{17}{|c|}{ Fator de autoatenuação } \\
\hline ABR02 & $1,50 \pm 0,02$ & $1,49 \pm 0,01$ & $1,38 \pm 0,02$ & $1,23 \pm 0,04$ & $1,24 \pm 0,02$ & $1,32 \pm 0,01$ & $1,21 \pm 0,01$ & $1,23 \pm 0,03$ & $1,092 \pm 0,002$ & $1,18 \pm 0,01$ & $1,17 \pm 0,03$ & $1,16 \pm 0,01$ & $1,15 \pm 0,01$ & $1,15 \pm 0,01$ & $1,05 \pm 0,01$ & $1,06 \pm 0,01$ & $1,14 \pm 0,01$ \\
\hline MAI02 & $1,29 \pm 0,02$ & $1,44 \pm 0,01$ & $1,36 \pm 0,02$ & $1,11 \pm 0,03$ & $1,13 \pm 0,02$ & $1,27 \pm 0,01$ & $1,12 \pm 0,01$ & $1,12 \pm 0,03$ & $1,111 \pm 0,003$ & $1,17 \pm 0,01$ & $1,14 \pm 0,03$ & $1,14 \pm 0,01$ & $1,14 \pm 0,01$ & $1,15 \pm 0,01$ & $1,06 \pm 0,01$ & $1,06 \pm 0,01$ & $1,12 \pm 0,01$ \\
\hline MAI03 & $1,52 \pm 0,02$ & $1,43 \pm 0,01$ & $1,33 \pm 0,02$ & $1,22 \pm 0,04$ & $1,25 \pm 0,02$ & $1,26 \pm 0,01$ & $1,21 \pm 0,01$ & $1,21 \pm 0,03$ & $1,101 \pm 0,002$ & $1,17 \pm 0,01$ & $1,12 \pm 0,03$ & $1,15 \pm 0,01$ & $1,14 \pm 0,01$ & $1,14 \pm 0,01$ & $1,08 \pm 0,01$ & $1,07 \pm 0,01$ & $1,12 \pm 0,01$ \\
\hline AGO04 & $1,35 \pm 0,02$ & $1,31 \pm 0,01$ & $1,25 \pm 0,01$ & $1,19 \pm 0,04$ & $1,20 \pm 0,02$ & $1,20 \pm 0,01$ & $1,18 \pm 0,01$ & $1,19 \pm 0,03$ & $1,091 \pm 0,002$ & $1,14 \pm 0,01$ & $1,12 \pm 0,03$ & $1,12 \pm 0,01$ & $1,12 \pm 0,01$ & $1,12 \pm 0,01$ & $1,07 \pm 0,01$ & $1,06 \pm 0,01$ & $1,13 \pm 0,01$ \\
\hline SET11 & $1,45 \pm 0,02$ & $1,45 \pm 0,01$ & $1,34 \pm 0,03$ & $1,23 \pm 0,04$ & $1,18 \pm 0,02$ & $1,19 \pm 0,01$ & $1,16 \pm 0,01$ & $1,17 \pm 0,03$ & $1,081 \pm 0,002$ & $1,12 \pm 0,01$ & $1,07 \pm 0,03$ & $1,12 \pm 0,01$ & $1,11 \pm 0,01$ & $1,11 \pm 0,01$ & $1,14 \pm 0,02$ & $1,09 \pm 0,01$ & $1,09 \pm 0,01$ \\
\hline NOV11 & $1,48 \pm 0,03$ & $1,29 \pm 0,01$ & $1,18 \pm 0,02$ & $1,23 \pm 0,05$ & $1,21 \pm 0,02$ & $1,19 \pm 0,01$ & $1,19 \pm 0,01$ & $1,18 \pm 0,04$ & $1,148 \pm 0,003$ & $1,15 \pm 0,02$ & $1,13 \pm 0,03$ & $1,12 \pm 0,01$ & $1,10 \pm 0,01$ & $1,10 \pm 0,01$ & $1,17 \pm 0,02$ & $1,13 \pm 0,02$ & $1,11 \pm 0,01$ \\
\hline
\end{tabular}


Fatores de autoatenuação para as amostras de densidade $1,66 \mathrm{~g} . \mathrm{cm}^{-3}$

\begin{tabular}{|c|c|c|c|c|c|c|c|c|c|c|c|c|c|c|c|c|c|}
\hline & \multicolumn{17}{|c|}{ Energia (keV) } \\
\hline & ${ }^{133} \mathrm{Ba}$ & ${ }^{152} \mathrm{Eu}$ & ${ }^{152} \mathrm{Eu}$ & ${ }^{133} \mathrm{Ba}$ & ${ }^{133} \mathrm{Ba}$ & ${ }^{152} \mathrm{Eu}$ & ${ }^{133} \mathrm{Ba}$ & ${ }^{133} \mathrm{Ba}$ & ${ }^{37} \mathrm{Cs}$ & ${ }^{152} \mathrm{Eu}$ & ${ }^{152} \mathrm{Eu}$ & ${ }^{152} \mathrm{Eu}$ & ${ }^{152} \mathrm{Eu}$ & ${ }^{152} \mathrm{Eu}$ & ${ }^{60} \mathrm{Co}$ & ${ }^{60} \mathrm{Co}$ & ${ }^{152} \mathrm{Eu}$ \\
\hline & 80,99 & 121,78 & 244,69 & 276,39 & 302,85 & 344,28 & 356,01 & 383,85 & 661,66 & 778,9 & 867,39 & 964,05 & 1085,84 & 1112,08 & 1173,24 & 1332,5 & 1408,02 \\
\hline Amostra & \multicolumn{17}{|c|}{ Fator de autoatenuação } \\
\hline ABR04 & $1,48 \pm 0,02$ & $1,46 \pm 0,01$ & $1,34 \pm 0,02$ & $1,19 \pm 0,04$ & $1,22 \pm 0,02$ & $1,28 \pm 0,01$ & $1,19 \pm 0,01$ & $1,17 \pm 0,03$ & $1,122 \pm 0,003$ & $1,17 \pm 0,01$ & $1,16 \pm 0,03$ & $1,15 \pm 0,01$ & $1,15 \pm 0,01$ & $1,15 \pm 0,01$ & $1,07 \pm 0,01$ & $1,06 \pm 0,01$ & $1,13 \pm 0,01$ \\
\hline MAI11 & $1,54 \pm 0,02$ & $1,45 \pm 0,01$ & $1,35 \pm 0,02$ & $1,27 \pm 0,04$ & $1,25 \pm 0,02$ & $1,29 \pm 0,01$ & $1,21 \pm 0,01$ & $1,20 \pm 0,03$ & $1,105 \pm 0,003$ & $1,18 \pm 0,01$ & $1,17 \pm 0,03$ & $1,16 \pm 0,01$ & $1,14 \pm 0,01$ & $1,14 \pm 0,01$ & $1,07 \pm 0,01$ & $1,06 \pm 0,01$ & $1,18 \pm 0,01$ \\
\hline JUL09 & $1,42 \pm 0,02$ & $1,34 \pm 0,01$ & $1,24 \pm 0,02$ & $1,23 \pm 0,04$ & $1,19 \pm 0,02$ & $1,21 \pm 0,01$ & $1,18 \pm 0,01$ & $1,13 \pm 0,03$ & $1,114 \pm 0,003$ & $1,15 \pm 0,01$ & $1,13 \pm 0,03$ & $1,14 \pm 0,01$ & $1,12 \pm 0,01$ & $1,12 \pm 0,01$ & $1,06 \pm 0,01$ & $1,07 \pm 0,01$ & $1,12 \pm 0,01$ \\
\hline OUT01 & $1,49 \pm 0,02$ & $1,27 \pm 0,01$ & $1,18 \pm 0,02$ & $1,25 \pm 0,04$ & $1,18 \pm 0,02$ & $1,10 \pm 0,01$ & $1,17 \pm 0,01$ & $1,22 \pm 0,03$ & $1,098 \pm 0,002$ & $1,10 \pm 0,01$ & $1,06 \pm 0,03$ & $1,10 \pm 0,01$ & $1,08 \pm 0,01$ & $1,10 \pm 0,01$ & $1,13 \pm 0,02$ & $1,08 \pm 0,01$ & $1,08 \pm 0,01$ \\
\hline DEZ10 & $1,38 \pm 0,03$ & $1,26 \pm 0,02$ & $1,22 \pm 0,05$ & $1,21 \pm 0,05$ & $1,18 \pm 0,02$ & $1,18 \pm 0,02$ & $1,11 \pm 0,01$ & $1,14 \pm 0,04$ & $1,173 \pm 0,003$ & $1,13 \pm 0,02$ & $1,14 \pm 0,04$ & $1,10 \pm 0,01$ & $1,11 \pm 0,02$ & $1,11 \pm 0,01$ & $1,10 \pm 0,02$ & $1,09 \pm 0,02$ & $1,10 \pm 0,01$ \\
\hline
\end{tabular}


Fatores de autoatenuação para as amostras de densidade $1,67 \mathrm{~g} . \mathrm{cm}^{-3}$

\begin{tabular}{|c|c|c|c|c|c|c|c|c|c|c|c|c|c|c|c|c|c|}
\hline & \multicolumn{17}{|c|}{ Energia $(\mathrm{keV})$} \\
\hline & ${ }^{133} \mathrm{Ba}$ & ${ }^{152} \mathrm{Eu}$ & ${ }^{152} \mathrm{Eu}$ & ${ }^{133} \mathrm{Ba}$ & ${ }^{133} \mathrm{Ba}$ & ${ }^{152} \mathrm{Eu}$ & ${ }^{133} \mathrm{Ba}$ & ${ }^{133} \mathrm{Ba}$ & ${ }^{37} \mathrm{Cs}$ & ${ }^{152} \mathrm{Eu}$ & ${ }^{152} \mathrm{Eu}$ & ${ }^{152} \mathrm{Eu}$ & ${ }^{152} \mathrm{Eu}$ & ${ }^{152} \mathrm{Eu}$ & ${ }^{60} \mathrm{Co}$ & ${ }^{60} \mathrm{Co}$ & ${ }^{152} \mathrm{Eu}$ \\
\hline & 80,99 & 121,78 & 244,69 & 276,39 & 302,85 & 344,28 & 356,01 & 383,85 & 661,66 & 778,9 & 867,39 & 964,05 & 1085,84 & 1112,08 & 1173,24 & 1332,5 & 1408,02 \\
\hline Amostra & \multicolumn{17}{|c|}{ Fator de autoatenuação } \\
\hline FEV10 & $1,58 \pm 0,02$ & $1,26 \pm 0,01$ & $1,18 \pm 0,01$ & $1,30 \pm 0,02$ & $1,29 \pm 0,01$ & $1,16 \pm 0,01$ & $1,26 \pm 0,01$ & $1,26 \pm 0,01$ & $1,134 \pm 0,003$ & $1,12 \pm 0,01$ & $1,11 \pm 0,03$ & $1,09 \pm 0,01$ & $1,10 \pm 0,01$ & $1,10 \pm 0,01$ & $1,10 \pm 0,01$ & $1,08 \pm 0,01$ & $1,09 \pm 0,01$ \\
\hline MAR10 & $1,44 \pm 0,02$ & $1,37 \pm 0,01$ & $1,30 \pm 0,02$ & $1,18 \pm 0,03$ & $1,18 \pm 0,02$ & $1,24 \pm 0,01$ & $1,17 \pm 0,01$ & $1,20 \pm 0,03$ & $1,094 \pm 0,002$ & $1,16 \pm 0,01$ & $1,14 \pm 0,03$ & $1,14 \pm 0,01$ & $1,13 \pm 0,01$ & $1,12 \pm 0,01$ & $1,06 \pm 0,01$ & $1,07 \pm 0,01$ & $1,11 \pm 0,01$ \\
\hline MAI04 & $1,55 \pm 0,02$ & $1,44 \pm 0,01$ & $1,31 \pm 0,02$ & $1,21 \pm 0,04$ & $1,24 \pm 0,02$ & $1,28 \pm 0,01$ & $1,21 \pm 0,01$ & $1,22 \pm 0,03$ & $1,104 \pm 0,003$ & $1,17 \pm 0,01$ & $1,14 \pm 0,03$ & $1,14 \pm 0,01$ & $1,15 \pm 0,01$ & $1,14 \pm 0,01$ & $1,08 \pm 0,01$ & $1,06 \pm 0,01$ & $1,12 \pm 0,01$ \\
\hline MAI09 & $1,58 \pm 0,02$ & $1,50 \pm 0,01$ & $1,39 \pm 0,02$ & $1,24 \pm 0,04$ & $1,24 \pm 0,02$ & $1,31 \pm 0,01$ & $1,21 \pm 0,01$ & $1,21 \pm 0,03$ & $1,108 \pm 0,003$ & $1,18 \pm 0,01$ & $1,16 \pm 0,03$ & $1,16 \pm 0,01$ & $1,16 \pm 0,01$ & $1,16 \pm 0,01$ & $1,07 \pm 0,01$ & $1,07 \pm 0,01$ & $1,14 \pm 0,01$ \\
\hline AGO03 & $1,37 \pm 0,02$ & $1,31 \pm 0,01$ & $1,25 \pm 0,01$ & $1,17 \pm 0,04$ & $1,20 \pm 0,02$ & $1,20 \pm 0,01$ & $1,18 \pm 0,01$ & $1,18 \pm 0,03$ & $1,094 \pm 0,002$ & $1,14 \pm 0,01$ & $1,12 \pm 0,03$ & $1,13 \pm 0,01$ & $1,12 \pm 0,011$ & $1,12 \pm 0,01$ & $1,07 \pm 0,01$ & $1,06 \pm 0,01$ & $1,11 \pm 0,01$ \\
\hline AGO09 & $1,43 \pm 0,02$ & $1,34 \pm 0,01$ & $1,25 \pm 0,02$ & $1,17 \pm 0,04$ & $1,21 \pm 0,02$ & $1,21 \pm 0,01$ & $1,19 \pm 0,01$ & $1,19 \pm 0,03$ & $1,097 \pm 0,002$ & $1,14 \pm 0,01$ & $1,13 \pm 0,03$ & $1,12 \pm 0,01$ & $1,11 \pm 0,01$ & $1,12 \pm 0,01$ & $1,08 \pm 0,01$ & $1,08 \pm 0,01$ & $1,14 \pm 0,01$ \\
\hline SET05 & $1,71 \pm 0,03$ & $1,48 \pm 0,01$ & $1,35 \pm 0,03$ & $1,32 \pm 0,04$ & $1,25 \pm 0,02$ & $1,23 \pm 0,01$ & $1,22 \pm 0,01$ & $1,24 \pm 0,04$ & $1,081 \pm 0,002$ & $1,14 \pm 0,01$ & $1,06 \pm 0,03$ & $1,13 \pm 0,01$ & $1,12 \pm 0,01$ & $1,12 \pm 0,01$ & $1,10 \pm 0,01$ & $1,09 \pm 0,01$ & $1,10 \pm 0,01$ \\
\hline OUT08 & $1,56 \pm 0,02$ & $1,19 \pm 0,01$ & $1,15 \pm 0,02$ & $1,30 \pm 0,04$ & $1,20 \pm 0,02$ & $1,11 \pm 0,01$ & $1,18 \pm 0,01$ & $1,24 \pm 0,03$ & $1,093 \pm 0,003$ & $1,10 \pm 0,01$ & $1,11 \pm 0,03$ & $1,09 \pm 0,01$ & $1,12 \pm 0,01$ & $1,12 \pm 0,01$ & $1,08 \pm 0,01$ & $1,09 \pm 0,01$ & $1,08 \pm 0,01$ \\
\hline DEZ08 & $1,37 \pm 0,06$ & $1,35 \pm 0,03$ & $1,30 \pm 0,06$ & $1,21 \pm 0,10$ & $1,19 \pm 0,05$ & $1,22 \pm 0,02$ & $1,11 \pm 0,02$ & $1,14 \pm 0,08$ & $1,14 \pm 0,01$ & $1,14 \pm 0,02$ & $1,10 \pm 0,04$ & $1,11 \pm 0,01$ & $1,12 \pm 0,02$ & $1,15 \pm 0,01$ & $1,14 \pm 0,04$ & $1,14 \pm 0,04$ & $1,11 \pm 0,01$ \\
\hline DEZ11 & $1,40 \pm 0,03$ & $1,28 \pm 0,02$ & $1,21 \pm 0,05$ & $1,19 \pm 0,05$ & $1,19 \pm 0,02$ & $1,18 \pm 0,02$ & $1,11 \pm 0,01$ & $1,18 \pm 0,04$ & $1,177 \pm 0,003$ & $1,15 \pm 0,02$ & $1,14 \pm 0,04$ & $1,12 \pm 0,01$ & $1,11 \pm 0,02$ & $1,13 \pm 0,01$ & $1,11 \pm 0,02$ & $1,09 \pm 0,02$ & $1,10 \pm 0,01$ \\
\hline
\end{tabular}


Fatores de autoatenuação para as amostras de densidade $1,68 \mathrm{~g} . \mathrm{cm}^{-3}$

\begin{tabular}{|c|c|c|c|c|c|c|c|c|c|c|c|c|c|c|c|c|c|}
\hline & \multicolumn{17}{|c|}{ Energia (keV) } \\
\hline & ${ }^{133} \mathrm{Ba}$ & ${ }^{152} \mathrm{Eu}$ & ${ }^{152} \mathrm{Eu}$ & ${ }^{133} \mathrm{Ba}$ & ${ }^{133} \mathrm{Ba}$ & ${ }^{152} \mathrm{Eu}$ & ${ }^{133} \mathrm{Ba}$ & ${ }^{133} \mathrm{Ba}$ & ${ }^{37} \mathrm{Cs}$ & ${ }^{152} \mathrm{Eu}$ & ${ }^{152} \mathrm{Eu}$ & ${ }^{152} \mathrm{Eu}$ & ${ }^{152} \mathrm{Eu}$ & ${ }^{152} \mathrm{Eu}$ & ${ }^{60} \mathrm{Co}$ & ${ }^{60} \mathrm{Co}$ & ${ }^{152} \mathrm{Eu}$ \\
\hline & 80,99 & 121,78 & 244,69 & 276,39 & 302,85 & 344,28 & 356,01 & 383,85 & 661,66 & 778,9 & 867,39 & 964,05 & 1085,84 & 1112,08 & 1173,24 & 1332,5 & 1408,02 \\
\hline Amostra & \multicolumn{17}{|c|}{ Fator de autoatenuação } \\
\hline JAN06 & $1,44 \pm 0,02$ & $1,38 \pm 0,01$ & $1,28 \pm 0,02$ & $1,20 \pm 0,04$ & $1,20 \pm 0,02$ & $1,24 \pm 0,01$ & $1,10 \pm 0,01$ & $1,16 \pm 0,04$ & $1,132 \pm 0,003$ & $1,14 \pm 0,01$ & $1,12 \pm 0,03$ & $1,11 \pm 0,01$ & $1,10 \pm 0,01$ & $1,11 \pm 0,01$ & $1,15 \pm 0,02$ & $1,14 \pm 0,02$ & $1,12 \pm 0,01$ \\
\hline FEV11 & $1,58 \pm 0,02$ & $1,30 \pm 0,01$ & $1,23 \pm 0,01$ & $1,31 \pm 0,02$ & $1,30 \pm 0,01$ & $1,19 \pm 0,01$ & $1,27 \pm 0,01$ & $1,26 \pm 0,02$ & $1,135 \pm 0,003$ & $1,13 \pm 0,01$ & $1,10 \pm 0,03$ & $1,11 \pm 0,01$ & $1,11 \pm 0,01$ & $1,12 \pm 0,01$ & $1,08 \pm 0,01$ & $1,08 \pm 0,01$ & $1,13 \pm 0,01$ \\
\hline MAR03 & $1,66 \pm 0,02$ & $1,38 \pm 0,01$ & $1,32 \pm 0,02$ & $1,28 \pm 0,04$ & $1,26 \pm 0,02$ & $1,26 \pm 0,01$ & $1,22 \pm 0,01$ & $1,20 \pm 0,03$ & $1,156 \pm 0,003$ & $1,18 \pm 0,01$ & $1,13 \pm 0,03$ & $1,15 \pm 0,01$ & $1,14 \pm 0,01$ & $1,14 \pm 0,01$ & $1,09 \pm 0,01$ & $1,09 \pm 0,01$ & $1,12 \pm 0,01$ \\
\hline MAR04 & $1,53 \pm 0,02$ & $1,40 \pm 0,01$ & $1,31 \pm 0,02$ & $1,21 \pm 0,04$ & $1,23 \pm 0,02$ & $1,28 \pm 0,01$ & $1,19 \pm 0,01$ & $1,22 \pm 0,03$ & $1,144 \pm 0,003$ & $1,18 \pm 0,01$ & $1,15 \pm 0,03$ & $1,15 \pm 0,01$ & $1,14 \pm 0,01$ & $1,14 \pm 0,01$ & $1,07 \pm 0,01$ & $1,07 \pm 0,01$ & $1,14 \pm 0,01$ \\
\hline MAR09 & $1,43 \pm 0,02$ & $1,40 \pm 0,01$ & $1,29 \pm 0,02$ & $1,20 \pm 0,04$ & $1,21 \pm 0,02$ & $1,26 \pm 0,01$ & $1,17 \pm 0,01$ & $1,19 \pm 0,03$ & $1,102 \pm 0,002$ & $1,17 \pm 0,01$ & $1,16 \pm 0,03$ & $1,16 \pm 0,01$ & $1,15 \pm 0,01$ & $1,14 \pm 0,01$ & $1,07 \pm 0,01$ & $1,07 \pm 0,01$ & $1,13 \pm 0,01$ \\
\hline ABR10 & $1,56 \pm 0,02$ & $1,54 \pm 0,01$ & $1,41 \pm 0,02$ & $1,28 \pm 0,04$ & $1,27 \pm 0,02$ & $1,35 \pm 0,01$ & $1,23 \pm 0,01$ & $1,24 \pm 0,03$ & $1,104 \pm 0,003$ & $1,20 \pm 0,01$ & $1,19 \pm 0,03$ & $1,18 \pm 0,01$ & $1,17 \pm 0,01$ & $1,16 \pm 0,01$ & $1,06 \pm 0,01$ & $1,07 \pm 0,01$ & $1,15 \pm 0,01$ \\
\hline MAI01 & $1,33 \pm 0,02$ & $1,45 \pm 0,01$ & $1,34 \pm 0,02$ & $1,11 \pm 0,03$ & $1,13 \pm 0,01$ & $1,28 \pm 0,01$ & $1,12 \pm 0,01$ & $1,11 \pm 0,03$ & $1,111 \pm 0,003$ & $1,17 \pm 0,01$ & $1,12 \pm 0,03$ & $1,15 \pm 0,01$ & $1,14 \pm 0,01$ & $1,14 \pm 0,01$ & $1,05 \pm 0,01$ & $1,05 \pm 0,01$ & $1,14 \pm 0,01$ \\
\hline MAI10 & $1,55 \pm 0,02$ & $1,47 \pm 0,01$ & $1,39 \pm 0,02$ & $1,24 \pm 0,04$ & $1,24 \pm 0,02$ & $1,32 \pm 0,01$ & $1,21 \pm 0,01$ & $1,22 \pm 0,03$ & $1,107 \pm 0,003$ & $1,18 \pm 0,01$ & $1,15 \pm 0,03$ & $1,16 \pm 0,01$ & $1,15 \pm 0,01$ & $1,15 \pm 0,01$ & $1,08 \pm 0,01$ & $1,07 \pm 0,01$ & $1,13 \pm 0,01$ \\
\hline JUL11 & $1,38 \pm 0,02$ & $1,29 \pm 0,01$ & $1,24 \pm 0,02$ & $1,20 \pm 0,04$ & $1,21 \pm 0,02$ & $1,20 \pm 0,01$ & $1,18 \pm 0,01$ & $1,18 \pm 0,03$ & $1,113 \pm 0,003$ & $1,15 \pm 0,01$ & $1,08 \pm 0,03$ & $1,12 \pm 0,01$ & $1,13 \pm 0,01$ & $1,12 \pm 0,01$ & $1,05 \pm 0,01$ & $1,07 \pm 0,01$ & $1,14 \pm 0,01$ \\
\hline SET06 & $1,42 \pm 0,02$ & $1,35 \pm 0,01$ & $1,34 \pm 0,03$ & $1,19 \pm 0,04$ & $1,19 \pm 0,02$ & $1,16 \pm 0,01$ & $1,17 \pm 0,01$ & $1,19 \pm 0,03$ & $1,103 \pm 0,003$ & $1,11 \pm 0,01$ & $1,09 \pm 0,03$ & $1,11 \pm 0,01$ & $1,10 \pm 0,01$ & $1,14 \pm 0,01$ & $1,08 \pm 0,01$ & $1,08 \pm 0,01$ & $1,09 \pm 0,01$ \\
\hline SET10 & $1,48 \pm 0,02$ & $1,42 \pm 0,01$ & $1,37 \pm 0,03$ & $1,25 \pm 0,04$ & $1,20 \pm 0,02$ & $1,19 \pm 0,01$ & $1,17 \pm 0,01$ & $1,21 \pm 0,03$ & $1,095 \pm 0,003$ & $1,13 \pm 0,01$ & $1,12 \pm 0,03$ & $1,11 \pm 0,01$ & $1,15 \pm 0,01$ & $1,16 \pm 0,01$ & $1,15 \pm 0,02$ & $1,10 \pm 0,01$ & $1,10 \pm 0,01$ \\
\hline OUT10 & $1,52 \pm 0,02$ & $1,29 \pm 0,01$ & $1,22 \pm 0,02$ & $1,18 \pm 0,04$ & $1,19 \pm 0,02$ & $1,13 \pm 0,01$ & $1,16 \pm 0,01$ & $1,15 \pm 0,03$ & $1,075 \pm 0,002$ & $1,12 \pm 0,01$ & $1,06 \pm 0,03$ & $1,11 \pm 0,01$ & $1,11 \pm 0,01$ & $1,10 \pm 0,01$ & $1,11 \pm 0,01$ & $1,06 \pm 0,01$ & $1,09 \pm 0,01$ \\
\hline DEZ06 & $1,37 \pm 0,03$ & $1,43 \pm 0,03$ & $1,41 \pm 0,07$ & $1,23 \pm 0,05$ & $1,18 \pm 0,02$ & $1,29 \pm 0,02$ & $1,11 \pm 0,01$ & $1,15 \pm 0,03$ & $1,174 \pm 0,003$ & $1,16 \pm 0,02$ & $1,20 \pm 0,04$ & $1,13 \pm 0,01$ & $1,13 \pm 0,02$ & $1,13 \pm 0,01$ & $1,11 \pm 0,02$ & $1,11 \pm 0,02$ & $1,11 \pm 0,01$ \\
\hline
\end{tabular}


Fatores de autoatenuação para as amostras de densidade 1,69 g.cm ${ }^{-3}$

\begin{tabular}{|c|c|c|c|c|c|c|c|c|c|c|c|c|c|c|c|c|c|}
\hline & \multicolumn{17}{|c|}{ Energia $(\mathrm{keV})$} \\
\hline & ${ }^{133} \mathrm{Ba}$ & ${ }^{152} \mathrm{Eu}$ & ${ }^{152} \mathrm{Eu}$ & ${ }^{133} \mathrm{Ba}$ & ${ }^{133} \mathrm{Ba}$ & ${ }^{152} \mathrm{Eu}$ & ${ }^{133} \mathrm{Ba}$ & ${ }^{133} \mathrm{Ba}$ & ${ }^{37} \mathrm{Cs}$ & ${ }^{152} \mathrm{Eu}$ & ${ }^{152} \mathrm{Eu}$ & ${ }^{152} \mathrm{Eu}$ & ${ }^{152} \mathrm{Eu}$ & ${ }^{152} \mathrm{Eu}$ & ${ }^{60} \mathrm{Co}$ & ${ }^{60} \mathrm{Co}$ & ${ }^{152} \mathrm{Eu}$ \\
\hline & 80,99 & 121,78 & 244,69 & 276,39 & 302,85 & 344,28 & 356,01 & 383,85 & 661,66 & 778,9 & 867,39 & 964,05 & 1085,84 & 1112,08 & 1173,24 & 1332,5 & 1408,02 \\
\hline Amostra & \multicolumn{17}{|c|}{ Fator de autoatenuação } \\
\hline FEV06 & $1,52 \pm 0,02$ & $1,81 \pm 0,01$ & $1,60 \pm 0,03$ & $1,24 \pm 0,02$ & $1,24 \pm 0,01$ & $1,49 \pm 0,01$ & $1,22 \pm 0,01$ & $1,22 \pm 0,01$ & $1,131 \pm 0,003$ & $1,24 \pm 0,01$ & $1,21 \pm 0,03$ & $1,22 \pm 0,01$ & $1,19 \pm 0,01$ & $1,19 \pm 0,01$ & $1,10 \pm 0,01$ & $1,09 \pm 0,01$ & $1,17 \pm 0,01$ \\
\hline ABR08 & $1,49 \pm 0,02$ & $1,48 \pm 0,01$ & $1,38 \pm 0,02$ & $1,29 \pm 0,04$ & $1,27 \pm 0,02$ & $1,33 \pm 0,01$ & $1,24 \pm 0,01$ & $1,27 \pm 0,03$ & $1,110 \pm 0,003$ & $1,18 \pm 0,01$ & $1,16 \pm 0,03$ & $1,17 \pm 0,01$ & $1,16 \pm 0,01$ & $1,14 \pm 0,01$ & $1,07 \pm 0,01$ & $1,07 \pm 0,01$ & $1,14 \pm 0,01$ \\
\hline ABR11 & $1,53 \pm 0,02$ & $1,67 \pm 0,01$ & $1,53 \pm 0,02$ & $1,27 \pm 0,04$ & $1,26 \pm 0,02$ & $1,42 \pm 0,01$ & $1,22 \pm 0,01$ & $1,22 \pm 0,03$ & $1,105 \pm 0,003$ & $1,23 \pm 0,02$ & $1,20 \pm 0,03$ & $1,20 \pm 0,03$ & $1,19 \pm 0,01$ & $1,18 \pm 0,01$ & $1,05 \pm 0,01$ & $1,06 \pm 0,01$ & $1,17 \pm 0,01$ \\
\hline JUN10 & $1,51 \pm 0,02$ & $1,34 \pm 0,01$ & $1,23 \pm 0,02$ & $1,25 \pm 0,04$ & $1,23 \pm 0,02$ & $1,21 \pm 0,01$ & $1,20 \pm 0,01$ & $1,19 \pm 0,03$ & $1,112 \pm 0,003$ & $1,14 \pm 0,01$ & $1,11 \pm 0,03$ & $1,13 \pm 0,01$ & $1,12 \pm 0,01$ & $1,13 \pm 0,01$ & $1,08 \pm 0,01$ & $1,06 \pm 0,01$ & $1,12 \pm 0,01$ \\
\hline JUN11 & $1,52 \pm 0,02$ & $1,37 \pm 0,01$ & $1,27 \pm 0,03$ & $1,26 \pm 0,04$ & $1,25 \pm 0,02$ & $1,23 \pm 0,01$ & $1,20 \pm 0,01$ & $1,22 \pm 0,03$ & $1,115 \pm 0,003$ & $1,15 \pm 0,02$ & $1,12 \pm 0,05$ & $1,15 \pm 0,02$ & $1,13 \pm 0,02$ & $1,13 \pm 0,02$ & $1,08 \pm 0,01$ & $1,08 \pm 0,01$ & $1,12 \pm 0,01$ \\
\hline JUL06 & $1,40 \pm 0,02$ & $1,43 \pm 0,01$ & $1,35 \pm 0,02$ & $1,20 \pm 0,04$ & $1,21 \pm 0,02$ & $1,29 \pm 0,01$ & $1,19 \pm 0,01$ & $1,16 \pm 0,03$ & $1,123 \pm 0,003$ & $1,18 \pm 0,01$ & $1,14 \pm 0,03$ & $1,17 \pm 0,01$ & $1,15 \pm 0,01$ & $1,17 \pm 0,01$ & $1,08 \pm 0,01$ & $1,07 \pm 0,01$ & $1,15 \pm 0,01$ \\
\hline DEZ07 & $1,37 \pm 0,02$ & $1,42 \pm 0,03$ & $1,30 \pm 0,06$ & $1,25 \pm 0,05$ & $1,19 \pm 0,02$ & $1,26 \pm 0,02$ & $1,11 \pm 0,01$ & $1,08 \pm 0,03$ & $1,174 \pm 0,003$ & $1,16 \pm 0,02$ & $1,26 \pm 0,05$ & $1,13 \pm 0,01$ & $1,15 \pm 0,02$ & $1,13 \pm 0,01$ & $1,11 \pm 0,02$ & $1,08 \pm 0,02$ & $1,09 \pm 0,01$ \\
\hline
\end{tabular}


Fatores de autoatenuação para as amostras de densidade 1,70 g.cm ${ }^{-3}$

\begin{tabular}{|c|c|c|c|c|c|c|c|c|c|c|c|c|c|c|c|c|c|}
\hline & \multicolumn{17}{|c|}{ Energia $(\mathrm{keV})$} \\
\hline & ${ }^{133} \mathrm{Ba}$ & ${ }^{152} \mathrm{Eu}$ & ${ }^{152} \mathrm{Eu}$ & ${ }^{133} \mathrm{Ba}$ & ${ }^{133} \mathrm{Ba}$ & ${ }^{152} \mathrm{Eu}$ & ${ }^{133} \mathrm{Ba}$ & ${ }^{133} \mathrm{Ba}$ & ${ }^{37} \mathrm{Cs}$ & ${ }^{152} \mathrm{Eu}$ & ${ }^{152} \mathrm{Eu}$ & ${ }^{152} \mathrm{Eu}$ & ${ }^{152} \mathrm{Eu}$ & ${ }^{152} \mathrm{Eu}$ & ${ }^{60} \mathrm{Co}$ & ${ }^{60} \mathrm{Co}$ & ${ }^{152} \mathrm{Eu}$ \\
\hline & 80,99 & 121,78 & 244,69 & 276,39 & 302,85 & 344,28 & 356,01 & 383,85 & 661,66 & 778,9 & 867,39 & 964,05 & 1085,84 & 1112,08 & 1173,24 & 1332,5 & 1408,02 \\
\hline Amostra & \multicolumn{17}{|c|}{ Fator de autoatenuação } \\
\hline JAN08 & $1,46 \pm 0,02$ & $1,41 \pm 0,01$ & $1,25 \pm 0,02$ & $1,23 \pm 0,05$ & $1,22 \pm 0,02$ & $1,25 \pm 0,01$ & $1,12 \pm 0,01$ & $1,21 \pm 0,04$ & $1,154 \pm 0,003$ & $1,16 \pm 0,01$ & $1,11 \pm 0,03$ & $1,13 \pm 0,01$ & $1,12 \pm 0,01$ & $1,11 \pm 0,01$ & $1,15 \pm 0,02$ & $1,16 \pm 0,02$ & $1,14 \pm 0,01$ \\
\hline MAR07 & $1,52 \pm 0,02$ & $1,40 \pm 0,01$ & $1,32 \pm 0,02$ & $1,22 \pm 0,04$ & $1,24 \pm 0,02$ & $1,28 \pm 0,01$ & $1,21 \pm 0,01$ & $1,21 \pm 0,03$ & $1,151 \pm 0,003$ & $1,17 \pm 0,01$ & $1,13 \pm 0,03$ & $1,16 \pm 0,01$ & $1,15 \pm 0,01$ & $1,15 \pm 0,01$ & $1,08 \pm 0,01$ & $1,08 \pm 0,01$ & $1,12 \pm 0,01$ \\
\hline JUN04 & $1,48 \pm 0,02$ & $1,60 \pm 0,01$ & $1,48 \pm 0,02$ & $1,26 \pm 0,04$ & $1,24 \pm 0,02$ & $1,38 \pm 0,01$ & $1,22 \pm 0,01$ & $1,21 \pm 0,03$ & $1,115 \pm 0,003$ & $1,21 \pm 0,01$ & $1,17 \pm 0,03$ & $1,18 \pm 0,01$ & $1,17 \pm 0,01$ & $1,18 \pm 0,01$ & $1,08 \pm 0,01$ & $1,11 \pm 0,02$ & $1,16 \pm 0,01$ \\
\hline JUL03 & $1,40 \pm 0,02$ & $1,53 \pm 0,01$ & $1,35 \pm 0,02$ & $1,21 \pm 0,04$ & $1,21 \pm 0,02$ & $1,32 \pm 0,01$ & $1,18 \pm 0,01$ & $1,19 \pm 0,03$ & $1,120 \pm 0,003$ & $1,20 \pm 0,01$ & $1,16 \pm 0,03$ & $1,17 \pm 0,01$ & $1,17 \pm 0,01$ & $1,15 \pm 0,01$ & $1,07 \pm 0,01$ & $1,07 \pm 0,01$ & $1,15 \pm 0,01$ \\
\hline JUL04 & $1,38 \pm 0,02$ & $1,45 \pm 0,01$ & $1,34 \pm 0,02$ & $1,18 \pm 0,04$ & $1,20 \pm 0,02$ & $1,29 \pm 0,01$ & $1,18 \pm 0,01$ & $1,20 \pm 0,03$ & $1,115 \pm 0,003$ & $1,18 \pm 0,02$ & $1,14 \pm 0,03$ & $1,15 \pm 0,01$ & $1,15 \pm 0,01$ & $1,14 \pm 0,01$ & $1,07 \pm 0,01$ & $1,07 \pm 0,01$ & $1,13 \pm 0,01$ \\
\hline JUL08 & $1,37 \pm 0,02$ & $1,42 \pm 0,01$ & $1,35 \pm 0,02$ & $1,18 \pm 0,04$ & $1,19 \pm 0,02$ & $1,28 \pm 0,01$ & $1,17 \pm 0,01$ & $1,17 \pm 0,03$ & $1,111 \pm 0,003$ & $1,18 \pm 0,01$ & $1,14 \pm 0,03$ & $1,15 \pm 0,01$ & $1,14 \pm 0,01$ & $1,15 \pm 0,01$ & $1,07 \pm 0,01$ & $1,07 \pm 0,01$ & $1,14 \pm 0,01$ \\
\hline DEZ05 & $1,56 \pm 0,03$ & $1,57 \pm 0,04$ & $1,43 \pm 0,07$ & $1,24 \pm 0,05$ & $1,20 \pm 0,02$ & $1,33 \pm 0,02$ & $1,12 \pm 0,01$ & $1,15 \pm 0,04$ & $1,143 \pm 0,003$ & $1,18 \pm 0,02$ & $1,20 \pm 0,04$ & $1,14 \pm 0,01$ & $1,15 \pm 0,02$ & $1,18 \pm 0,02$ & $1,11 \pm 0,02$ & $1,10 \pm 0,02$ & $1,12 \pm 0,01$ \\
\hline
\end{tabular}


Fatores de autoatenuação para as amostras de densidade 1,71 g.cm ${ }^{-3}$

\begin{tabular}{|c|c|c|c|c|c|c|c|c|c|c|c|c|c|c|c|c|c|}
\hline & \multicolumn{17}{|c|}{ Energia (keV) } \\
\hline & ${ }^{133} \mathrm{Ba}$ & ${ }^{152} \mathrm{Eu}$ & ${ }^{152} \mathrm{Eu}$ & ${ }^{133} \mathrm{Ba}$ & ${ }^{133} \mathrm{Ba}$ & ${ }^{152} \mathrm{Eu}$ & ${ }^{133} \mathrm{Ba}$ & ${ }^{133} \mathrm{Ba}$ & ${ }^{37} \mathrm{Cs}$ & ${ }^{152} \mathrm{Eu}$ & ${ }^{152} \mathrm{Eu}$ & ${ }^{152} \mathrm{Eu}$ & ${ }^{152} \mathrm{Eu}$ & ${ }^{152} \mathrm{Eu}$ & ${ }^{60} \mathrm{Co}$ & ${ }^{60} \mathrm{Co}$ & ${ }^{152} \mathrm{Eu}$ \\
\hline & 80,99 & 121,78 & 244,69 & 276,39 & 302,85 & 344,28 & 356,01 & 383,85 & 661,66 & 778,9 & 867,39 & 964,05 & 1085,84 & 1112,08 & 1173,24 & 1332,5 & 1408,02 \\
\hline Amostra & \multicolumn{17}{|c|}{ Fator de autoatenuação } \\
\hline FEV03 & $1,56 \pm 0,02$ & $1,85 \pm 0,02$ & $1,64 \pm 0,03$ & $1,30 \pm 0,02$ & $1,30 \pm 0,01$ & $1,51 \pm 0,01$ & $1,27 \pm 0,01$ & $1,26 \pm 0,02$ & $1,134 \pm 0,003$ & $1,26 \pm 0,01$ & $1,23 \pm 0,03$ & $1,21 \pm 0,01$ & $1,21 \pm 0,01$ & $1,21 \pm 0,01$ & $1,11 \pm 0,01$ & $1,09 \pm 0,01$ & $1,21 \pm 0,01$ \\
\hline JUN09 & $1,63 \pm 0,03$ & $1,38 \pm 0,01$ & $1,29 \pm 0,02$ & $1,28 \pm 0,04$ & $1,26 \pm 0,02$ & $1,23 \pm 0,01$ & $1,22 \pm 0,01$ & $1,23 \pm 0,03$ & $1,124 \pm 0,003$ & $1,15 \pm 0,01$ & $1,12 \pm 0,03$ & $1,14 \pm 0,01$ & $1,13 \pm 0,01$ & $1,14 \pm 0,01$ & $1,06 \pm 0,01$ & $1,08 \pm 0,01$ & $1,12 \pm 0,01$ \\
\hline SET07 & $1,43 \pm 0,02$ & $1,41 \pm 0,01$ & $1,28 \pm 0,03$ & $1,27 \pm 0,05$ & $1,22 \pm 0,02$ & $1,20 \pm 0,01$ & $1,19 \pm 0,01$ & $1,23 \pm 0,03$ & $1,111 \pm 0,003$ & $1,13 \pm 0,01$ & $1,10 \pm 0,03$ & $1,12 \pm 0,01$ & $1,14 \pm 0,01$ & $1,13 \pm 0,01$ & $1,14 \pm 0,02$ & $1,09 \pm 0,01$ & $1,09 \pm 0,01$ \\
\hline NOV07 & $1,37 \pm 0,02$ & $1,29 \pm 0,01$ & $1,22 \pm 0,02$ & $1,11 \pm 0,04$ & $1,19 \pm 0,02$ & $1,19 \pm 0,01$ & $1,20 \pm 0,01$ & $1,22 \pm 0,04$ & $1,147 \pm 0,003$ & $1,14 \pm 0,01$ & $1,13 \pm 0,03$ & $1,12 \pm 0,01$ & $1,10 \pm 0,01$ & $1,10 \pm 0,01$ & $1,12 \pm 0,02$ & $1,10 \pm 0,01$ & $1,10 \pm 0,01$ \\
\hline NOV11 & $1,48 \pm 0,03$ & $1,29 \pm 0,01$ & $1,18 \pm 0,02$ & $1,23 \pm 0,05$ & $1,21 \pm 0,02$ & $1,19 \pm 0,01$ & $1,19 \pm 0,01$ & $1,18 \pm 0,04$ & $1,148 \pm 0,003$ & $1,15 \pm 0,02$ & $1,13 \pm 0,03$ & $1,12 \pm 0,01$ & $1,10 \pm 0,01$ & $1,10 \pm 0,01$ & $1,17 \pm 0,02$ & $1,13 \pm 0,02$ & $1,11 \pm 0,01$ \\
\hline
\end{tabular}


Fatores de autoatenuação para as amostras de densidade 1,72 g.cm ${ }^{-3}$

\begin{tabular}{|c|c|c|c|c|c|c|c|c|c|c|c|c|c|c|c|c|c|}
\hline & \multicolumn{17}{|c|}{ Energia $(\mathrm{keV})$} \\
\hline & ${ }^{133} \mathrm{Ba}$ & ${ }^{152} \mathrm{Eu}$ & ${ }^{152} \mathrm{Eu}$ & ${ }^{133} \mathrm{Ba}$ & ${ }^{133} \mathrm{Ba}$ & ${ }^{152} \mathrm{Eu}$ & ${ }^{133} \mathrm{Ba}$ & ${ }^{133} \mathrm{Ba}$ & ${ }^{37} \mathrm{Cs}$ & ${ }^{152} \mathrm{Eu}$ & ${ }^{152} \mathrm{Eu}$ & ${ }^{152} \mathrm{Eu}$ & ${ }^{152} \mathrm{Eu}$ & ${ }^{152} \mathrm{Eu}$ & ${ }^{60} \mathrm{Co}$ & ${ }^{60} \mathrm{Co}$ & ${ }^{152} \mathrm{Eu}$ \\
\hline & 80,99 & 121,78 & 244,69 & 276,39 & 302,85 & 344,28 & 356,01 & 383,85 & 661,66 & 778,9 & 867,39 & 964,05 & 1085,84 & 1112,08 & 1173,24 & 1332,5 & 1408,02 \\
\hline Amostra & \multicolumn{17}{|c|}{ Fator de autoatenuação } \\
\hline JAN07 & $1,39 \pm 0,02$ & $1,38 \pm 0,01$ & $1,29 \pm 0,02$ & $1,26 \pm 0,04$ & $1,20 \pm 0,02$ & $1,26 \pm 0,01$ & $1,10 \pm 0,01$ & $1,20 \pm 0,04$ & $1,135 \pm 0,003$ & $1,14 \pm 0,01$ & $1,14 \pm 0,03$ & $1,11 \pm 0,01$ & $1,11 \pm 0,01$ & $1,12 \pm 0,01$ & $1,16 \pm 0,01$ & $1,11 \pm 0,01$ & $1,12 \pm 0,01$ \\
\hline ABR09 & $1,66 \pm 0,01$ & $1,53 \pm 0,01$ & $1,40 \pm 0,02$ & $1,24 \pm 0,04$ & $1,26 \pm 0,02$ & $1,33 \pm 0,01$ & $1,23 \pm 0,01$ & $1,20 \pm 0,01$ & $1,107 \pm 0,003$ & $1,20 \pm 0,01$ & $1,18 \pm 0,03$ & $1,18 \pm 0,01$ & $1,17 \pm 0,01$ & $1,16 \pm 0,01$ & $1,06 \pm 0,01$ & $1,06 \pm 0,01$ & $1,16 \pm 0,01$ \\
\hline
\end{tabular}

Fatores de autoatenuação para as amostras de densidade 1,73 g.cm ${ }^{-3}$

\begin{tabular}{|c|c|c|c|c|c|c|c|c|c|c|c|c|c|c|c|c|c|}
\hline & \multicolumn{17}{|c|}{ Energia (keV) } \\
\hline & ${ }^{133} \mathrm{Ba}$ & ${ }^{152} \mathrm{Eu}$ & ${ }^{152} \mathrm{Eu}$ & ${ }^{133} \mathrm{Ba}$ & ${ }^{133} \mathrm{Ba}$ & ${ }^{152} \mathrm{Eu}$ & ${ }^{133} \mathrm{Ba}$ & ${ }^{133} \mathrm{Ba}$ & ${ }^{37} \mathrm{Cs}$ & ${ }^{152} \mathrm{Eu}$ & ${ }^{152} \mathrm{Eu}$ & ${ }^{152} \mathrm{Eu}$ & ${ }^{152} \mathrm{Eu}$ & ${ }^{152} \mathrm{Eu}$ & ${ }^{60} \mathrm{Co}$ & ${ }^{60} \mathrm{Co}$ & ${ }^{152} \mathrm{Eu}$ \\
\hline & 80,99 & 121,78 & 244,69 & 276,39 & 302,85 & 344,28 & 356,01 & 383,85 & 661,66 & 778,9 & 867,39 & 964,05 & 1085,84 & 1112,08 & 1173,24 & 1332,5 & 1408,02 \\
\hline Amostra & \multicolumn{17}{|c|}{ Fator de autoatenuação } \\
\hline MAR06 & $1,55 \pm 0,02$ & $1,41 \pm 0,01$ & $1,35 \pm 0,02$ & $1,24 \pm 0,04$ & $1,25 \pm 0,02$ & $1,28 \pm 0,01$ & $1,23 \pm 0,01$ & $1,21 \pm 0,03$ & $1162 \pm 0,003$ & $1,19 \pm 0,01$ & $1,14 \pm 0,03$ & $1,16 \pm 0,01$ & $1,16 \pm 0,01$ & $1,15 \pm 0,01$ & $1,10 \pm 0,01$ & $1,10 \pm 0,01$ & $1,14 \pm 0,01$ \\
\hline ABR05 & $1,63 \pm 0,03$ & $1,52 \pm 0,01$ & $1,40 \pm 0,02$ & $1,23 \pm 0,04$ & $1,25 \pm 0,02$ & $1,32 \pm 0,01$ & $1,22 \pm 0,01$ & $1,22 \pm 0,03$ & $1,103 \pm 0,002$ & $1,20 \pm 0,01$ & $1,16 \pm 0,03$ & $1,15 \pm 0,01$ & $1,15 \pm 0,01$ & $1,16 \pm 0,01$ & $1,06 \pm 0,01$ & $1,06 \pm 0,01$ & $1,14 \pm 0,01$ \\
\hline
\end{tabular}


Fatores de autoatenuação para as amostras de densidade 1,74 g.cm ${ }^{-3}$

\begin{tabular}{|c|c|c|c|c|c|c|c|c|c|c|c|c|c|c|c|c|c|}
\hline & \multicolumn{17}{|c|}{ Energia (keV) } \\
\hline & ${ }^{133} \mathrm{Ba}$ & ${ }^{152} \mathrm{Eu}$ & ${ }^{152} \mathrm{Eu}$ & ${ }^{133} \mathrm{Ba}$ & ${ }^{133} \mathrm{Ba}$ & ${ }^{152} \mathrm{Eu}$ & ${ }^{133} \mathrm{Ba}$ & ${ }^{133} \mathrm{Ba}$ & ${ }^{37} \mathrm{Cs}$ & ${ }^{152} \mathrm{Eu}$ & ${ }^{152} \mathrm{Eu}$ & ${ }^{152} \mathrm{Eu}$ & ${ }^{152} \mathrm{Eu}$ & ${ }^{152} \mathrm{Eu}$ & ${ }^{60} \mathrm{Co}$ & ${ }^{60} \mathrm{Co}$ & ${ }^{152} \mathrm{Eu}$ \\
\hline & 80,99 & 121,78 & 244,69 & 276,39 & 302,85 & 344,28 & 356,01 & 383,85 & 661,66 & 778,9 & 867,39 & 964,05 & 1085,84 & 1112,08 & 1173,24 & 1332,5 & 1408,02 \\
\hline Amostra & \multicolumn{17}{|c|}{ Fator de autoatenuação } \\
\hline JAN04 & $1,45 \pm 0,02$ & $1,40 \pm 0,01$ & $1,29 \pm 0,01$ & $1,16 \pm 0,04$ & $1,27 \pm 0,02$ & $1,25 \pm 0,01$ & $1,12 \pm 0,01$ & $1,16 \pm 0,04$ & $1,140 \pm 0,003$ & $1,14 \pm 0,01$ & $1,11 \pm 0,03$ & $1,13 \pm 0,01$ & $1,11 \pm 0,01$ & $1,12 \pm 0,01$ & $1,13 \pm 0,02$ & $1,14 \pm 0,02$ & $1,12 \pm 0,01$ \\
\hline JAN09 & $1,45 \pm 0,02$ & $1,43 \pm 0,01$ & $1,30 \pm 0,02$ & $1,23 \pm 0,05$ & $1,22 \pm 0,02$ & $1,26 \pm 0,01$ & $1,14 \pm 0,01$ & $1,15 \pm 0,01$ & $1,157 \pm 0,003$ & $1,16 \pm 0,01$ & $1,14 \pm 0,03$ & $1,14 \pm 0,01$ & $1,14 \pm 0,01$ & $1,12 \pm 0,01$ & $1,16 \pm 0,01$ & $1,16 \pm 0,01$ & $1,14 \pm 0,01$ \\
\hline FEV04 & $1,57 \pm 0,02$ & $1,74 \pm 0,01$ & $1,57 \pm 0,02$ & $1,25 \pm 0,02$ & $1,26 \pm 0,01$ & $1,45 \pm 0,01$ & $1,24 \pm 0,01$ & $1,24 \pm 0,02$ & $1,146 \pm 0,003$ & $1,24 \pm 0,01$ & $1,20 \pm 0,03$ & $1,20 \pm 0,01$ & $1,20 \pm 0,01$ & $1,19 \pm 0,01$ & $1,11 \pm 0,01$ & $1,09 \pm 0,01$ & $1,17 \pm 0,01$ \\
\hline
\end{tabular}


Fatores de autoatenuação para as amostras de densidade 1,75 g.cm ${ }^{-3}$

\begin{tabular}{|c|c|c|c|c|c|c|c|c|c|c|c|c|c|c|c|c|c|}
\hline & \multicolumn{17}{|c|}{ Energia (keV) } \\
\hline & ${ }^{133} \mathrm{Ba}$ & ${ }^{152} \mathrm{Eu}$ & ${ }^{152} \mathrm{Eu}$ & ${ }^{133} \mathrm{Ba}$ & ${ }^{133} \mathrm{Ba}$ & ${ }^{152} \mathrm{Eu}$ & ${ }^{133} \mathrm{Ba}$ & ${ }^{133} \mathrm{Ba}$ & ${ }^{37} \mathrm{Cs}$ & ${ }^{152} \mathrm{Eu}$ & ${ }^{152} \mathrm{Eu}$ & ${ }^{152} \mathrm{Eu}$ & ${ }^{152} \mathrm{Eu}$ & ${ }^{152} \mathrm{Eu}$ & ${ }^{60} \mathrm{Co}$ & ${ }^{60} \mathrm{Co}$ & ${ }^{152} \mathrm{Eu}$ \\
\hline & 80,99 & 121,78 & 244,69 & 276,39 & 302,85 & 344,28 & 356,01 & 383,85 & 661,66 & 778,9 & 867,39 & 964,05 & 1085,84 & 1112,08 & 1173,24 & 1332,5 & 1408,02 \\
\hline Amostra & \multicolumn{17}{|c|}{ Fator de autoatenuação } \\
\hline FEV05 & $1,63 \pm 0,02$ & $1,83 \pm 0,02$ & $1,64 \pm 0,03$ & $1,35 \pm 0,02$ & $1,34 \pm 0,01$ & $1,51 \pm 0,01$ & $1,30 \pm 0,01$ & $1,30 \pm 0,02$ & $1,145 \pm 0,003$ & $1,25 \pm 0,01$ & $1,23 \pm 0,01$ & $1,22 \pm 0,01$ & $1,04 \pm 0,01$ & $1,20 \pm 0,01$ & $1,15 \pm 0,01$ & $1,10 \pm 0,01$ & $1,20 \pm 0,01$ \\
\hline MAI08 & $1,62 \pm 0,03$ & $1,50 \pm 0,01$ & $1,39 \pm 0,02$ & $1,31 \pm 0,05$ & $1,28 \pm 0,02$ & $1,32 \pm 0,01$ & $1,25 \pm 0,01$ & $1,24 \pm 0,03$ & $1,134 \pm 0,003$ & $1,19 \pm 0,01$ & $1,20 \pm 0,03$ & $1,17 \pm 0,01$ & $1,17 \pm 0,01$ & $1,17 \pm 0,01$ & $1,09 \pm 0,01$ & $1,09 \pm 0,01$ & $1,15 \pm 0,01$ \\
\hline JUN03 & $1,59 \pm 0,03$ & $1,57 \pm 0,01$ & $1,44 \pm 0,02$ & $1,28 \pm 0,04$ & $1,26 \pm 0,02$ & $1,37 \pm 0,01$ & $1,22 \pm 0,01$ & $1,23 \pm 0,03$ & $1,120 \pm 0,003$ & $1,21 \pm 0,01$ & $1,17 \pm 0,01$ & $1,17 \pm 0,01$ & $1,17 \pm 0,01$ & $1,17 \pm 0,01$ & $1,08 \pm 0,01$ & $1,07 \pm 0,01$ & $1,15 \pm 0,01$ \\
\hline JUN08 & $1,56 \pm 0,02$ & $1,36 \pm 0,01$ & $1,29 \pm 0,02$ & $1,24 \pm 0,04$ & $1,26 \pm 0,02$ & $1,24 \pm 0,01$ & $1,23 \pm 0,01$ & $1,23 \pm 0,03$ & $1,130 \pm 0,003$ & $1,16 \pm 0,01$ & $1,12 \pm 0,03$ & $1,15 \pm 0,01$ & $1,15 \pm 0,01$ & $1,13 \pm 0,01$ & $1,08 \pm 0,01$ & $1,08 \pm 0,01$ & $1,12 \pm 0,01$ \\
\hline NOV06 & $1,44 \pm 0,02$ & $1,31 \pm 0,01$ & $1,21 \pm 0,02$ & $1,22 \pm 0,04$ & $1,26 \pm 0,02$ & $1,21 \pm 0,01$ & $1,20 \pm 0,01$ & $1,16 \pm 0,03$ & $1,195 \pm 0,003$ & $1,15 \pm 0,01$ & $1,12 \pm 0,03$ & $1,12 \pm 0,01$ & $1,10 \pm 0,01$ & $1,08 \pm 0,01$ & $1,16 \pm 0,02$ & $1,11 \pm 0,02$ & $1,11 \pm 0,01$ \\
\hline
\end{tabular}


Fatores de autoatenuação para as amostras de densidade 1,76 g.cm ${ }^{-3}$

\begin{tabular}{|c|c|c|c|c|c|c|c|c|c|c|c|c|c|c|c|c|c|}
\hline & \multicolumn{17}{|c|}{ Energia $(\mathrm{keV})$} \\
\hline & ${ }^{133} \mathrm{Ba}$ & ${ }^{152} \mathrm{Eu}$ & ${ }^{152} \mathrm{Eu}$ & ${ }^{133} \mathrm{Ba}$ & ${ }^{133} \mathrm{Ba}$ & ${ }^{152} \mathrm{Eu}$ & ${ }^{133} \mathrm{Ba}$ & ${ }^{133} \mathrm{Ba}$ & ${ }^{37} \mathrm{Cs}$ & ${ }^{152} \mathrm{Eu}$ & ${ }^{152} \mathrm{Eu}$ & ${ }^{152} \mathrm{Eu}$ & ${ }^{152} \mathrm{Eu}$ & ${ }^{152} \mathrm{Eu}$ & ${ }^{60} \mathrm{Co}$ & ${ }^{60} \mathrm{Co}$ & ${ }^{152} \mathrm{Eu}$ \\
\hline & 80,99 & 121,78 & 244,69 & 276,39 & 302,85 & 344,28 & 356,01 & 383,85 & 661,66 & 778,9 & 867,39 & 964,05 & 1085,84 & 1112,08 & 1173,24 & 1332,5 & 1408,02 \\
\hline Amostra & \multicolumn{17}{|c|}{ Fator de autoatenuação } \\
\hline JAN02 & $1,64 \pm 0,03$ & $1,47 \pm 0,01$ & $1,30 \pm 0,02$ & $1,23 \pm 0,05$ & $1,24 \pm 0,02$ & $1,27 \pm 0,01$ & $1,14 \pm 0,01$ & $1,19 \pm 0,04$ & $1,148 \pm 0,003$ & $1,15 \pm 0,01$ & $1,13 \pm 0,03$ & $1,13 \pm 0,01$ & $1,13 \pm 0,01$ & $1,13 \pm 0,01$ & $1,15 \pm 0,02$ & $1,12 \pm 0,02$ & $1,13 \pm 0,01$ \\
\hline JAN11 & $1,47 \pm 0,02$ & $1,42 \pm 0,01$ & $1,32 \pm 0,02$ & $1,21 \pm 0,05$ & $1,26 \pm 0,01$ & $1,27 \pm 0,01$ & $1,14 \pm 0,01$ & $1,21 \pm 0,04$ & $1,153 \pm 0,003$ & $1,15 \pm 0,01$ & $1,13 \pm 0,03$ & $1,13 \pm 0,01$ & $1,15 \pm 0,01$ & $1,12 \pm 0,01$ & $1,16 \pm 0,02$ & $1,16 \pm 0,02$ & $1,14 \pm 0,01$ \\
\hline MAI07 & $1,58 \pm 0,03$ & $1,49 \pm 0,01$ & $1,38 \pm 0,02$ & $1,30 \pm 0,04$ & $1,28 \pm 0,02$ & $1,31 \pm 0,01$ & $1,24 \pm 0,01$ & $1,22 \pm 0,03$ & $1,123 \pm 0,003$ & $1,19 \pm 0,01$ & $1,16 \pm 0,03$ & $1,17 \pm 0,01$ & $1,15 \pm 0,01$ & $1,16 \pm 0,01$ & $1,08 \pm 0,01$ & $1,07 \pm 0,01$ & $1,15 \pm 0,01$ \\
\hline JUL07 & $1,43 \pm 0,02$ & $1,45 \pm 0,01$ & $1,37 \pm 0,02$ & $1,26 \pm 0,04$ & $1,23 \pm 0,02$ & $1,30 \pm 0,01$ & $1,20 \pm 0,01$ & $1,22 \pm 0,03$ & $1,132 \pm 0,003$ & $1,19 \pm 0,01$ & $1,19 \pm 0,03$ & $1,17 \pm 0,01$ & $1,16 \pm 0,01$ & $1,16 \pm 0,01$ & $1,08 \pm 0,01$ & $1,09 \pm 0,01$ & $1,14 \pm 0,01$ \\
\hline JUL10 & $1,45 \pm 0,02$ & $1,34 \pm 0,01$ & $1,26 \pm 0,01$ & $1,24 \pm 0,04$ & $1,21 \pm 0,02$ & $1,22 \pm 0,01$ & $1,20 \pm 0,01$ & $1,18 \pm 0,03$ & $1,127 \pm 0,003$ & $1,16 \pm 0,01$ & $1,14 \pm 0,03$ & $1,13 \pm 0,01$ & $1,13 \pm 0,01$ & $1,12 \pm 0,01$ & $1,07 \pm 0,01$ & $1,07 \pm 0,01$ & $1,13 \pm 0,01$ \\
\hline SET08 & $1,39 \pm 0,02$ & $1,44 \pm 0,01$ & $1,31 \pm 0,03$ & $1,23 \pm 0,04$ & $1,21 \pm 0,02$ & $1,20 \pm 0,01$ & $1,20 \pm 0,01$ & $1,23 \pm 0,04$ & $1,119 \pm 0,003$ & $1,15 \pm 0,01$ & $1,13 \pm 0,03$ & $1,13 \pm 0,01$ & $1,12 \pm 0,01$ & $1,16 \pm 0,01$ & $1,14 \pm 0,02$ & $1,10 \pm 0,01$ & $1,10 \pm 0,01$ \\
\hline
\end{tabular}


Fatores de autoatenuação para as amostras de densidade 1,77 g.cm ${ }^{-3}$

\begin{tabular}{|c|c|c|c|c|c|c|c|c|c|c|c|c|c|c|c|c|c|}
\hline & \multicolumn{17}{|c|}{ Energia $(\mathrm{keV})$} \\
\hline & ${ }^{133} \mathrm{Ba}$ & ${ }^{152} \mathrm{Eu}$ & ${ }^{152} \mathrm{Eu}$ & ${ }^{133} \mathrm{Ba}$ & ${ }^{133} \mathrm{Ba}$ & ${ }^{152} \mathrm{Eu}$ & ${ }^{133} \mathrm{Ba}$ & ${ }^{133} \mathrm{Ba}$ & ${ }^{37} \mathrm{Cs}$ & ${ }^{152} \mathrm{Eu}$ & ${ }^{152} \mathrm{Eu}$ & ${ }^{152} \mathrm{Eu}$ & ${ }^{152} \mathrm{Eu}$ & ${ }^{152} \mathrm{Eu}$ & ${ }^{60} \mathrm{Co}$ & ${ }^{60} \mathrm{Co}$ & ${ }^{152} \mathrm{Eu}$ \\
\hline & 80,99 & 121,78 & 244,69 & 276,39 & 302,85 & 344,28 & 356,01 & 383,85 & 661,66 & 778,9 & 867,39 & 964,05 & 1085,84 & 1112,08 & 1173,24 & 1332,5 & 1408,02 \\
\hline Amostra & \multicolumn{17}{|c|}{ Fator de autoatenuação } \\
\hline ABR06 & $1,59 \pm 0,02$ & $1,52 \pm 0,01$ & $1,40 \pm 0,02$ & $1,31 \pm 0,04$ & $1,27 \pm 0,02$ & $1,34 \pm 0,01$ & $1,23 \pm 0,01$ & $1,23 \pm 0,03$ & $1,111 \pm 0,003$ & $1,20 \pm 0,01$ & $1,15 \pm 0,03$ & $1,18 \pm 0,01$ & $1,18 \pm 0,01$ & $1,16 \pm 0,01$ & $1,07 \pm 0,01$ & $1,06 \pm 0,01$ & $1,15 \pm 0,01$ \\
\hline ABR07 & $1,61 \pm 0,03$ & $1,56 \pm 0,01$ & $1,45 \pm 0,02$ & $1,29 \pm 0,04$ & $1,28 \pm 0,02$ & $1,36 \pm 0,01$ & $1,26 \pm 0,01$ & $1,24 \pm 0,03$ & $1,121 \pm 0,003$ & $1,22 \pm 0,01$ & $1,20 \pm 0,03$ & $1,19 \pm 0,01$ & $1,19 \pm 0,01$ & $1,17 \pm 0,01$ & $1,08 \pm 0,01$ & $1,07 \pm 0,01$ & $1,15 \pm 0,01$ \\
\hline MAI06 & $1,56 \pm 0,02$ & $1,47 \pm 0,01$ & $1,37 \pm 0,02$ & $1,25 \pm 0,04$ & $1,26 \pm 0,02$ & $1,31 \pm 0,01$ & $1,24 \pm 0,01$ & $1,24 \pm 0,03$ & $1,124 \pm 0,003$ & $1,19 \pm 0,01$ & $1,18 \pm 0,03$ & $1,16 \pm 0,01$ & $1,15 \pm 0,01$ & $1,15 \pm 0,01$ & $1,08 \pm 0,01$ & $1,08 \pm 0,01$ & $1,14 \pm 0,01$ \\
\hline JUN07 & $1,52 \pm 0,02$ & $1,34 \pm 0,01$ & $1,26 \pm 0,02$ & $1,23 \pm 0,04$ & $1,26 \pm 0,02$ & $1,20 \pm 0,01$ & $1,23 \pm 0,01$ & $1,22 \pm 0,03$ & $1,122 \pm 0,003$ & $1,16 \pm 0,01$ & $1,14 \pm 0,03$ & $1,14 \pm 0,01$ & $1,12 \pm 0,01$ & $1,12 \pm 0,01$ & $1,08 \pm 0,01$ & $1,08 \pm 0,01$ & $1,12 \pm 0,01$ \\
\hline
\end{tabular}


Fatores de autoatenuação para as amostras de densidade 1,78 g.cm ${ }^{-3}$

\begin{tabular}{|c|c|c|c|c|c|c|c|c|c|c|c|c|c|c|c|c|c|}
\hline & \multicolumn{17}{|c|}{ Energia $(\mathrm{keV})$} \\
\hline & ${ }^{133} \mathrm{Ba}$ & ${ }^{152} \mathrm{Eu}$ & ${ }^{152} \mathrm{Eu}$ & ${ }^{133} \mathrm{Ba}$ & ${ }^{133} \mathrm{Ba}$ & ${ }^{152} \mathrm{Eu}$ & ${ }^{133} \mathrm{Ba}$ & ${ }^{133} \mathrm{Ba}$ & ${ }^{37} \mathrm{Cs}$ & ${ }^{152} \mathrm{Eu}$ & ${ }^{152} \mathrm{Eu}$ & ${ }^{152} \mathrm{Eu}$ & ${ }^{152} \mathrm{Eu}$ & ${ }^{152} \mathrm{Eu}$ & ${ }^{60} \mathrm{Co}$ & ${ }^{60} \mathrm{Co}$ & ${ }^{152} \mathrm{Eu}$ \\
\hline & 80,99 & 121,78 & 244,69 & 276,39 & 302,85 & 344,28 & 356,01 & 383,85 & 661,66 & 778,9 & 867,39 & 964,05 & 1085,84 & 1112,08 & 1173,24 & 1332,5 & 1408,02 \\
\hline Amostra & \multicolumn{17}{|c|}{ Fator de autoatenuação } \\
\hline JUN06 & $1,52 \pm 0,02$ & $1,33 \pm 0,01$ & $1,27 \pm 0,02$ & $1,28 \pm 0,04$ & $1,25 \pm 0,02$ & $1,22 \pm 0,01$ & $1,23 \pm 0,01$ & $1,22 \pm 0,03$ & $1,125 \pm 0,003$ & $1,16 \pm 0,02$ & $1,15 \pm 0,04$ & $1,14 \pm 0,02$ & $1,13 \pm 0,02$ & $1,13 \pm 0,02$ & $1,09 \pm 0,01$ & $1,08 \pm 0,01$ & $1,12 \pm 0,01$ \\
\hline JUL02 & $1,49 \pm 0,02$ & $1,57 \pm 0,01$ & $1,40 \pm 0,02$ & $1,23 \pm 0,04$ & $1,25 \pm 0,02$ & $1,35 \pm 0,01$ & $1,22 \pm 0,01$ & $1,19 \pm 0,03$ & $1,117 \pm 0,003$ & $1,20 \pm 0,01$ & $1,15 \pm 0,03$ & $1,18 \pm 0,01$ & $1,18 \pm 0,01$ & $1,17 \pm 0,01$ & $1,09 \pm 0,01$ & $1,09 \pm 0,01$ & $1,16 \pm 0,01$ \\
\hline
\end{tabular}

Fatores de autoatenuação para as amostras de densidade 1,79 g.cm ${ }^{-3}$

\begin{tabular}{|c|c|c|c|c|c|c|c|c|c|c|c|c|c|c|c|c|c|}
\hline & \multicolumn{17}{|c|}{ Energia (keV) } \\
\hline & ${ }^{133} \mathrm{Ba}$ & ${ }^{152} \mathrm{Eu}$ & ${ }^{152} \mathrm{Eu}$ & ${ }^{133} \mathrm{Ba}$ & ${ }^{133} \mathrm{Ba}$ & ${ }^{152} \mathrm{Eu}$ & ${ }^{133} \mathrm{Ba}$ & ${ }^{133} \mathrm{Ba}$ & ${ }^{37} \mathrm{Cs}$ & ${ }^{152} \mathrm{Eu}$ & ${ }^{152} \mathrm{Eu}$ & ${ }^{152} \mathrm{Eu}$ & ${ }^{152} \mathrm{Eu}$ & ${ }^{152} \mathrm{Eu}$ & ${ }^{60} \mathrm{Co}$ & ${ }^{60} \mathrm{Co}$ & ${ }^{152} \mathrm{Eu}$ \\
\hline & 80,99 & 121,78 & 244,69 & 276,39 & 302,85 & 344,28 & 356,01 & 383,85 & 661,66 & 778,9 & 867,39 & 964,05 & 1085,84 & 1112,08 & 1173,24 & 1332,5 & 1408,02 \\
\hline Amostra & \multicolumn{17}{|c|}{ Fator de autoatenuação } \\
\hline JAN05 & $1,71 \pm 0,04$ & $1,46 \pm 0,01$ & $1,28 \pm 0,02$ & $1,17 \pm 0,04$ & $1,22 \pm 0,02$ & $1,27 \pm 0,01$ & $1,12 \pm 0,01$ & $1,18 \pm 0,04$ & $1,145 \pm 0,003$ & $1,16 \pm 0,01$ & $1,11 \pm 0,03$ & $1,12 \pm 0,01$ & $1,11 \pm 0,01$ & $1,12 \pm 0,01$ & $1,15 \pm 0,01$ & $1,12 \pm 0,02$ & $1,13 \pm 0,01$ \\
\hline ABR01 & $1,60 \pm 0,03$ & $1,55 \pm 0,01$ & $1,41 \pm 0,02$ & $1,29 \pm 0,04$ & $1,29 \pm 0,02$ & $1,35 \pm 0,01$ & $1,24 \pm 0,01$ & $1,25 \pm 0,03$ & $1,122 \pm 0,003$ & $1,21 \pm 0,01$ & $1,20 \pm 0,03$ & $1,18 \pm 0,01$ & $1,18 \pm 0,01$ & $1,17 \pm 0,01$ & $1,08 \pm 0,01$ & $1,07 \pm 0,01$ & $1,16 \pm 0,01$ \\
\hline
\end{tabular}


Fatores de autoatenuação para as amostras de densidade 1,81 g.cm ${ }^{-3}$

\begin{tabular}{|c|c|c|c|c|c|c|c|c|c|c|c|c|c|c|c|c|c|}
\hline & \multicolumn{17}{|c|}{ Energia (keV) } \\
\hline & ${ }^{133} \mathrm{Ba}$ & ${ }^{152} \mathrm{Eu}$ & ${ }^{152} \mathrm{Eu}$ & ${ }^{133} \mathrm{Ba}$ & ${ }^{133} \mathrm{Ba}$ & ${ }^{152} \mathrm{Eu}$ & ${ }^{133} \mathrm{Ba}$ & ${ }^{133} \mathrm{Ba}$ & ${ }^{37} \mathrm{Cs}$ & ${ }^{152} \mathrm{Eu}$ & ${ }^{152} \mathrm{Eu}$ & ${ }^{152} \mathrm{Eu}$ & ${ }^{152} \mathrm{Eu}$ & ${ }^{152} \mathrm{Eu}$ & ${ }^{60} \mathrm{Co}$ & ${ }^{60} \mathrm{Co}$ & ${ }^{152} \mathrm{Eu}$ \\
\hline & 80,99 & 121,78 & 244,69 & 276,39 & 302,85 & 344,28 & 356,01 & 383,85 & 661,66 & 778,9 & 867,39 & 964,05 & 1085,84 & 1112,08 & 1173,24 & 1332,5 & 1408,02 \\
\hline Amostra & \multicolumn{17}{|c|}{ Fator de autoatenuação } \\
\hline MAR11 & $1,64 \pm 0,03$ & $1,44 \pm 0,01$ & $1,31 \pm 0,02$ & $1,28 \pm 0,04$ & $1,25 \pm 0,04$ & $1,27 \pm 0,01$ & $1,23 \pm 0,01$ & $1,22 \pm 0,03$ & $1,166 \pm 0,003$ & $1,18 \pm 0,01$ & $1,14 \pm 0,03$ & $1,16 \pm 0,01$ & $1,15 \pm 0,01$ & $1,15 \pm 0,01$ & $1,10 \pm 0,01$ & $1,08 \pm 0,01$ & $1,13 \pm 0,01$ \\
\hline OUT05 & $2,46 \pm 0,25$ & $1,38 \pm 0,01$ & $1,25 \pm 0,02$ & $1,26 \pm 0,04$ & $1,23 \pm 0,02$ & $1,18 \pm 0,01$ & $1,20 \pm 0,01$ & $1,24 \pm 0,04$ & $1,105 \pm 0,003$ & $1,13 \pm 0,01$ & $1,10 \pm 0,03$ & $1,11 \pm 0,01$ & $1,12 \pm 0,01$ & $1,10 \pm 0,01$ & $1,14 \pm 0,01$ & $1,10 \pm 0,01$ & $1,09 \pm 0,01$ \\
\hline
\end{tabular}

TABELA . Fatores de autoatenuação para as amostras de densidade $1,82{\mathrm{~g} . \mathrm{cm}^{-3}}^{-3}$

\begin{tabular}{|c|c|c|c|c|c|c|c|c|c|c|c|c|c|c|c|c|c|}
\hline & \multicolumn{17}{|c|}{ Energia (keV) } \\
\hline & ${ }^{133} \mathrm{Ba}$ & ${ }^{152} \mathrm{Eu}$ & ${ }^{152} \mathrm{Eu}$ & ${ }^{133} \mathrm{Ba}$ & ${ }^{133} \mathrm{Ba}$ & ${ }^{152} \mathrm{Eu}$ & ${ }^{133} \mathrm{Ba}$ & ${ }^{133} \mathrm{Ba}$ & ${ }^{37} \mathrm{Cs}$ & ${ }^{152} \mathrm{Eu}$ & ${ }^{152} \mathrm{Eu}$ & ${ }^{152} \mathrm{Eu}$ & ${ }^{152} \mathrm{Eu}$ & ${ }^{152} \mathrm{Eu}$ & ${ }^{60} \mathrm{Co}$ & ${ }^{60} \mathrm{Co}$ & ${ }^{152} \mathrm{Eu}$ \\
\hline & 80,99 & 121,78 & 244,69 & 276,39 & 302,85 & 344,28 & 356,01 & 383,85 & 661,66 & 778,9 & 867,39 & 964,05 & 1085,84 & 1112,08 & 1173,24 & 1332,5 & 1408,02 \\
\hline Amostra & \multicolumn{17}{|c|}{ Fator de autoatenuação } \\
\hline MAR05 & $1,79 \pm 0,03$ & $1,50 \pm 0,02$ & $1,36 \pm 0,03$ & $1,27 \pm 0,04$ & $1,27 \pm 0,02$ & $1,31 \pm 0,02$ & $1,23 \pm 0,01$ & $1,22 \pm 0,03$ & $1,172 \pm 0,003$ & $1,20 \pm 0,02$ & $1,14 \pm 0,05$ & $1,16 \pm 0,02$ & $1,14 \pm 0,03$ & $1,16 \pm 0,02$ & $1,10 \pm 0,01$ & $1,09 \pm 0,01$ & $1,15 \pm 0,01$ \\
\hline
\end{tabular}


Fatores de autoatenuação para as amostras de densidade 1,83 g.cm $\mathrm{cm}^{-3}$

\begin{tabular}{|c|c|c|c|c|c|c|c|c|c|c|c|c|c|c|c|c|c|}
\hline & \multicolumn{17}{|c|}{ Energia $(\mathrm{keV})$} \\
\hline & ${ }^{133} \mathrm{Ba}$ & ${ }^{152} \mathrm{Eu}$ & ${ }^{152} \mathrm{Eu}$ & ${ }^{133} \mathrm{Ba}$ & ${ }^{133} \mathrm{Ba}$ & ${ }^{152} \mathrm{Eu}$ & ${ }^{133} \mathrm{Ba}$ & ${ }^{133} \mathrm{Ba}$ & ${ }^{37} \mathrm{Cs}$ & ${ }^{152} \mathrm{Eu}$ & ${ }^{152} \mathrm{Eu}$ & ${ }^{152} \mathrm{Eu}$ & ${ }^{152} \mathrm{Eu}$ & ${ }^{152} \mathrm{Eu}$ & ${ }^{60} \mathrm{Co}$ & ${ }^{60} \mathrm{Co}$ & ${ }^{152} \mathrm{Eu}$ \\
\hline & 80,99 & 121,78 & 244,69 & 276,39 & 302,85 & 344,28 & 356,01 & 383,85 & 661,66 & 778,9 & 867,39 & 964,05 & 1085,84 & 1112,08 & 1173,24 & 1332,5 & 1408,02 \\
\hline Amostra & \multicolumn{17}{|c|}{ Fator de autoatenuação } \\
\hline FEV08 & $2,04 \pm 0,03$ & $1,98 \pm 0,02$ & $1,68 \pm 0,03$ & $1,37 \pm 0,03$ & $1,37 \pm 0,01$ & $1,53 \pm 0,01$ & $1,33 \pm 0,01$ & $1,32 \pm 0,02$ & $1,144 \pm 0,003$ & $1,27 \pm 0,01$ & $1,30 \pm 0,03$ & $1,33 \pm 0,01$ & $1,31 \pm 0,02$ & $1,32 \pm 0,01$ & $1,14 \pm 0,01$ & $1,11 \pm 0,01$ & $1,28 \pm 0,01$ \\
\hline
\end{tabular}

Fatores de autoatenuação para as amostras de densidade 1,84 g.cm ${ }^{-3}$

\begin{tabular}{|c|c|c|c|c|c|c|c|c|c|c|c|c|c|c|c|c|c|}
\hline & \multicolumn{17}{|c|}{ Energia (keV) } \\
\hline & ${ }^{133} \mathrm{Ba}$ & ${ }^{152} \mathrm{Eu}$ & ${ }^{152} \mathrm{Eu}$ & ${ }^{133} \mathrm{Ba}$ & ${ }^{133} \mathrm{Ba}$ & ${ }^{152} \mathrm{Eu}$ & ${ }^{133} \mathrm{Ba}$ & ${ }^{133} \mathrm{Ba}$ & ${ }^{37} \mathrm{Cs}$ & ${ }^{152} \mathrm{Eu}$ & ${ }^{152} \mathrm{Eu}$ & ${ }^{152} \mathrm{Eu}$ & ${ }^{152} \mathrm{Eu}$ & ${ }^{152} \mathrm{Eu}$ & ${ }^{60} \mathrm{Co}$ & ${ }^{60} \mathrm{Co}$ & ${ }^{152} \mathrm{Eu}$ \\
\hline & 80,99 & 121,78 & 244,69 & 276,39 & 302,85 & 344,28 & 356,01 & 383,85 & 661,66 & 778,9 & 867,39 & 964,05 & 1085,84 & 1112,08 & 1173,24 & 1332,5 & 1408,02 \\
\hline Amostra & \multicolumn{17}{|c|}{ Fator de autoatenuação } \\
\hline MAI05 & $1,89 \pm 0,04$ & $1,58 \pm 0,01$ & $1,40 \pm 0,02$ & $1,31 \pm 0,05$ & $1,29 \pm 0,02$ & $1,34 \pm 0,01$ & $1,27 \pm 0,01$ & $1,26 \pm 0,03$ & $1,146 \pm 0,003$ & $1,21 \pm 0,01$ & $1,19 \pm 0,03$ & $1,18 \pm 0,01$ & $1,18 \pm 0,01$ & $1,16 \pm 0,01$ & $1,11 \pm 0,01$ & $1,09 \pm 0,01$ & $1,16 \pm 0,01$ \\
\hline AGO02 & $1,81 \pm 0,03$ & $1,51 \pm 0,01$ & $1,30 \pm 0,02$ & $1,29 \pm 0,05$ & $1,24 \pm 0,02$ & $1,24 \pm 0,01$ & $1,23 \pm 0,01$ & $1,23 \pm 0,03$ & $1,124 \pm 0,003$ & $1,17 \pm 0,01$ & $1,18 \pm 0,03$ & $1,14 \pm 0,01$ & $1,14 \pm 0,01$ & $1,14 \pm 0,01$ & $1,10 \pm 0,01$ & $1,12 \pm 0,01$ & $1,13 \pm 0,01$ \\
\hline
\end{tabular}


Fatores de autoatenuação para as amostras de densidade $1,86 \mathrm{~g} . \mathrm{cm}^{-3}$

\begin{tabular}{|c|c|c|c|c|c|c|c|c|c|c|c|c|c|c|c|c|c|}
\hline & \multicolumn{17}{|c|}{ Energia $(\mathrm{keV})$} \\
\hline & ${ }^{133} \mathrm{Ba}$ & ${ }^{152} \mathrm{Eu}$ & ${ }^{152} \mathrm{Eu}$ & ${ }^{133} \mathrm{Ba}$ & ${ }^{133} \mathrm{Ba}$ & ${ }^{152} \mathrm{Eu}$ & ${ }^{133} \mathrm{Ba}$ & ${ }^{133} \mathrm{Ba}$ & 整 & ${ }^{152} \mathrm{Eu}$ & ${ }^{152} \mathrm{Eu}$ & ${ }^{152} \mathrm{Eu}$ & ${ }^{152} \mathrm{Eu}$ & ${ }^{152} \mathrm{Eu}$ & 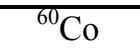 & ${ }^{60} \mathrm{Co}$ & ${ }^{152} \mathrm{Eu}$ \\
\hline & 80,99 & 121,78 & 244,69 & $\begin{array}{l}276,39 \\
\end{array}$ & 302,85 & 344,28 & 356,01 & 383,85 & 661,66 & $\begin{array}{l}778,9 \\
\end{array}$ & 867,39 & 964,05 & 1085,84 & 1112,08 & 1173,24 & 1332,5 & 1408,02 \\
\hline Amostra & \multicolumn{17}{|c|}{ Fator de autoatenuação } \\
\hline JUN02 & $1,71 \pm 0,03$ & $1,58 \pm 0,01$ & $1,46 \pm 0,02$ & $1,30 \pm 0,04$ & $1,29 \pm 0,02$ & $1,37 \pm 0,01$ & $1,26 \pm 0,01$ & $1,24 \pm 0,03$ & $1,142 \pm 0,003$ & $1,21 \pm 0,01$ & $1,21 \pm 0,03$ & $1,18 \pm 0,01$ & $1,17 \pm 0,01$ & $1,18 \pm 0,01$ & $1,10 \pm 0,01$ & $1,10 \pm 0,01$ & $1,16 \pm 0,01$ \\
\hline \multicolumn{18}{|c|}{ Fatores de autoatenuação para as amostras de densidade $1,88 \mathrm{~g} \cdot \mathrm{cm}^{-3}$} \\
\hline & \multicolumn{17}{|c|}{ Energia $(\mathrm{keV})$} \\
\hline & ${ }^{33} \mathrm{Ba}$ & ${ }^{152} \mathrm{Eu}$ & ${ }^{152} \mathrm{Eu}$ & ${ }^{133} \mathrm{Ba}$ & ${ }^{133} \mathrm{Ba}$ & ${ }^{152} \mathrm{Eu}$ & ${ }^{133} \mathrm{Ba}$ & ${ }^{133} \mathrm{Ba}$ & ${ }^{37} \mathrm{Cs}$ & ${ }^{152} \mathrm{Eu}$ & ${ }^{152} \mathrm{Eu}$ & ${ }^{152} \mathrm{Eu}$ & ${ }^{152} \mathrm{Eu}$ & ${ }^{152} \mathrm{Eu}$ & ${ }^{60} \mathrm{Co}$ & ${ }^{60} \mathrm{Co}$ & ${ }^{152} \mathrm{Eu}$ \\
\hline & 80,99 & 121,78 & 244,69 & 276,39 & 302,85 & 344,28 & 356,01 & 383,85 & 661,66 & 778,9 & 867,39 & 964,05 & 1085,84 & 1112,08 & 1173,24 & 1332,5 & 1408,02 \\
\hline
\end{tabular}


Fatores de autoatenuação para as amostras de densidade 1,89 g.cm ${ }^{-3}$

\begin{tabular}{|c|c|c|c|c|c|c|c|c|c|c|c|c|c|c|c|c|c|}
\hline & \multicolumn{17}{|c|}{ Energia (keV) } \\
\hline & ${ }^{133} \mathrm{Ba}$ & ${ }^{152} \mathrm{Eu}$ & ${ }^{152} \mathrm{Eu}$ & ${ }^{133} \mathrm{Ba}$ & ${ }^{133} \mathrm{Ba}$ & ${ }^{152} \mathrm{Eu}$ & ${ }^{133} \mathrm{Ba}$ & ${ }^{133} \mathrm{Ba}$ & ${ }^{37} \mathrm{Cs}$ & ${ }^{152} \mathrm{Eu}$ & ${ }^{152} \mathrm{Eu}$ & ${ }^{152} \mathrm{Eu}$ & ${ }^{152} \mathrm{Eu}$ & ${ }^{152} \mathrm{Eu}$ & ${ }^{60} \mathrm{Co}$ & ${ }^{60} \mathrm{Co}$ & ${ }^{152} \mathrm{Eu}$ \\
\hline & 80,99 & 121,78 & 244,69 & 276,39 & 302,85 & 344,28 & 356,01 & 383,85 & 661,66 & 778,9 & 867,39 & 964,05 & 1085,84 & 1112,08 & 1173,24 & 1332,5 & 1408,02 \\
\hline Amostra & \multicolumn{17}{|c|}{ Fator de autoatenuação } \\
\hline JUL05 & $2,07 \pm 0,05$ & $1,63 \pm 0,01$ & $1,42 \pm 0,02$ & $1,22 \pm 0,04$ & $1,23 \pm 0,02$ & $1,34 \pm 0,01$ & $1,23 \pm 0,01$ & $1,21 \pm 0,03$ & $1,150 \pm 0,003$ & $1,21 \pm 0,01$ & $1,16 \pm 0,03$ & $1,18 \pm 0,01$ & $1,01 \pm 0,01$ & $1,17 \pm 0,01$ & $1,16 \pm 0,02$ & $1,12 \pm 0,02$ & $1,24 \pm 0,01$ \\
\hline
\end{tabular}

Fatores de autoatenuação para as amostras de densidade 1,96 g.cm ${ }^{-3}$

\begin{tabular}{|c|c|c|c|c|c|c|c|c|c|c|c|c|c|c|c|c|c|}
\hline & \multicolumn{17}{|c|}{ Energia (keV) } \\
\hline & ${ }^{133} \mathrm{Ba}$ & ${ }^{152} \mathrm{Eu}$ & ${ }^{152} \mathrm{Eu}$ & ${ }^{133} \mathrm{Ba}$ & ${ }^{133} \mathrm{Ba}$ & ${ }^{152} \mathrm{Eu}$ & ${ }^{133} \mathrm{Ba}$ & ${ }^{133} \mathrm{Ba}$ & ${ }^{37} \mathrm{Cs}$ & ${ }^{152} \mathrm{Eu}$ & ${ }^{152} \mathrm{Eu}$ & ${ }^{152} \mathrm{Eu}$ & ${ }^{152} \mathrm{Eu}$ & ${ }^{152} \mathrm{Eu}$ & ${ }^{60} \mathrm{Co}$ & ${ }^{60} \mathrm{Co}$ & ${ }^{152} \mathrm{Eu}$ \\
\hline & 80,99 & 121,78 & 244,69 & 276,39 & 302,85 & 344,28 & 356,01 & 383,85 & 661,66 & 778,9 & 867,39 & 964,05 & 1085,84 & 1112,08 & 1173,24 & 1332,5 & 1408,02 \\
\hline Amostra & \multicolumn{17}{|c|}{ Fator de autoatenuação } \\
\hline DEZ01 & $2,00 \pm 0,07$ & $1,70 \pm 0,02$ & $1,33 \pm 0,02$ & $1,28 \pm 0,06$ & $1,29 \pm 0,03$ & $1,27 \pm 0,01$ & $1,24 \pm 0,01$ & $1,27 \pm 0,04$ & $1,181 \pm 0,003$ & $1,17 \pm 0,01$ & $1,14 \pm 0,04$ & $1,13 \pm 0,01$ & $1,16 \pm 0,02$ & $1,10 \pm 0,01$ & $1,13 \pm 0,02$ & $1,13 \pm 0,02$ & $1,16 \pm 0,01$ \\
\hline
\end{tabular}


Fatores de autoatenuação para as amostras de densidade 2,35 g.cm $\mathrm{cm}^{-3}$

\begin{tabular}{|c|c|c|c|c|c|c|c|c|c|c|c|c|c|c|c|c|c|}
\hline & \multicolumn{17}{|c|}{ Energia $(\mathrm{keV})$} \\
\hline & ${ }^{133} \mathrm{Ba}$ & ${ }^{152} \mathrm{Eu}$ & ${ }^{152} \mathrm{Eu}$ & ${ }^{133} \mathrm{Ba}$ & ${ }^{133} \mathrm{Ba}$ & ${ }^{152} \mathrm{Eu}$ & ${ }^{133} \mathrm{Ba}$ & ${ }^{133} \mathrm{Ba}$ & ${ }^{37} \mathrm{Cs}$ & ${ }^{152} \mathrm{Eu}$ & ${ }^{152} \mathrm{Eu}$ & ${ }^{152} \mathrm{Eu}$ & ${ }^{152} \mathrm{Eu}$ & ${ }^{152} \mathrm{Eu}$ & ${ }^{60} \mathrm{Co}$ & ${ }^{60} \mathrm{Co}$ & ${ }^{152} \mathrm{Eu}$ \\
\hline & 80,99 & 121,78 & 244,69 & 276,39 & 302,85 & 344,28 & 356,01 & 383,85 & 661,66 & 778,9 & 867,39 & 964,05 & 1085,84 & 1112,08 & 1173,24 & 1332,5 & 1408,02 \\
\hline Amostra & \multicolumn{17}{|c|}{ Fator de autoatenuação } \\
\hline JUN05 & $3,99 \pm 0,55$ & $2,00 \pm 0,03$ & $1,41 \pm 0,02$ & $1,27 \pm 0,04$ & $1,40 \pm 0,02$ & $1,34 \pm 0,01$ & $1,40 \pm 0,01$ & $1,27 \pm 0,03$ & $1,236 \pm 0,002$ & $1,22 \pm 0,01$ & $1,20 \pm 0,03$ & $1,16 \pm 0,01$ & $1,15 \pm 0,01$ & $1,13 \pm 0,01$ & $1,12 \pm 0,01$ & $1,15 \pm 0,01$ & $1,19 \pm 0,01$ \\
\hline
\end{tabular}




\section{APÊNDICE B - Concentração de atividade de ${ }^{226} \mathrm{Ra},{ }^{232} \mathrm{Th}$ e ${ }^{40} \mathrm{~K}$ das amostras de areia coletadas na Praia de Camburi durante o ano de 2011.}

Concentração de atividade de ${ }^{226} \mathrm{Ra},{ }^{232} \mathrm{Th}$ e ${ }^{40} \mathrm{~K}$ nos Pontos de coleta (1-11) em janeiro de 2011

\begin{tabular}{cccccccccccc}
\hline \hline Pontos & 01 & 02 & 03 & 04 & 05 & 06 & 07 & 08 & 09 & 10 & 11 \\
\hline \multirow{7}{*}{ Concentração de atividade $\left(\mathrm{Bq}^{-\mathrm{kg}^{-1}}\right)$} \\
${ }^{226} \mathrm{Ra}$ & $8 \pm 1$ & $185 \pm 11$ & $9 \pm 1$ & $29 \pm 2$ & $265 \pm 16$ & $33 \pm 2$ & $33 \pm 2$ & $19 \pm 1$ & $46 \pm 3$ & $5 \pm 1$ & $5 \pm 1$ \\
${ }^{232} \mathrm{Th}$ & $25 \pm 2$ & $1106 \pm 51$ & $15 \pm 1$ & $112 \pm 6$ & $1159 \pm 57$ & $126 \pm 7$ & $123 \pm 7$ & $73 \pm 4$ & $165 \pm 9$ & $13 \pm 1$ & $16 \pm 1$ \\
${ }^{40} \mathrm{~K}$ & $193 \pm 27$ & $112 \pm 14$ & $29 \pm 8$ & $54 \pm 9$ & $105 \pm 14$ & $83 \pm 12$ & $27 \pm 8$ & $73 \pm 10$ & $37 \pm 8$ & $37 \pm 8$ & $30 \pm 8$ \\
\hline \hline
\end{tabular}

Concentração de atividade de ${ }^{226} \mathrm{Ra},{ }^{232} \mathrm{Th}$ e ${ }^{40} \mathrm{~K}$ nos Pontos de coleta (1-11) em fevereiro de 2011

\begin{tabular}{cccccccccccc}
\hline \hline Pontos & 01 & 02 & 03 & 04 & 05 & 06 & 07 & 08 & 09 & 10 & 11 \\
\hline & & & \multicolumn{7}{c}{ Concentração de atividade $\left(\mathrm{Bq} \cdot \mathrm{kg}^{-1}\right)$} \\
${ }^{226} \mathrm{Ra}$ & $11 \pm 1$ & $40 \pm 2$ & $28 \pm 1$ & $12 \pm 1$ & $25 \pm 1$ & $7 \pm 1$ & $9 \pm 1$ & $325 \pm 11$ & $11 \pm 1$ & $16 \pm 1$ & $6 \pm 1$ \\
${ }^{232} \mathrm{Th}$ & $33 \pm 1$ & $212 \pm 7$ & $85 \pm 3$ & $35 \pm 1$ & $113 \pm 4$ & $16 \pm 1$ & $22 \pm 1$ & $1929 \pm 53$ & $37 \pm 1$ & $41 \pm 2$ & $15 \pm 1$ \\
${ }^{40} \mathrm{~K}$ & $94 \pm 9$ & $31 \pm 7$ & $40 \pm 7$ & $33 \pm 6$ & $182 \pm 12$ & $51 \pm 7$ & $34 \pm 8$ & $175 \pm 13$ & $97 \pm 9$ & $45 \pm 8$ & $245 \pm 22$ \\
\hline \hline
\end{tabular}

Concentração de atividade de ${ }^{226} \mathrm{Ra},{ }^{232} \mathrm{Th}$ e ${ }^{40} \mathrm{~K}$ nos Pontos de coleta (1-11) em março de 2011

\begin{tabular}{ccccccccccccc}
\hline \hline Pontos & 01 & 02 & 03 & 04 & 05 & 06 & 07 & 08 & 09 & 10 & 11 \\
\hline${ }^{226} \mathrm{Ra}$ & $26 \pm 1$ & $32 \pm 2$ & $17 \pm 1$ & $31 \pm 2$ & $119 \pm 7$ & $12 \pm 1$ & $14 \pm 1$ & $14 \pm 1$ & $29 \pm 1$ & $22 \pm 1$ & $8 \pm 1$ \\
${ }^{232} \mathrm{Th}$ & $130 \pm 5$ & $93 \pm 4$ & $51 \pm 2$ & $119 \pm 5$ & $545 \pm 25$ & $36 \pm 2$ & $44 \pm 3$ & $42 \pm 2$ & $107 \pm 4$ & $71 \pm 3$ & $21 \pm 1$ \\
${ }^{40} \mathrm{~K}$ & $105 \pm 11$ & $78 \pm 8$ & $31 \pm 5$ & $65 \pm 9$ & $65 \pm 8$ & $30 \pm 5$ & $45 \pm 10$ & $19 \pm 7$ & $28 \pm 7$ & $35 \pm 7$ & $40 \pm 5$ \\
\hline \hline
\end{tabular}

Concentração de atividade de ${ }^{226} \mathrm{Ra},{ }^{232} \mathrm{Th}$ e ${ }^{40} \mathrm{~K}$ nos Pontos de coleta (1-11) em abril de 2011

\begin{tabular}{cccccccccccc}
\hline \hline Pontos & 01 & 02 & 03 & 04 & 05 & 06 & 07 & 08 & 09 & 10 & 11 \\
\hline \multirow{2}{*}{${ }^{226} \mathrm{Ra}$} & $24 \pm 1$ & $10 \pm 1$ & $17 \pm 1$ & $39 \pm 2$ & $67 \pm 3$ & $30 \pm 1$ & $41 \pm 2$ & $12 \pm 1$ & $78 \pm 3$ & $7 \pm 1$ & $6 \pm 1$ \\
${ }^{232} \mathrm{Th}$ & $99 \pm 4$ & $32 \pm 2$ & $53 \pm 2$ & $161 \pm 6$ & $279 \pm 10$ & $108 \pm 4$ & $136 \pm 5$ & $30 \pm 1$ & $313 \pm 11$ & $16 \pm 1$ & $13 \pm 1$ \\
${ }^{40} \mathrm{~K}$ & $43 \pm 5$ & $40 \pm 8$ & $55 \pm 6$ & $54 \pm 8$ & $27 \pm 1$ & $6 \pm 5$ & $16 \pm 7$ & $11 \pm 5$ & $53 \pm 6$ & $23 \pm 6$ & $44 \pm 7$ \\
\hline \hline
\end{tabular}


Concentração de atividade de ${ }^{226} \mathrm{Ra},{ }^{232} \mathrm{Th}$ e ${ }^{40} \mathrm{~K}$ nos Pontos de coleta (1-11) em maio de 2011

\begin{tabular}{cccccccccccc}
\hline \hline Pontos & 01 & 02 & 03 & 04 & 05 & 06 & 07 & 08 & 09 & 10 & 11 \\
\hline${ }^{226} \mathrm{Ra}$ & $41 \pm 2$ & $39 \pm 2$ & $8 \pm 1$ & $25 \pm 1$ & $189 \pm 8$ & $8 \pm 1$ & $19 \pm 1$ & $7 \pm 1$ & $30 \pm 1$ & $6 \pm 1$ & $5 \pm 1$ \\
${ }^{232} \mathrm{Th}$ & $181 \pm 7$ & $178 \pm 7$ & $26 \pm 1$ & $17 \pm 1$ & $908 \pm 30$ & $25 \pm 1$ & $68 \pm 3$ & $13 \pm 1$ & $94 \pm 3$ & $15 \pm 1$ & $12 \pm 1$ \\
${ }^{40} \mathrm{~K}$ & $60 \pm 8$ & $44 \pm 6$ & $18 \pm 7$ & $20 \pm 6$ & $102 \pm 11$ & $15 \pm 6$ & $48 \pm 7$ & $40 \pm 5$ & $20 \pm 5$ & $16 \pm 6$ & $36 \pm 7$ \\
\hline \hline
\end{tabular}

Concentração de atividade de ${ }^{226} \mathrm{Ra},{ }^{232} \mathrm{Th}$ e ${ }^{40} \mathrm{~K}$ nos Pontos de coleta (1-11) em junho de 2011

\begin{tabular}{cccccccccccc}
\hline \hline Pontos & 01 & 02 & 03 & 04 & 05 & 06 & 07 & 08 & 09 & 10 & 11 \\
\hline \multirow{2}{*}{${ }^{226} \mathrm{Ra}$} & $10 \pm 1$ & $25 \pm 1$ & $33 \pm 1$ & $18 \pm 1$ & $1380 \pm 62$ & $10 \pm 1$ & $22 \pm 1$ & $5 \pm 1$ & $97 \pm 5$ & $9 \pm 1$ & $5 \pm 1$ \\
${ }^{232} \mathrm{Th}$ & $29 \pm 1$ & $70 \pm 3$ & $106 \pm 4$ & $66 \pm 3$ & $7453 \pm 274$ & $29 \pm 2$ & $75 \pm 4$ & $9 \pm 1$ & $370 \pm 15$ & $22 \pm 1$ & $11 \pm 1$ \\
${ }^{40} \mathrm{~K}$ & $185 \pm 14$ & $85 \pm 8$ & $35 \pm 7$ & $27 \pm 6$ & $504 \pm 41$ & $15 \pm 6$ & $28 \pm 7$ & $37 \pm 7$ & $43 \pm 9$ & $26 \pm 7$ & $23 \pm 6$ \\
\hline \hline
\end{tabular}

Concentração de atividade de ${ }^{226} \mathrm{Ra},{ }^{232} \mathrm{Th}$ e ${ }^{40} \mathrm{~K}$ nos Pontos de coleta (1-11) em julho de 2011

\begin{tabular}{cccccccccccc}
\hline \hline Pontos & 01 & 02 & 03 & 04 & 05 & 06 & 07 & 08 & 09 & 10 & 11 \\
\hline \multirow{8}{*}{${ }^{226} \mathrm{Ra}$} & $9 \pm 1$ & $32 \pm 1$ & $33 \pm 2$ & $20 \pm 1$ & $483 \pm 20$ & $7 \pm 1$ & $7 \pm 1$ & $7 \pm 1$ & $19 \pm 1$ & $6 \pm 1$ & $6 \pm 1$ \\
${ }^{232} \mathrm{Th}$ & $28 \pm 2$ & $96 \pm 4$ & $103 \pm 4$ & $76 \pm 3$ & $2592 \pm 88$ & $22 \pm 1$ & $23 \pm 1$ & $19 \pm 1$ & $62 \pm 3$ & $18 \pm 1$ & $14 \pm 1$ \\
${ }^{40} \mathrm{~K}$ & $209 \pm 18$ & $49 \pm 7$ & $44 \pm 7$ & $7 \pm 6$ & $228 \pm 19$ & $18 \pm 6$ & $15 \pm 6$ & $27 \pm 6$ & $63 \pm 9$ & $40 \pm 7$ & $23 \pm 5$ \\
\hline \hline
\end{tabular}

Concentração de atividade de ${ }^{226} \mathrm{Ra},{ }^{232} \mathrm{Th}$ e ${ }^{40} \mathrm{~K}$ nos Pontos de coleta (1-11) em agosto de 2011

\begin{tabular}{cccccccccccc}
\hline \hline Pontos & 01 & 02 & 03 & 04 & 05 & 06 & 07 & 08 & 09 & 10 & 11 \\
\hline & & & \multicolumn{7}{c}{ Concentração de atividade $\left(\mathrm{Bq} \cdot \mathrm{kg}^{-1}\right)$} \\
${ }^{226} \mathrm{Ra}$ & $32 \pm 2$ & $404 \pm 17$ & $11 \pm 1$ & $9 \pm 1$ & $40 \pm 2$ & $6 \pm 1$ & $18 \pm 1$ & $5 \pm 1$ & $30 \pm 2$ & $7 \pm 1$ & $5 \pm 1$ \\
${ }^{232} \mathrm{Th}$ & $127 \pm 7$ & $2676 \pm 94$ & $34 \pm 2$ & $25 \pm 1$ & $155 \pm 7$ & $16 \pm 1$ & $62 \pm 3$ & $14 \pm 1$ & $115 \pm 5$ & $16 \pm 1$ & $11 \pm 1$ \\
${ }^{40} \mathrm{~K}$ & $88 \pm 11$ & $220 \pm 19$ & $28 \pm 7$ & $25 \pm 2$ & $33 \pm 7$ & $28 \pm 7$ & $25 \pm 7$ & $40 \pm 7$ & $43 \pm 8$ & $27 \pm 7$ & $34 \pm 8$ \\
\hline \hline
\end{tabular}


Concentração de atividade de ${ }^{226} \mathrm{Ra},{ }^{232} \mathrm{Th}$ e ${ }^{40} \mathrm{~K}$ nos Pontos de coleta (1-11) em setembro de 2011

\begin{tabular}{cccccccccccc}
\hline \hline Pontos & 01 & 02 & 03 & 04 & 05 & 06 & 07 & 08 & 09 & 10 & 11 \\
\hline${ }^{226} \mathrm{Ra}$ & $7 \pm 1$ & $580 \pm 26$ & $14 \pm 1$ & $29 \pm 1$ & $97 \pm 4$ & $13 \pm 1$ & $15 \pm 1$ & $5 \pm 1$ & $97 \pm 5$ & $10 \pm 1$ & $6 \pm 1$ \\
${ }^{232} \mathrm{Th}$ & $22 \pm 1$ & $4122 \pm 150$ & $43 \pm 2$ & $110 \pm 4$ & $365 \pm 13$ & $38 \pm 2$ & $53 \pm 3$ & $11 \pm 1$ & $408 \pm 17$ & $29 \pm 2$ & $12 \pm 1$ \\
${ }^{40} \mathrm{~K}$ & $58 \pm 9$ & $320 \pm 26$ & $45 \pm 6$ & $17 \pm 6$ & $45 \pm 8$ & $44 \pm 8$ & $35 \pm 5$ & $47 \pm 7$ & $71 \pm 8$ & $8 \pm 5$ & $190 \pm 16$ \\
\hline \hline
\end{tabular}

Concentração de atividade de ${ }^{226} \mathrm{Ra},{ }^{232} \mathrm{Th}$ e ${ }^{40} \mathrm{~K}$ nos Pontos de coleta (1-11) em outubro de 2011

\begin{tabular}{cccccccccccc}
\hline \hline Pontos & 01 & 02 & 03 & 04 & 05 & 06 & 07 & 08 & 09 & 10 & 11 \\
\hline \multirow{2}{*}{${ }^{226} \mathrm{Ra}$} & $65 \pm 5$ & $14 \pm 1$ & $17 \pm 2$ & $8 \pm 1$ & $241 \pm 90$ & $11 \pm 2$ & $13 \pm 2$ & $4 \pm 1$ & $74 \pm 10$ & $10 \pm 1$ & $5 \pm 1$ \\
${ }^{232} \mathrm{Th}$ & $275 \pm 16$ & $43 \pm 3$ & $67 \pm 7$ & $25 \pm 3$ & $1177 \pm 342$ & $35 \pm 4$ & $46 \pm 6$ & $11 \pm 2$ & $293 \pm 30$ & $24 \pm 1$ & $11 \pm 1$ \\
${ }^{40} \mathrm{~K}$ & $76 \pm 12$ & $34 \pm 6$ & $7 \pm 5$ & $34 \pm 10$ & $134 \pm 87$ & $40 \pm 10$ & $17 \pm 5$ & $23 \pm 9$ & $75 \pm 18$ & $37 \pm 6$ & $34 \pm 6$ \\
\hline \hline
\end{tabular}

Concentração de atividade de ${ }^{226} \mathrm{Ra},{ }^{232} \mathrm{Th}$ e ${ }^{40} \mathrm{~K}$ nos Pontos de coleta (1-11) em novembro de 2011

\begin{tabular}{cccccccccccc}
\hline \hline Pontos & 01 & 02 & 03 & 04 & 05 & 06 & 07 & 08 & 09 & 10 & 11 \\
\hline & & \multicolumn{7}{c}{ Concentração de atividade $\left(\mathrm{Bq}^{\left.-\mathrm{kg}^{-1}\right)}\right.$} \\
${ }^{226} \mathrm{Ra}$ & $125 \pm 10$ & $14 \pm 1$ & $8 \pm 1$ & $6 \pm 1$ & $13 \pm 1$ & $14 \pm 2$ & $14 \pm 1$ & $6 \pm 1$ & $146 \pm 11$ & $8 \pm 1$ & $5 \pm 1$ \\
${ }^{232} \mathrm{Th}$ & $578 \pm 37$ & $57 \pm 4$ & $21 \pm 2$ & $13 \pm 1$ & $38 \pm 3$ & $44 \pm 4$ & $37 \pm 3$ & $14 \pm 1$ & $580 \pm 35$ & $19 \pm 2$ & $13 \pm 1$ \\
${ }^{40} \mathrm{~K}$ & $73 \pm 12$ & $55 \pm 9$ & $58 \pm 12$ & $15 \pm 7$ & $20 \pm 6$ & $25 \pm 8$ & $37 \pm 7$ & $46 \pm 10$ & $60 \pm 11$ & $25 \pm 6$ & $22 \pm 5$ \\
\hline \hline
\end{tabular}

Concentração de atividade de ${ }^{226} \mathrm{Ra},{ }^{232} \mathrm{Th}$ e ${ }^{40} \mathrm{~K}$ nos Pontos de coleta (1-11) em dezembro de 2011

\begin{tabular}{cccccccccccc}
\hline \hline Pontos & 01 & 02 & 03 & 04 & 05 & 06 & 07 & 08 & 09 & 10 & 11 \\
\hline${ }^{226} \mathrm{Ra}$ & $806 \pm 39$ & $8 \pm 1$ & $10 \pm 2$ & $6 \pm 2$ & $194 \pm 17$ & $11 \pm 2$ & $34 \pm 7$ & $6 \pm 1$ & $37 \pm 14$ & $7 \pm 2$ & $4 \pm 1$ \\
${ }^{232} \mathrm{Th}$ & $5283 \pm 206$ & $28 \pm 3$ & $28 \pm 5$ & $14 \pm 4$ & $773 \pm 55$ & $34 \pm 5$ & $127 \pm 20$ & $13 \pm 2$ & $139 \pm 42$ & $16 \pm 5$ & $10 \pm 3$ \\
${ }^{40} \mathrm{~K}$ & $415 \pm 36$ & $63 \pm 15$ & $18 \pm 8$ & $18 \pm 13$ & $101 \pm 18$ & $24 \pm 9$ & $59 \pm 21$ & $39 \pm 11$ & $52 \pm 36$ & $29 \pm 18$ & $22 \pm 15$ \\
\hline \hline
\end{tabular}

